\title{
A MECHANISTIC-EMPIRICAL METHOD FOR CHARACTERISATION OF RAILWAY TRACK FORMATION
}

\section{Horacio Alejandro Mones Ruiz Martin}

A dissertation submitted in partial fulfilment of the requirements for the degree of

\author{
MASTER OF ENGINEERING \\ (TRANSPORTATION ENGINEERING) \\ In the \\ FACULTY OF ENGINEERING \\ UNIVERSITY OF PRETORIA
}

July 2018 


\title{
DISSERTATION SUMMARY
}

\section{A MECHANISTIC-EMPIRICAL METHOD FOR CHARACTERISATION OF RAILWAY TRACK FORMATION}

\section{HORACIO ALEJANDRO MONES RUIZ MARTIN}

\author{
Supervisor: Professor Johannes Gräbe \\ Co-Supervisor: Professor James Maina
}

Department: Civil Engineering

University: University of Pretoria

Degree: Master of Engineering (Transportation engineering)

The demand on South African railway freight lines is growing constantly with respect to train speeds and axle loading, thus increasing the forces and stresses experienced by the track structure. This may lead to rapid track deterioration as a result of a loss in track geometry caused by the poor and nonuniform underlying support. The railway engineering industry has moved towards gaining a better understanding of track formation behaviour for development of practical and effective deflection measurement techniques that allow accurate determination of formation structural capacity, identification of track problem areas and evaluation of track condition. Thus, there is a need to develop a deflection measurement method that can accurately evaluate the track formation condition through analysis of the full deflection basin under train passage, in order to quantify the formation structural capacity based on the relevant in-service conditions.

In this research study, a mechanistic-empirical method (referred to as the inverse method) is proposed with the main objective of developing an alternative method for evaluation of formation layer structural capacity through the inverse estimation of formation layers' elastic moduli. The method was founded on surface deflection theory from falling weight deflectometer (FWD) analysis. Finite element analysis and field data from railway substructure deflections under train transient loading 
obtained through multi-depth deflectometers (MDDs) were used to assess the validity of the inverse method by comparing measured and modelled railway substructure responses.

The results showed that substructure deflections and stresses are affected by the complex superposition of different bogie loading configurations on a particular superstructure. The increase in axle loading was found to be directly proportional to the increase in formation peak deflection. The effect of travelling speed was however insignificant for speeds less than $80 \mathrm{~km} / \mathrm{h}$. Furthermore, the load distribution in the railway substructure did not follow a $45^{\circ}$ influence line as commonly assumed in surface deflection theory. On the contrary, railway equilibrium influence lines (EILs) were significantly influenced by the elastic moduli of the formation layers and in-situ subgrade, therefore governed by the structural capacity of the substructure layers.

The research therefore concluded that the formation layers are expected to gradually deteriorate and experience increased deflections over time. However, the top of formation may vary as it seems to be highly influenced by the superstructure load distribution. The inverse method strongly agreed with the long-term formation peak strains measured with MDDs. Furthermore, the method was determined suitable for evaluation of formation structural capacity, as good agreement was found between the measured and estimated formation layers' elastic moduli. 


\section{DECLARARATION}

I, the undersigned hereby declare that:

I understand what plagiarism is and I am aware of the University's policy in this regard;

The work contained in this thesis is my own original work;

I did not refer to work of current or previous students, lecture notes, handbooks or any other study material without proper referencing;

Where other people's work has been used this has been properly acknowledged and referenced;

I have not allowed anyone to copy any part of my thesis;

I have not previously in its entirety or in part submitted this thesis at any university for a degree.

Author: Horacio Alejandro Mones Ruiz Martin

Signature:

Student number: 12233626

Date: 09/07/2018 


\section{ACKNOWLEDGEMENT}

I wish to express my appreciation to the following organisations and persons who made this dissertation possible:

a) To the University of Pretoria for allowing access to the facilities, laboratory and providing security;

b) To my supervisor Professor Johannes Gräbe and co-supervisor Professor James Maina for their immeasurable guidance and support throughout the years;

c) To Transnet Freight Rail Chair in Railway Engineering at the University of Pretoria for the financial support for the duration of the study;

d) Frederik Shaw and Jacobus Vorster for their assistance in this research study;

e) To my colleagues and friends for their support, motivation and discussions during the past two years;

f) Rick Vandoorne for his guidance and support as a friend as well as for helping proof read and correct this report;

g) Timothy Jideani and Nahungu Lionjanga for their motivation and encouragement as friends;

h) Mario Schulz-Poblete for his immeasurable friendship and the encouragement to pursue this degree together;

i) To my family for the financial and unconditional emotional support throughout my life;

j) To my girlfriend Ana Carolina Tome Pires for her support and motivation during the past years as well as for helping correct this report. 


\section{TABLE OF CONTENTS}

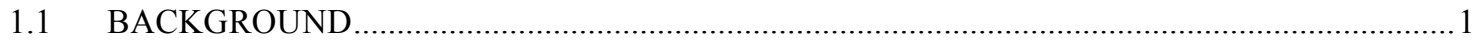

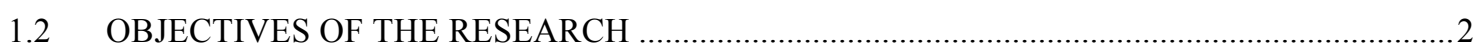

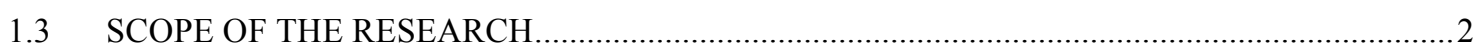

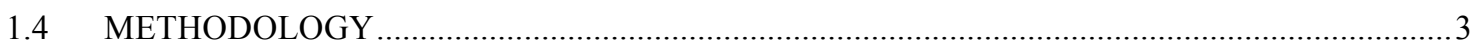

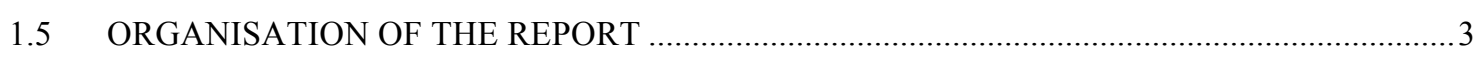

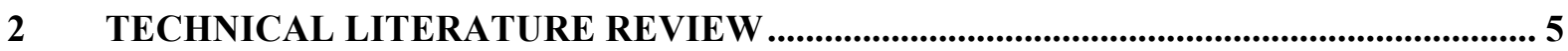

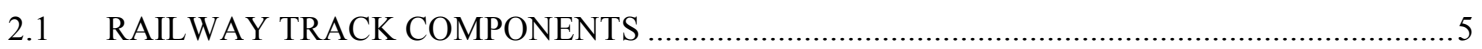

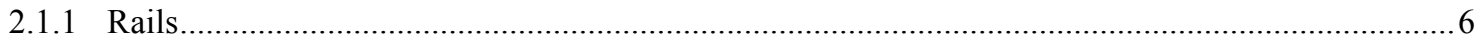

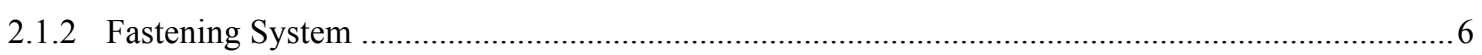

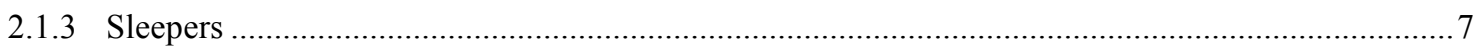

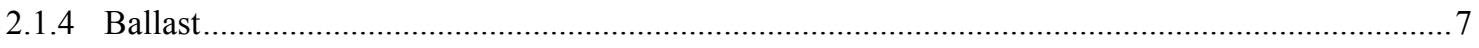

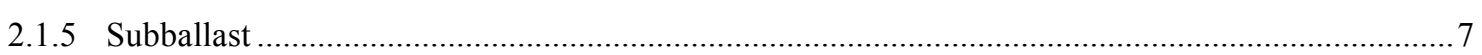

2.1.6 Subgrade

2.2 LOADING CONDITIONS ON RAILWAY FORMATION ….........................................................

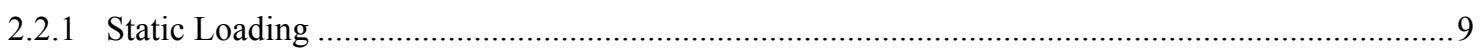

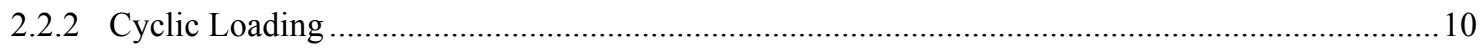

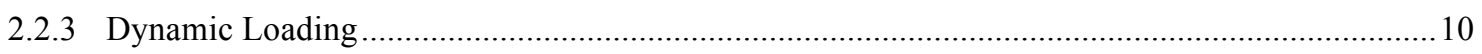

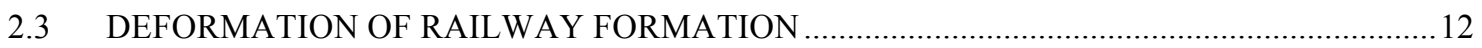

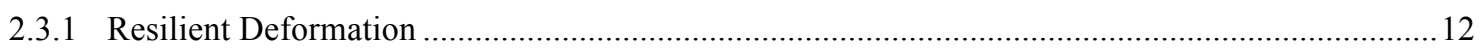

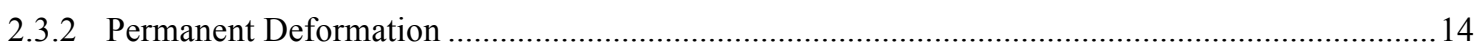

2.3.3 The Influence of Water on the Formation Deformation ............................................................. 16

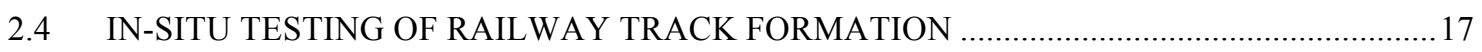

2.4.1 Advantages and Limitations of Non-Destructive In-Situ Testing ................................................... 17

2.4.2 Instrumentation for Deflection Measurements....................................................................... 19

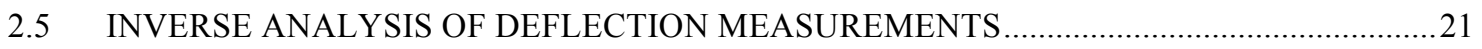

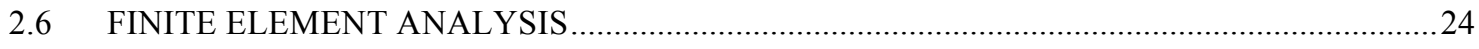

2.7 INTERPRETATION OF DEFLECTION MEASUREMENTS …..................................................2

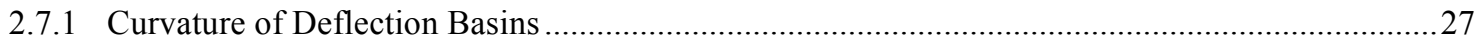

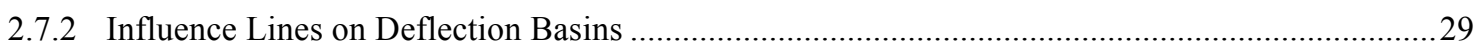

2.8 FACTORS AFFECTING SHAPE OF DEFLECTION MEASUREMENTS ....................................

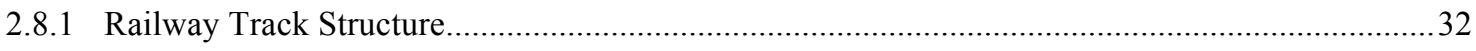

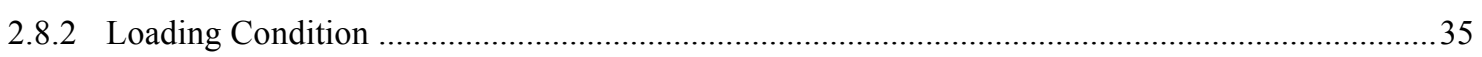


3 EXPERIMENTAL TEST SITE

3.1 FORMATION DESIGN AND MATERIAL SPECIFICATIONS ...........................................41

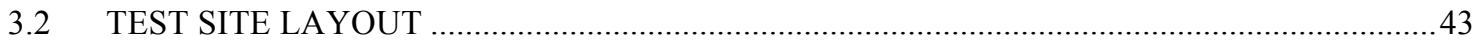

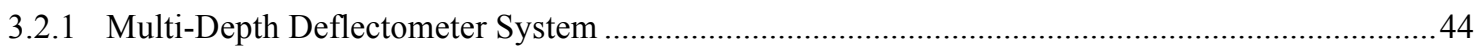

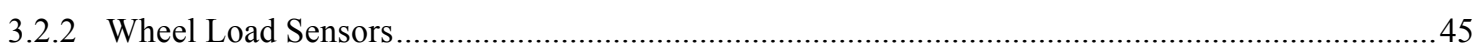

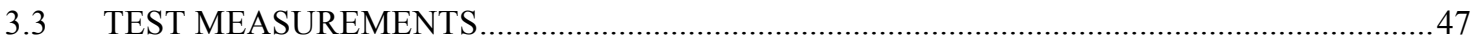

3.4 SUMMARY OF EXPERIMENTAL TEST SITE …...........................................................49

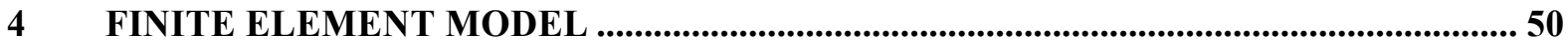

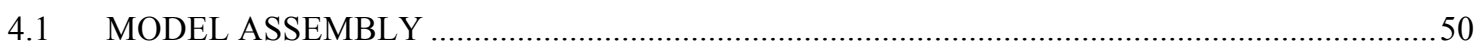

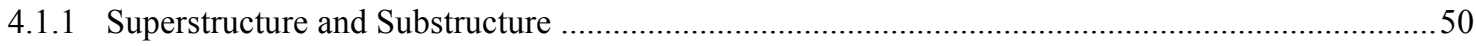

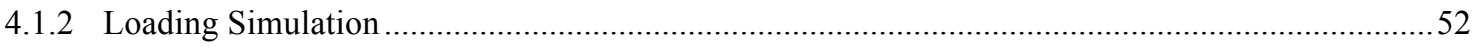

4.2 SUPERSTRUCTURE SENSITIVITY ANALYSIS ..............................................................5

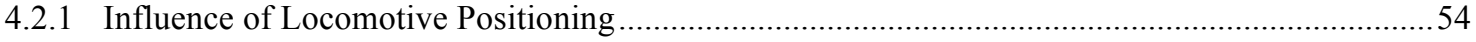

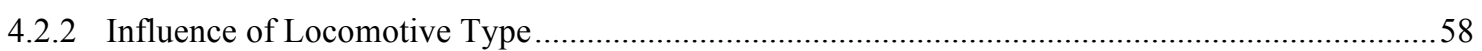

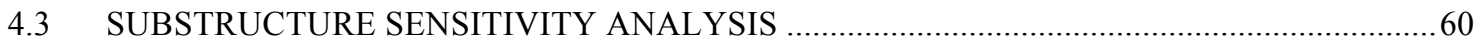

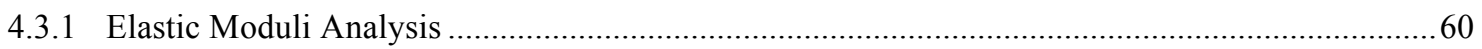

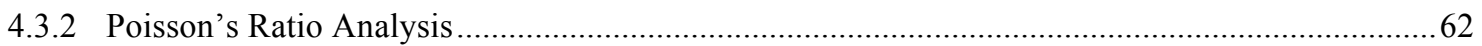

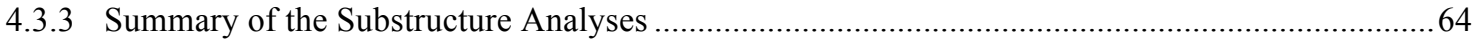

4.4 RAILWAY EQUILIBRIUM INFLUENCE LINES ........................................................6

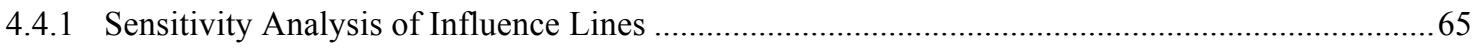

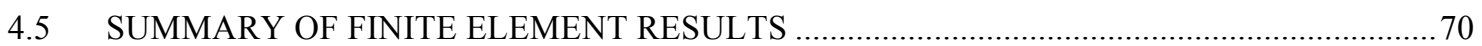

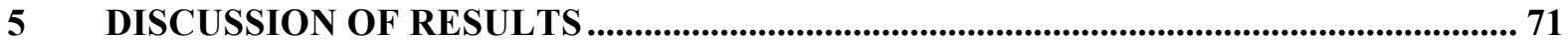

5.1 SENSITIVITY ANALYSIS OF DEFLECTION MEASUREMENTS ....................................71

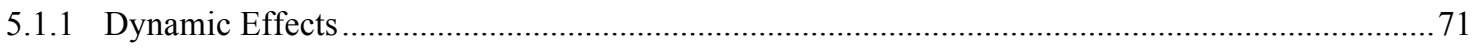

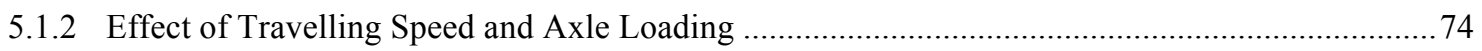

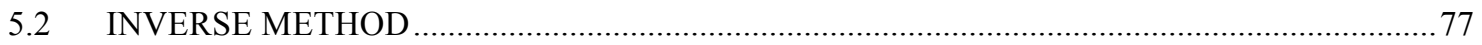

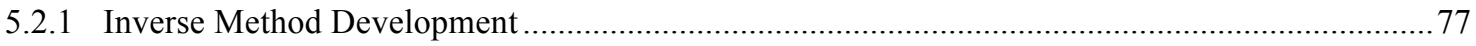

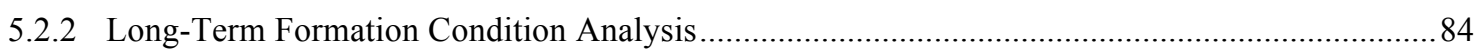

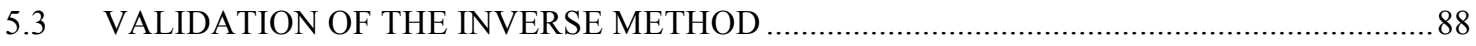

5.4 CHARACTERISATION OF LONG-TERM FORMATION BEHAVIOUR...............................93 
6 CONCLUSIONS AND RECOMMENDATIONS ........................................................... 102

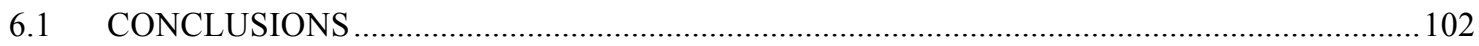

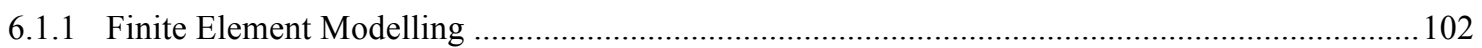

6.1.2 Sensitivity Analysis of Deflection Measurements .................................................................. 103

6.1.3 Equilibrium Influence Lines for Railway Track formation ............................................... 104

6.1.4 Long-Term Behaviour of Railway Track Formation .............................................................. 104

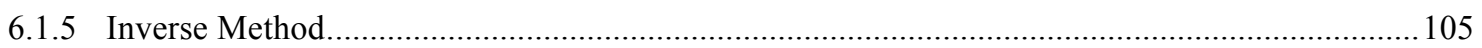

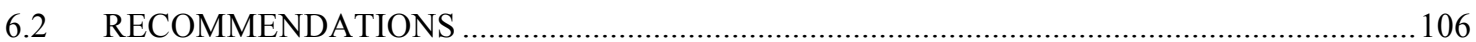

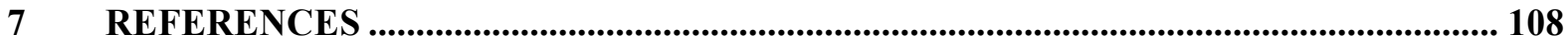

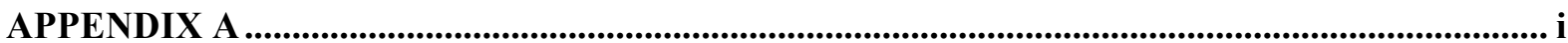

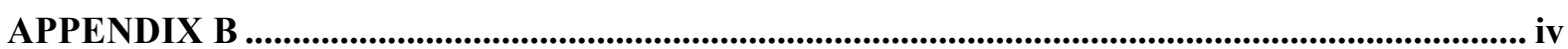

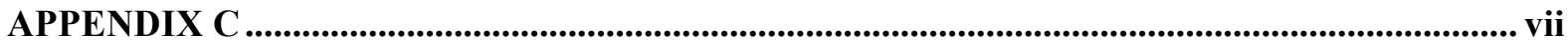

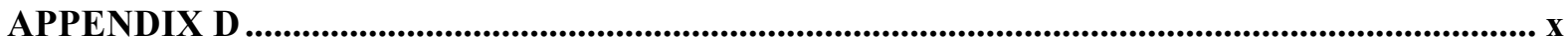




\section{LIST OF TABLES}

Table 2.1: Typical capabilities and advantages of finite element analysis .......................................... 25

Table 3.1: S410 material properties specification (Transnet Freight Rail, 2006)............................... 42

Table 3.2: Bloubank formation material properties (adapted from Gräbe and Shaw, 2010)............... 43

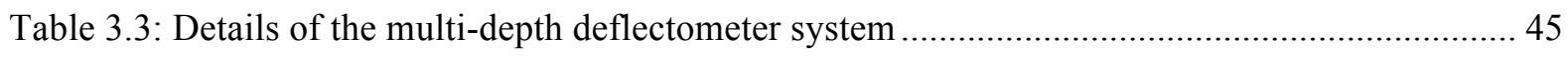

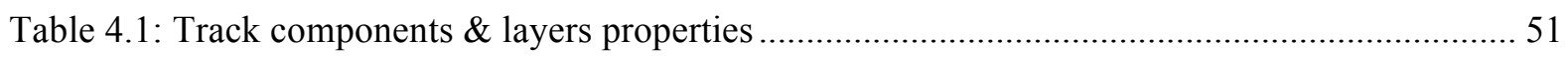

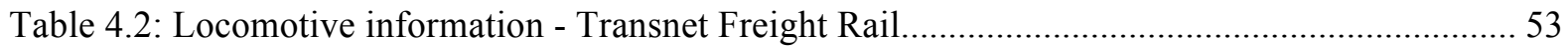

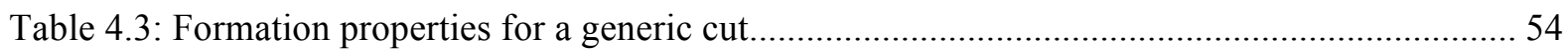

Table 4.4: Properties for standard granular materials (Maree et al., 1981) ......................................... 64

Table 4.5: Recommended properties for subgrade soils (Maree et al., 1981) ........................................ 64

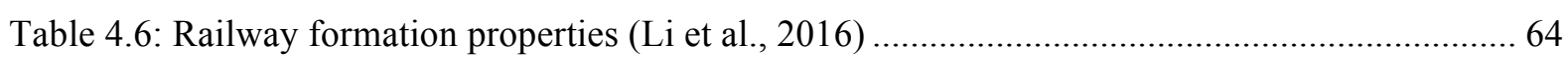

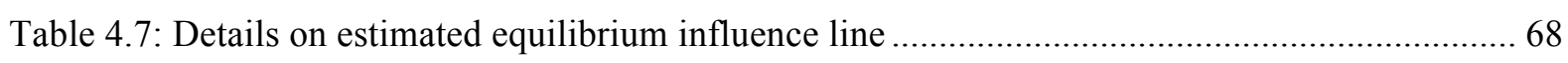

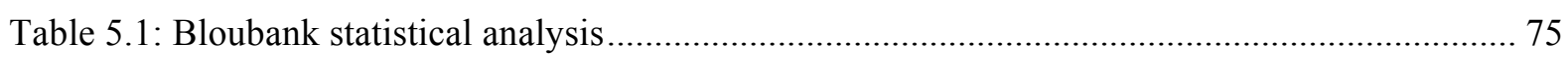

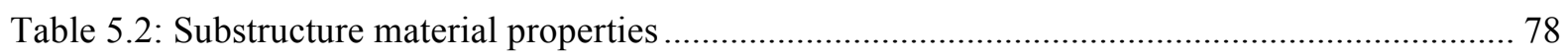

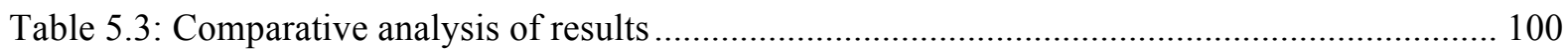




\section{LIST OF FIGURES}

Figure 2.1: Railway track structure components (adapted from Selig and Waters, 1994) .................... 6

Figure 2.2: Dead and live static loading on the formation stress distribution (Li et al., 2016) ............. 9

Figure 2.3: Stress contours due to different ballast support conditions (Gräbe et al., 2005)................ 11

Figure 2.4: Soil strain during one load cycle (adapted from Huang, 2004)........................................ 13

Figure 2.5: Resilient and permanent strains over infinite number of load cycles

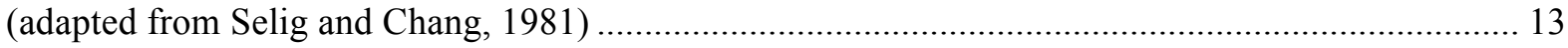

Figure 2.6: Principal stress rotation (adapted from Lekarp et al., 2000a) ......................................... 14

Figure 2.7: Elastic and plastic shakedown phases (adapted from Collins and Boulbibane, 2000)...... 15

Figure 2.8: Effect of water saturation $(S)$ on settlement of granular materials

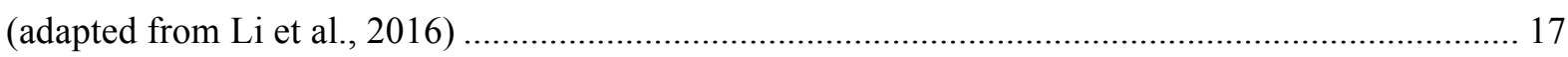

Figure 2.9: Remote video monitoring setup (Vorster and Gräbe, 2013) .......................................... 21

Figure 2.10: Relative MDD measured deflection versus estimated deflections

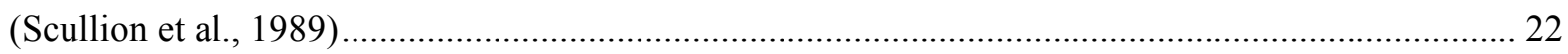

Figure 2.11: Common features of all inverse analysis methods (adapted from Lytton, 1988)............. 23

Figure 2.12: General multi-layered linear-elastic system

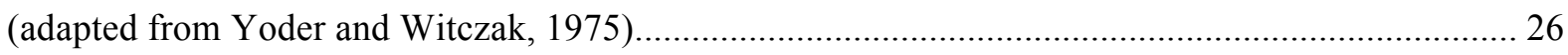

Figure 2.13: Ranges of pavement layer on the deflection basin shape (Li et al., 2016)..................... 28

Figure 2.14: Curvature zones of deflection basins (adapted from Horak, 2008).................................. 29

Figure 2.15: Multi-layer pavement system response (adapted from Jooste, 1992) ............................ 30

Figure 2.16: $45^{\circ}$ load distribution through pavement layers (adapted from Ullidtz, 1987)................. 31

Figure 2.17: The effect of pavement structure on deflection basins (SAPEM, 2014)......................... 32

Figure 2.18: The variation of pavement elastic modulus on deflection measurements

(Tam, 1985).

Figure 2.19: Typical wheel load distribution into railway ballasted track structures

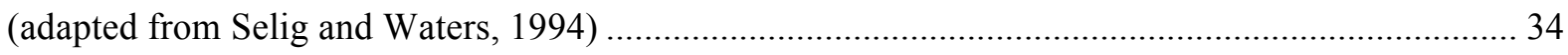

Figure 2.20: Overlap of influence lines in the ballast layer

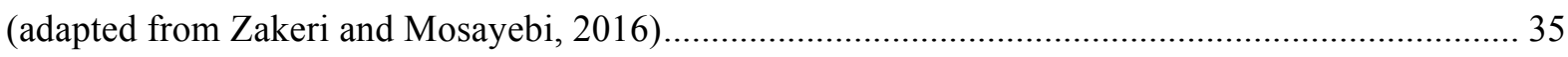

Figure 2.21: (a) 38 tonnes axle load and $2.4 \mathrm{~m}$ spacing; (b) 30 tonnes axle load and $4.8 \mathrm{~m}$ spacing

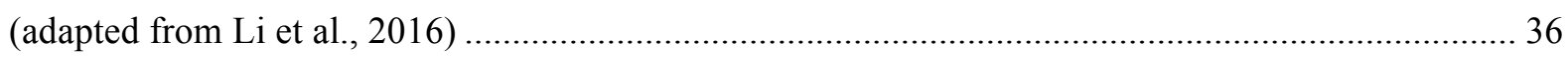

Figure 2.22: (a) Surface deflection basin (FWD); (b) In-depth deflection profile (MDDs)................ 38

Figure 2.23: (a) Total formation deflection with inverse method; ..................................................... 39

Figure 3.1: Foundation design at Bloubank test site (Gräbe and Shaw, 2010) ................................... 42

Figure 3.2: Plan view of test section layout (adapted from Gräbe and Shaw, 2010)........................... 44 
Figure 3.3: Cross section of test station layout (adapted from Shaw, 2005)

Figure 3.4: Multi-depth deflectometer system

Figure 3.5: (a) Vertical strain gauge layout; (b) Cross section layout (A-A)

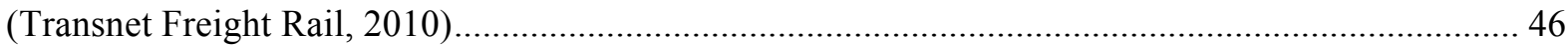

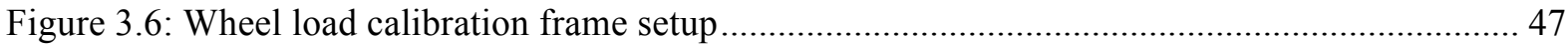

Figure 3.7: Typical formation deflection measurements in time-domain............................................. 48

Figure 3.8: Typical formation deflection measurements in space-domain......................................... 48

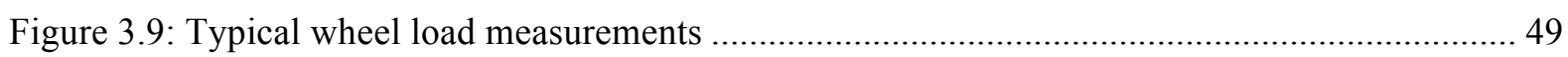

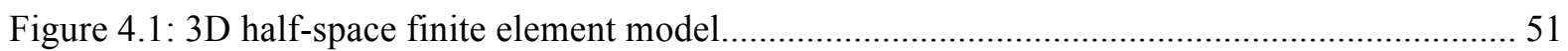

Figure 4.2: Cross section of finite element railway track model ....................................................... 52

Figure 4.3: Finite element modelling of a single moving wheel load ............................................... 53

Figure 4.4: Finite element modelling of 7E or 11E locomotive bogie loading .................................. 53

Figure 4.5: (a) Centre of sleeper - Position 1; (b) Between sleepers - Position 2 ................................ 55

Figure 4.6: Substructure deflection with increasing distance at the top of the ballast layer................. 56

Figure 4.7: Substructure deflection at the top of special subballast layer calculated at Line A ........... 56

Figure 4.8: Transient substructure deflection for moving point loads calculated at Point C................ 57

Figure 4.9: Substructure vertical stress for different load positions calculated at Line B ................... 58

Figure 4.10: Transient substructure deflection for different locomotive types at centre of sleeper ..... 59

Figure 4.11: Substructure vertical stress for different locomotive types at centre of sleeper............... 60

Figure 4.12: Transient substructure deflection for different elastic moduli at centre of sleeper .......... 61

Figure 4.13: Substructure vertical stress for different elastic moduli at centre of sleeper.................... 62

Figure 4.14: Transient substructure deflection for different Poisson's ratio at centre of sleeper......... 63

Figure 4.15: Substructure vertical stress for different Poisson's ratio at centre of sleeper .................. 63

Figure 4.16: Wheel load positioning and influence lines on individual substructure layers ............... 65

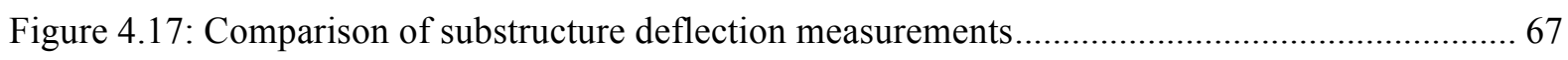

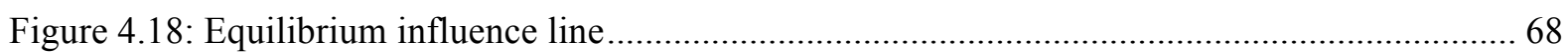

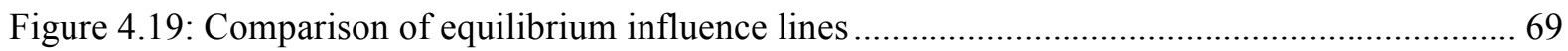

Figure 5.1: Normalization of bogie transverse dynamic effects ....................................................... 72

Figure 5.2: Normalization of noise and bogie longitudinal dynamic effects..................................... 72

Figure 5.3: Characterisation of half-space deflection measurements and parameters .......................... 73

Figure 5.4: Normalization of deflection curvature for inverse analyses............................................ 74

Figure 5.5: Analysis of axle loading on deflection parameters ....................................................... 75

Figure 5.6: Influence of travelling speed and axle loading on deflection parameters .......................... 76

Figure 5.7: Transient substructure deflections converted to the space domain ................................... 79

Figure 5.8: Normalization of curvature for transient substructure deflections ...................................... 79 
Figure 5.9: Local substructure deflections for different subgrades 80

Figure 5.10: Equilibrium influence lines for different subgrades.................................................... 81

Figure 5.11: Linearization of formation equilibrium influence lines ............................................... 82

Figure 5.12: Piecewise regression on formation equilibrium influence lines..................................... 82

Figure 5.13: Substructure vertical stress for different subgrades ...................................................... 84

Figure 5.14: Transient substructure deflection measurements for long-term model ............................. 85

Figure 5.15: Normalization of deflection curvature for long-term model .......................................... 86

Figure 5.16: Local substructure deflection measurements for long-term model ................................. 86

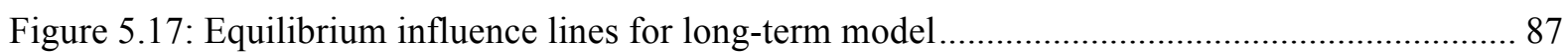

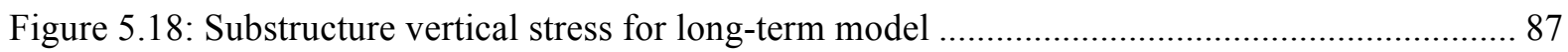

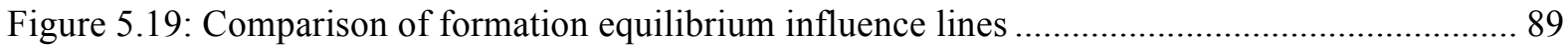

Figure 5.20: Comparison of inverse model and Bloubank local substructure deflections

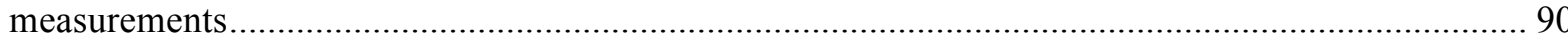

Figure 5.21: Comparison of inverse model and Bloubank transient substructure deflection measurements

Figure 5.22: Estimated formation layer boundaries on transient substructure deflection

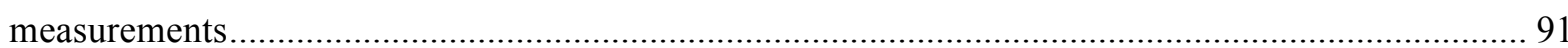

Figure 5.23: Validation of the inverse method through peak strain comparison.................................. 92

Figure 5.24: Long-term analysis of cumulative local deflection measurements ................................. 93

Figure 5.25: Long-term deflection analysis of formation layers ........................................................ 94

Figure 5.26: Long-term analysis of cumulative transient deflection measurements ........................... 95

Figure 5.27: Long-term analysis of formation equilibrium influence lines........................................ 96

Figure 5.28: Analysis of the inverse method for long-term condition assessment .............................. 97

Figure 5.29: Formation equilibrium influence line for the modelled conditions................................. 99

Figure 5.30: Vertical Substructure stress for the modelled conditions .............................................. 99

Figure 5.31: Inverse method on remote video monitoring measurements........................................ 100 


\section{LIST OF ABBREVIATIONS}

$\begin{array}{ll}\text { BOEF } & \text { Beam on Elastic Foundation } \\ \text { EIL } & \text { Equilibrium Influence Line } \\ \text { FEA } & \text { Finite Element Analysis } \\ \text { FEM } & \text { Finite Element Model } \\ \text { FWD } & \text { Falling Weight Deflectometer } \\ \text { HBM } & \text { Hottinger Baldwin Messtechnik } \\ \text { HDPE } & \text { High Density Polyethylene } \\ \text { LVDT } & \text { Linear Variable Differential Transformer } \\ \text { MDD } & \text { Multi-Depth Deflectometer } \\ \text { MGT } & \text { Million Gross Tonnage } \\ \text { PIV } & \text { Particle Image Velocimetry } \\ \text { RVM } & \text { Remote Video Monitoring } \\ \text { SAPEM } & \text { South African Pavement Engineering Manual } \\ \text { SB } & \text { Subballast } \\ \text { SSB } & \text { Special Subballast } \\ \text { TRF } & \text { Transnet Freight Rail }\end{array}$




\section{INTRODUCTION}

In this chapter, the background to the problem addressed in this research study is discussed as well as the objectives and scope of the research. The organisation of the report is then presented.

\subsection{BACKGROUND}

The demand on South African railway freight lines is growing constantly with respect to train speeds and axle loading, thus increasing the forces and stresses experienced by the track structure. This may lead to rapid track deterioration as a result of a loss in track geometry caused by the poor and nonuniform underlying support. The railway engineering industry has moved towards gaining a better understanding of track formation behaviour for development of practical and effective deflection measurement techniques that allow accurate determination of formation structural capacity, assisting with the identification of track problem areas and evaluation of track condition. This also includes providing a long-term solution to improving track performance in addition to what is provided by existing visual track inspection, thus lengthening the service life through cost-effective maintenance.

Several deflection measurement techniques have been developed for evaluating railway track formation structural capacity under static or dynamic impulsive loading by deriving the elastic moduli and/or stiffness values of the substructure layers. This is commonly done by means of depth deflection profiles or surface deflection basins measured with multi-depth deflectometers (MDDs) and the falling weight deflectometer (FWD) respectively. However, there is a need to develop a deflection measurement method that can accurately evaluate the track formation condition through analysis of the full deflection basin under train passage, in order to quantify the formation structural capacity based on the relevant in-service conditions. Furthermore, an ideal method should be inexpensive, non-destructive, simple to install and operate, allow measurement at different locations, provide high levels of deflection measurement reproducibility and estimate structural integrity under train transient loading.

Numerous factors affect the size and shape of deflection basins of a railway track structure such as: loading configuration, superstructure characteristics and substructure condition. Finite element analysis (FEA) is a useful engineering tool that allows testing of infinite permutations of track loading and subsequent evaluation of railway formation deflections and stresses for an improved understanding of railway track formation response. 
This research study aims to provide insight into the development of an innovative mechanistic-empirical method based on surface deflection theory that will allow estimation of formation elastic moduli under train transient loading using an inversion technique.

\subsection{OBJECTIVES OF THE RESEARCH}

The objective of this research is to characterise railway track formation condition by inferring the elastic modulus of the formation layers through the inverse analysis of substructure deflections measured at a single point on the ballast/subballast interface under train transient loading. To this end, a mechanisticempirical method was developed based on the pavement surface deflection theory adapted from FWD analysis as utilised in road pavement engineering. The method was founded on the hypothesis that a railway track formation could also be assessed through the analysis of formation deflection measurements and an estimated railway influence line. Subsequently, estimating the relative formation layer deflections and elastic moduli with the aim of determining the structural capacity of the formation over the design life. The main objectives of this research are to:

- Investigate the influence of different bogie loading and substructure material properties on railway track formation deflections, stresses and railway formation influence lines;

- Normalise the train loading dynamic effects and determine its influence on formation deflection measurements;

- Evaluate whether the $45^{\circ}$ influence line (commonly assumed in the FWD and other surface deflection measuring techniques) is an appropriate assumption for railway track structures. Alternatively, determine and discuss the railway formation influence line for inverse analysis;

- Determine the suitability of the inverse method for estimation of the long-term railway track formation behaviour;

- Evaluate and critically discuss whether the inverse method is adequate for characterisation of a railway track formation.

\subsection{SCOPE OF THE RESEARCH}

This research focuses on the characterisation of a railway track formation through the inverse analysis of substructure deflections under train loading. The deflection of the ballast layer was disregarded due to its large influence on the track substructure response. A 3D half-spaced linear-elastic finite element railway track model based on the Transnet Freight Rail 26 tonne/axle heavy haul line specification was built. All materials were assumed to respect Hooke's Law with linear elastic, homogenous and isotropic 
properties. Different bogie loading as well as substructure material properties were analysed and the results were discussed. Superstructure components as well as ballast layer characteristics were kept constant and railway formation equilibrium influence lines were determined.

The effects of train travelling speed and axle loading on MDD formation deflection measurements were evaluated. The validation of a generic railway track model was conducted through the comparison of the estimated formation layer strains and the actual measured strains. Formation layer strains were calculated under the assumptions that permanent deformations are negligible. Thus, formation thickness was kept constant. The evaluation of long-term formation response was conducted on 7E locomotive results measured at a single MDD station considering field data from 2004 to 2017. The implementation of the method was conducted through the inverse deflection analysis of remote video monitoring measurements only.

\subsection{METHODOLOGY}

A literature review was conducted to understand railway track formation behaviour under train transient loading. The inverse analysis of pavement surface deflection measurements was studied with the objective of developing a mechanistic-empirical method for railway formation characterisation. A brief description of the investigated experimental test site is presented. Thereafter, a finite element linearelastic railway track model based on the experimental test site was developed using Strand 7 FEA software, with the aim of investigating railway track formation deflections and the true formation influence line.

Furthermore, field data was analysed in order to determine the effect of train transient loading on deflection measurement variability. The hypothesised inverse method is then presented and the results are discussed with regard to its applicability for characterisation of railway track formation. Conclusions and recommendation are subsequently drawn.

\subsection{ORGANISATION OF THE REPORT}

The report consists of the following chapters and appendices:

- Chapter 1 describes the importance, objectives, limitations and methodology of the research;

- Chapter 2 presents a literature review on rail track components, formation loading and deformation, in-situ deflection measuring techniques and inverse analysis of deflection 
measurements;

- Chapter 3 describes the experimental test site, instrumentation and the typical measurement results obtained from it;

- Chapter 4 describes the developed finite element model for preliminary investigation of railway track responses;

- Chapter 5 presents and discusses the results for the developed inverse method;

- Chapter 6 provides the conclusions that were drawn from this research and includes the recommendations for future research;

- Chapter 7 presents the list of references used in the research;

- Appendices A-D contain the inverse analysis results of different locomotives and substructure compositions. 


\section{TECHNICAL LITERATURE REVIEW}

This chapter provides a brief discussion of the railway track components and a comprehensive review of loading conditions and track formation deformation. A discussion of the aforementioned topics is important as railway track formation behaviour under train transient loading is considered relevant for this investigation. The focus is then shifted to the inverse analysis of deflection measurements. Thus, various in-situ instruments for deflection measurements are presented. Literature on the premise of inverse analysis and finite element analysis is presented followed by a review of the interpretation and the influential factors related to the shape of surface deflection measurements. This chapter is then concluded with a discussion on how the presented sections are relevant for this research, followed by a brief description of the hypothesised method.

\subsection{RAILWAY TRACK COMPONENTS}

The primary objective of railway transportation is to provide safe and economic transportation. It is noticeable how the railway industry has evolved during the past 150 years due to the need for development, associated with the increase of daily trains, speed and axle loads (Li et al., 2016). To meet the objectives, it is fundamental to construct a durable, reliable and stable track structure that performs satisfactorily under the train loading and prevails through the environmental conditions (Selig and Waters, 1994).

As illustrated in Figure 2.1, the track structure can be divided into two main categories: superstructure and substructure, consisting of the following components:

- Superstructure: Rails, fastening system and sleepers. The purpose of these components is to sustain the train loading by reducing the stresses at the wheel-rail interface to acceptable levels for the substructure.

- Substructure can be subdivided into two further categories: ballasted and ballastless substructure.

- Ballasted: Ballast, subballast and subgrade;

- Ballastless: Subbase and subgrade. 


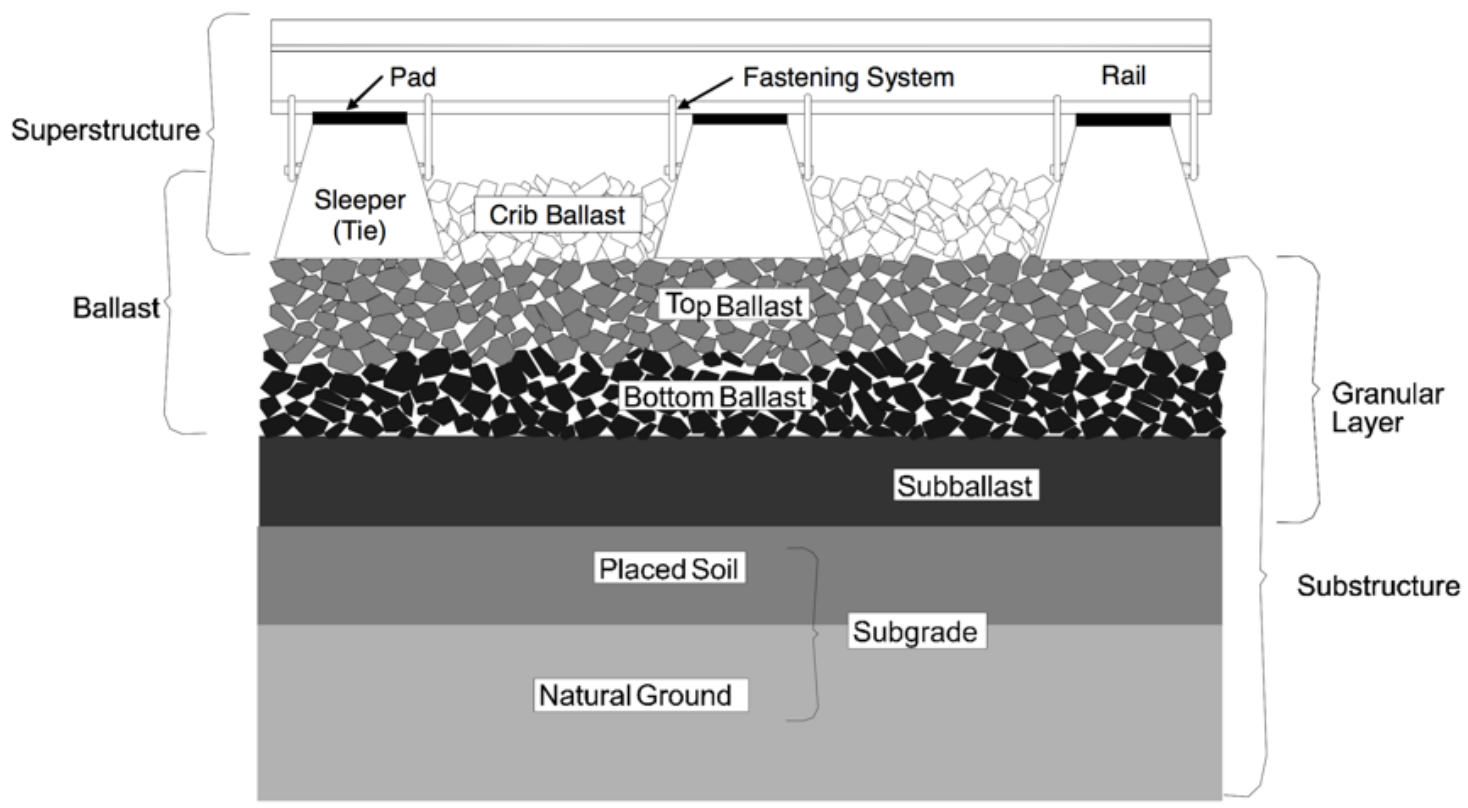

Figure 2.1: Railway track structure components (adapted from Selig and Waters, 1994)

\subsubsection{Rails}

The rails are the two continuous longitudinal high-strength steel members which may be either bolted together or welded. The rail's function is to guide the wheels in an even and continuous manner, minimizing wheel-rail wear (Li et al., 2016). Rails should have appropriate stiffness to support and transfer the wheel loads to the spaced sleepers restricting track deflections. Furthermore, rails serve as electrical conductors for the signalling system as well as the ground line for the electric locomotive power circuit (Selig and Waters, 1994).

\subsubsection{Fastening System}

The fastening system (or fasteners) consists of the components that connect the rails and sleepers, restricting the movement (transversal, longitudinal, vertical and overturning) of the rails relative to the sleepers. Additionally, rail pads are utilised to insulate the fastener from the sleeper, providing resiliency, damping the induced wheel vibrations, reducing dynamic load attenuation and preventing contact attrition between the rail and sleeper (Selig and Waters, 1994). 


\subsubsection{Sleepers}

Sleepers (or cross-ties) are the transverse supporting members underneath the rails. In South Africa, the sleepers are predominantly made of concrete, even though wood, steel and plastic may also be found. According to Selig and Waters (1994) sleepers have the following functions:

- Transfer of the rail load at acceptable levels to the supporting ballast;

- Maintain adequate track gauge and hold the fastening system;

- Restrain lateral, longitudinal and vertical movements by anchoring into the crib ballast.

\subsubsection{Ballast}

Ballast is a granular selected material that consists of hard, large, crushed, angular, uniformly graded particles and is also free of dust and dirt. This material can be found in the upper part of the substructure which makes contact with the sleepers, acting as the foundation for the superstructure. The ballast functions for a well-supported track structure are (Selig and Waters, 1994; Li et al., 2016):

- To support lateral, longitudinal and vertical (including uplift) forces on the sleeper/ballast interface and maintain the track in its position;

- To provide large voids for fouling material storage;

- To facilitate the adjustment of track geometry (lining operations) and maintenance operations;

- To provide resiliency and energy absorption for dynamic forces;

- To provide drainage;

- To reduce airborne noises;

- To provide electrical resistance between rails.

To accomplish all the ballast functions, it is essential to obtain an adequate layer thickness, particle size, gradation, compaction, drainage and storage for fouling material. These ballast characteristics are fundamental for adequate structural capacity and train loading transfer, reducing the stress levels and the rate of deformation of the subgrade over its life (Li et al., 2016).

\subsubsection{Subballast}

The subballast also known as the blanket or protective layer is located between the ballast and the subgrade. The subballast layer is a granular selected material, with a specific thickness, particle size, 
gradation and compaction. The availability and economical aspects of this material are the main factors that determine the selection of subballast materials for construction. Thus, a large variety of materials have been used for this application (Selig and Waters, 1994). Similar to the ballast, the subballast layer distributes the train loading and reduces the induced stresses to acceptable levels for the deeper layers (Li et al., 2016). Furthermore, the functions that must be fulfilled by the subballast alone are (Selig and Waters, 1994):

- To prevent interpenetration of ballast into subgrade and act as a filter to avoid the upwards subgrade fines to migrate into the ballast;

- To provide drainage for the upwards flowing water from the subgrade;

- To restrict the water flowing from the ballast into the subgrade, re-directing it into the side ditches or drainage system.

\subsubsection{Subgrade}

The subgrade or formation is the platform that provides uniform and adequate support to the entire track structure and consists of soil or rock. The subgrade material generally consists of natural soil (coarse types of sand and gravel or fine types of silt and clay) or placed soil, depending on the track section (Li et al., 2016).

Emphases on the design, construction method and soil characteristics such as: soil type, grading, physical state (moisture content and density), mechanical properties (strength and stiffness) are critical aspects for an adequate and serviceable track structure, ensuring that (Brown, 1996; Li et al., 2016):

- The subgrade is stable under self-weight, with low deterioration under consolidation settlement, substantial track instability or shearing and insensitive to environmental damages;

- No occurrence of plastic strains is allowed under moving train loading, forming into a progressive shear failure (subgrade squeeze) resulting in ballast pockets.

\subsection{LOADING CONDITIONS ON RAILWAY FORMATION}

The main objective of formation materials is to sustain the traffic load by spreading the induced stresses to the underneath layers, ensuring that substructure layers are not overstressed at any given time during their service life. Railway track formation loading can occur in three manners namely: static, cyclic and dynamic. This section discusses each formation loading and their effects on the formation behaviour. 


\subsubsection{Static Loading}

Static loading on the formation can be divided into two categories: dead and live load. The two static load categories are defined as follows (Li et al., 2016):

- Dead load is the resultant of the self-weight of the railway track structure: superstructure components and substructure layers. The self-weight of each railway track is unique as it depends on the design: type of track, rail type, sleeper spacing and type, and selected granular substructure materials. This is known as overburden pressure (Ullidtz, 2002).

- Live load is an additional and temporarily induced load that can vary according to the train length, axle load and the resultant directional components (longitudinal, vertical and lateral forces).

Dead and live loads result in different formation stress distribution behaviour with depth, as shown in Figure 2.2. The dead load stress distribution tends to increase with depth due to the overburden pressure of each individual layer as depth increases. The stresses may be insignificant depending on the depth, becoming more significant at depths greater than 1 meter. On the contrary, the live load stress distribution from a static wheel load dissipates with increasing depth. The track live load spreading capabilities are influenced by the rail stiffness, sleeper spacing and the structural capacity of the supporting granular layers (Li et al., 2016).

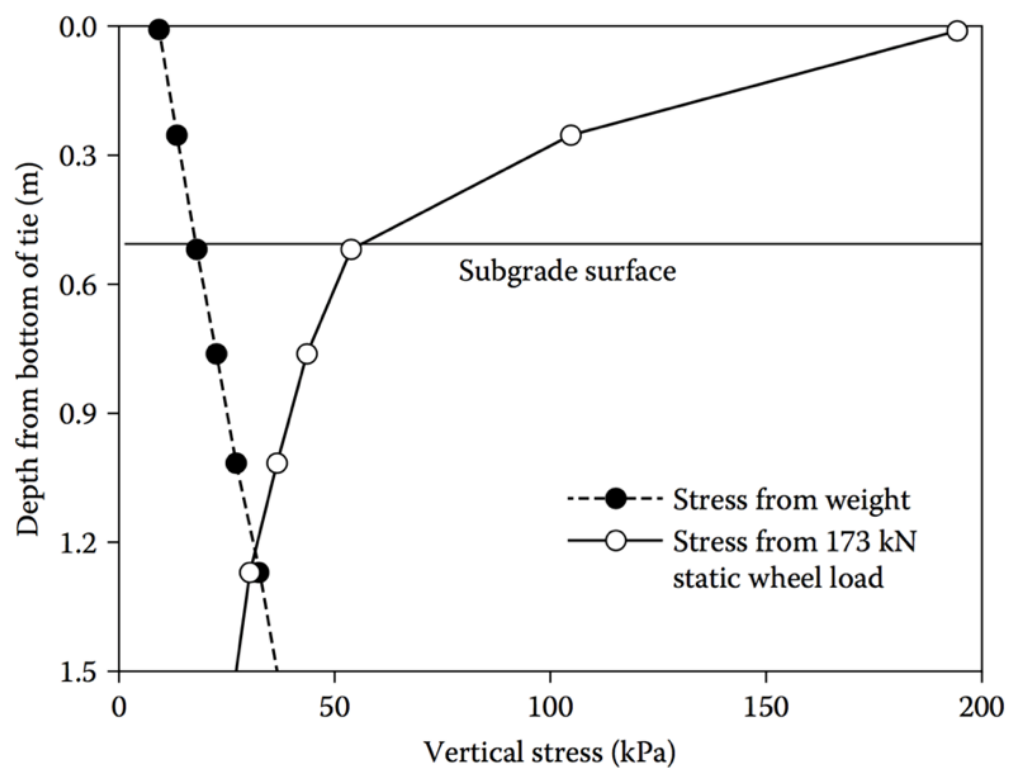

Figure 2.2: Dead and live static loading on the formation stress distribution (Li et al., 2016) 


\subsubsection{Cyclic Loading}

Cyclic loading is repeated train wheel loading pulses that dissipate in relation to the superstructure components and the substructure condition with depth. Cyclic loading pulses result in different formation stresses and strains compared to stresses and strains from static loads. The effect of cyclic loading on railway formation is influenced by the following factors (Li et al., 2016):

- Load shape;

- Load duration;

- Loading pulse magnitude;

- Time interval between successive loading cycles;

- Total number of loading cycles.

In terms of train transient loading, these influential factors can be translated into train operational speed, axle loading, bogie wheel spacing, train length and total experienced traffic. Furthermore, the cyclic loading rate (train travelling speed) and its variation (axle loading) has an effect on the strength and stiffness of the supporting layers. This effect is relatively small for ballast and subballast materials, while subgrade materials tend to be more susceptible to the loading rate. Yet all granular materials are susceptible to cyclic loading under saturated undrained conditions ( $\mathrm{Li}, 1991)$.

\subsubsection{Dynamic Loading}

Dynamic loading is generally characterized as short or long duration forces. Short duration forces are high frequency impact loads resulting from localized structural imperfections, such as rail or wheel discontinuities. Alternatively, long duration forces are low frequency dynamic loads produced by the long wave lengths due to track geometry irregularities (Li et al., 2016).

Dynamic wheel loads can also occur as a result of bogie miss-alignment and variation in rail temperature (contraction and expansion) inducing transverse and longitudinal forces respectively (Jenkins et al., 1974). A dynamic increase in cyclic formation loading commonly causes localised formation distress due to overstressing of the various track components which leads to ballast breakage and an overall reduction in sleeper support at a specific location (Gräbe et al., 2005). This decrease in sleeper support generates an increase in formation loading which influences the contact forces, stress path and levels. This results in higher stresses deeper in the substructure, eventually weakening the material and causing a structural impairment that leads to formation deformations (Gräbe et al., 2005; 
Lundqvist and Dahlberg, 2005; Priest and Powrie, 2009; Yang et al., 2009; Wilk et al., 2016). This process is illustrated in Figure 2.3.

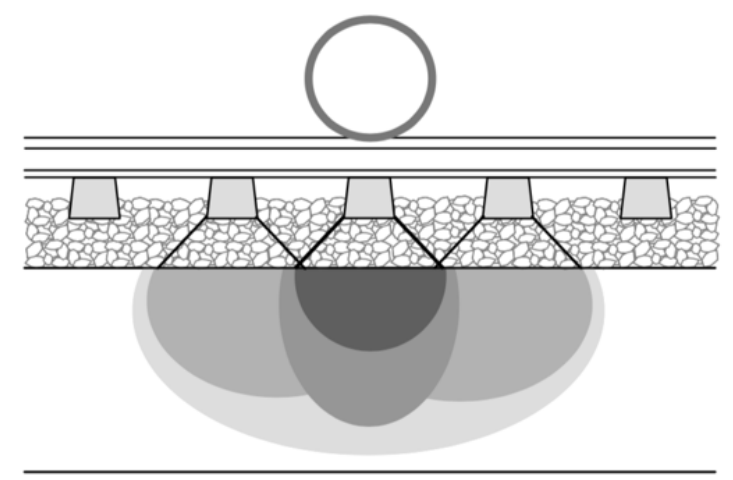

(a) Track with uniform ballast support

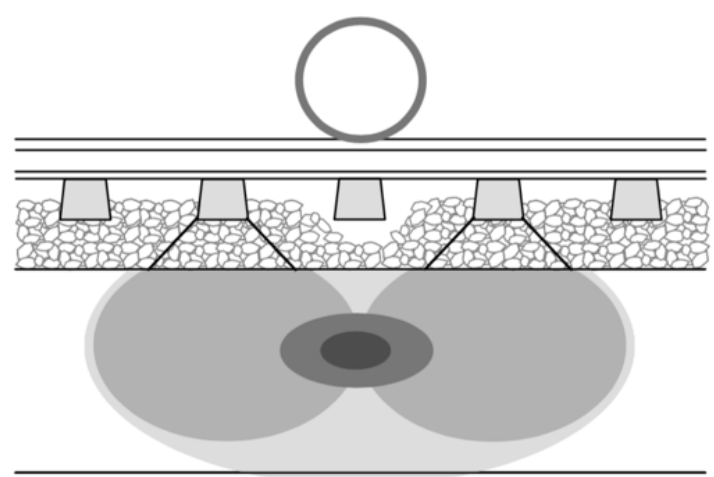

(b) Track with non-uniform ballast support

Figure 2.3: Stress contours due to different ballast support conditions (Gräbe et al., 2005)

For design purposes, the dynamic wheel load can be calculated using a dynamic impact factor multiplied by the designed static wheel load (Li et al., 2016). In South Africa, Transnet Freight Rail uses Eisenmann's statistical approach for the determination of the dynamic impact factor and wheel load as presented in Equations 2.1 and 2.2 respectively (Eisenmann, 1975):

$$
\varphi=1+\delta \eta t
$$

(Equation 2.1)

Where:

$\varphi=$ dynamic impact factor;

$\delta=$ track condition;

$\eta=$ speed factor;

$t=$ upper confidence level.

$$
P_{\text {dynamic }}=\varphi \times P_{\text {static }}
$$

Where:

$P_{\text {dynamic }}=$ dynamic wheel load;

$P_{\text {static }}=$ static wheel load.

In order to overcome some of the differences observed in granular material responses under static and dynamic testing, Brown and Selig (1991) suggested measuring railway track formation behaviour under train transient loading, thus allowing characterisation of the relevant in-service conditions 
(Priest and Powrie, 2009). In this regard, it is vital to investigate and determine the effect of travelling speed and axle loading as well as mitigating all dynamic effects on the railway track structure.

\subsection{DEFORMATION OF RAILWAY FORMATION}

Railway substructure materials can experience either resilient or permanent deformations under train transient loading. This section discusses granular material deformation in terms of loading conditions, soil characteristics and physical soil states.

\subsubsection{Resilient Deformation}

Resilient deformation is the short term recoverable elastic deformation that takes place in the formation after being subjected to train transient loading allowing for almost full recovery as the soil particles are unloaded, resulting in small elastic strains relative to the plastic strains (Brown, 1996; Gräbe, 2002; Gräbe et al., 2005). Furthermore, the rate of resilient deformation is dependent on the material strength under repetitive loads. Figure 2.4 shows how the resilient strain $\left(\varepsilon_{r}\right)$ of granular materials is characterised by the resilient modulus $\left(M_{R}\right)$ and the deviator stress $\left(\sigma_{d}=\sigma_{l}-\sigma_{3}\right)$ (see Equation 2.3 (Huang, 2004)).

$$
M_{R}=\frac{\sigma_{d}}{\varepsilon_{r}}
$$

Where:

$\sigma_{d}=$ Deviator stress;

$\varepsilon_{r}=$ Elastic strain

The difference between resilient and permanent strains with cyclic loading are illustrated in Figures 2.4 and 2.5. Furthermore, the resilient and permanent deformation of granular materials are influenced by the following factors ( $\mathrm{Li}$ and Selig, 1996; Lekarp et al., 2000a; Lekarp et al., 2000b; Soliman and Shalaby, 2015):

- Loading condition: Magnitude and confinement of stresses, principal stress rotation, repetition of loads, as well as their successions and stress history;

- Soil characteristics: Aggregate type, particle shape, proportion of fines, gradation, compaction effort and methodology; 
- Physical soil state: Density, moisture content, void ratio and the prevailing environmental conditions.

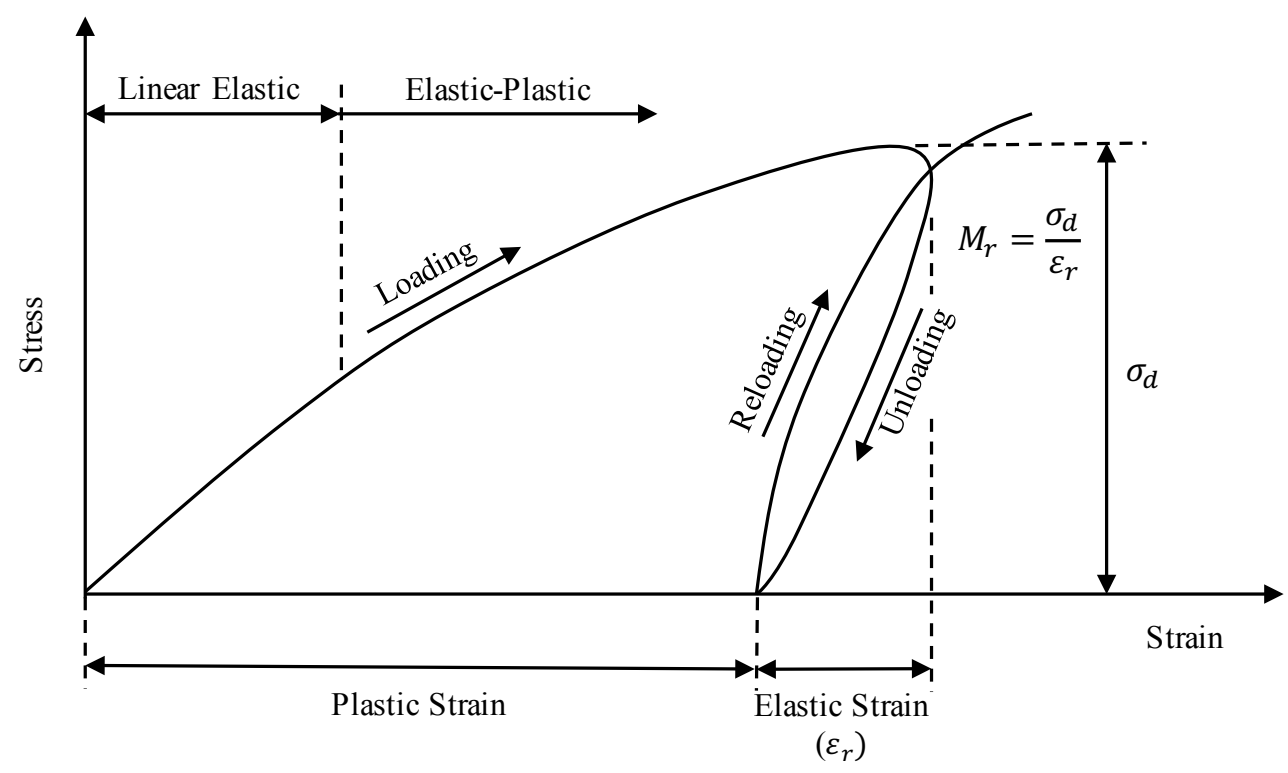

Figure 2.4: Soil strain during one load cycle (adapted from Huang, 2004)

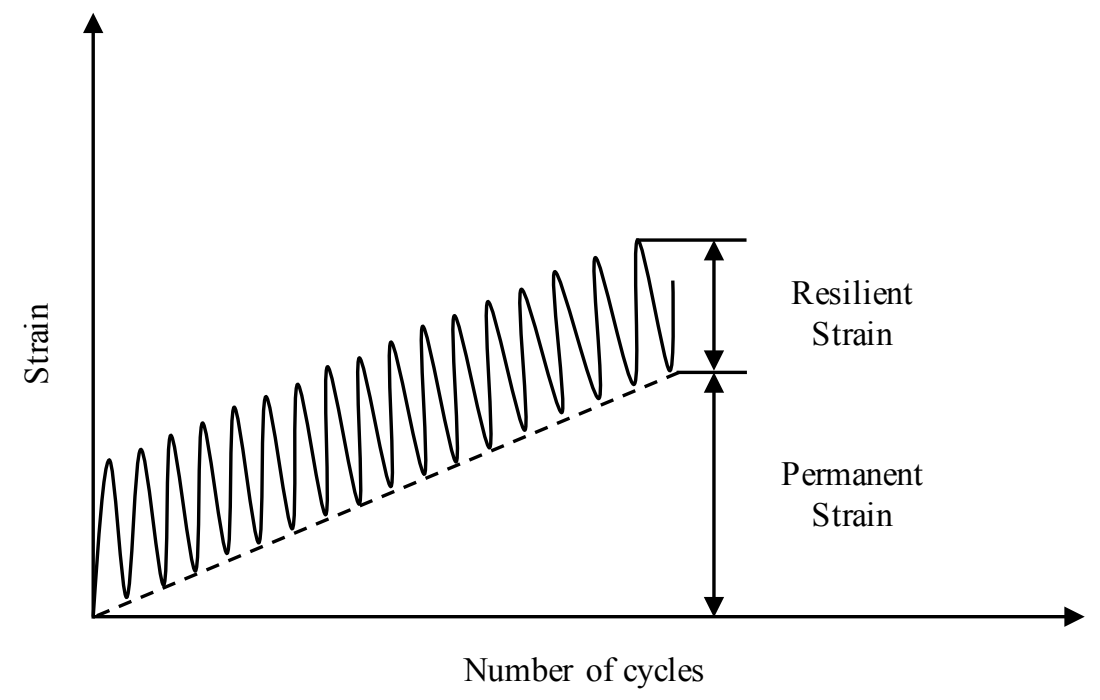

Figure 2.5: Resilient and permanent strains over infinite number of load cycles (adapted from Selig and Chang, 1981)

In addition to the above, the South African Pavement Engineering Manual (SAPEM, 2014) also characterised the influential properties that affect pavement material behaviour as follows:

- Fundamental properties: Particle size, grading, inter-particle friction, cohesion, elasticity, plasticity, viscosity, particles hardness, durability, porosity and absorption; 
- Situational properties: Density, moisture content, soil suction, temperature and degree of support;

- Engineering properties: Ultimate strength in terms of shear, tensile and compression strength, elastic modulus, resistance to deformation and fatigue.

\subsubsection{Permanent Deformation}

Permanent deformation of granular materials occurs as the number of repeated load cycles increases causing irrecoverable plastic strains which strongly influence the long-term performance of the railway track due to progressive formation settlement (Li and Selig, 1996). Furthermore, Gräbe et al. (2005) also noted that principle stress rotation reduces the stiffness of the formation material during train transient (cyclic) loading and increases the permanent deformation with time. As shown in Figure 2.6, principle stress rotation influences the vertical, horizontal and shear stresses in relation to the wheel load movement and orientation (Yoder and Witczak, 1975; Lekarp et al., 2000a).

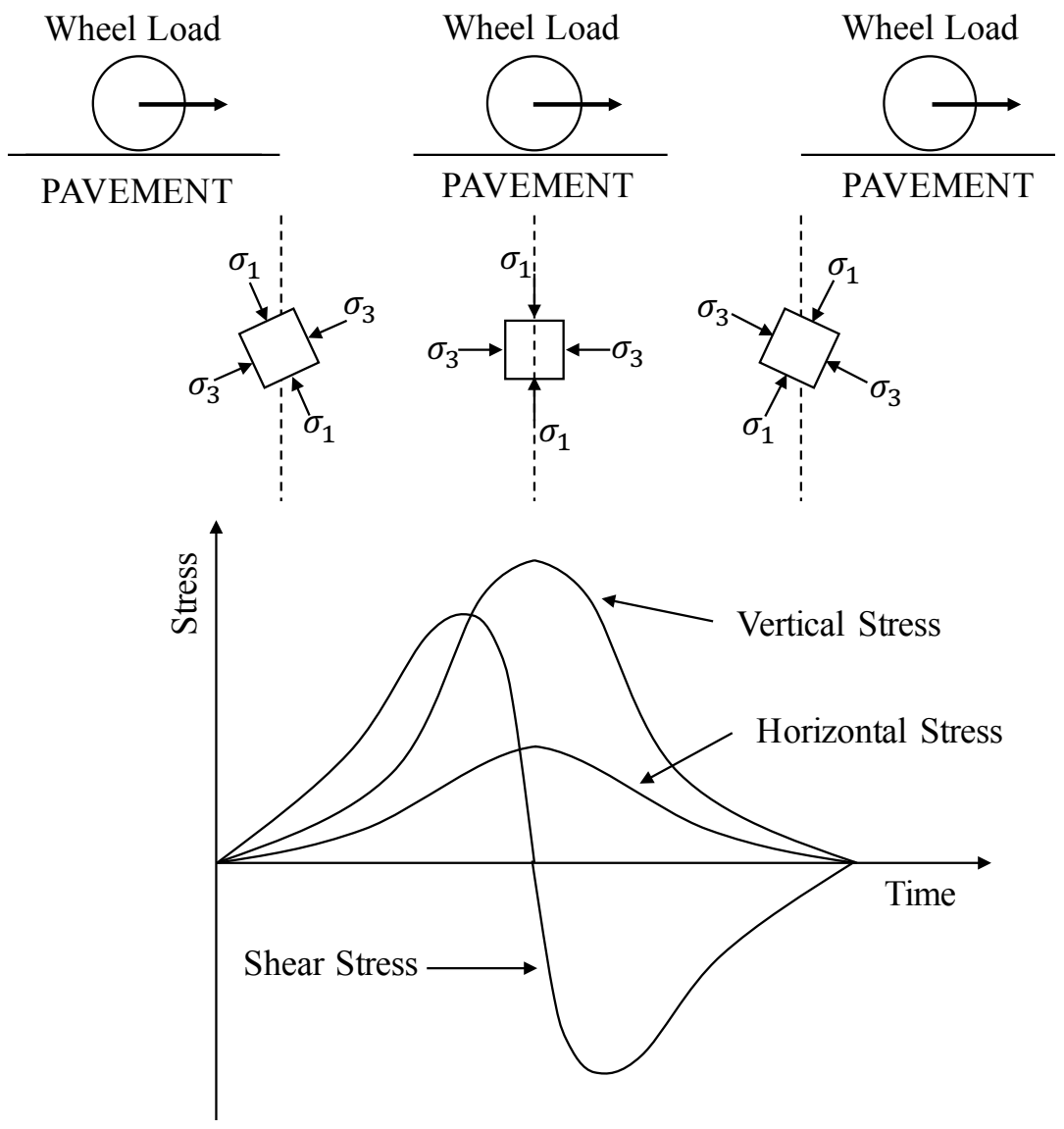

Figure 2.6: Principal stress rotation (adapted from Lekarp et al., 2000a) 
Permanent deformation manifests through the combination of two mechanisms namely: densification (change in volume) and repetitive shear deformation (plastic flow with no volume change). Densification and shear deformation can be compensated through appropriate construction and material design ensuring the minimum required compaction effort, layer thickness and stiffness subsequently mitigating the potential increase of permanent strain (Monismith et al., 1975; Yoder and Witczak, 1975; Lekarp et al., 2000a).

Furthermore, the formation deformation is governed by the shakedown behaviour of unbound granular material under repeated loading (Soliman and Shalaby, 2015). As shown in Figure 2.7, resilient (elastic) and permanent (plastic) deformation are defined by the granular material limits according to the four shakedown phases.

1) The elastic phase occurs under the condition that the applied load does not exceed the elastic load for a finite number of applied load cycles, thus, only experiencing elastic strains;

2) Elastic shakedown occurs as the load exceeds the elastic load inducing small permanent strains which converge to a constant resilient strain as the applied load cycles increase;

3) Plastic shakedown occurs as the material experiences higher loads resulting in transient constant permanent deformations with finite number of cycles;

4) The ratchetting phase occurs as the permanent deformation increases indefinitely leading towards granular material failure.

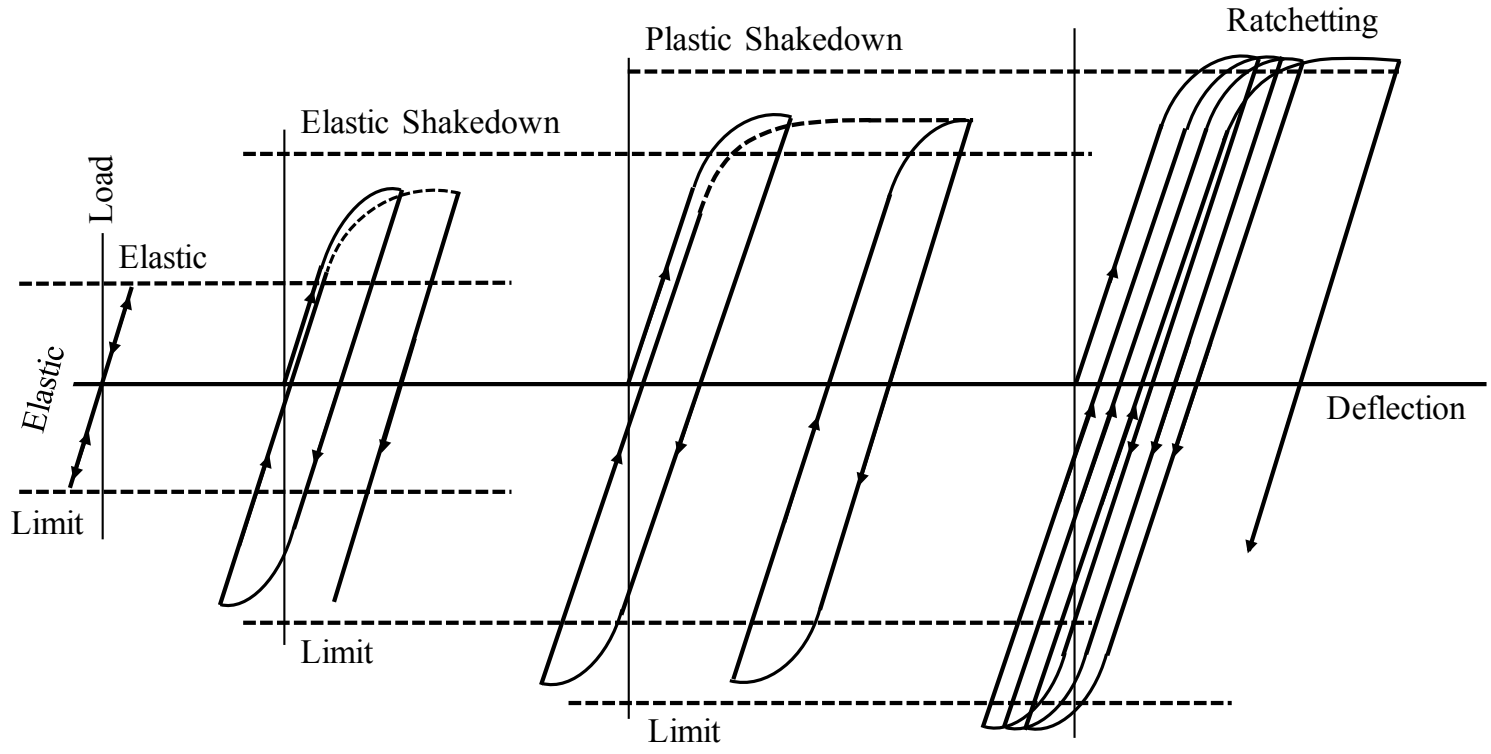

Figure 2.7: Elastic and plastic shakedown phases (adapted from Collins and Boulbibane, 2000) 
As noted, the railway track substructure materials are affected by previous loading and stress history. Furthermore, the rate of permanent deformation in granular material is greatly influenced by the drainage conditions (Brown, 1996) due to the fact that at high levels of saturation, the resistance to deformation of the granular material decreases rapidly. Proper drainage of granular pavement layers and railway track structures is thus of the paramount importance (Li et al., 2016).

\subsubsection{The Influence of Water on the Formation Deformation}

The presence of water in railway track structures is a root cause for substructure problems. There are three main sources from which water may ingress into the railway track structure: direct water, runoff water and groundwater. Independent of the source, excess water remaining in the substructure for prolonged periods of time eventually leads to higher rates and magnitudes of deformation, lower resilient modulus, higher plastic strains and lower shear strength. These characteristics are true for all railway track substructure materials, however, the mechanisms of behaviour differ according to the type of soil, namely granular non-cohesive and fine-grained cohesive soils (Li et al., 2016).

The strength and deformation characteristics of granular non-cohesive soils are governed by the pore water pressure, total and effective stresses. As formulated in Equation 2.4, the increase in pore water pressure weakens the soil strength by reducing the effective stress and consequently lowering the soil strength. Theoretically, if pore water pressure is equal to or greater than the total stress, the material has zero strength.

$$
\sigma^{\prime}=\sigma_{t}-u
$$

Where:

$\sigma^{\prime}=$ effective stress;

$\sigma_{t}=$ total stress;

$u=$ pore water pressure.

Furthermore, Li et al. (2016) stated that particular granular soils under partially saturated or saturated conditions, subjected to cyclic loading due to train passage, develop pore pressures that exceed the total stresses, consequently resulting in excessive deformation, severe rail settlement and loss of structural capacity in the formation layers. Figure 2.8 shows the effect of water saturation on granular materials under a finite number of cyclic loads. 
Similar to granular soils, fine-grained cohesive soils strength and deformation characteristics are governed by the effective stress condition, although fine-grained cohesive soils are also strongly influenced by the clay mineralogy due to the fact that clay particles have electrical charges on their surfaces that dictate the soil strength relative to the presence of water.

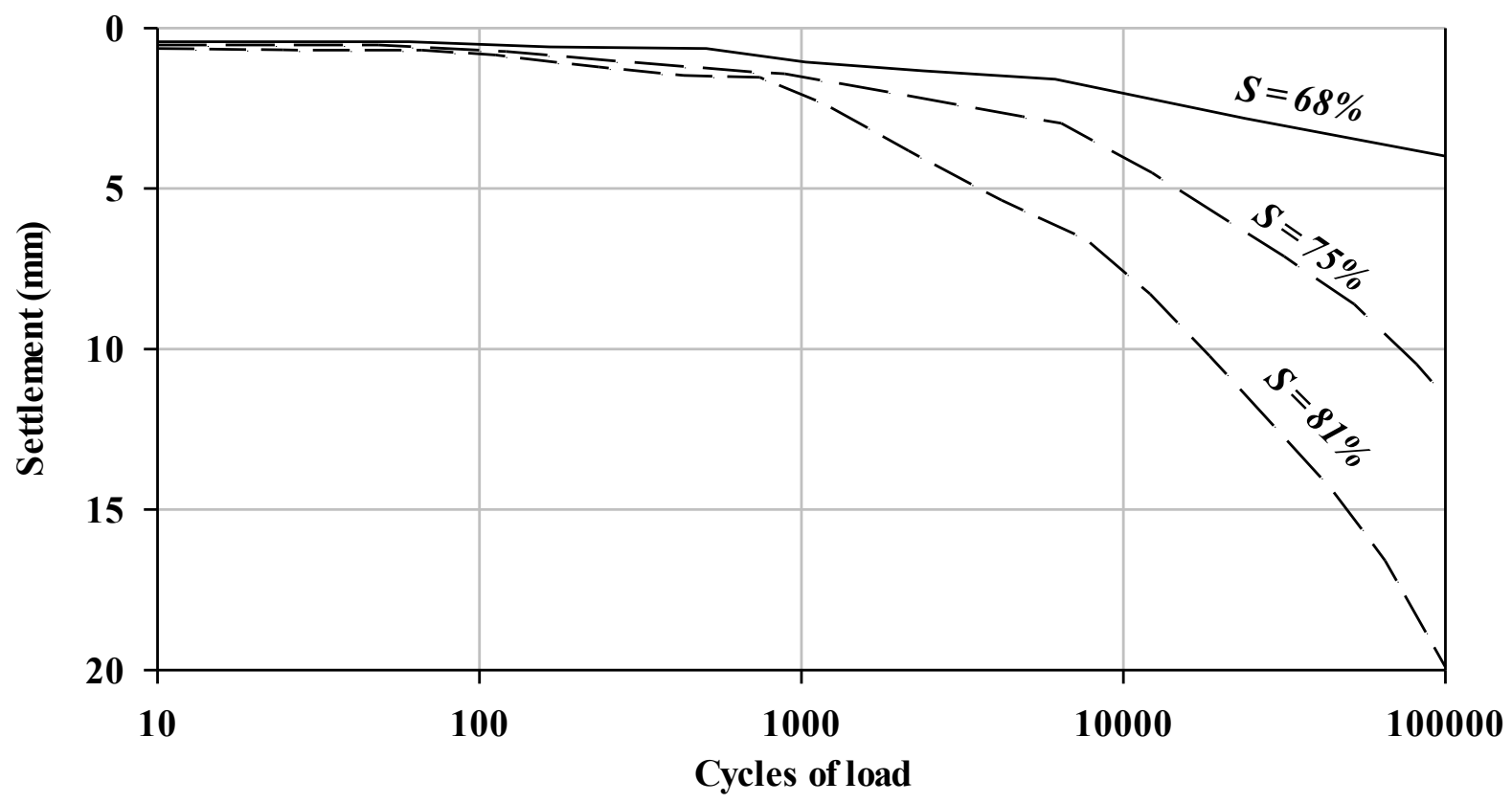

Figure 2.8: Effect of water saturation $(S)$ on settlement of granular materials

(adapted from Li et al., 2016)

\subsection{IN-SITU TESTING OF RAILWAY TRACK FORMATION}

This section discusses the advantages and limitations of non-destructive in-situ instrumentation as well as the applicability of certain railway deflection instruments for inverse analysis of formation material properties. The aim of these analyses is to evaluate the in-service formation condition in a more effective and non-disruptive manner under train transient loading.

\subsubsection{Advantages and Limitations of Non-Destructive In-Situ Testing}

Non-destructive in-situ testing of pavements for inverse analysis of material properties is a highly explored field in railway and pavement engineering, due to the simple and convenient method of proper evaluating the structural integrity and predict the remaining life of pavement structures (Maina et al., 2009). Bush and Baladi (1989) highlighted the main applications of non-destructive insitu pavement testing as follows: 
- Measuring of surface deflections under moving wheel loads for inverse analysis of pavement layer moduli;

- Determining the structural capacity and load transfer of pavements sections,

- Assessing the rate of deterioration and critical times for rehabilitation;

- Analysing the effects of heavier axle loading on the remaining pavement life.

The advantages of in-situ testing for evaluation of track formation condition are (Selig and Waters, 1994; Shaw, 2005):

- Allows testing of highly disruptive soils (difficult to sample), such as granular materials;

- Soil properties can be determined under their natural physical state and over time;

- Soils can be tested under their in-situ stress conditions;

- Soil variability along the track and with depth can be assessed;

- Large volume of soils can be tested;

- Soil sampling and disturbance is avoided;

- In-situ instruments are versatile and easy to install at different locations;

- Testing duration and costs can be significantly reduced.

Deflection measurement is one of few non-destructive in-situ test techniques that allows insight into the pavement system below the surface (Theyse et al., 2015). As a limiting factor, in-situ tests do not measure the real soil properties. Instead, they provide a measure of some soil responses such as displacement, which is used to infer the soil behaviour. These measurements are then translated into soil properties such as stiffness and/or elastic moduli (Selig and Waters, 1994). These soil properties can be obtained through laboratory testing or inverse analysis of either in-situ surface deflection or depth deflection measurements (De Beer et al., 1989) under certain assumptions. In this regard, Selig and Waters (1994) highlighted that the accuracy of in-situ testing is directly associated with the assumptions made for each different testing and calculation method. It is therefore essential to consider these limitations when evaluating results obtained from different tests (Shaw, 2005). According to Selig and Waters (1994), the in-situ testing limitations for inverse analysis of material properties are:

- Boundary conditions may be poorly defined;

- Drainage conditions and soil disturbance are commonly unknown;

- Nature of soils being tested is usually unknown;

- Environmental effects on soils are difficult to assess;

- Repeatability is difficult to obtain. 


\subsubsection{Instrumentation for Deflection Measurements}

Over the years, numerous instruments have been developed and used for the measurement of railway track deflection. In order to maintain brevity, this section discusses the deflection measurement instrumentation that can potentially be utilised for inverse analysis of formation properties under train transient loading.

\section{Multi-Depth Deflectometers}

The multi-depth deflectometer (MDD) system is an instrument developed by the Council for Scientific and Industrial Research (CSIR) in South Africa which comprises a string of linear variable differential transformers (LVDTs) embedded into the pavement structure. The MDDs allow for long term performance monitoring of pavement and railway structures (De Beer et al., 1989; Scullion et al., 1989; Sussmann and Selig, 2000) resulting in an accurate, reliable and stable instrument that allows a better understanding of soil behaviour through the investigation of deflection measurements (De Beer et al., 1989; Gräbe et al., 2005; Gräbe, 2009).

MDD systems allow the measurement of resilient and permanent deformation with depth under train transient loading (Gräbe et al., 2005). MDD modules are commonly placed at the intersection of formation layers allowing for inverse analysis of material properties under the following conditions: known applied load, layer thickness, measured relative layer deflection and an estimated Poisson's ratio. The advantages of MDD systems according to Shaw (2005) are:

- Small strain can be accurately measured since the bedding error is not a factor due to the instrumentation technique;

- Material disturbance during drilling was found to be minimal;

- MDDs do not alter the soil behaviour in the borehole as they are isolated by a flexible tube.

\section{Falling Weight Deflectometer}

The falling weight deflectometer (FWD) is a movable device commonly used in pavement engineering consisting of the measurement of in-situ surface deflections generated by a transient impulsive force. This impulsive force resembles the magnitude and duration of moving wheel loads on a railway track. The deflection magnitude is measured through geophones positioned at increasing distances from the point load. Once these measurements are obtained, an inverse analysis can be conducted to determine 
the stiffness (Horak, 2008; Li et al., 2016) and effective resilient modulus of each pavement layer (Brown, 1996). According to Jooste (1992) the FWD technique has the following advantages:

- Accurate measurements of pavement deflection basins;

- No fixed reference is needed since geophones are utilised;

- Practical device for data acquisition;

- Traffic load magnitude and duration can be simulated;

- No pre-load is required and a wide range of loading can be applied.

Similar to MDD systems, the reliability of the FWD inverse analysis is dependent on the in-depth knowledge of pavement materials and their behaviour as well as the accuracy of the assumptions made regarding the material's Poisson's ratio and layer thickness (Horak, 2008).

\section{Linear Variable Differential Transformer}

A linear variable differential transformer (LVDT) is a widely used instrument for track deflection measurement under train transient loading. As defined by Dunnicliff (1993), LVDTs are frictionless instruments that are suitable for dynamic loading measurement that allows small accurate displacement measurements with no induced hysteresis. LVDTs are commonly used for rail and sleeper deflection measurements for track modulus determination. These measurements are obtained by either clamping the LVDTs to rods embedded into the track formation below the ballast or to a mechanically designed arm that extend past the train vibration influence zone without interrupting train traffic (Gräbe, 2009; Costa et al., 2017). The limiting factor for accurate field deflection measurements using this technique is to find a stationary reference point. Therefore, relative deflection between track components is often utilised to obtain reliable measurements (Gräbe, 2009).

\section{Remote Video Monitoring}

Remote video monitoring (RVM) consists of utilising a calibrated video camera with high resolution and frames per second to measure railway track and formation deflections under train transient loading (Vorster and Gräbe, 2013). The RVM technique is based on recording the movement of a target mounted on the track component of importance from a distance far enough to eliminate any ground borne vibration effects (Bowness et al., 2007). Figure 2.9 presents the RVM setup and illustrates how the track and formation deflection can be measured in relation to the targets on the sleeper and formation respectively. 


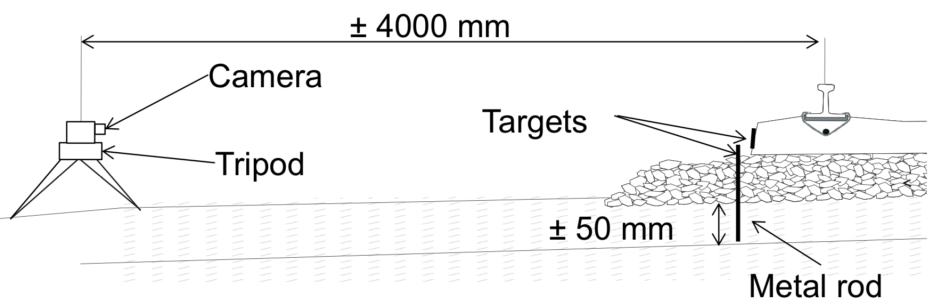

Figure 2.9: Remote video monitoring setup (Vorster and Gräbe, 2013)

This measuring technique has been used for condition evaluation of railway track formations, investigation of high axle loading on formation behaviour and track modulus determination though beam on elastic foundation (BOEF) theory (Vorster and Gräbe, 2013). Alternatively, RVM can also be used for inverse analysis of material properties under certain soil assumptions and careful installation.

\section{Particle Image Velocimetry}

Particle image velocimetry (PIV) is a measuring technique based on continuous photographs that allows the identification of individual particle movement with time. The individual particle movement is then translated into velocity vectors which enables monitoring of landfill settlement (White et al., 2003) and measuring of railway track displacements/deflections under train transient loading (Bowness et al., 2007; Gräbe, 2009). Some of the advantages of this technique as highlighted by Gräbe (2009) can be summarised as follows:

- The equipment is relatively simple, available, affordable and reliable;

- No calibration is needed as the accuracy relies on the target dimensions;

- Horizontal and vertical deflections up to $100 \mathrm{~mm}$ can be measured during a single test.

Similar to RVM, this fast and effective measuring technique can be adopted for measuring track formation deflection for further inverse analysis.

\subsection{INVERSE ANALYSIS OF DEFLECTION MEASUREMENTS}

Inverse analysis, also known as back-calculation is commonly used to evaluate the pavement structure by inversely obtaining a quantitative indication of the layer modulus on the basis of deflection measurements. Accurate assumptions are required in this procedure regarding the applied load, pavement Poisson's ratio and the layer thickness while the elastic moduli are commonly derived from the specific material ranges (Freeme, 1983). In addition, Maina et al. (2009) and Horak et al. (2015) 
determined the pavement layer thickness as the most critical parameter for accurate back-calculation, yet Jooste (2002) found that layer thickness variation have a greater influence on the upper layers than any other layer. Furthermore, the inverse analysis consists of adopting the measured pavement deflection as reference, thus, iteratively adjusting the elastic modulus of the various pavement layers until the estimated deflection agrees with the measured deflection, as illustrated in Figure 2.10 (Ullidtz, 2002; Horak, 2008; Horak et al., 2015). There are three distinct methods from which the different pavement layer properties may be evaluated (De Beer et al., 1989):

i. Laboratory determination;

ii. Back-calculation from the FWD surface deflection basin;

iii. Back-calculation from the MDD deflection profile.

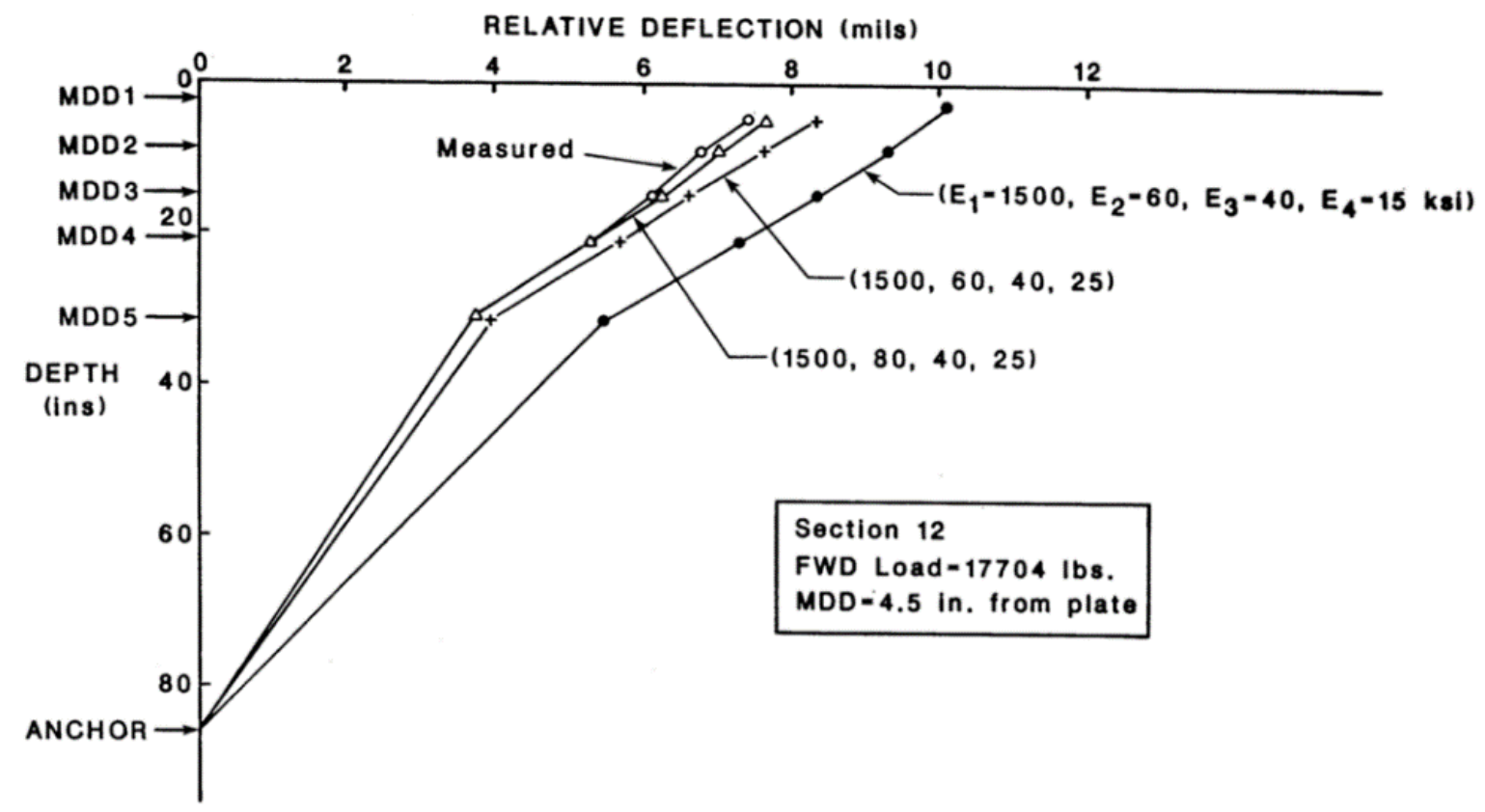

Figure 2.10: Relative MDD measured deflection versus estimated deflections (Scullion et al., 1989)

In general, the inverse analysis of FWD and MDD measurements is conducted by multi-layered linear elastic methods in an iterative and automated manner (Scullion et al., 1989) calculating stresses, strains and deflections under loading at any point within the pavement structure. In order to maintain brevity, the common features of all developed inverse methods were summarised by Lytton (1988) as follows and are presented in Figure 2.11.

- Measured deflections: The surface deflections are measured at distances relative from the load applied; 
- Layer thickness, material properties and loading: These describe the composition and conditions at which the pavement is tested;

- Seed moduli: These are the initially assumed layer modulus values which can be assumed or auto-generated from the measured deflection in some methods. Poisson's ratio is typically assumed for all methods;

- Controlled range of moduli: The process of seed moduli can be optimised by pre-setting an acceptable range of controlled layer moduli, discarding the possibility of unreasonable results;

- Deflection calculation: Multi-layered linear elastic programs are utilised to calculate the surface deflection at selected locations by taking into account the layer thickness, sets of layer moduli and loading condition;

- Error check: This process consists of iteratively verifying the error of each iteration against the acceptable levels of tolerance until an acceptable iteration is found;

- Results: These usually includes the measured and calculated deflection, their difference in deflection, the accepted set of layer moduli and the error sums.

- Constitutive relations: These are related to the constitutive equations associated with the method adopted, linear elastic or non-linear methods;

- Stress and strain corrections: These use the constitutive relations and the calculated stresses or strain to estimate the new layer moduli for the next corrective iteration;

- Search for new moduli: This is achieved by utilising the efficient multi-dimensional search technique to find the best fit of the measured basin and the layer moduli.

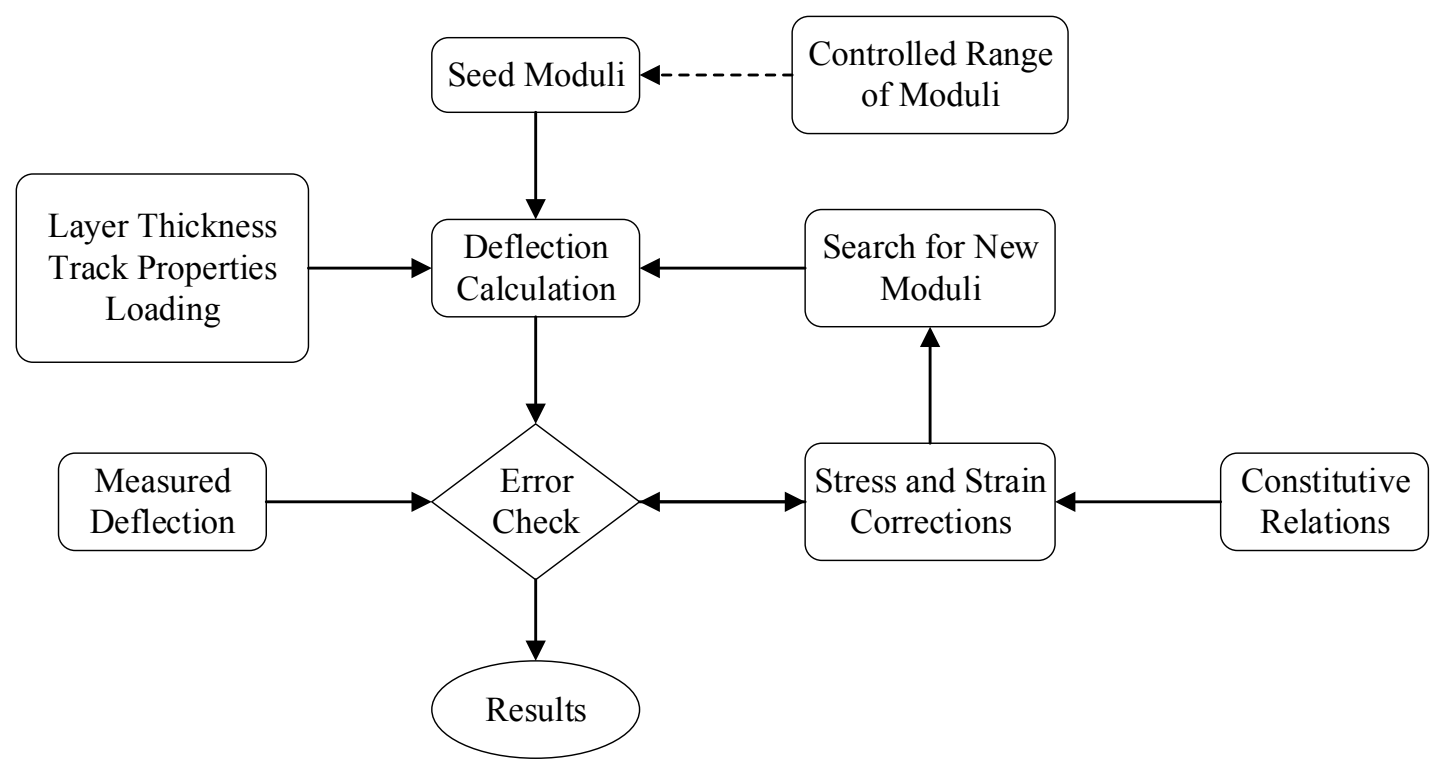

Figure 2.11: Common features of all inverse analysis methods (adapted from Lytton, 1988) 
Alternatively, the inverse analysis can be also done manually or by means of finite element modelling (Jooste, 1992), although inverse analysis requires some engineering skills, knowledge and experience to be accurately performed (Stubstad et al., 2006; Maina et al., 2009). Thus, it is important to comprehend how the individual layer properties affect the surface deflection basins, having a good understanding of the material behaviour (SAPEM, 2014) since the inverse calculation of granular pavement moduli is influenced by the change in pavement state or behaviour as it is a function of the specific pavement structure, traffic loading and the environmental conditions (De Beer et al., 1989). In addition, Theyse et al. (2015) found that the best overall back-calculation accuracy is expected for full-depth granular pavements with low modular ratios.

It is fundamental to understand that corresponding deflections are not necessarily a guarantee that the stress and strains will coincide with the actual values (Ullidtz, 2002) as it is not unexpected to obtain unreliable and inaccurate results even when there is a close match between the calculated and the measured deflections (Jooste, 1992) as it will always contain some degree of error due to the variation in layer thickness (Jooste, 2002). Even though the underlying principles of all mechanistic deflection evaluations is that there is a unique deflection basin for each pavement configuration (Jooste, 1992), it is well understood that a particular set of pavement moduli is not the only mathematical solution (Lytton, 1989; Maina et al., 2009), hence, back-calculation is more of an art than an exact science (Jooste, 1992; Stubstad et al., 2006).

Therefore, this study focused on analysing the effect of loading condition and track characteristics (superstructure and substructure composition) on the shape of the formation deflection basins through finite element analysis. Thus, allowing a detailed interpretation and understanding of railway track deflection measurements with the objective of accurately estimating the formation structural capacity through the inverse analysis of formation deflection measurements.

\subsection{FINITE ELEMENT ANALYSIS}

The development of finite element methods began in the 1940s in the field of structural engineering being extended through the years by many researchers. Currently, finite element analysis (FEA) is a useful engineering tool for the analysis of structural and non-structural problems. Typical FEA features are presented in Table 2.1 (Logan, 2011). 
Table 2.1: Typical capabilities and advantages of finite element analysis

\begin{tabular}{|c|c|}
\hline Capabilities & Advantages \\
\hline $\begin{array}{l}\text { Types of elements: beam, plane stress, } \\
\text { plain strain and three-dimensional } \\
\text { models } \\
\text { - Analysis type: static or dynamic } \\
\text { Materials behaviour: linear-elastic or } \\
\text { non-linear } \\
\text { - Load type: localized, distributed, } \\
\text { thermal and displacements - } \\
\text { settlement } \\
\text { Data generation: automated } \\
\text { generation of nodes, elements and } \\
\text { restrains } \\
\text { Plotting: geometry (original or } \\
\text { deformed), stress and temperature } \\
\text { contours } \\
\text { Displacement: small and large } \\
\text { displacements, and buckling } \\
\text { Selective outputs: specific nodes, } \\
\text { elements, maximum and minimum } \\
\text { values }\end{array}$ & $\begin{array}{l}\text { - It can model irregular shaped bodies } \\
\text { and bodies composed of various } \\
\text { materials evaluating individual } \\
\text { element equations } \\
\text { - Applicable for general load conditions } \\
\text { - Unlimited number of boundaries } \\
\text { conditions } \\
\text { - Numerous sizes of elements } \\
\text { - Easy utilisation in terms of alteration } \\
\text { - of finite element models } \\
\text { - Inclusion of dynamic analysis } \\
\text { Non-linear material behaviour and } \\
\text { large deformations }\end{array}$ \\
\hline
\end{tabular}

In terms of railway engineering, FEA is a particularly useful application that incorporates all railway track structural components and substructure characteristics, thus, calculating stresses, deflections, strains and especially predicting the behaviour and responses of the railway track structure under dynamic loads as well as allowing the assessment of railway track performance and formation design (Li et al., 2016).

Railway track structures and substructures are typically modelled as two or three-dimensional structures in FEA. In general, finite element models of railway track structures are simplified by using half-track cross section, assuming symmetrical geometry and behaviour along its longitudinal structural centreline. However, special attention is needed for the boundary conditions and linear elastic or nonlinear material behaviour of the superstructure components and substructure layers (Li et al., 2016).

Considering that FEA allows for linear elasticity to compute the displacements, stresses and strains of the track structure, Figure 2.12 illustrates the general concept of a multi-layered linear elastic system. The multi-layered linear elastic theory has the following assumptions (Yoder and Witczak, 1975):

- The material properties in each individual layer are homogeneous - same properties can be found in $A_{i}$ and $B_{i}$; 
- Each individual layer has a finite layer thickness $(t)$ in the vertical direction except for the lower layer and all layers are infinite in the horizontal direction;

- Each individual layer is isotropic, meaning that the properties at a specific point $A_{i}$ in the layer is the same in all directions;

- Friction is developed between each individual layer interface;

- No shear forces are present at the surface;

- Stress solution is characterised by two material properties for each layer, namely Poisson's ratio $(v)$ and elastic modulus $(E)$.

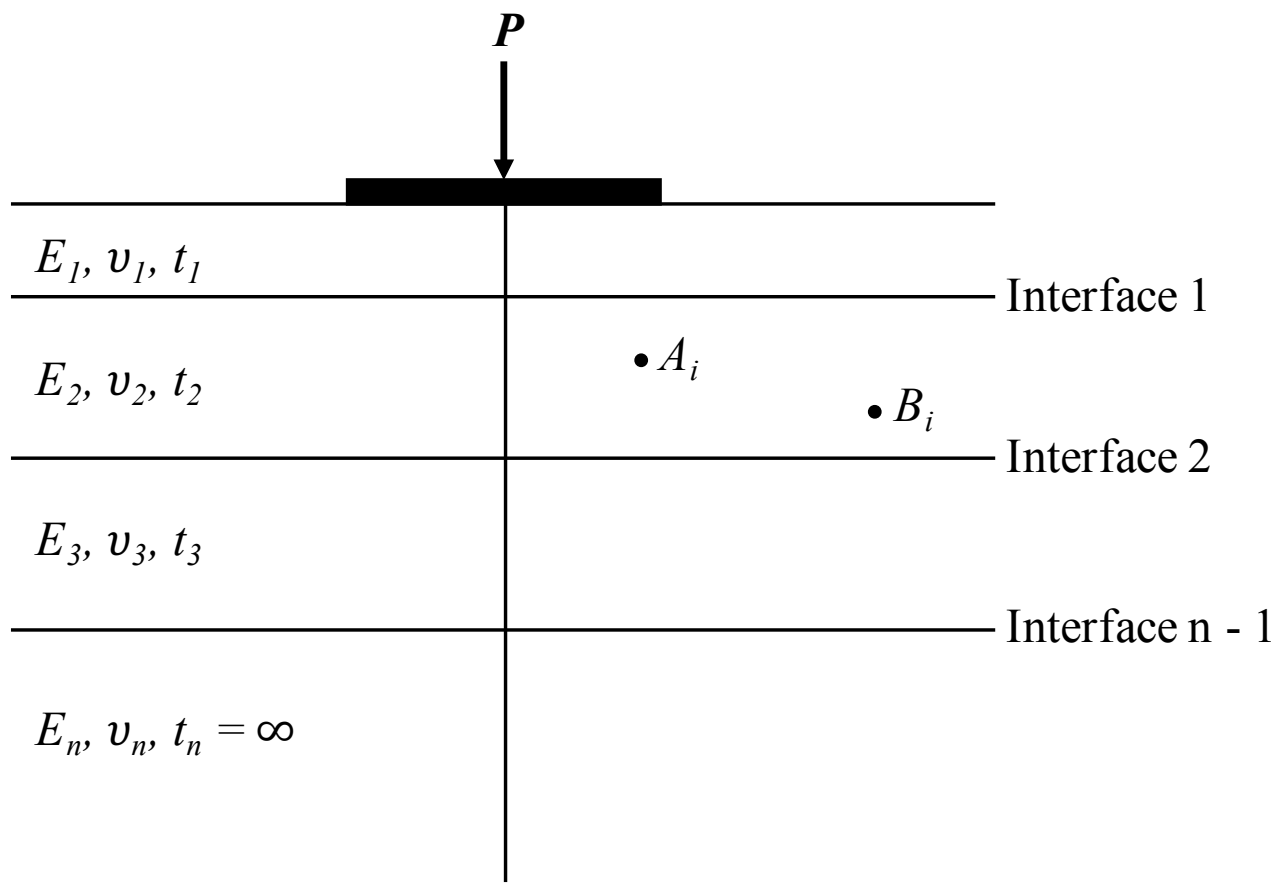

Figure 2.12: General multi-layered linear-elastic system

(adapted from Yoder and Witczak, 1975)

FEA can also be used for modelling of non-linear material behaviour as suggested by Jooste (1992). It is, however, important to notice that the correlation of pavement deflection basin differs in terms of back-calculated elastic moduli between linear elastic and non-linear pavement models as shown by Hoffman and Thompson (1982). Ullidtz (1987) also highlighted the importance of material behaviour for inverse deflection analysis given the following:

- Non-linear material deflection profiles are seen to be steeper than those of linear elastic materials with increasing distance from the load;

- Vertical stresses off the axis of the load disagree at shallow depths, although at depths larger than the offset from the axis, the agreement was satisfactory. 
Furthermore, Ullidtz (2002) states that non-linearity has a pronounced effect on the subgrade strain and shape of deflection basins, yet it has a small influence on the stress distribution of semi-infinite halfspace models. In addition, Stubstad et al. (2006) did not find a major difference between linear and nonlinear models.

The FEA model may be useful if the stress and strain obtained are reasonably close to the stresses and strains in real pavements regardless of the assumptions on which a model is based. A particular model can then be considered useful or not by comparing the results predicted by the model to the real measured pavement response (Ullidtz, 2002). In conclusion, all pavement models are at best an approximation of the real behaviour of the pavement structure (Ullidtz, 1987) and the results produced should be interpreted with sound engineering judgement (Jooste, 1992).

\subsection{INTERPRETATION OF DEFLECTION MEASUREMENTS}

This section discusses the interpretation of deflection measurements with focus on the theory behind FWD surface deflection for pavement condition evaluation, characterising the zones of curvature of deflection basins as well as the importance of influence lines for this investigation.

\subsubsection{Curvature of Deflection Basins}

The interpretation of pavement deflection measurements has been widely researched in South Africa by De Beer et al. (1989), Jooste (1992) and Horak (2008) utilising FWD and MDDs for pavement structural evaluation. The analysis of deflection basins has been used to identify weak areas in the depth of the pavement structure and over the length of a uniform section, without the need of in-depth investigation and simply analysing the shape of deflection measurements (SAPEM, 2014).

The pavement deflection basin measurements tend to vary in size and shape depending on the following factors: pavement composition, structural strength during life cycle, load contact area, load magnitude, loading durations, instrumentation utilised and climate changes (Horak, 1988; Maina et al., 2009). Therefore, it is imperative to move towards describing the pavement behaviour based on the entire deflection basin curvature and certain deflection parameters, rather than through maximum peak deflection, since different zones of the deflection basin represents a different pavement layer's response (Horak, 1988; Maina et al., 2009). Thus, Figure 2.13 illustrates the ranges of different structural layers based on the FWD surface deflection basin. 


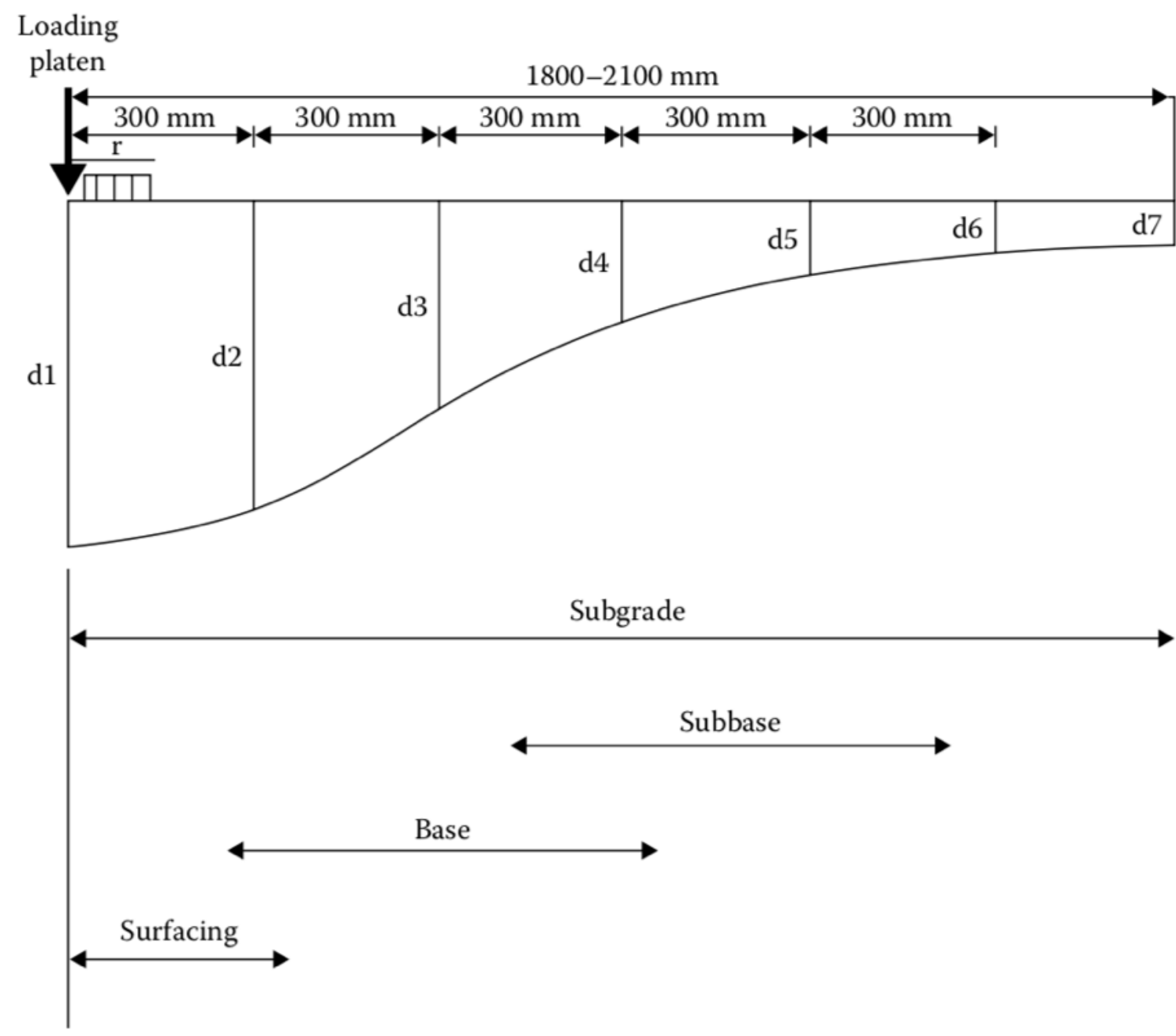

Figure 2.13: Ranges of pavement layer on the deflection basin shape (Li et al., 2016)

Furthermore, Horak (2008) indicated that the shape of pavement deflection basins under wheel loading can be generally classified into three distinct zones of curvature, as illustrated in Figure 2.14:

- Zone 1: This is the closest point of loading with a positive curvature which indicates the structural condition of the upper layers;

- Zone 2: This is the inflected zone in which the curvature switches from positive to reverse, being highly influenced by the pavement structural composition;

- Zone 3: This is the furthest zone from the point of loading with a reverse curvature converging to zero which indicates the structural response of the lower layers, being governed by the actual depth of the pavement structure. 


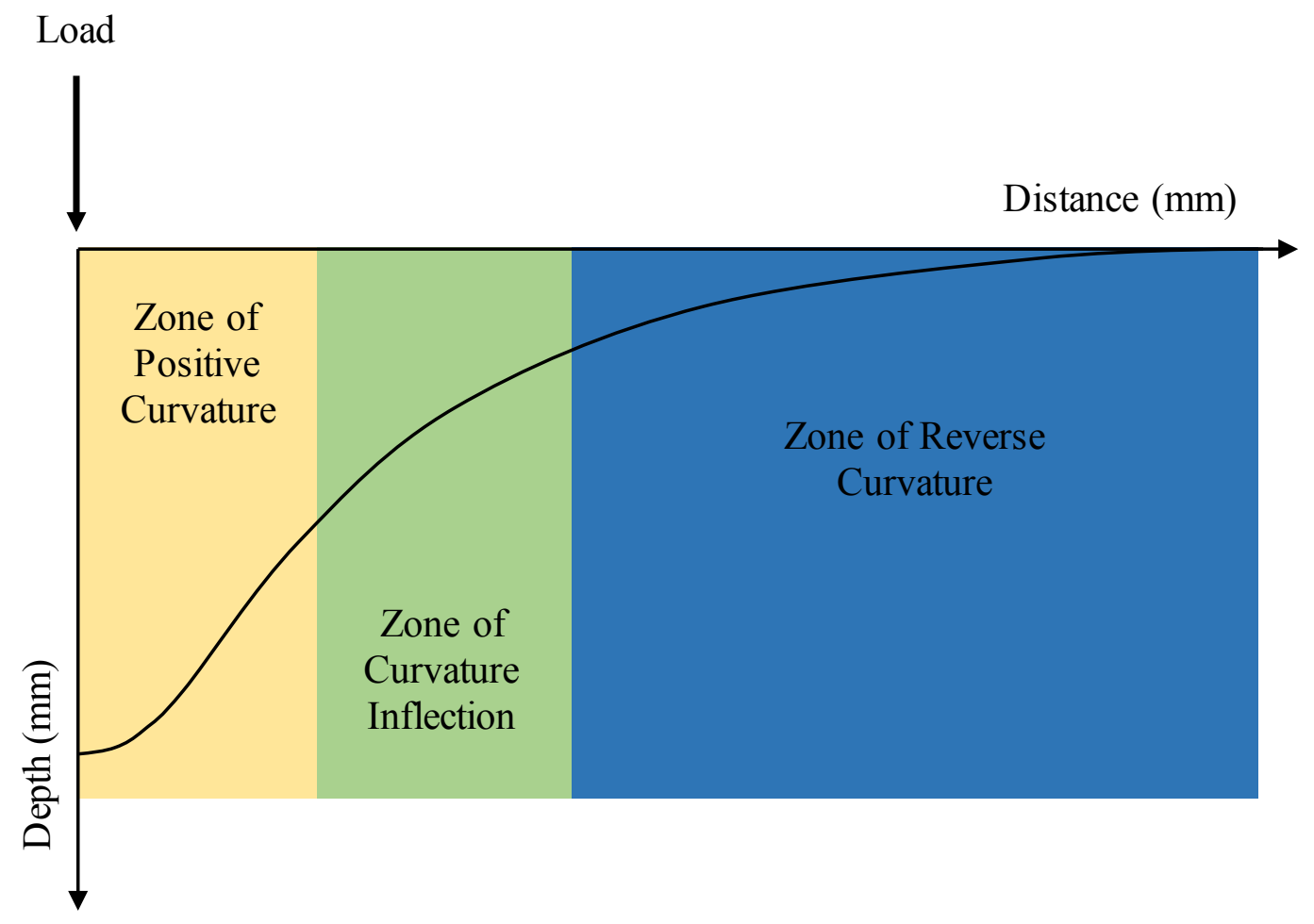

Figure 2.14: Curvature zones of deflection basins (adapted from Horak, 2008)

As seen in Figure 2.14, the pavement analysis is commonly conducted using a half-space approach for the deflection basin of the leading wheel load, due to potential plastic deformations and the probability of superimposing wheel load effects from trailing wheels at different speeds. For that reason, Horak (1988) advised manipulating the deflection measurements so that the maximum deflection is set as the origin of the deflection basin and the half-space deflection curvature remains unchanged until zero deflection is measured, ensuring that the data is relatively free of plastic deformation and errors in the deflection basin curvature.

\subsubsection{Influence Lines on Deflection Basins}

The deflection of a pavement structure is the response to induced loads which generate stresses in the system that dissipate with increasing depth. The stress distribution, also known as the influence line or influence zone, is affected by the pavement loading characteristics and the individual material properties in the pavement system (Jooste, 1992):

- $\quad$ Elastic modulus $(E)$;

- Layer thickness $(t)$

- Poisson's ratio (v). 
Thus, the deflection of a multi-layered system is proportionally governed by the stress distribution angle $(\alpha)$ of the individual layers as investigated by Zakeri and Mosayebi (2016) in ballasted track structures. However, the pavement wheel loads are normally assumed to spread from the top layer to the underlying layers through an influence line of about $45^{\circ}$ (Horak, 2008). Furthermore, any material above the zone of influence is assumed to not contribute towards carrying the applied load. Figure 2.15 illustrates the zone of influence and the proportional contribution along the longitudinal direction of multi-layered pavement system (Jooste, 1992).

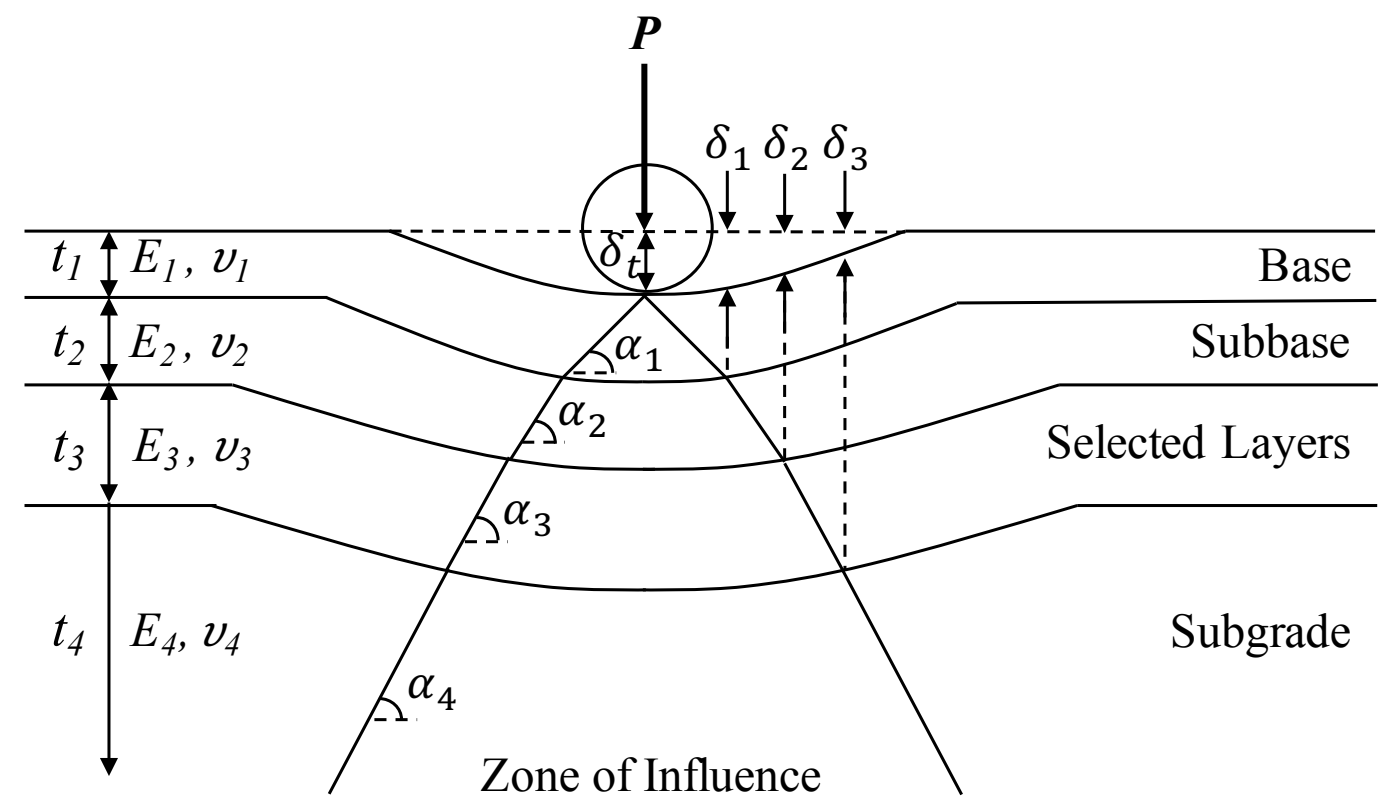

Figure 2.15: Multi-layer pavement system response (adapted from Jooste, 1992)

As obversed in Figure 2.15, the pavement deflection varies in relation to the zone of influence. The maximum total deflection $\left(\delta_{t}\right)$ is commonly measured beneath the applied load and it decreases as the applied load dissipates into the layered pavement system. The estimated deflections of the layered system are calculated corresponding to the intersection of the layers with the assumed influence line. For instance, the proportional deflection of the base layer is estimated by deducting the measured deflection of the base/subbase layers $\left(\delta_{l}\right)$ intersection from the maximum total deflection $\left(\delta_{t}\right)$.

Ullidtz (1987) also defined the pavement response according to the commonly assumed $45^{\circ}$ influence line as adapted in Figure 2.16. According to Horak (2008) there is reason to believe that the surface pavement deflection can be interpreted with respect to the shape of the deflection basin and the $45^{\circ}$ influence line, indicating the structural capacity of the different layers. 


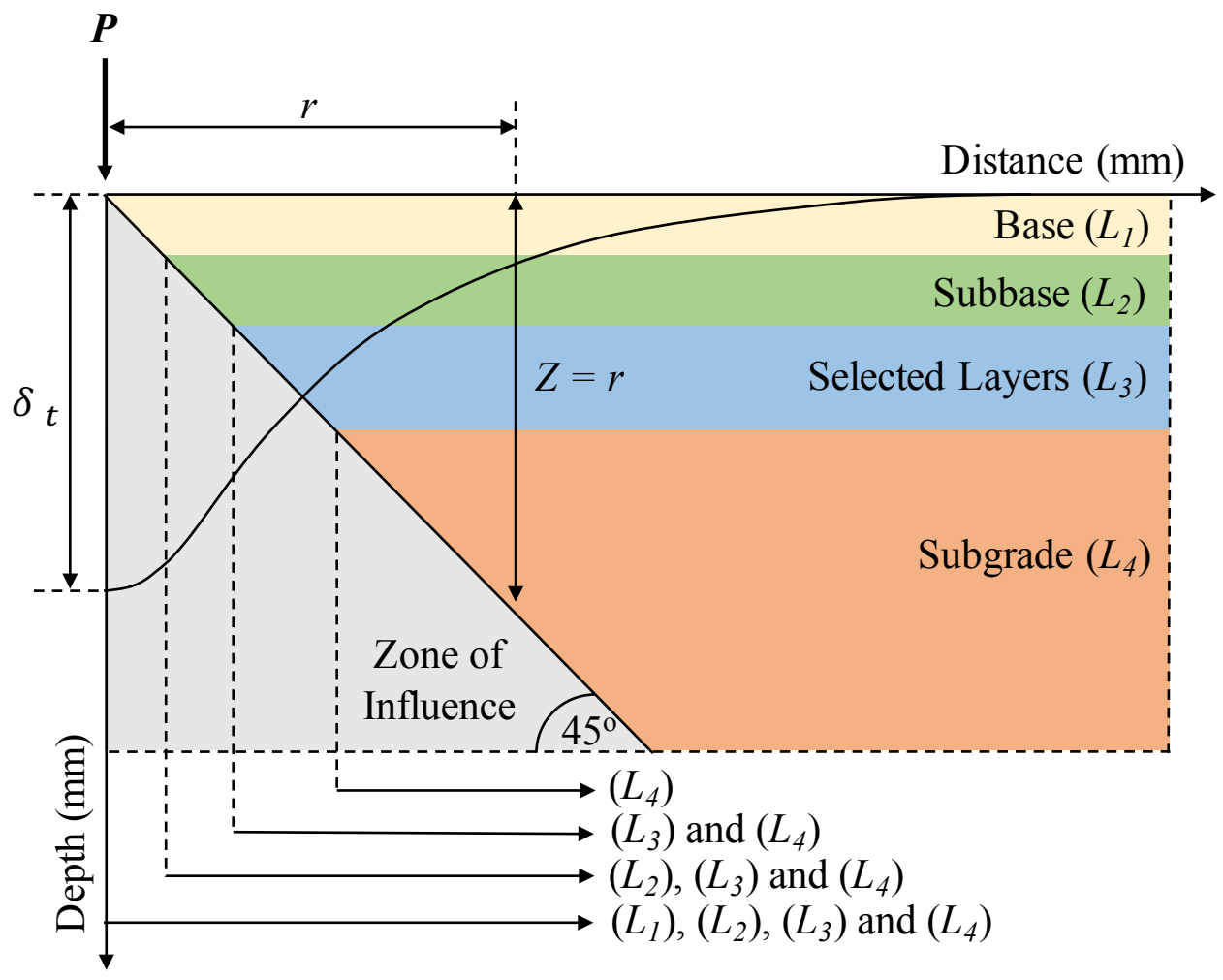

Figure 2.16: $45^{\circ}$ load distribution through pavement layers (adapted from Ullidtz, 1987)

Referring to Figure 2.16, the zone of influence defines the contributing layers. Thus, as the horizontal distance $(r)$ increases, a point is reached where only the subgrade $\left(L_{4}\right)$ falls within the zone of influence, reflecting the subgrade deflection only. If this method is then inversely applied, working from the bottom layer towards the uppermost layer, it is possible to obtain the proportional deflection of each individual pavement layer (Horak, 1988, 2008; SAPEM, 2014). Furthermore, obtaining the relative deflection of each contributing pavement layer, it is possible to iteratively and inversely estimate the pavement moduli from a single surface deflection basin (De Beer et al., 1989; Jooste, 2002; Horak, 2008).

\subsection{FACTORS AFFECTING SHAPE OF DEFLECTION MEASUREMENTS}

This section reviews the influential factors for deflection measurements with the objective of understanding how the superstructure characteristics, formation structural capacity, loading configuration and climate changes may affect the formation deflection shape under train transient loading. 


\subsubsection{Railway Track Structure}

The influence of substructure components on formation deflection, similar to road pavements, is associated with the structural capacity and thickness of each individual pavement layer as well as the in-situ subgrade support (stiffness) which affect the magnitude and shape of the measured formation deflections (SAPEM, 2014). For example, the influence of three different pavement structures on the deflection basins is illustrated through the FWD measurements shown in Figure 2.17.

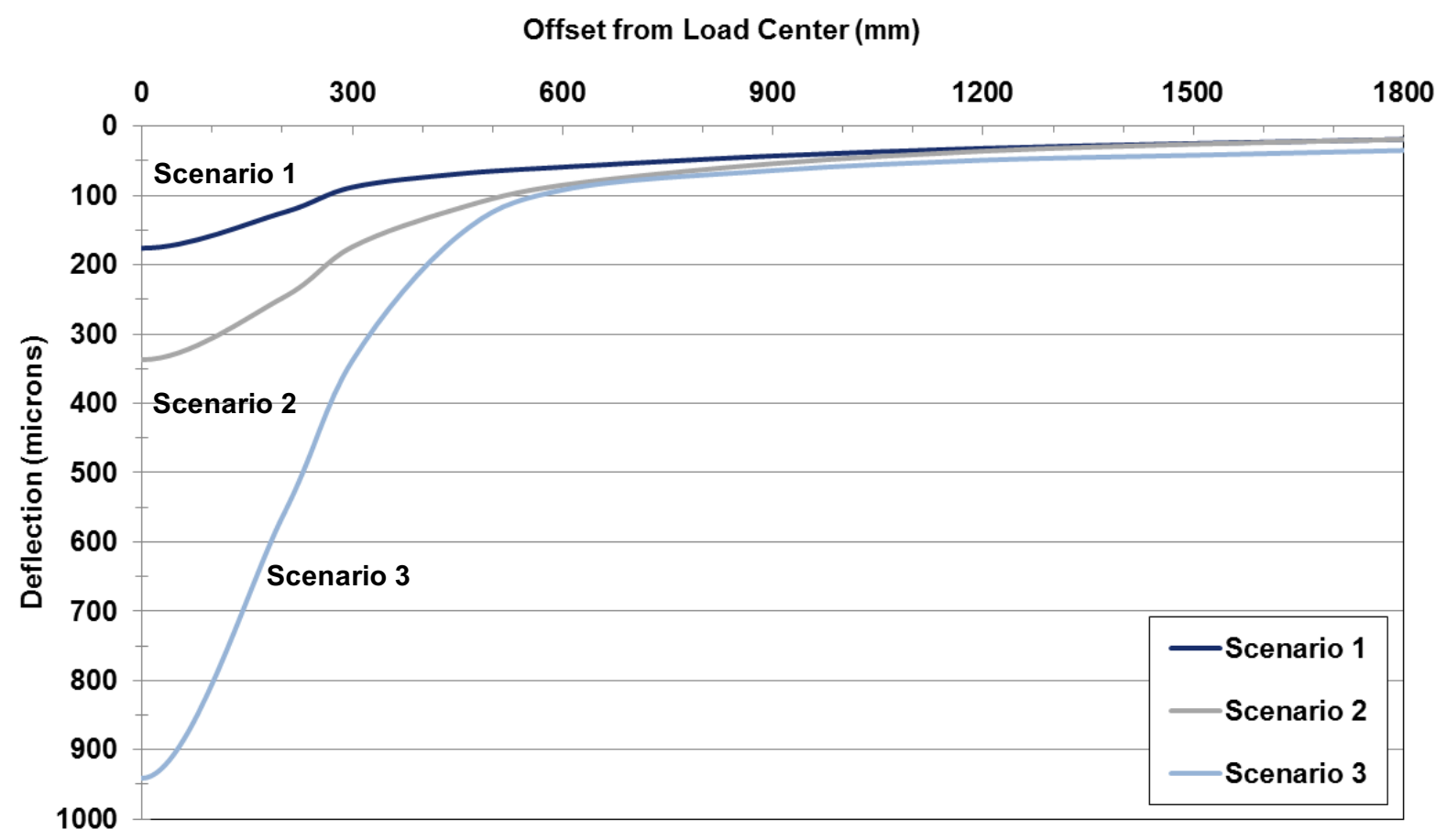

Figure 2.17: The effect of pavement structure on deflection basins (SAPEM, 2014)

The scenarios in Figure 2.17 are described as follows:

- Scenario 1 was classified as a stiff pavement with a relatively stiff and strong cemented subbase layer which resulted in the lowest and narrower deflection basin;

- Scenario 2 represents a relatively old structure with high quality materials being less stiff than Scenario 1, thus resulting in higher deflections;

- Scenario 3 had the largest deflections due to the old pavement structure comprised of poor quality materials and a moist subbase and subgrade layers.

Furthermore, Tam (1985) also investigated the variation of granular base and subgrade stiffness on deflection basins concluding that the variation of base layer thickness had the greatest influence on the 
maximum deflection and spread of the deflection basin, followed by the subgrade and base layer stiffness. In addition, Ullidtz (1987) indicated that the subgrade strength contributes between $60 \%$ to $80 \%$ of the maximum peak deflection. As observed in Figure 2.18, the weaker the base or subgrade stiffness, the higher the maximum deflection and spread. Although this investigation was done for road pavement structures, it is understood that a railway track formation has similar responses to the variation in layer thickness and stiffness.

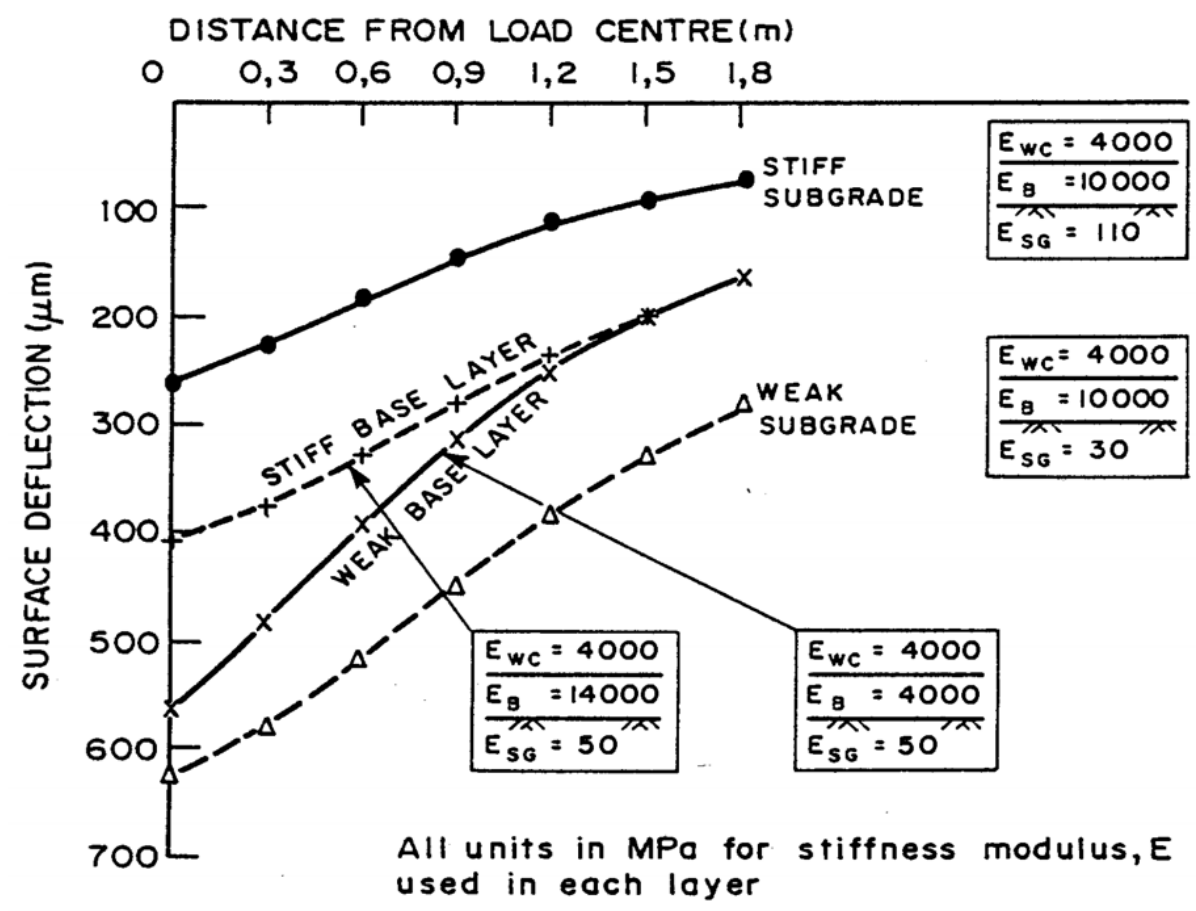

Figure 2.18: The variation of pavement elastic modulus on deflection measurements (Tam, 1985)

Given the fact that surface deflection analysis has been widely investigated in the past. It is important to note that railway ballasted track structures have complex stress distribution due to the indirect load transfer through the superstructure, different from that of road pavement structures which are directly transferred to the pavement structure. It is therefore essential to investigate the superstructure effect on formation stresses and deflections. The railway track stress distribution is shown in Figure 2.19. The formation deflection is affected by the following superstructure factors (Lundqvist and Dahlberg, 2005):

- Sleeper spacing: This affects the stiffness along the track inducing frequency vibrations in the track structure resulting in an increase in track deflection due to local substructure deformations; 
- Sleeper support: The number and degree of unsupported sleepers increase the contact forces and subsequent formation deflections are induced.

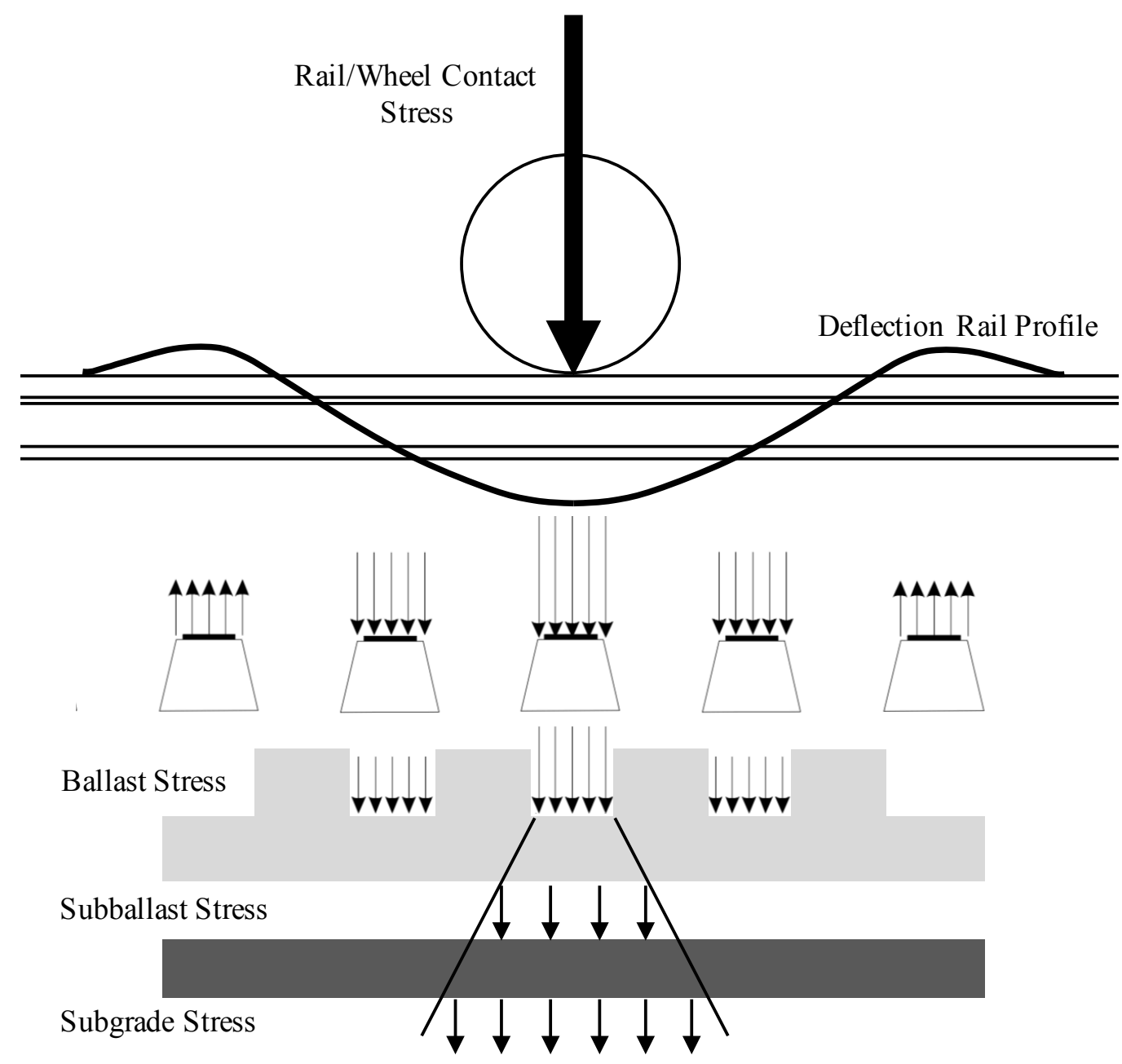

Figure 2.19: Typical wheel load distribution into railway ballasted track structures (adapted from Selig and Waters, 1994)

Zakeri and Mosayebi (2016) also indicated that the reduction in sleeper spacing $\left(\mathrm{L}_{\mathrm{s}}\right)$ and the increase in ballast depth $\left(\mathrm{H}_{\mathrm{b}}\right)$ and fouling content are the three factors that can particularly influence the load transfer to the formation resulting in a stress path overlap in the ballast layer $\left(\mathrm{H}_{\mathrm{o}}\right)$ subsequently increasing the stresses and deflections of formation layers as seen in Figure 2.20. 


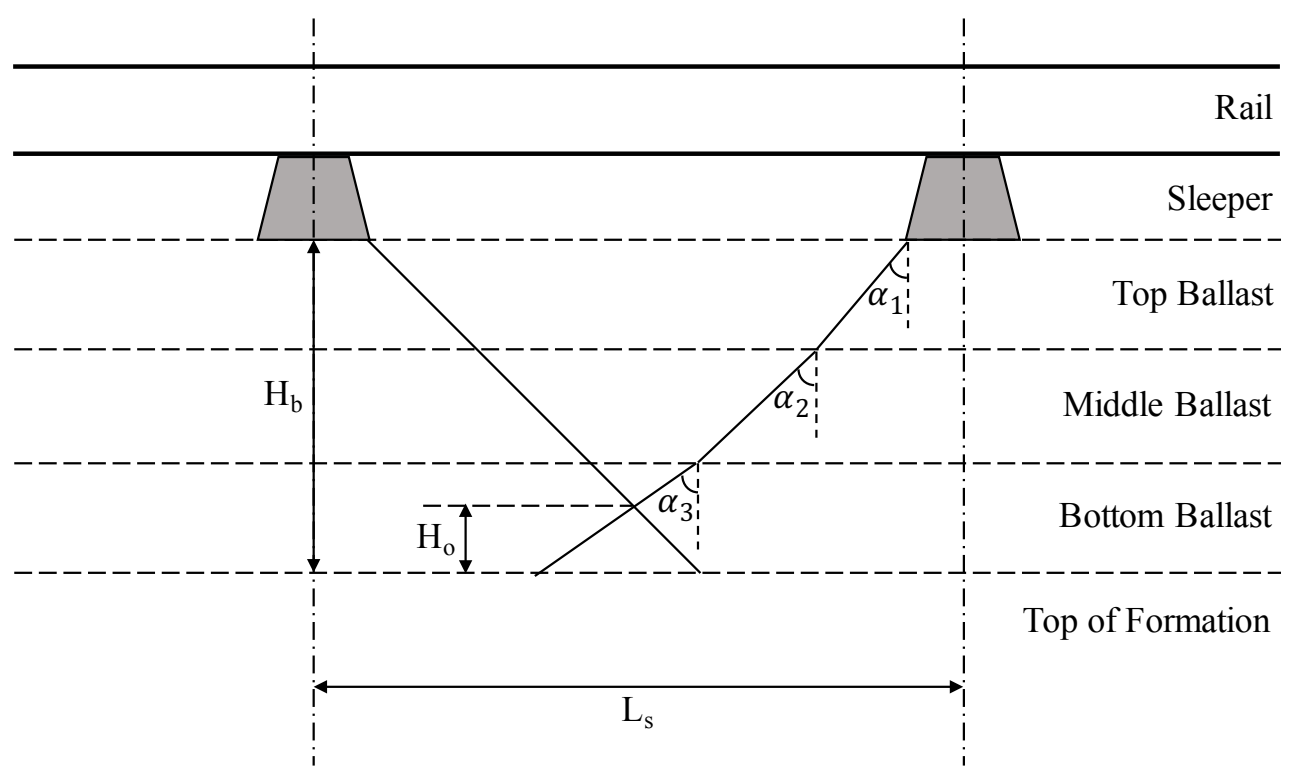

Figure 2.20: Overlap of influence lines in the ballast layer (adapted from Zakeri and Mosayebi, 2016)

Track formation deflection is furthermore influenced by the complex interaction between loading configuration and the superstructure characteristics. In brief, bogie spacing and number of axles of the locomotive/wagon do not necessarily match the sleeper spacing. Thus, the axle load transfer results in a complex superposition which can be transferred to either the nearest sleeper or, alternately, can be subdivided between the two adjacent sleepers depending on the position along the track (Li et al., 2016). Hence, formation deflection basins may vary according to the rolling stock and ballasted track characteristics.

\subsubsection{Loading Condition}

The effect of train transient loading on formation deflection is dependent on the rolling stock characteristics: axle load, axles/bogie, bogie spacing and train speed. Vorster and Gräbe (2013) investigated the effect of axle loading on formation deflection finding that deflection increases less rapidly with higher axle loads following a logarithmic relationship. Furthermore, Li et al. (2016) shows in Figure 2.21 how the interaction of adjacent wheel loads affects the shape of formation deflection according to the different axle loads, bogie spacing and depths.

The increase in train speed also affects the formation deflections as it decreases the effective track modulus, consequently resulting in larger effective axles loads, formation deflections and also reducing the resolution of the deflection measurements (Priest and Powrie, 2009). Yet, Yang et al. (2009) indicated that these effects are mainly observed if train speed approaches the critical speed of the track 
system, which in the South African Heavy Haul Coal Export Lines is not possible since trains do not exceed the critical speed. In the case of trains not approaching the critical speed, it is generally seen that maximum vertical formation deflection occurs directly beneath the leading train axle, reducing with depth and transiting from axle loading to bogie loading with increasing depth (Priest et al., 2010). This can also be observed in Figure 2.21.
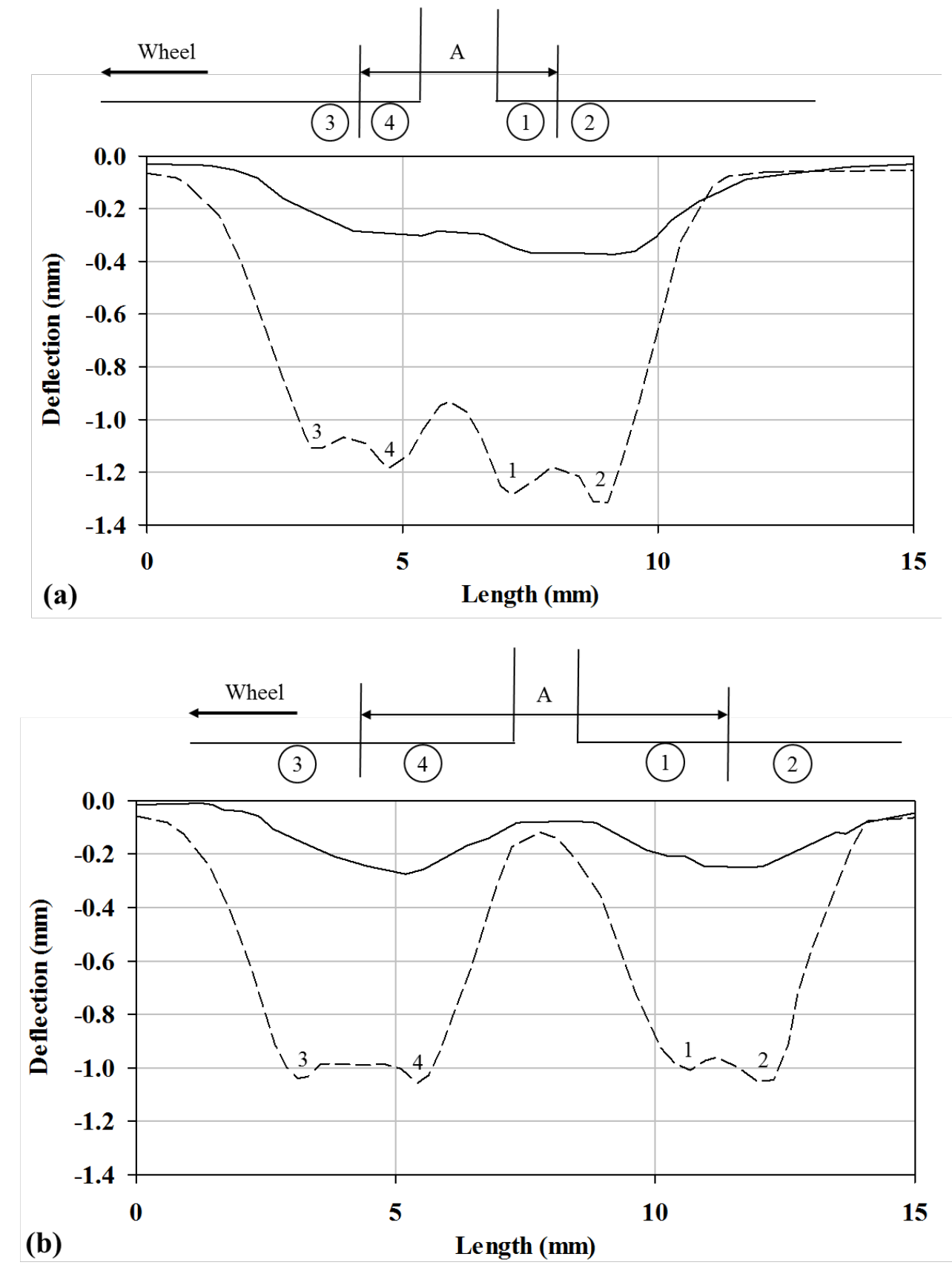

Figure 2.21: (a) 38 tonnes axle load and $2.4 \mathrm{~m}$ spacing; (b) 30 tonnes axle load and $4.8 \mathrm{~m}$ spacing (adapted from Li et al., 2016) 


\subsubsection{Climate}

The most important climatic factors influencing pavement structures are temperature, moisture changes and the effect of frost (Ullidtz, 1987). The temperature variation can be defined as an insignificant factor in the railway substructure due to the fact that formation layers are mainly constituted of unbound granular materials which are not susceptible to temperature differences (SAPEM, 2014). However, there is evidence that granular materials can expand with temperature variation causing a "lock up" behaviour which stiffens the material and leads to lower deflections (Jooste, 1992).

In most parts of South Africa, rainfall is the determining factor that governs the railway track performance due to the variation in moisture content. The changes in moisture content of unbound granular and cemented materials commonly affects the pavement moduli (Ullidtz, 1987) as it reduces the structural capacity and results in high formation deflections (SAPEM, 2014). This leads to the conclusion that only regions with high rainfall will be susceptible to climatic changes. Furthermore, frost is rarely found in South Africa, therefore, its effect is not discussed in order to maintain brevity.

\subsection{DISCUSSION}

The literature review gives a brief understanding of a ballasted railway track structure and the function of each of its components in the system. The track loading conditions were reviewed indicating the influence of various factors on substructure behaviour. Railway track deformations were then discussed as a means of comprehending the different effects of train passage and the presence of water on the track formation layers.

In order to overcome limitations of the other discussed methods of track condition assessment, cited researchers have suggested to move towards the characterisation of in-service track conditions under train transient loading. Thus, it is hypothesised that future developed methods should focus on the evaluation of the actual formation deflection measurements by means of investigating the behaviour and interaction of the various layers, as well as inversely characterising the formation structural properties under transient loading. Hence, non-destructive in-situ instruments for measurement of railway formation deflections were shortly reviewed.

A background to the premise of inverse analysis of granular pavement properties through deflection measurements was presented. This was subsequently followed by a discussion of the importance of comprehending pavement behaviour for inverse deflection analysis and surface deflection basin interpretation. Thus, finite element analysis was briefly reviewed as the engineering tool of choice for 
the investigation of railway formation deflection basins in this research. Furthermore, studies were cited indicating the relationship between the shape of pavement surface deflection basins and the stress influence lines of the pavement system. The literature review was then concluded by presenting the factors that affect the shape of deflection measurements for characterisation of a railway track formation.

The literature review shows that the FWD is extensively used for the evaluation of road pavement structures, allowing for the estimation of individual layer deflection through the analysis of surface deflection basins. It is crucial to comprehend that this measuring technique relies on the direct wheel/pavement load transfer which is assumed to dissipate at a stress influence angle of approximately 45 degrees (see Figure 2.22 (a)). However, railway track structures are suspected to have a distinctly different influence line given the complex relationship and superposition between axle and bogie loading as well as the track superstructure influencing load transfer. A hypothetical influence line is presented in Figure 2.22 (b). Due to the aforementioned factors, it is believed that the $45^{\circ}$ stress influence line is an unsuitable assumption for railway track formation characterisation leaving scope for investigation into the behaviour of railway track structures.

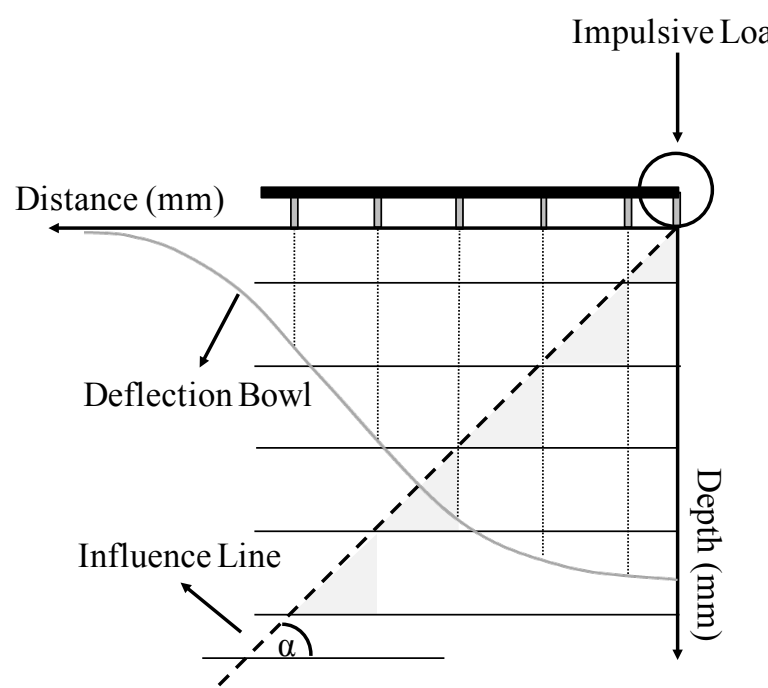

(a)

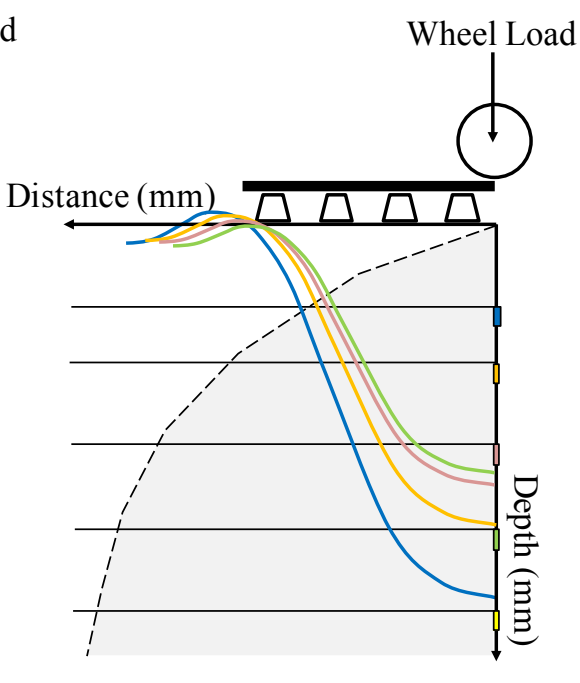

(b)

Figure 2.22: (a) Surface deflection basin (FWD); (b) In-depth deflection profile (MDDs)

It is assumed that railway formation properties can be inversely estimated from surface formation deflection measurements by determining the relationship between the railway track influence line and the formation deflections under train transient loading. Therefore, this leads to the development and investigation of a mechanistic-empirical method referred to as the inverse method. The inverse method was based on FWD surface deflection basin theory, see Figure 2.22 (b). 
The inverse method hypothesised that FWD horizontally spaced sensors and a single impulsive wheel load (see Figure 2.22 (a)) could be substituted for a more simple, practical and economical alternative. The substitution consisted of measuring the transient leading wheel load at multiple distances with a single sensor embedded in the top formation. Thus, measuring the total formation deflections relative to the railway influence line and the wheel load position as presented in Figure 2.23 (a). Subsequently, Figure 2.23 (b) shows that the total formation deflection can be translated into relative formation deflections. Therefore, it is postulated that the inverse method can be adopted for inverse estimation of formation layer properties by measuring the proportional deflection of formation layers.
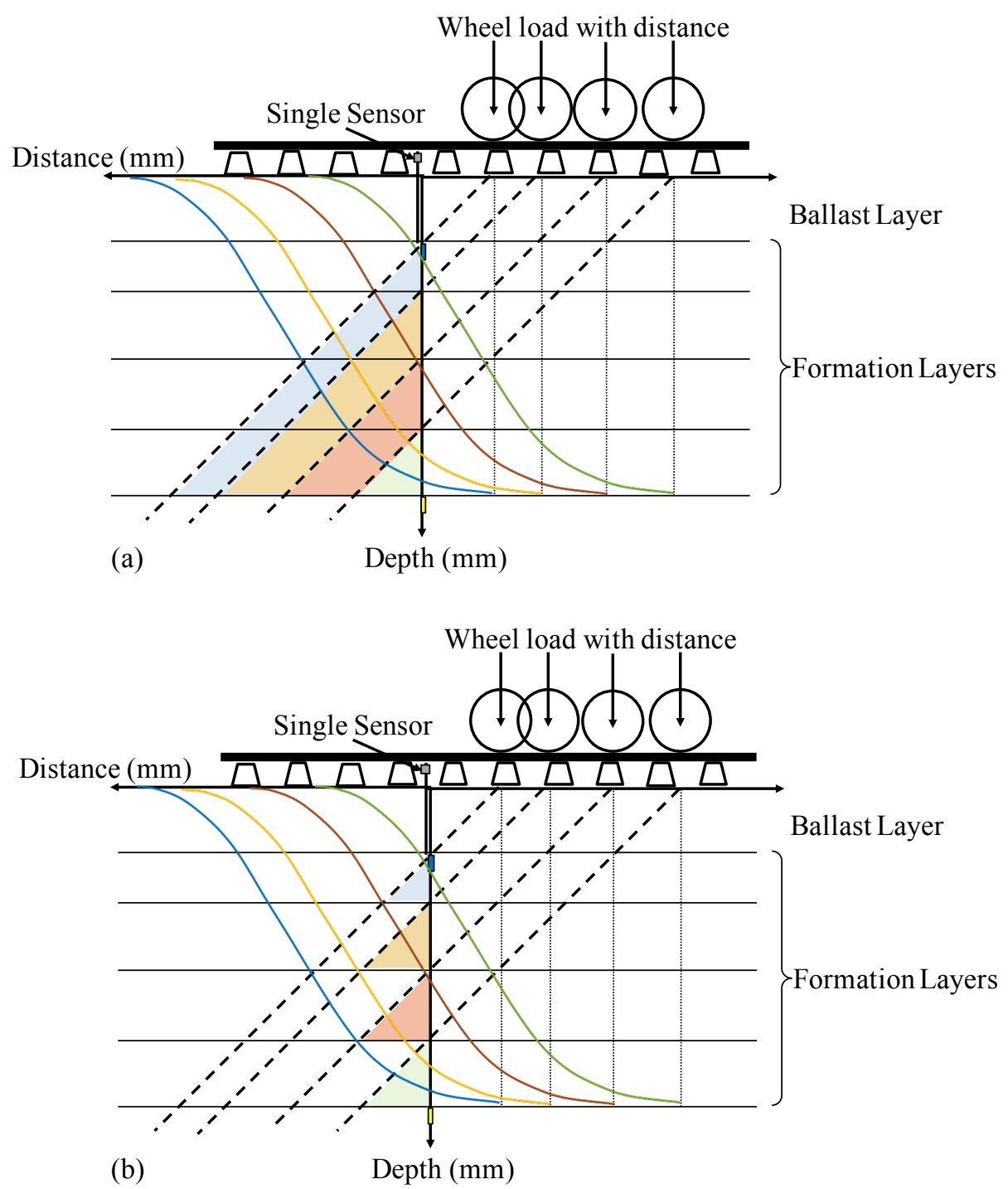

Figure 2.23: (a) Total formation deflection with inverse method;

(b) Estimation of relative formation deflection with inverse method 
In concluding the extensive discussion regarding the review of previous literature, this research will provide insight into the investigated experimental test site in Chapter 3. Furthermore, a railway track finite element model is presented in Chapter 4 which aims to analyse the railway track responses under train transient loading. 


\section{EXPERIMENTAL TEST SITE}

During 1994-1995 signs of foundation failure were observed on the Transnet Freight Rail (TFR) heavy haul Coal Export Line between Vryheid and Richards Bay. Sections of rail track formation was subsequently rehabilitated and upgraded for 26 tonnes/axle loading. In 2004, the Bloubank test site was commissioned and instrumented on Line 1 which carries the loaded trains destined for Richards Bay. Bloubank is located $60 \mathrm{~km}$ South of Vryheid. The rehabilitation provided an opportunity to install extensive instrumentation in order to monitor and characterise formation behaviour under transient train loading from the initial construction of the formation over an extended period of time.

This chapter presents the foundation design, material specification, instrumentation layout and typical measurements at the Bloubank test site. The instrumented test site comprises of numerous arrays of multi-depth deflectometers (MDDs) and wheel load sensors which were utilised to investigate formation deflections and influence lines under train transient loading.

\subsection{FORMATION DESIGN AND MATERIAL SPECIFICATIONS}

The formation design entailed an $800 \mathrm{~mm}$ by $4000 \mathrm{~mm}$ excavation of old foundation material, reconstructing the formation in four high-quality structural layers of $200 \mathrm{~mm}$ each at a slope of 1:25 for surface water drainage. The design also incorporated an extensive fin drain system on both sides with a geosynthetic at the interface between the B layer and the in-situ subgrade for groundwater cut-off and separation. A schematic of the design is shown in Figure 3.1. Furthermore, the track superstructure comprised of $60 \mathrm{~kg} / \mathrm{m} \mathrm{CrMg}$ rails, Fist fasteners and PY concrete sleepers (30 tonnes/axle capacity) spaced at $650 \mathrm{~mm}$ centre-to-centre on a 280 to $300 \mathrm{~mm}$ ballast layer (Gräbe and Shaw, 2010).

The rehabilitated railway foundation was built in accordance with the Specification for Railway Earthworks (S410) by Transnet Freight Rail (2006). 


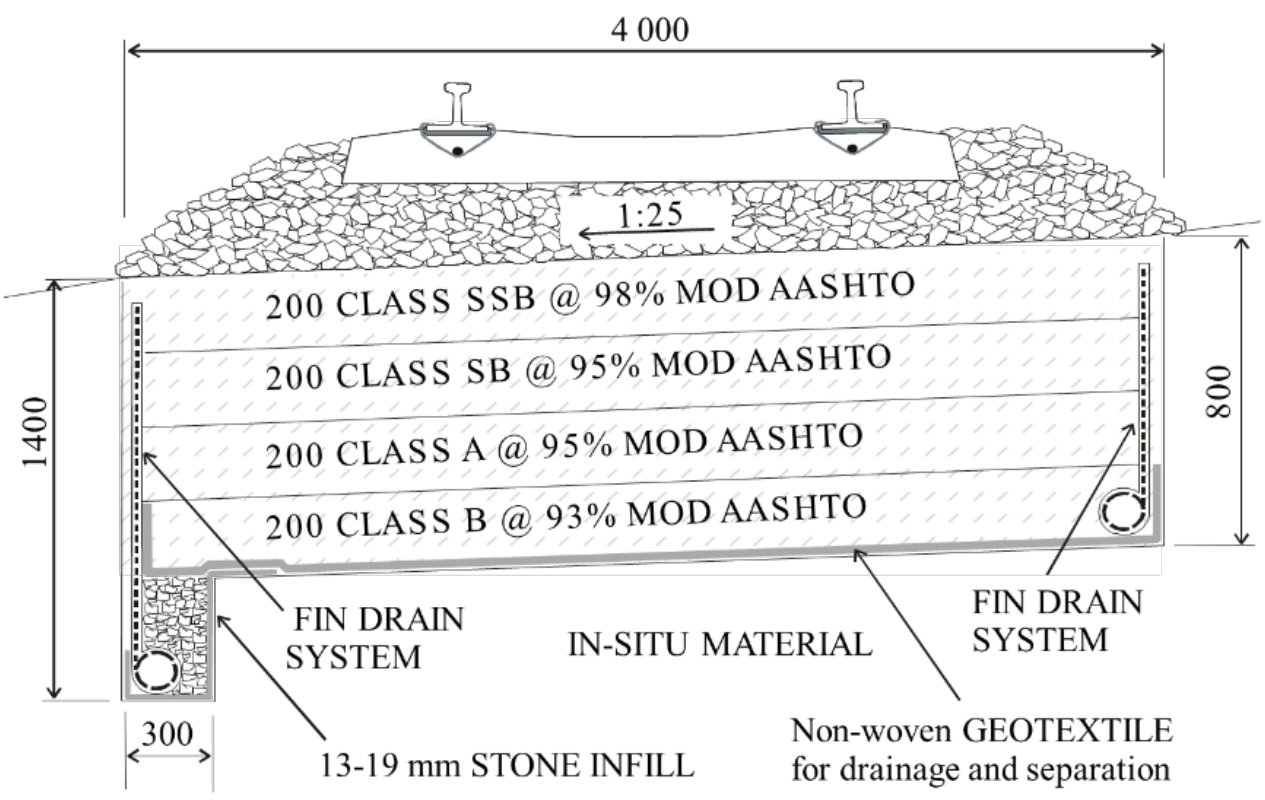

Figure 3.1: Foundation design at Bloubank test site (Gräbe and Shaw, 2010)

The S410 material properties specification and the actual Bloubank material properties per structural layer are presented in Tables 3.1 and 3.2, respectively.

Table 3.1: S410 material properties specification (Transnet Freight Rail, 2006)

\begin{tabular}{|c|c|c|c|c|c|c|c|c|c|c|c|c|}
\hline \multirow{3}{*}{\multicolumn{2}{|c|}{ LAYERS }} & \multicolumn{9}{|c|}{ MATERIAL PROPERTIES } & \multirow{3}{*}{$\begin{array}{c}\text { Minimum } \\
\text { compaction } \\
\text { of modified } \\
\text { AASHTO } \\
\text { Density (\%) }\end{array}$} & \multirow{3}{*}{$\begin{array}{c}\text { Minimum } \\
\text { strength } \\
\text { after } \\
\text { compaction } \\
\text { CBR }\end{array}$} \\
\hline & & \multirow{2}{*}{$\begin{array}{l}\text { SAR } \\
\text { Index }\end{array}$} & \multirow{2}{*}{$\begin{array}{c}\text { Minimum } \\
\text { Grading } \\
\text { Modulus }\end{array}$} & \multicolumn{5}{|c|}{$\begin{array}{c}\text { \% BY MASS PASSING SIEVE } \\
\text { (sieve size in } \mathrm{mm})\end{array}$} & \multirow{2}{*}{ PI } & \multirow{2}{*}{$\begin{array}{c}\text { Max } \\
\text { CBR } \\
\text { Swell } \\
\%\end{array}$} & & \\
\hline & & & & 75.0 & 13.2 & 2.0 & 0.425 & 0.075 & & & & \\
\hline \multirow{2}{*}{ 象竞 } & SSB & $<50$ & 2.0 & 100 & $60-85$ & $20-50$ & $10-30$ & $5-15$ & $3-10$ & 0.5 & 98 & $\begin{array}{c}60(\mathrm{o}) \\
(1.5-3 \mathrm{Mpa})\end{array}$ \\
\hline & SB & $<80$ & 1.8 & 100 & $70-100$ & $20-60$ & $10-40$ & $5-20$ & $3-10$ & 0.5 & 95 & $\begin{array}{c}+30(\mathrm{o}) \\
(1.5-3 \mathrm{Mpa})\end{array}$ \\
\hline \multicolumn{2}{|c|}{ A } & $<110$ & 1.0 & & & & & $<40$ & $<12$ & & $95 / 100 *$ & 20 \\
\hline \multicolumn{2}{|c|}{ B } & $<155$ & 0.5 & & & & & $<70$ & $<17$ & & $93 / 98 *$ & 10 \\
\hline \multicolumn{2}{|c|}{$\begin{array}{l}\text { Bulk } \\
\text { Earthworks }\end{array}$} & & & & & & & & $<25$ & 2 & $90 / 95^{*}$ & 5 \\
\hline
\end{tabular}

* These densities apply to non-cohesive soils

(o) Strengths in brackets apply in place of CBR values where subbballast is stabilised

$+\quad$ Increase to 45 in the absence of layer SSB unless otherwise specified (Increase not normally required in dry areas) 
Table 3.2: Bloubank formation material properties (adapted from Gräbe and Shaw, 2010)

\begin{tabular}{|c|c|c|c|c|}
\hline \multirow[b]{2}{*}{ Property } & \multicolumn{4}{|c|}{ Material Class } \\
\hline & SSB & SB & $\mathbf{A}$ & B \\
\hline Gravel (\%) & 71 & 70 & 31 & 30 \\
\hline Sand $(\%)$ & 21 & 22 & 55 & 55 \\
\hline Silt (\%) & 6 & 6 & 8 & 9 \\
\hline Clay $(\%)$ & 2 & 3 & 6 & 6 \\
\hline $\begin{array}{c}\text { Natural Mois ture Content } \\
(\%)\end{array}$ & 4 & 6 & 8 & 7 \\
\hline Liquid Limit & $\mathrm{SP}$ & $\mathrm{SP}$ & 29 & 30 \\
\hline Plas ticity Index & $\mathrm{SP}[10]$ & $\mathrm{SP}[10]$ & $12[\leq 12]$ & $13[\leq 17]$ \\
\hline Grading Modulus & $2.5[>2]$ & $2.4[>1.8]$ & $1.9[>1.0]$ & $1.9[>0.5]$ \\
\hline \multicolumn{5}{|c|}{ CBR at } \\
\hline $100 \%$ & 190 & 190 & 76 & 76 \\
\hline $98 \%$ & $148[>60]$ & 148 & 68 & 68 \\
\hline $95 \%$ & 101 & $101[>30]$ & $58[>20]$ & 58 \\
\hline $93 \%$ & 79 & 79 & 40 & $40[>10]$ \\
\hline \multicolumn{5}{|c|}{ Mod. AASHTO } \\
\hline \multicolumn{5}{|c|}{ Soil Classification } \\
\hline AASHTO & A-1-a (0) & A-1-a (0) & A-2-6(0) & A-2-6(0) \\
\hline Unified & GP-GM & GP-GM & $\mathrm{SC}$ & $\mathrm{SC}$ \\
\hline
\end{tabular}

\subsection{TEST SITE LAYOUT}

The test site comprised of three stations positioned $5200 \mathrm{~mm}$ apart with a total of 18 MDD modules and two wheel load sensors per station, summing to a total of 54 modules and 6 wheel load sensors. The plan view and cross section of the instrumented test site is illustrated in Figures 3.2 and 3.3 respectively. The reader is referred to Shaw (2005) for further detail regarding the Bloubank test site including a detailed description of the installation. 


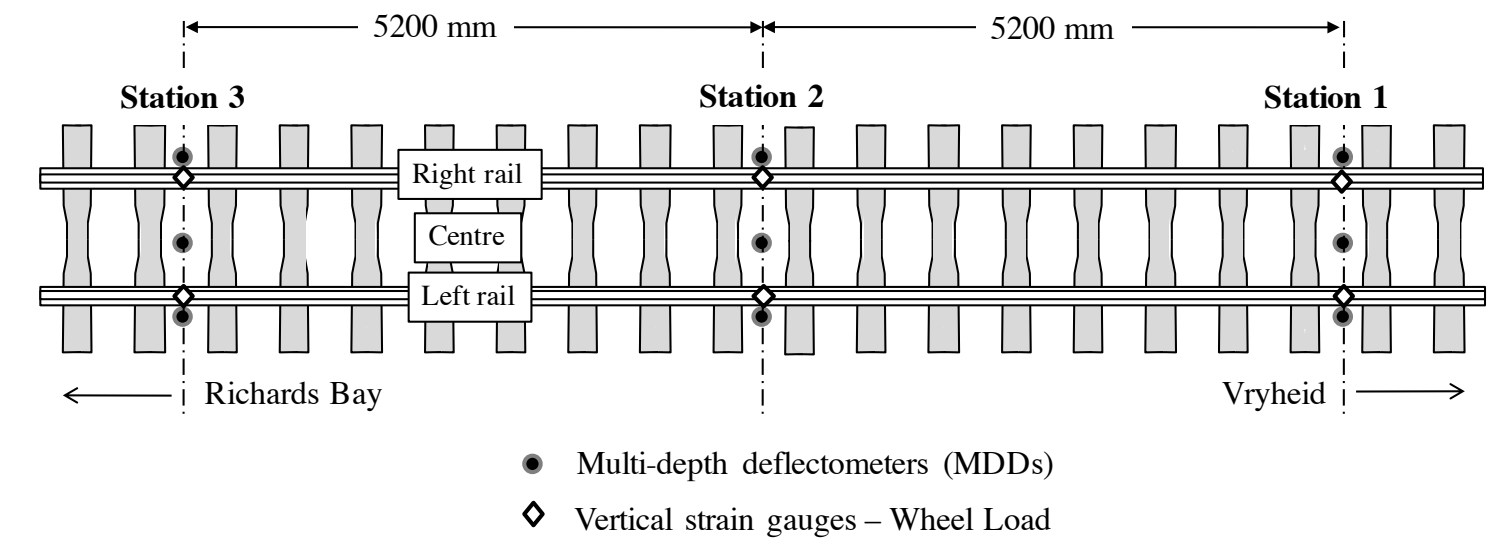

Figure 3.2: Plan view of test section layout (adapted from Gräbe and Shaw, 2010)

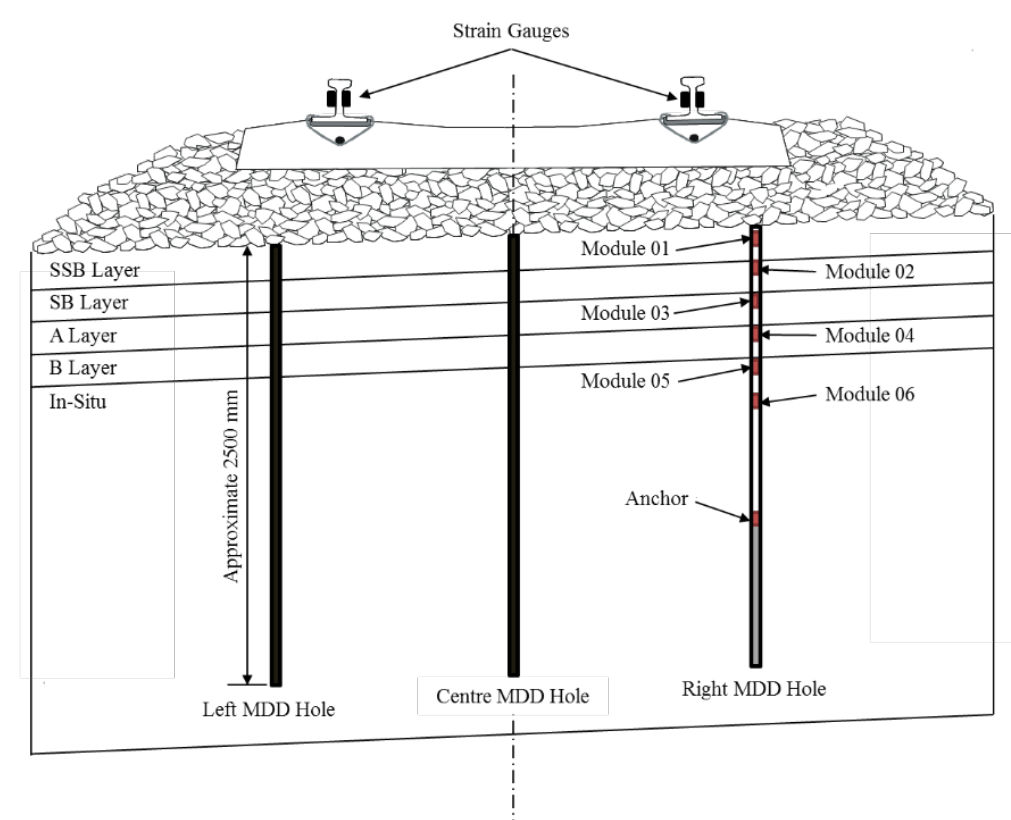

Figure 3.3: Cross section of test station layout (adapted from Shaw, 2005)

\subsubsection{Multi-Depth Deflectometer System}

As described in Section 2.4.2, the MDD system comprises a series of linear variable differential transformers (LVDTs) that are coupled in a linear vertical array. The vertical array comprises six LVDTs positioned at various depths. The number of LVDT modules which can be connected to form a single MDD system is limited by borehole diameter and the space required for the cabling. The borehole depth is limited by the drill length and soil disturbance. This borehole is lined with a thin rubber membrane preventing the ingress of moisture and loose material. It is then anchored and fixed by cement grout to restrain the vertical movement of the flexible lining. A typical MDD system installed in a railway formation is visualised in Figure 3.4. 


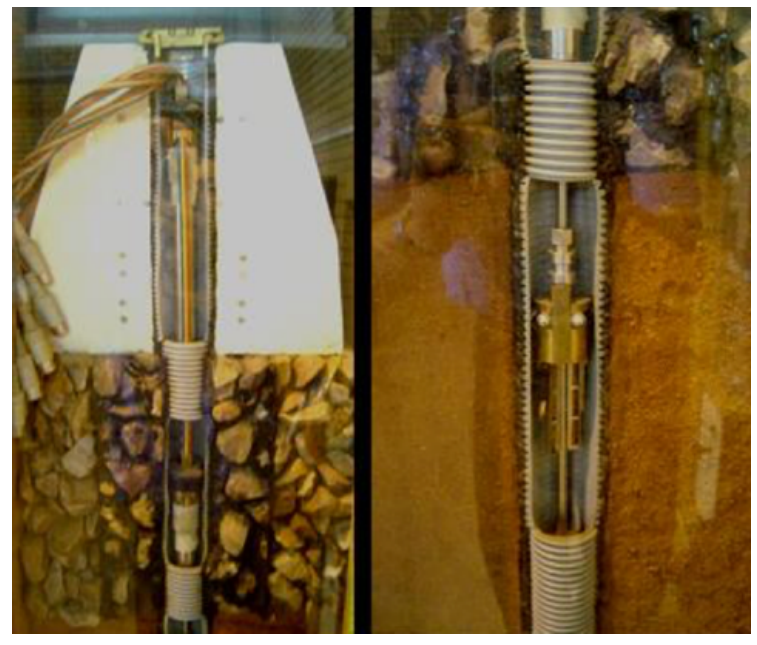

Figure 3.4: Multi-depth deflectometer system

It can be seen from Table 3.3 that the upper most module is not placed at the ballast/special subballast (SSB) layer interface, effectively measuring only $120 \mathrm{~mm}$ of the SSB layer. This is due to the required anchoring space and to prevent module damage from ballast penetration, further reducing the likelihood of erratic measurements (Shaw, 2005).

Table 3.3: Details of the multi-depth deflectometer system

\begin{tabular}{|c|c|c|c|}
\hline Modules & Layer & $\begin{array}{c}\text { Position from top of } \\
\text { formation }(\mathrm{mm})\end{array}$ & $\begin{array}{c}\text { Effective Measuring } \\
\text { Thickness }(\mathrm{mm})\end{array}$ \\
\hline 1 & SSB & 80 & 120 \\
2 & SSB/SB Interface & 200 & 200 \\
3 & SB/A Interface & 400 & 200 \\
4 & A/B Interface & 600 & 200 \\
5 & B/In-situ Interface & 800 & 200 \\
6 & In-situ 200mm & 1000 & 1500 \\
Anchor & In-situ 1500mm & 2500 & - \\
\hline
\end{tabular}

\subsubsection{Wheel Load Sensors}

The wheel load sensors comprised a system of strain gauges that were installed in accordance with the Specification for Vertical and Lateral Rail Load Gauges by Transnet Freight Rail (2010). The vertical wheel load measurements were obtained using Hottinger Baldwin Messtechnik (HBM) shear strain gauges $(350 \Omega)$ connected in a full Wheatstone bridge configuration. The vertical shear strain gauges $(80 \mathrm{~mm} \times 30 \mathrm{~mm} \times 0.25 \mathrm{~mm}$ ) were then positioned as shown in Figure 3.5. The longitudinal axis of the strain gauges was aligned with the neutral axis of the rail profile and spaced $60 \mathrm{~mm}$ away from the central point between the two sleepers. 


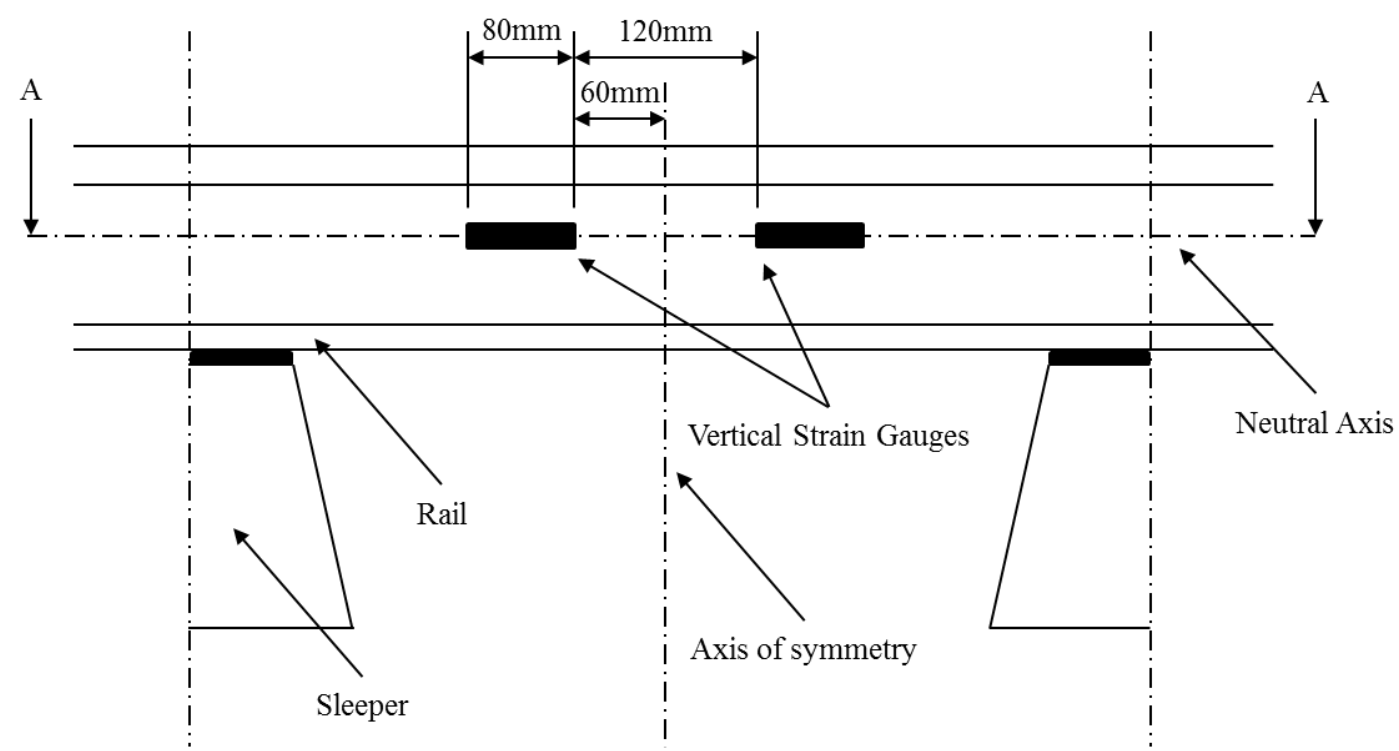

(a)

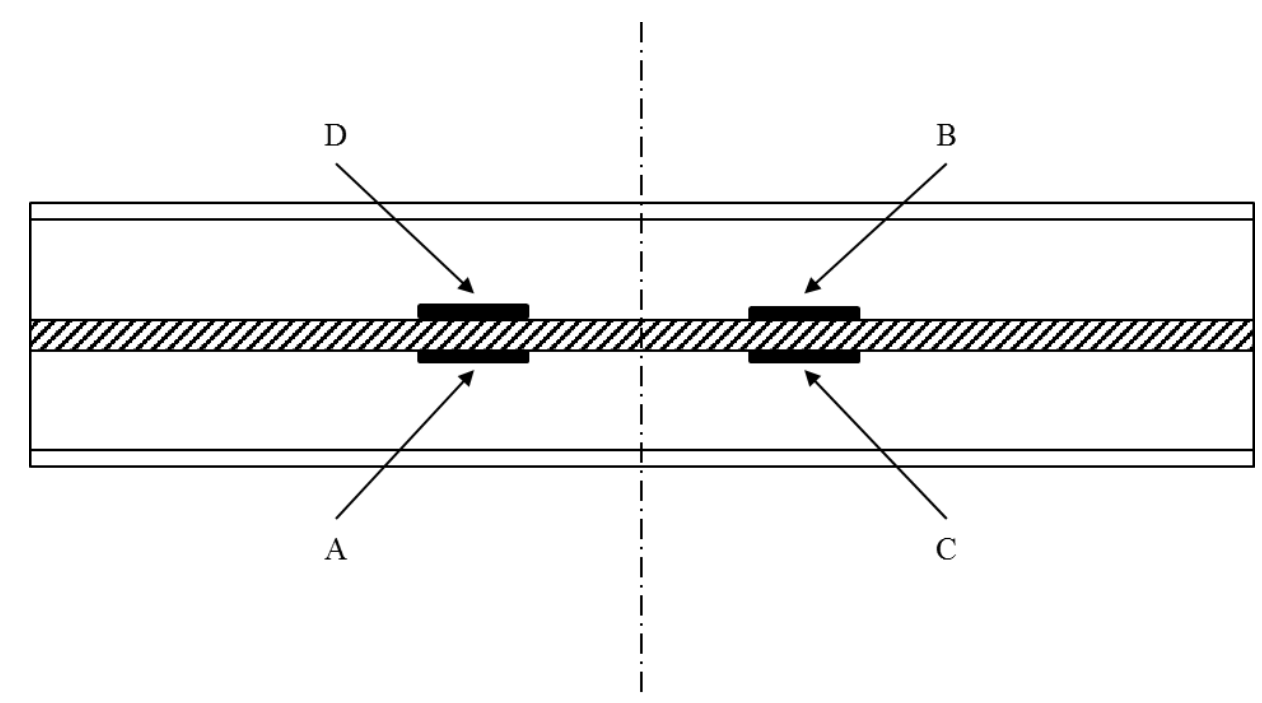

(b)

Figure 3.5: (a) Vertical strain gauge layout; (b) Cross section layout (A-A)

(Transnet Freight Rail, 2010)

The setup used to calibrate the wheel load sensors comprised of a wheel load calibration frame, load cell and hydraulic jack. The calibration frame was designed to anchor onto the rail crown to restrain longitudinal and transverse movement as well as the vertical force exerted by the hydraulic jack. The load cell is pre-calibrated to measure up to 10 tonnes. The configuration of the wheel load calibration frame, the load cell and the hydraulic jack is shown in Figure 3.6. 


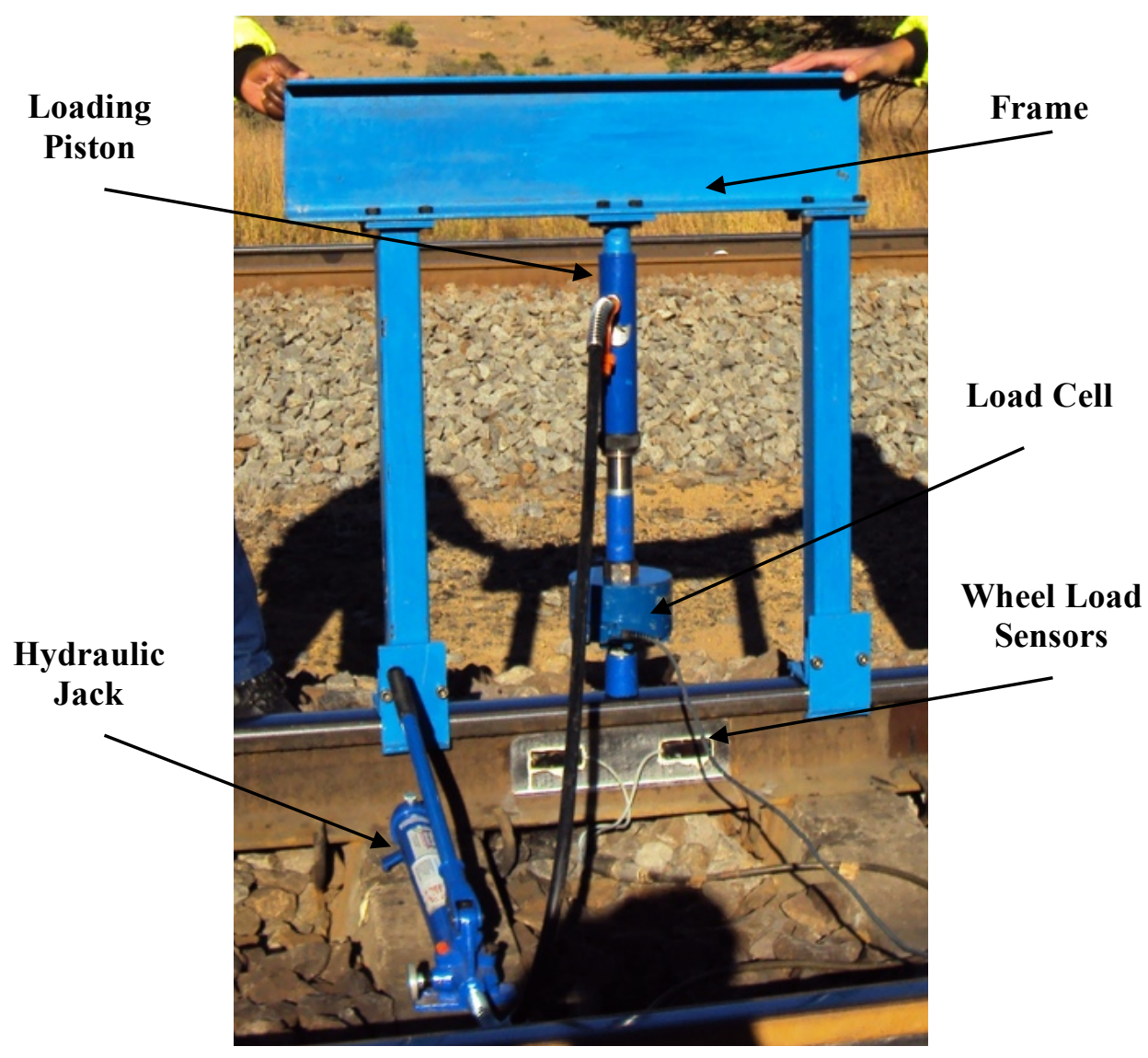

Figure 3.6: Wheel load calibration frame setup

\subsection{TEST MEASUREMENTS}

The real-time deflection measurements of the MDD system are logged in the time domain. The time domain measurements may be transformed into the space domain using the known distance between two adjacent axles on a given bogie. The cumulative deflections of the MDDs and their corresponding formation layers during passage of a typical train at the Bloubank test site in time and space domain are presented in Figures 3.7 and 3.8 respectively. Furthermore, Figure 3.9 illustrates the calibrated wheel load measurements for a fully loaded coal train, consisting of four 11E locomotives (29 tonnes/axle) and approximately 200 Jumbo wagons (26 tonnes/axle). 


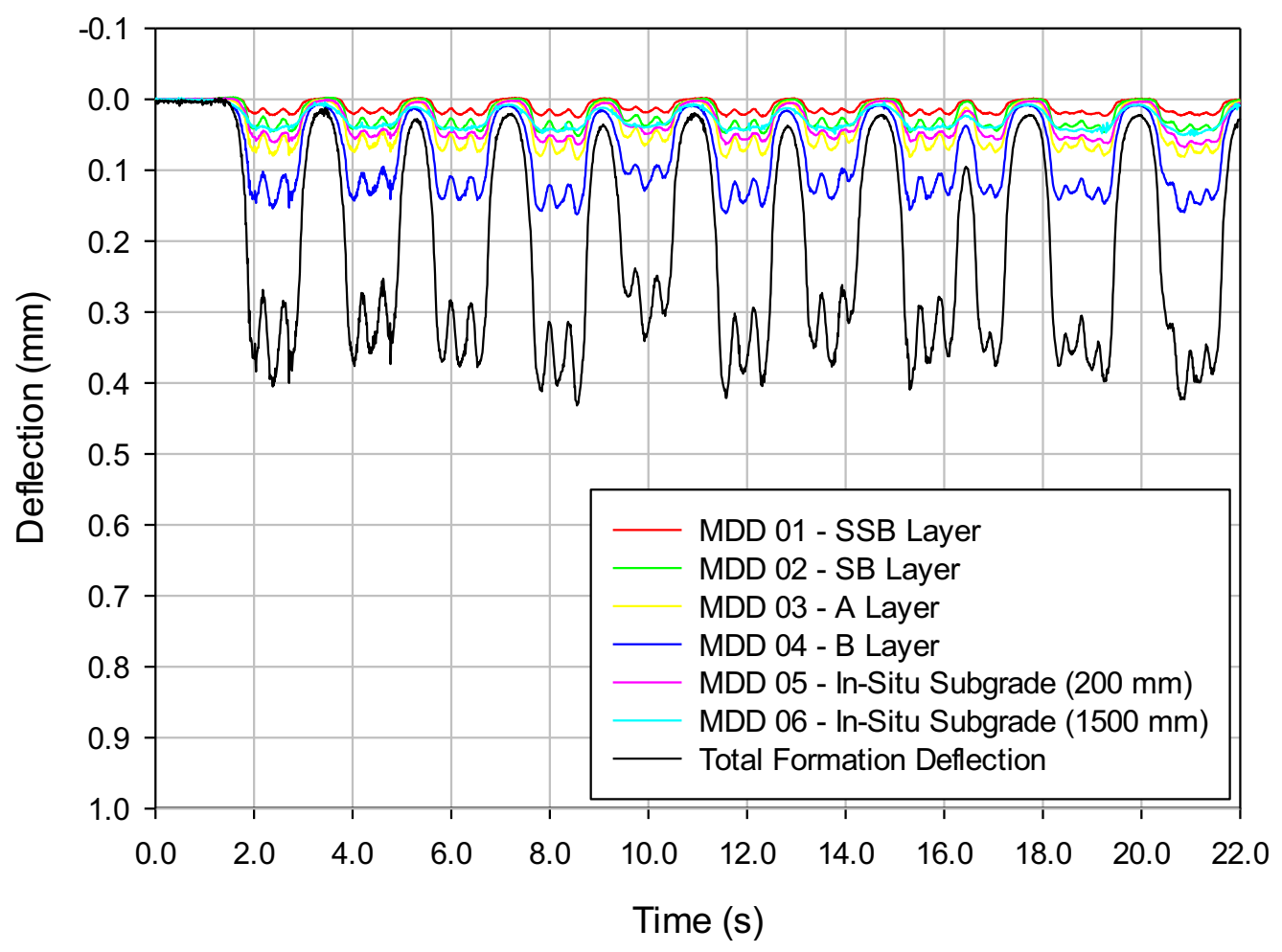

Figure 3.7: Typical formation deflection measurements in time-domain

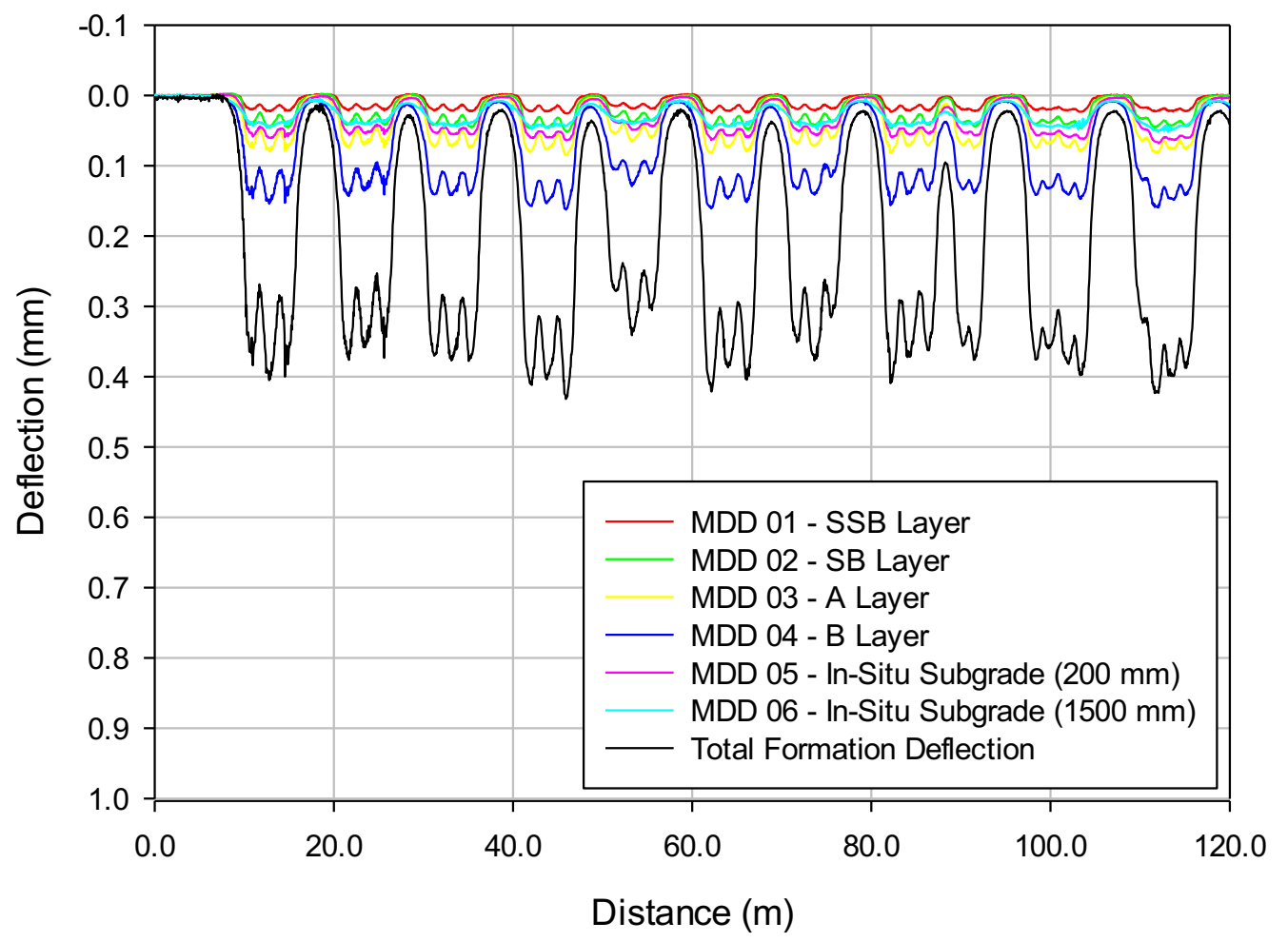

Figure 3.8: Typical formation deflection measurements in space-domain 


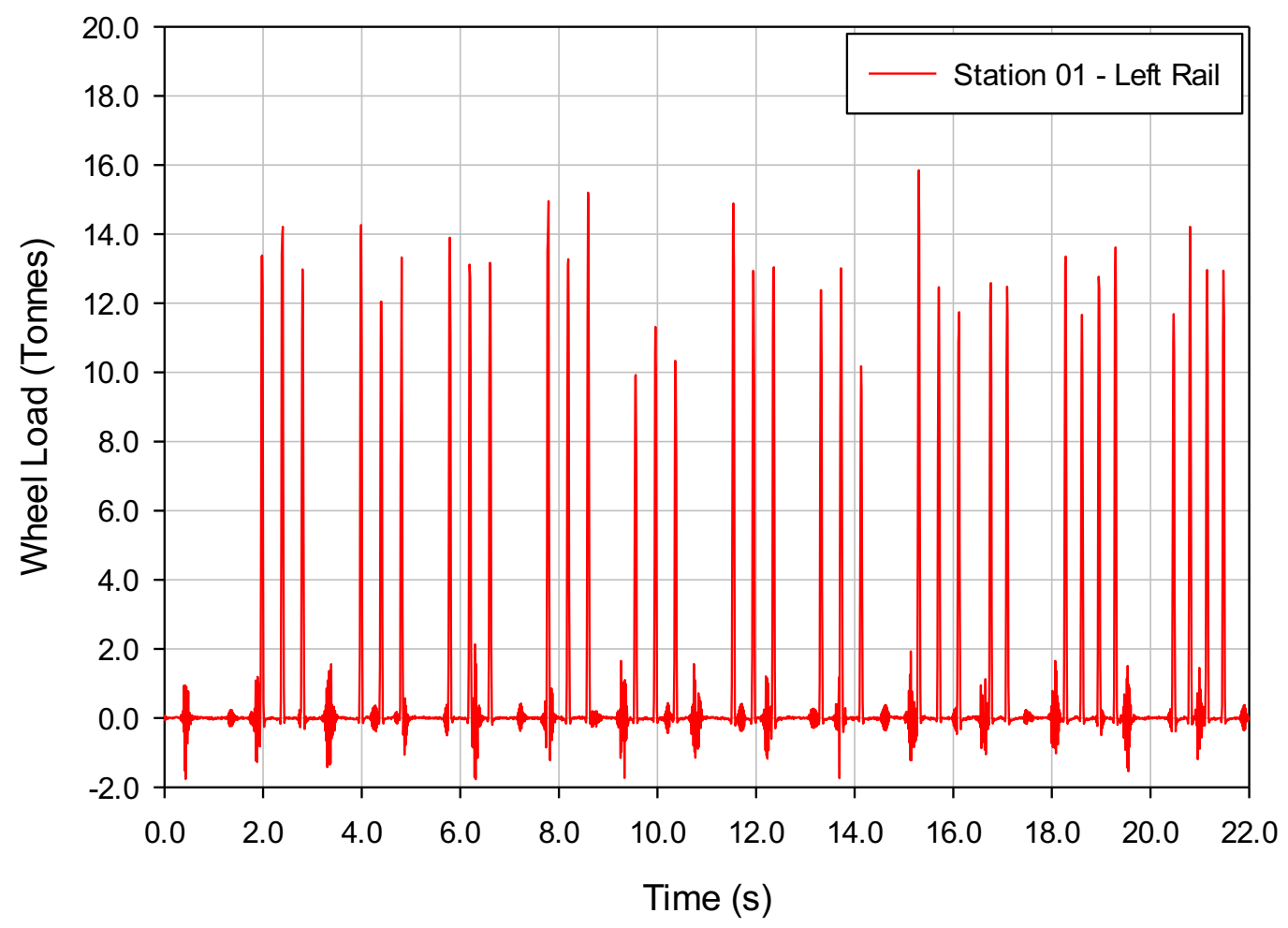

Figure 3.9: Typical wheel load measurements

\subsection{SUMMARY OF EXPERIMENTAL TEST SITE}

The Bloubank experimental test site has allowed for several comprehensive investigations of rail track formation responses under train transient loading as researched by Gräbe et al. 2005, Yang et al. 2009; Gräbe and Shaw, 2010, Priest et al. 2010, Vorster and Gräbe, 2013, Vandoorne et al. 2017 among others. MDDs have been of great significance for the analysis of transient foundation behaviour, investigating formation life prediction, environmental changes, stresses and deflections of in-service heavy haul railway lines. In this research, transient and local formation deflections were analysed through MDD measurements allowing for the calibration and validation of the inverse analysis of rail track formation properties. However, finite element modelling was adopted as a means of preliminarily determining the effect of superstructure components, substructure material properties and railway equilibrium influence lines as presented in Chapter 4. 


\section{FINITE ELEMENT MODEL}

This chapter provides an overview of the assembly of the finite element model (FEM) used in this study with particular focus on the superstructure and substructure components as well as loading simulation. The results of sensitivity analyses are presented with regard to assessing the influence of load positioning on sleeper load distribution and the formation properties namely elastic moduli and Poisson's ratio. Finally, this chapter investigates the development of railway formation equilibrium influence lines and their application towards investigating the validity of the commonly assumed $45^{\circ}$ influence line for ballasted railway tracks.

\subsection{MODEL ASSEMBLY}

The model assembly is described with particular attention to the superstructure and substructure components in Section 4.1.1 and the loading simulation in Section 4.1.2.

\subsubsection{Superstructure and Substructure}

A 3D half-space FEM representing a physical size of $4667 \mathrm{~mm}$ x $19500 \mathrm{~mm}$ x $6800 \mathrm{~mm}$ was constructed using Strand 7 in accordance with the Manual for Track Maintenance and Specification for Railway Earthworks (S410) by Transnet Freight Rail.

The model was based on a heavy haul Class Line (S) with the following standard specifications:

- Maximum axle load: 26 tonnes;

- Rail type: $60 \mathrm{~kg} / \mathrm{m}$ - UIC60;

- Sleeper type and spacing: Concrete PY at $650 \mathrm{~mm}$;

- Ballast depth: $300 \mathrm{~mm}$.

The 3D half-space model is shown in Figure 4.1. Symmetry about the ZY plane was used to reduce the number of elements required thus achieving a computationally more efficient model. Translational and rotational restraints in the $\mathrm{X}, \mathrm{Y}$ and $\mathrm{Z}$ directions are indicated with the symbols $\mathrm{X}, \mathrm{Y}$ and $\mathrm{Z}$; and $\mathrm{RX}$, $\mathrm{RY}$ and RZ in the figure respectively. Separate restraints were imposed on the superstructure (denoted in bold) and substructure as indicated in Figure 4.1. 


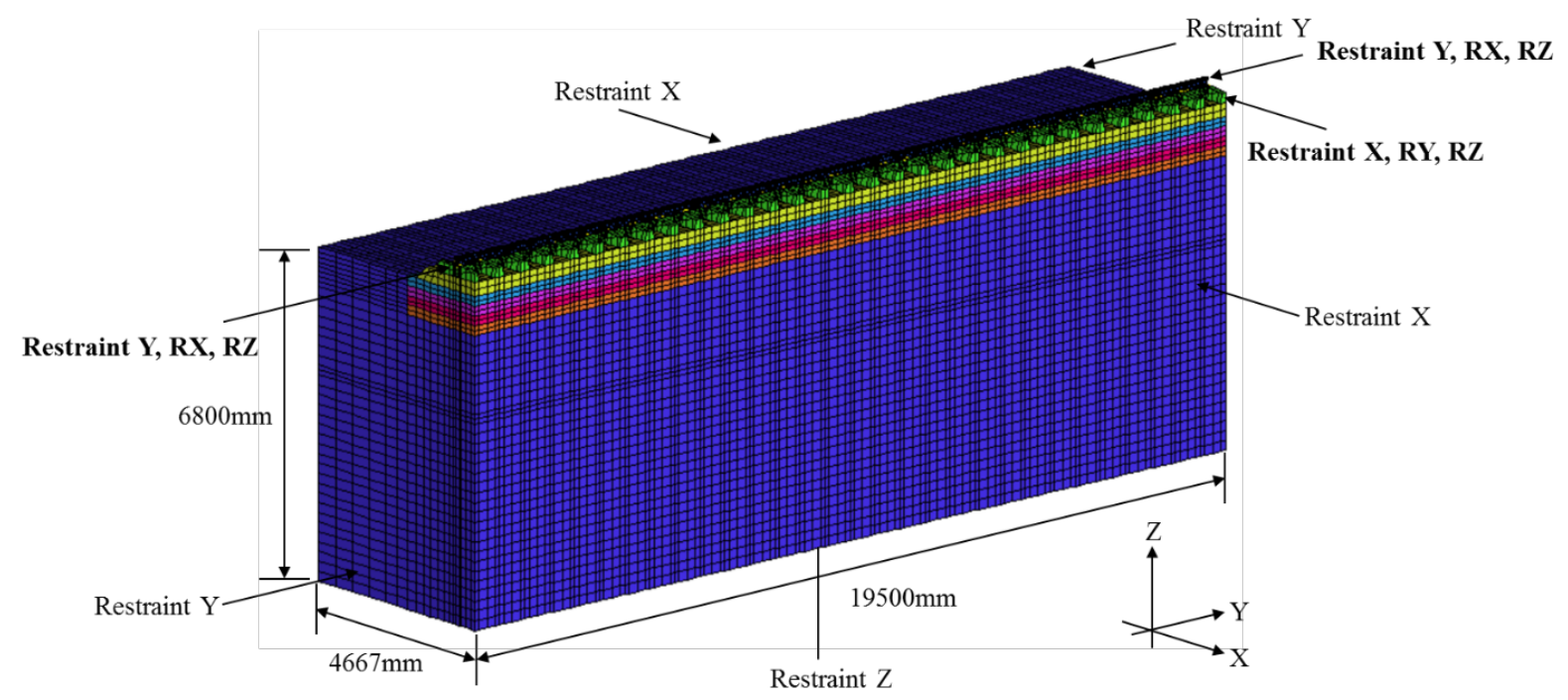

Figure 4.1: 3D half-space finite element model

The model consisted of 108000 hexahedral 8-noded brick elements, 127947 nodes, 444 links, 50 vertices and 93 faces. An additional face attachment was necessitated by a mismatch between the nodes of the elements representing the high density polyethylene (HDPE) pads and concrete sleepers. Therefore, 444 links, 50 vertices and 93 faces were inserted to facilitate model convergence. The properties of the track components and layers used in the model are shown in Table 4.1. Figure 4.2 shows a cross section of the model along the $\mathrm{XZ}$ plane indicating the various track components modelled and the dimensions thereof.

Table 4.1: Track components \& layers properties

\begin{tabular}{|c|c|c|c|}
\hline $\begin{array}{c}\text { Track Components \& } \\
\text { Formation Layers }\end{array}$ & $\begin{array}{c}\text { Poisson's } \\
\text { Ratio }\end{array}$ & $\begin{array}{c}\text { Density } \\
\left(\mathrm{kg} / \mathrm{m}^{3}\right)\end{array}$ & $\begin{array}{c}\text { Elastic Modulus } \\
(\mathrm{MPa})\end{array}$ \\
\hline Rail & 0.25 & 7870 & 200000 \\
\hline Pad (HDPE) & 0.40 & 900 & 1000 \\
\hline Sleeper (PY) & 0.20 & 2400 & 34290 \\
\hline Ballast & 0.30 & 1800 & 250 \\
\hline SSB & 0.35 & 2200 & 300 \\
\hline SB & 0.35 & 2050 & 250 \\
\hline A & 0.35 & 1900 & 150 \\
\hline B & 0.35 & 1850 & 50 \\
\hline In-Situ Subgrade & 0.35 & 2300 & 400 \\
\hline
\end{tabular}




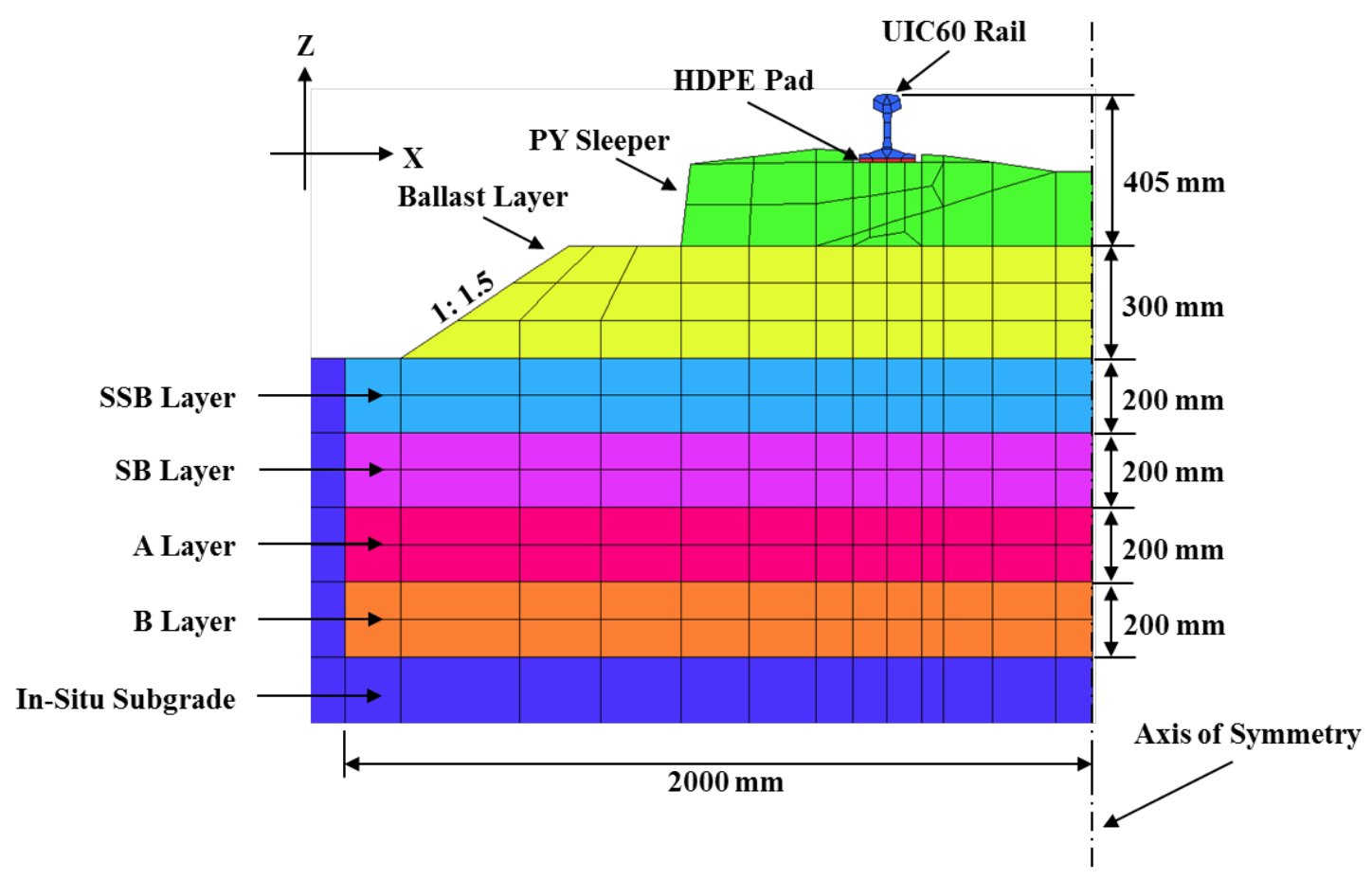

Figure 4.2: Cross section of finite element railway track model

\subsubsection{Loading Simulation}

The loading used in the analyses consisted of simulating only the leading locomotive bogie of a full train, assuming that the other bogie of the same locomotive has no significant influence on the other bogie. The formation response beneath the leading wheel load was the focus of this study. This was decided in order to mitigate complications arising from the following:

- Inherent variability in wagon loading;

- Resilient deformation accumulation with repeated loading cycles during train passage;

- Soil recovery throughout train transient loading.

The wheel loading was modelled via static point loads positioned on top of the rail crown and aligned with the neutral axis of the rail profile. The moving wheel loads were modelled by sequential static point loads spaced at $25 \mathrm{~mm}$ increments to simulate the transient nature of the locomotive, thus replicating continuous longitudinal movement. Figure 4.4 illustrates the static point loads for simulation of a single moving wheel load. The bogie was subsequently modelled in accordance with the specific locomotive being considered. The locomotive details as used for modelling purposes are shown in Table 4.2. Figure 4.4 shows the placement of the bogie wheel loads for a $7 \mathrm{E}$ or 11E locomotive. 


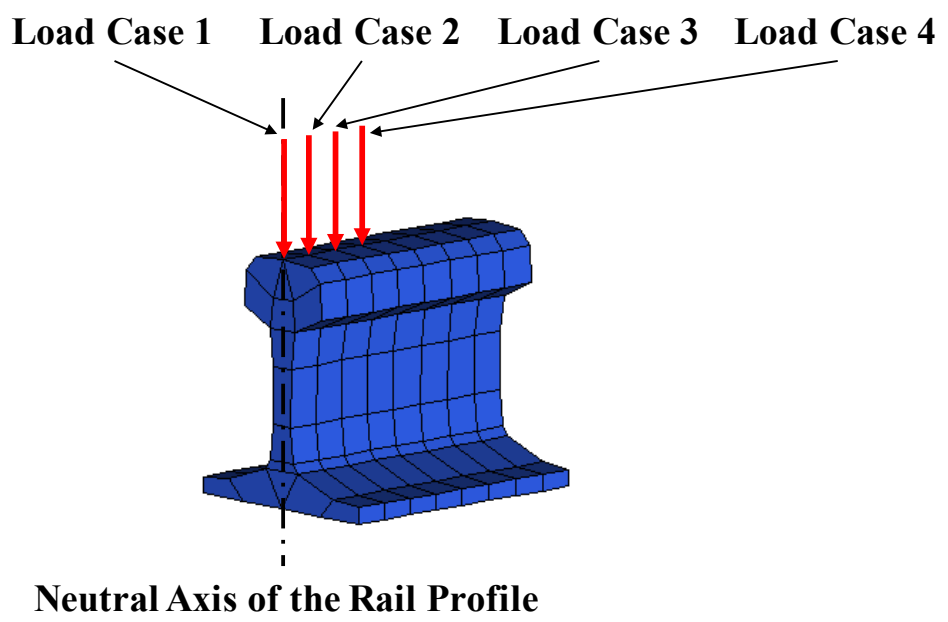

Figure 4.3: Finite element modelling of a single moving wheel load

Table 4.2: Locomotive information - Transnet Freight Rail

\begin{tabular}{|c|c|c|c|}
\hline Locomotive Type & $\begin{array}{c}\text { Axle Load } \\
\text { (Tonnes) }\end{array}$ & Axles/Bogie & Bogie Length (mm) \\
\hline $7 \mathrm{E}$ & 21 & 3 & 4400 \\
\hline $11 \mathrm{E}$ & 29 & 3 & 4400 \\
\hline $19 \mathrm{E}$ & 26 & 2 & 3000 \\
\hline $21 \mathrm{E}$ & 26 & 2 & 2700 \\
\hline
\end{tabular}

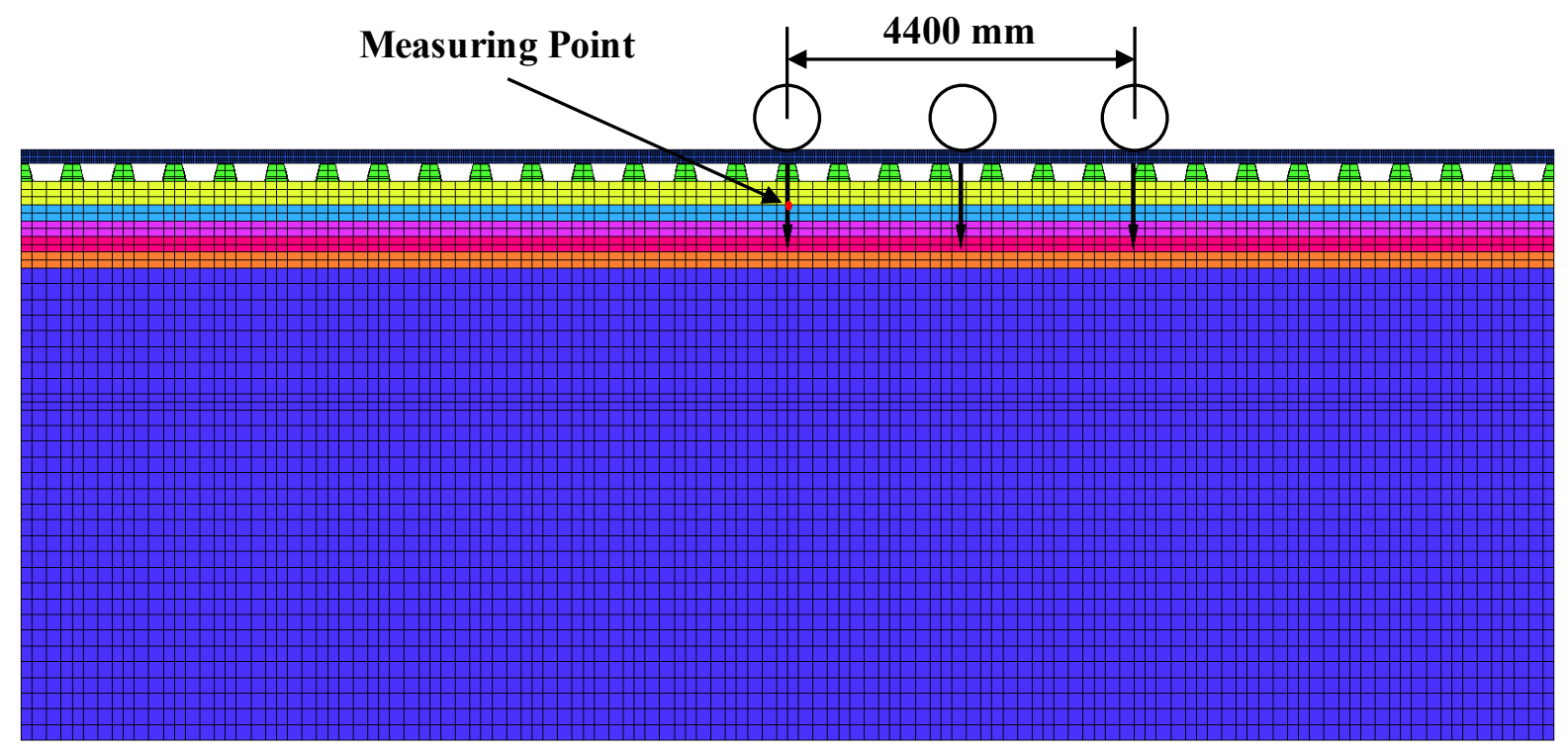

Figure 4.4: Finite element modelling of $7 \mathrm{E}$ or $11 \mathrm{E}$ locomotive bogie loading

The self-weight loading was disregarded due to the relatively insignificant stress increase with depth caused by the superstructure and the shallow nature (less than 1 meter) of the formation, as suggested by Li et al. (2016). Thus, the focus was on the stresses and deflections as a result of train loading. 


\subsection{SUPERSTRUCTURE SENSITIVITY ANALYSIS}

The sensitivity analysis of the superstructure was concerned with determining the effects of locomotive positioning relative to the sleepers and locomotive type (axle load, axle/bogie and bogie length) on the response of a conventional railway track structure with formation properties as given in Table 4.3, representing a typical formation constructed on competent rock as in the case of a cut.

Table 4.3: Formation properties for a generic cut

\begin{tabular}{|c|c|c|c|}
\hline Formation Layers & $\begin{array}{c}\text { Poisson's } \\
\text { Ratio }\end{array}$ & $\begin{array}{c}\text { Density } \\
\left(\mathrm{kg} / \mathrm{m}^{3}\right)\end{array}$ & $\begin{array}{c}\text { Elastic Modulus } \\
(\mathrm{MPa})\end{array}$ \\
\hline SSB & 0.35 & 2200 & 300 \\
\hline SB & 0.35 & 2050 & 250 \\
\hline A & 0.35 & 1900 & 150 \\
\hline B & 0.35 & 1850 & 50 \\
\hline In-Situ Subgrade & 0.35 & 2300 & 400 \\
\hline
\end{tabular}

\subsubsection{Influence of Locomotive Positioning}

This part of the sensitivity analysis is concerned with the influence of locomotive positioning relative to the sleeper spacing on the observed formation deformation and stress at various positions. The positioning of the locomotive in relation to the sleeper spacing will influence the manner in which the load is received by the sleepers and propagated into the substructure. The discontinuous nature of the sleeper support is a vital consideration to account for in characterising the formation response.

Therefore, two load cases of locomotive bogie positioning were considered and are illustrated in Figure 4.5. The first case represents the scenario where the leading axle is positioned directly on top of a sleeper and the second case represents the scenario where the leading axle is positioned at the centre between two sleepers. Both cases were analysed using $7 \mathrm{E}$ locomotive bogie loading. The influence of loading positioning on superstructure load distribution, formation deflection and stress was investigated through the following:

- Line $\mathrm{A}$ is where the total formation deflection with increasing distance was calculated as a result of a single load case located at Positions 1 and 2;

- Line B is where the vertical formation stress with increased depth was calculated as a result of a single load case located at Positions 1 and 2;

- Point $\mathrm{C}$ is where the transient formation deflection at a single point (Ballast/Special Subballast interface) caused by spaced load applications at increasing distances (i.e. train transient loading) was calculated. 
Furthermore, unless explicitly stated, all deflections presented here were obtained at the singular measuring point (centre-of-sleeper) with 7E bogie loading.

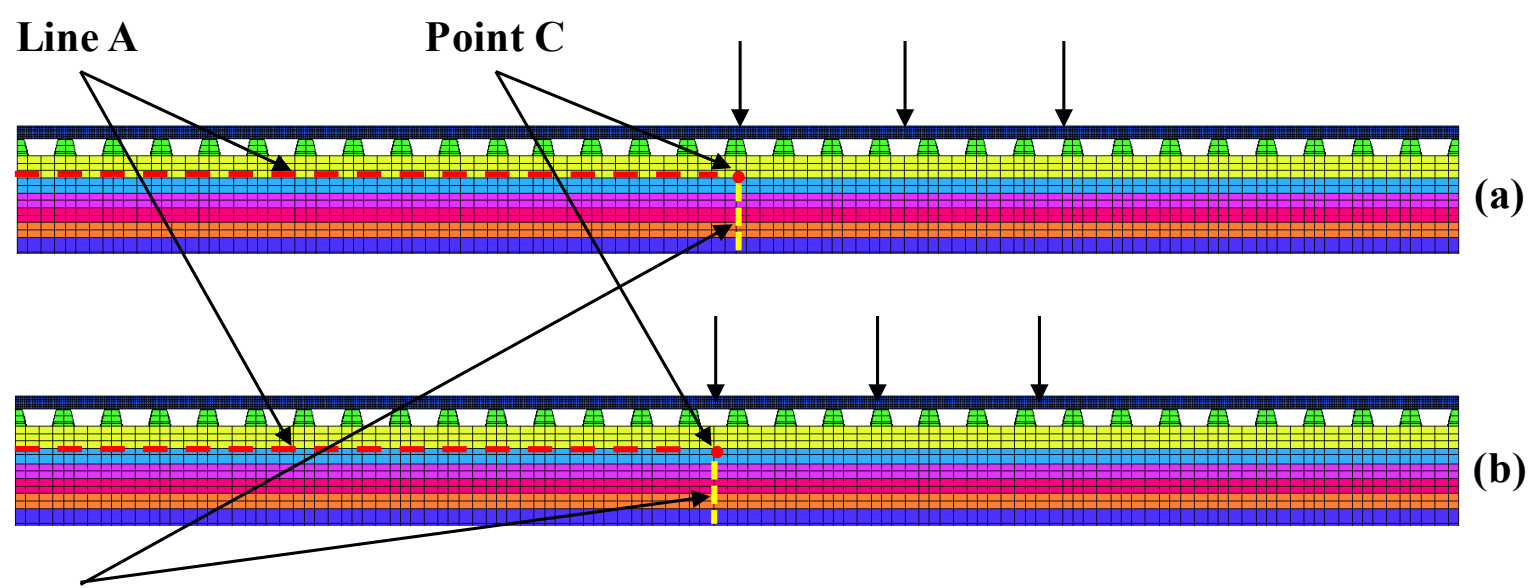

\section{Line B}

Figure 4.5: (a) Centre of sleeper - Position 1; (b) Between sleepers - Position 2

Line A shown in Figure 4.5 is used to assess the influence of load distribution through the sleepers as a result of the different wheel load positions on top of the rail crown. Figure 4.6 shows that the load distribution through the superstructure is directly related to the load positioning being clearly indicated by the symbols (see Figure 4.6) which illustrates the contribution of each sleeper relative to the position of the leading axle of the locomotive bogie. Furthermore, Figure 4.7 shows that Position 2 causes a wider load distribution with smaller peak deflection, while Position 1 results in a larger peak deflection and narrower spread at the top of the special subballast. 


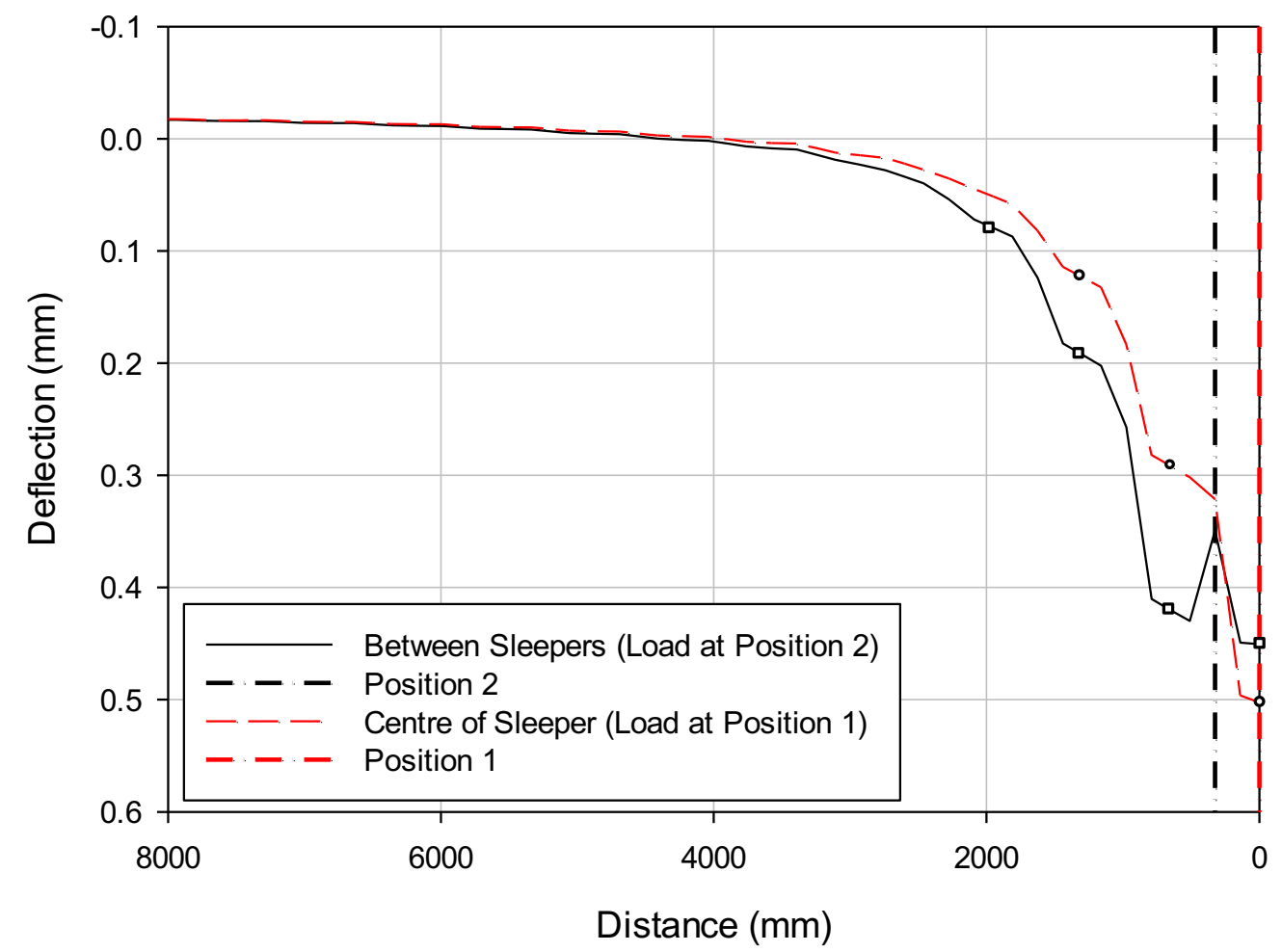

Figure 4.6: Substructure deflection with increasing distance at the top of the ballast layer

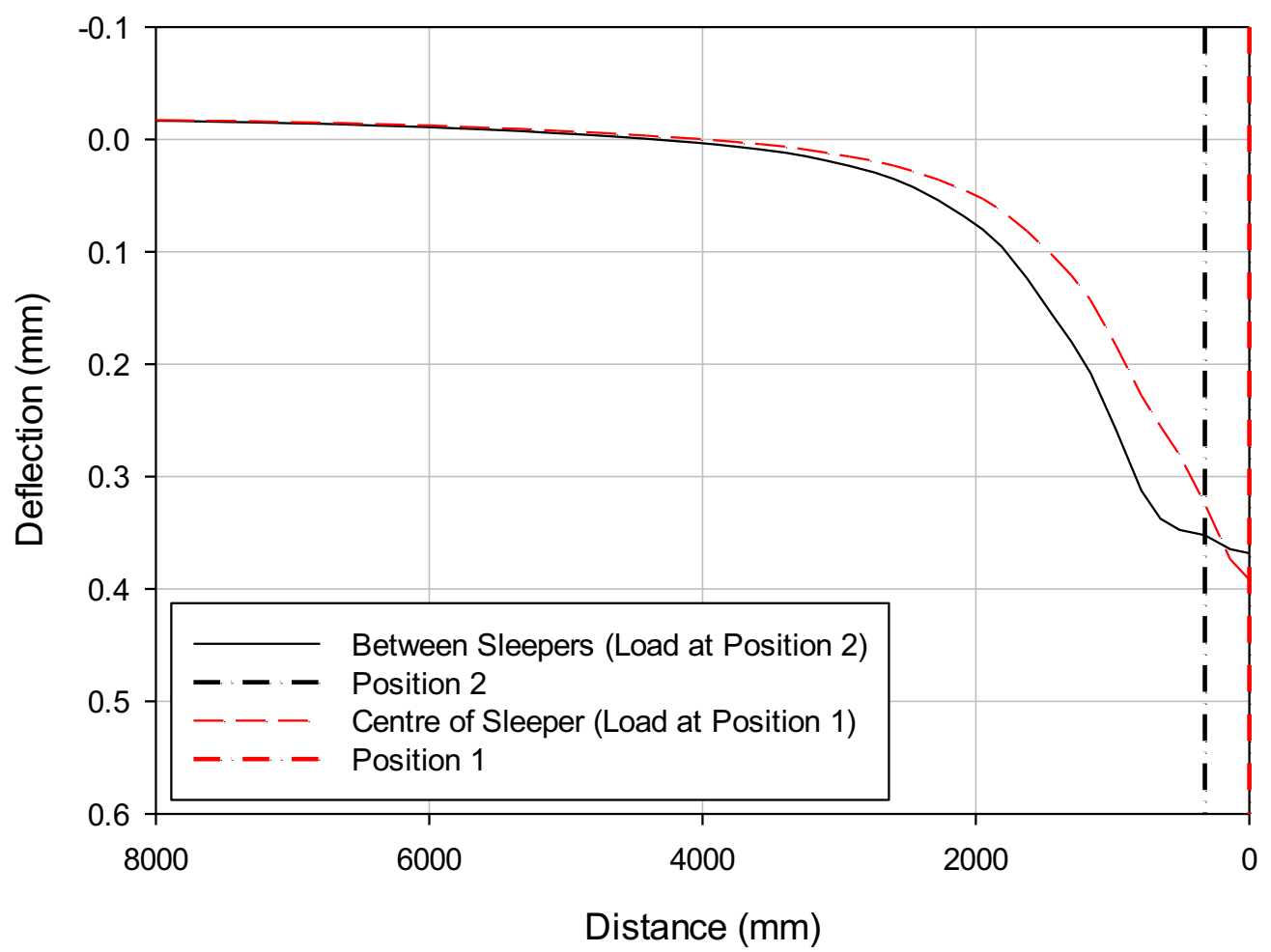

Figure 4.7: Substructure deflection at the top of special subballast layer calculated at Line A 
The effect of load positioning was further analysed at Point $C$ shown in Figure 4.5. Figure 4.8 shows that loading at Position 2 results in lower transient deflections as a result of the wider load distribution through the superstructure in comparison to Position 1. In addition, Figure 4.9 shows the distribution of stress beneath Point C and along Line B. The result illustrated in Figure 4.9 is important because it shows that formation stress between sleepers (Position 2) is non-monotonic in nature, due to the stress path from the adjacent sleepers not yet intersecting at shallow depth. The stress path overlap is illustrated by the inflection point at the top of the subballast. Thus, lower stresses result at the special subballast and higher stresses at the subballast layer as a product of stress path overlap.

Furthermore, it is important to note that vertical stresses of finite element models do not converge to zero with depth regardless of the model depth, load configuration and structural properties. Vertical stresses are in fact limited by the mathematical solution due to the sum of natural exponential functions raised to the negative and positive power of the specific depth. For that reason, zero stresses only exist as the limit of the depth approaches infinity, additionally the lateral extent of the model may also influence the stresses.

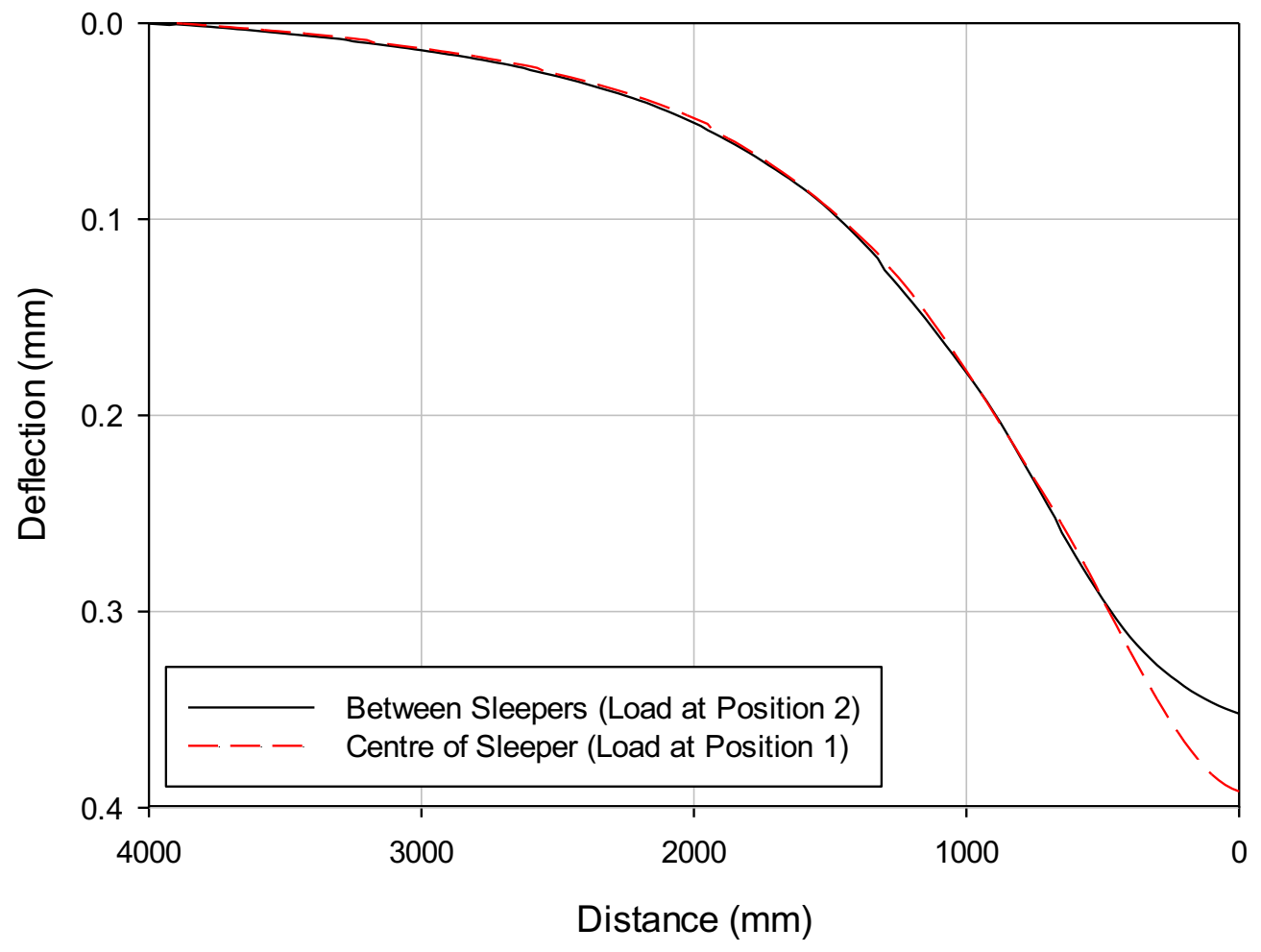

Figure 4.8: Transient substructure deflection for moving point loads calculated at Point $\mathrm{C}$ 


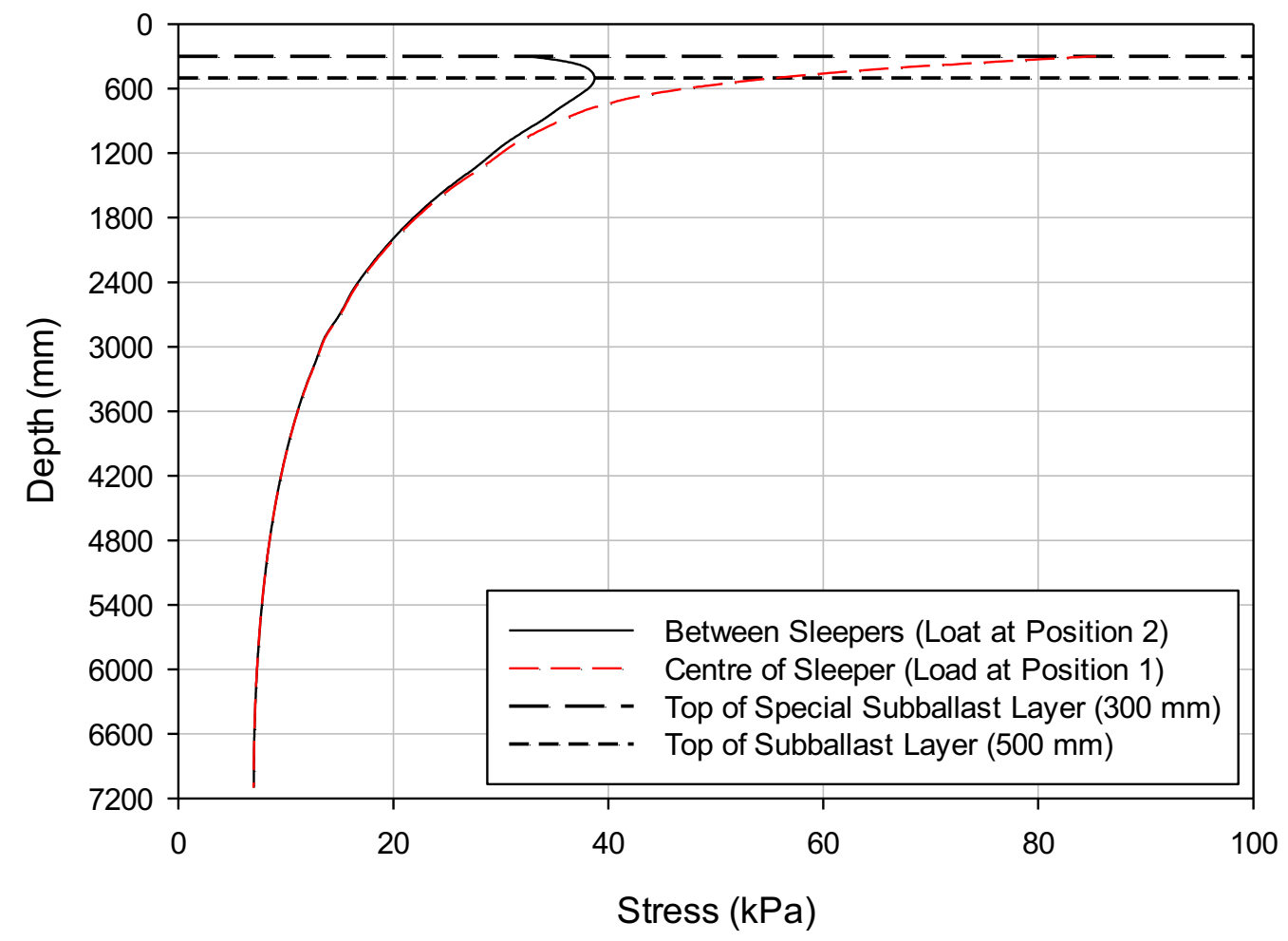

Figure 4.9: Substructure vertical stress for different load positions calculated at Line B

\subsubsection{Influence of Locomotive Type}

The influence of locomotive type on substructure deflection was investigated with regard to their varying design specification namely axle load, number of axles per bogie and bogie length. This is due to the fact that these characteristics are known to affect the shape of deflection basins and the range of soil influenced (Li et al., 2016). These analyses were based on calculating the deflection at Point $\mathrm{C}$ located at the centre-of-sleeper. The following similarities were found between the compared locomotive types shown in Table 4.2:

- The 7E and 11E locomotives are identical with the exception of axle load - 7E (21 tonnes/axle) and 11E (29 tonnes/axle);

- The 19E and 21E locomotives are identical with the exception of bogie length - 19E (3000 mm) and $21 \mathrm{E}(2700 \mathrm{~mm})$.

Figure 4.10 shows that the substructure response is governed predominantly by the locomotive axle load, also indicating that the decrease in bogie length from a $19 \mathrm{E}$ to $21 \mathrm{E}$ locomotive increases the 
formation deflection. It is further presumed that the increase in deflection spread is associated with the superposition of the particular bogies on the given superstructure characteristics, resulting in a complex interaction between bogie loading (axles/bogie and bogie length) and sleeper spacing.

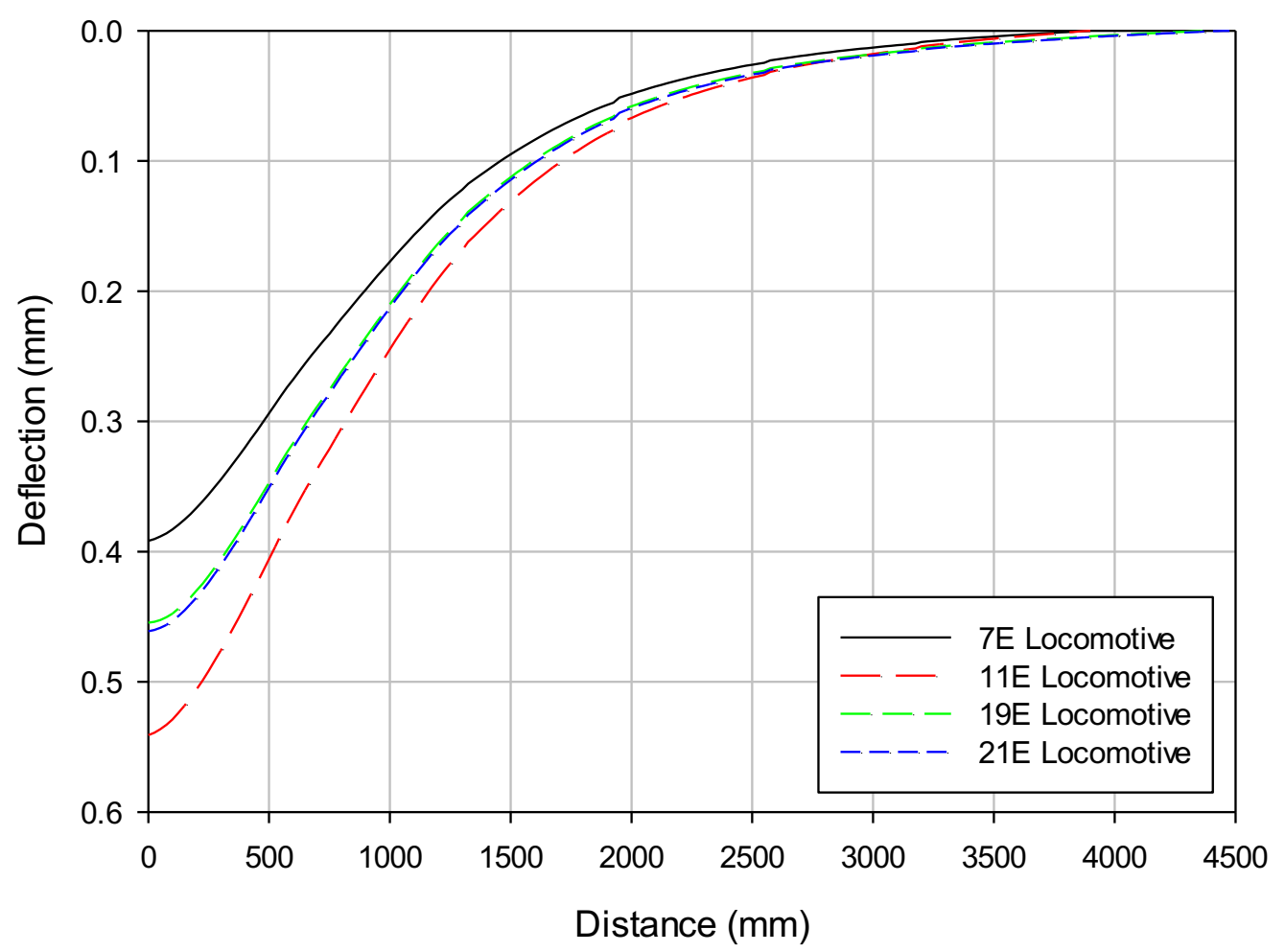

Figure 4.10: Transient substructure deflection for different locomotive types at centre of sleeper

Figure 4.11 illustrates the variation in stress distribution with the different locomotive types considered. When comparing locomotives with the same number of axles per bogie (7E and 11E; 19E and 21E) it was identified that two-axle bogies resulted in a greater total vertical stress dissipation than three-axle bogies. Therefore, it is concluded that substructure deflections and stresses are dependent on the interaction between each particular locomotive bogie and superstructure characteristics and not only by the substructure composition. 


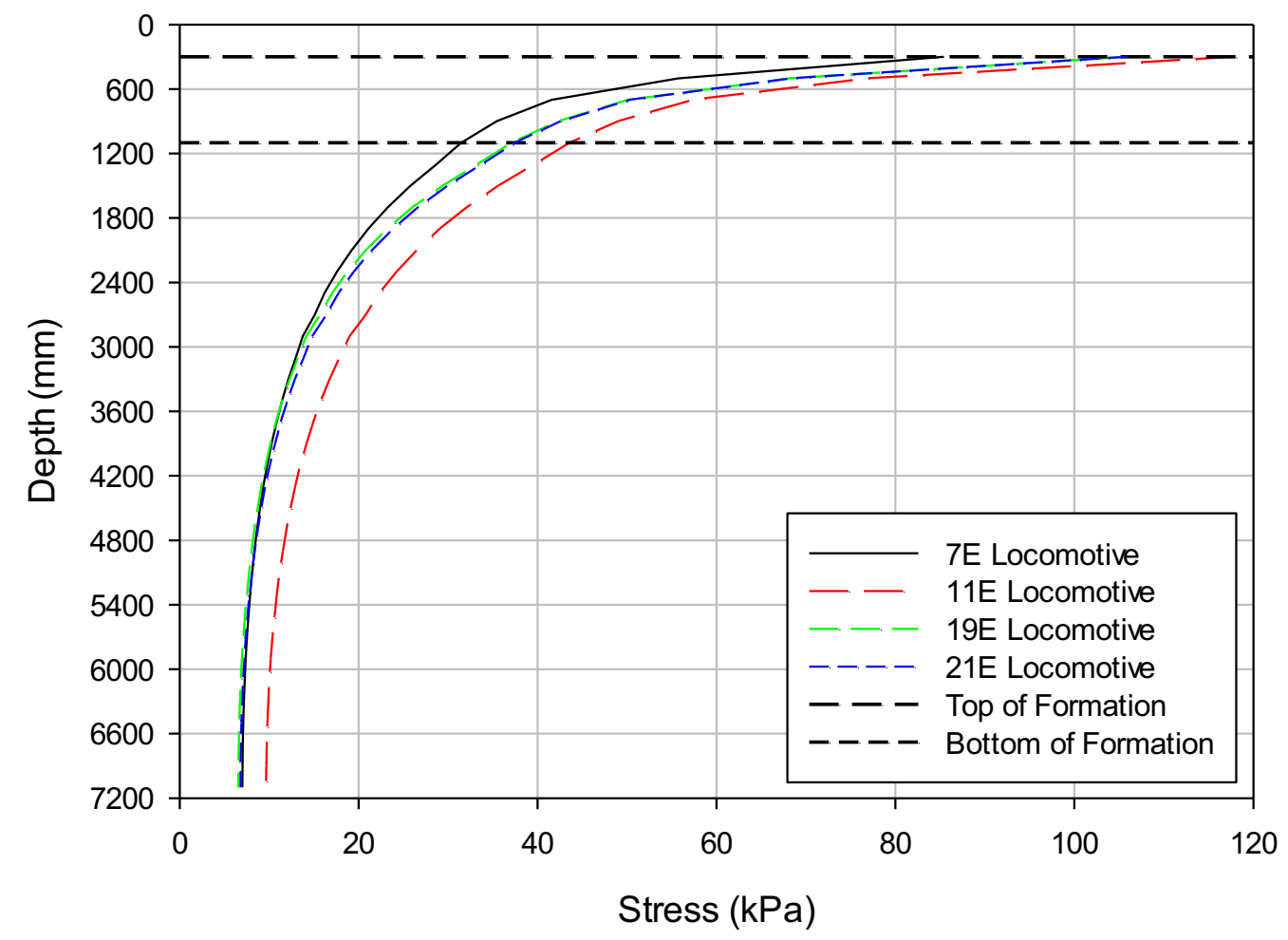

Figure 4.11: Substructure vertical stress for different locomotive types at centre of sleeper

\subsection{SUBSTRUCTURE SENSITIVITY ANALYSIS}

The substructure sensitivity analyses focused on determining the effect of the substructure properties: elastic moduli and Poisson's ratio. The substructure was modelled as homogeneous with the objective of assessing the influence of each material property in terms of its influence on substructure deflection and stresses. The reference substructure properties assumed for this analysis were: elastic modulus of $200 \mathrm{MPa}$; Poisson's ratio of 0.35 and density of $1850 \mathrm{~kg} / \mathrm{m}^{3}$ (constant). However, elastic moduli and Poisson's ratio were individually investigated as independent variables.

\subsubsection{Elastic Moduli Analysis}

The elastic modulus analyses were conducted on a homogenous substructure with elastic moduli of 50, $100,200,300$ and $400 \mathrm{MPa}$. A heterogeneous substructure decreasing from 400 to $50 \mathrm{MPa}$ at $200 \mathrm{~mm}$ increments throughout the entire substructure depth $(6800 \mathrm{~mm})$ was also modelled pre-assessing the differential response between homogenous and heterogeneous substructures.

Figure 4.12 shows how the increase in elastic moduli significantly affects the substructure deflection measurements. The results shown in Figure 4.12 reinforces the belief that deflection basins are directly 
related to the substructure composition, as characterised by the variations in the shape of the deflection basins. According to Horak (2008) the shape of deflection basins is dependent on pavement composition, structural strength, size of the load contact area, load magnitude, duration of loading, instrumentation and temperature. Furthermore, Horak and Emery (2006) stated that deflection basin parameters can be used for identification of weak pavements over the length and in the depth of the structure allowing for benchmarking and optimisation of detailed investigations. In this research, the variations in the shape of the deflection basin was categorised according to the change in the following deflection parameters:

- Peak deflection;

- Spread of deflection;

- Deflection curvature;

Figure 4.12 demonstrates that the peak deflection and the deflection basin curvature are the most influential deflection parameters with the increase in homogeneous elastic moduli for a constant Poisson's ratio of 0.35 . On the contrary, heterogeneous substructure shows a different change in deflection curvature with greater spread deflection as result of the decrease in elastic moduli with depth.

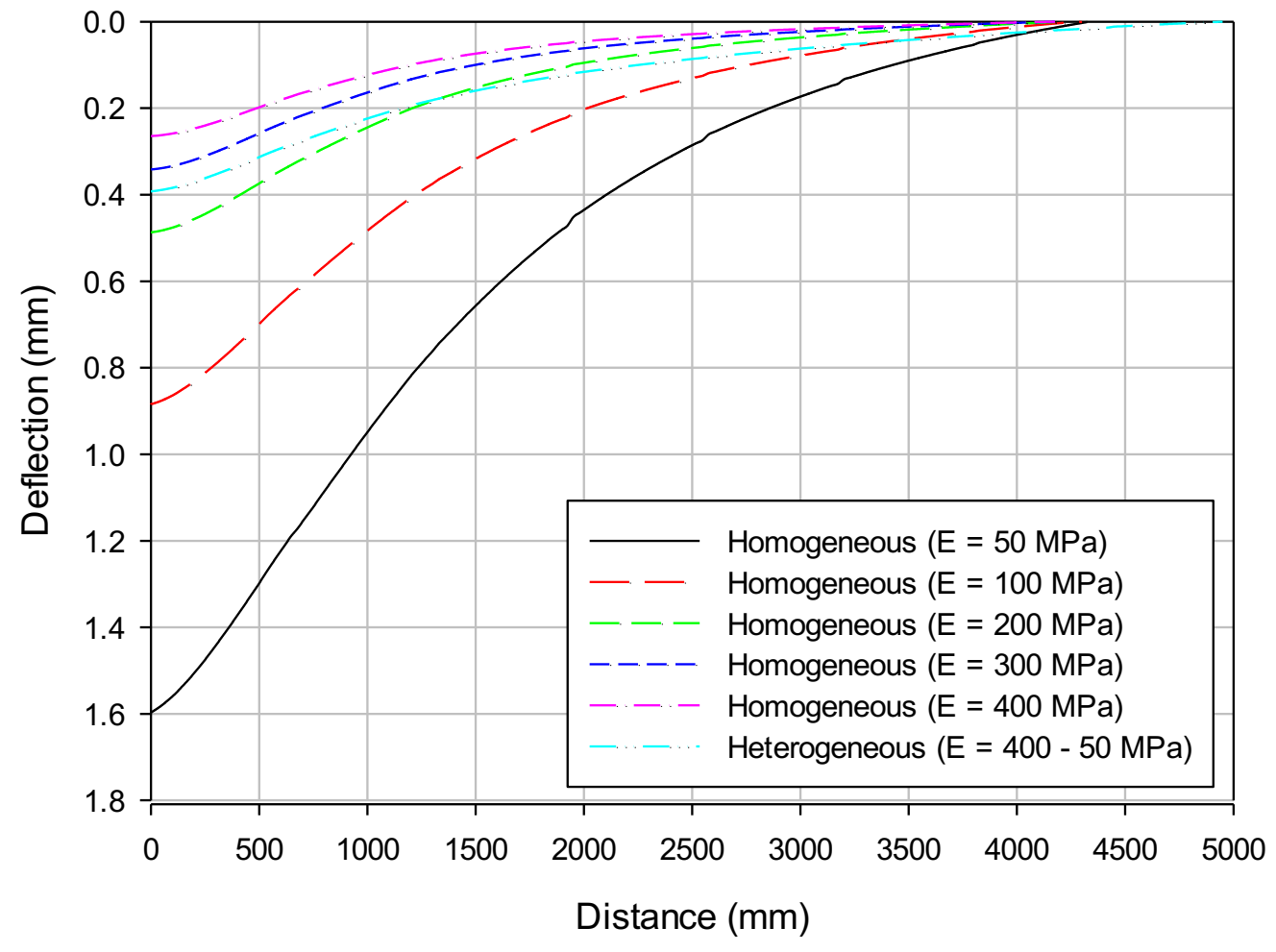

Figure 4.12: Transient substructure deflection for different elastic moduli at centre of sleeper 
The formation stress was further analysed with regard to the considered substructure types as shown in Figure 4.13. A homogenous substructure with a high elastic modulus results in a higher stress at the top of the formation and vice-versa. This phenomenon is analogous to a beam on elastic foundation (BEOF). For instance, a weaker substructure has a minor support on the superstructure and thus the superstructure acts as an unsupported stiff beam overlying the softer substructure. This results in a longitudinal distribution of stresses through the rail member subsequently lessening the stress levels within the formation. Alternatively, a strong substructure offers greater support to the superstructure and is capable of sustaining and distributing higher stresses throughout the formation.

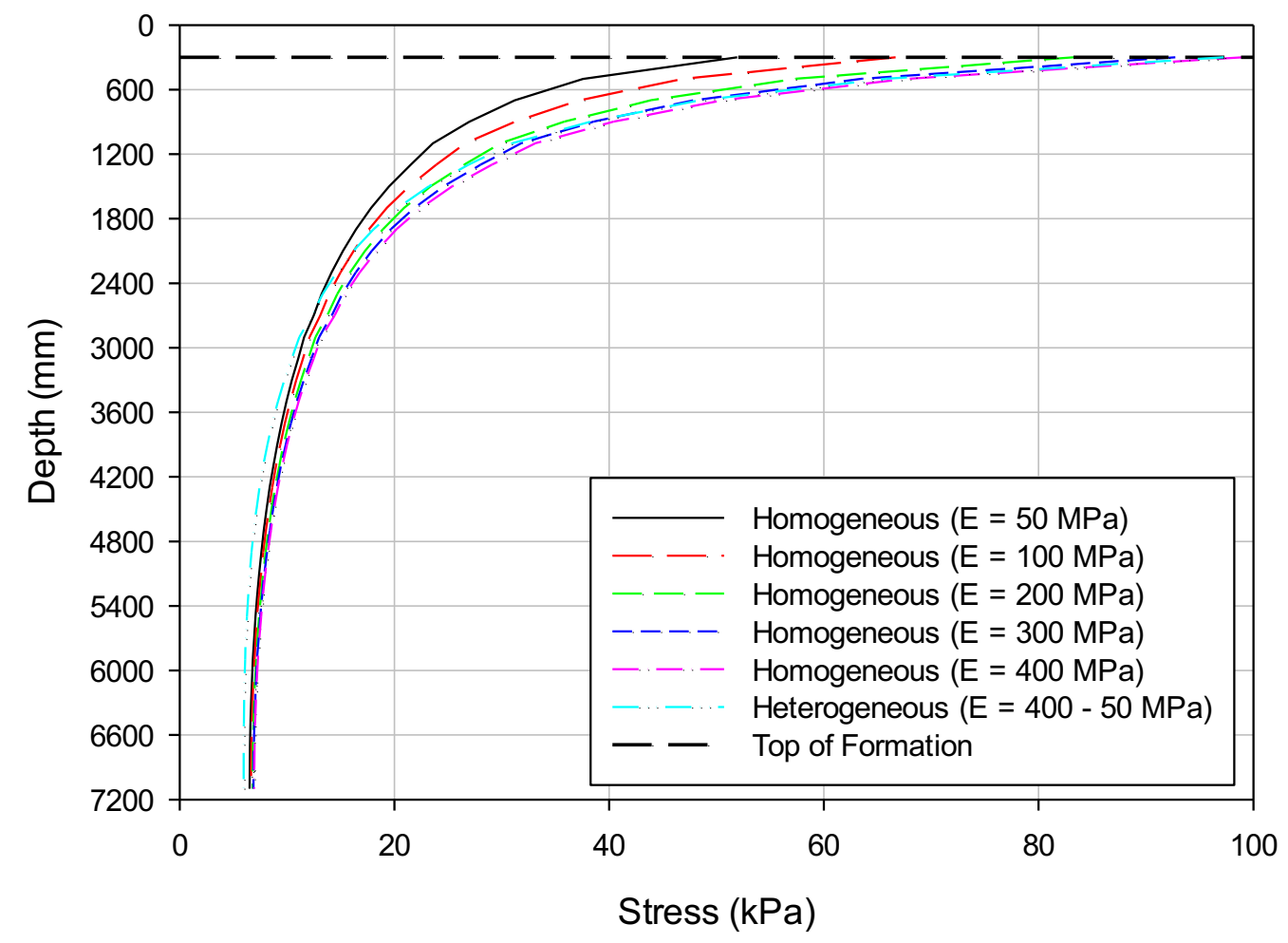

Figure 4.13: Substructure vertical stress for different elastic moduli at centre of sleeper

\subsubsection{Poisson's Ratio Analysis}

The effect of Poisson's ratio on a homogenous substructure was determined with the following values: $0.45,0.35,0.25$, and 0.15 . Figure 4.14 presents how the increase in Poisson's ratio prominently reduces the deflection spread, subsequently reducing the peak deflection due to the change in horizontal extension and vertical contraction of the substructure. Figure 4.15 further shows that the change in Poisson's ratio is insignificant in terms of vertical stresses with depth. This is expected as Poisson's ratio has a minor effect on stress distribution right beneath the wheel load application. 


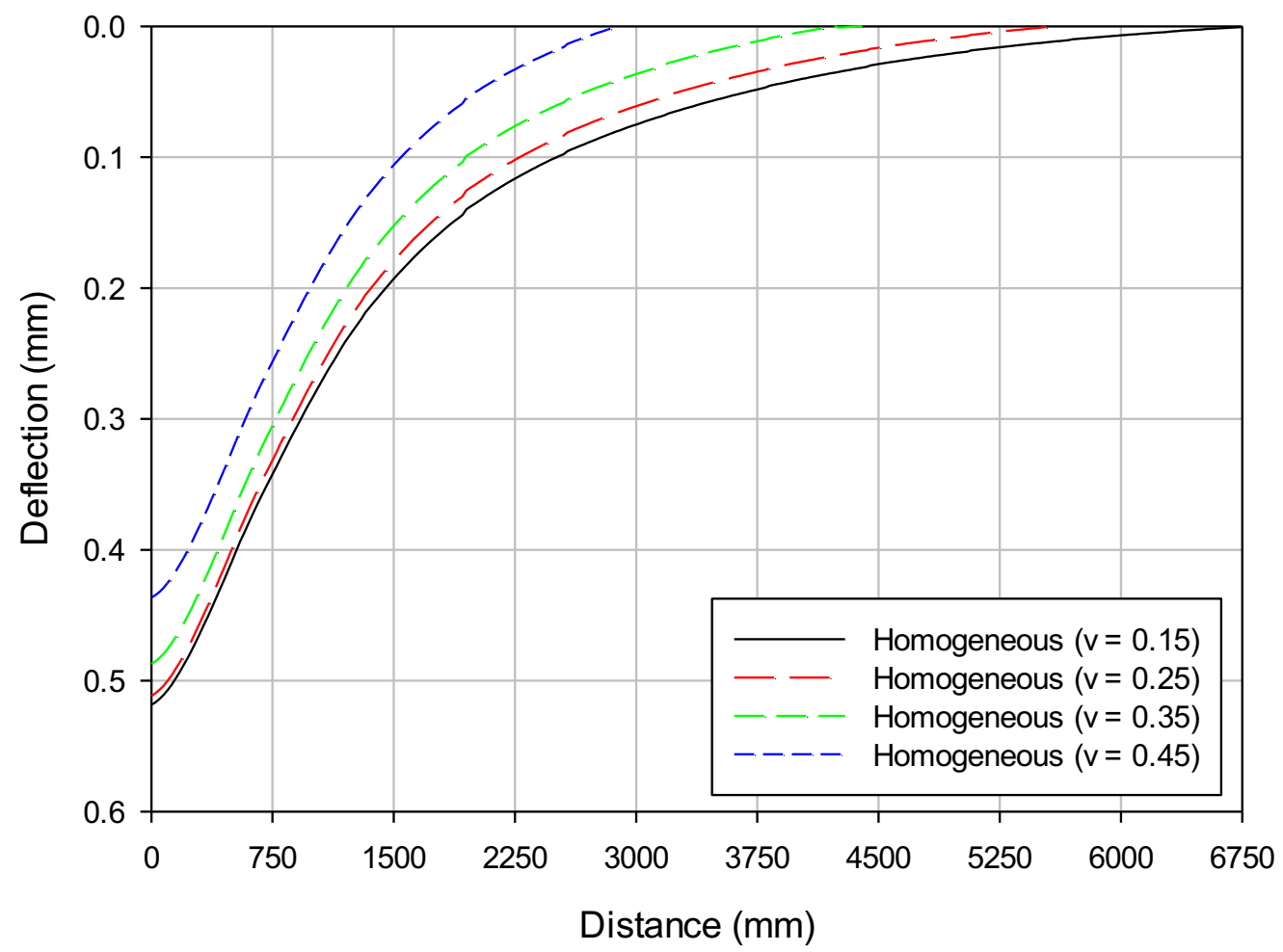

Figure 4.14: Transient substructure deflection for different Poisson's ratio at centre of sleeper

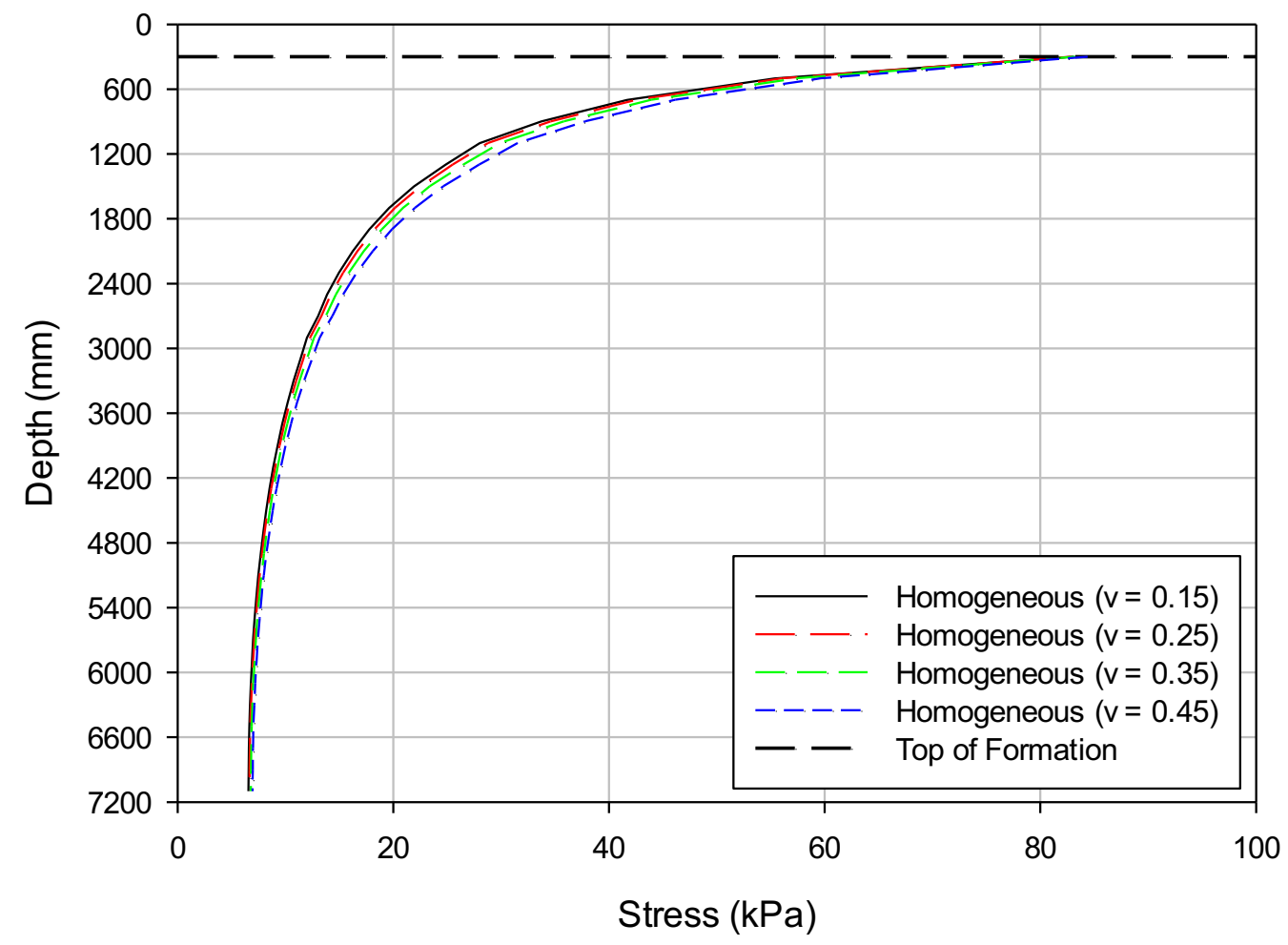

Figure 4.15: Substructure vertical stress for different Poisson's ratio at centre of sleeper 


\subsubsection{Summary of the Substructure Analyses}

In conclusion, both elastic modulus and Poisson's ratio affect railway substructure deflection and stress dissipation in different manners. Consequently, numerous combinations of material properties can lead to a similar deflection measurement. In addition, elastic moduli, stiffness and Poisson's ratio of granular materials are also dependent on stress conditions, layer thickness, structural support, confinement, among others (SAPEM, 2014). Therefore, this complex process was simplified by adopting the granular material properties investigated and recommended for road and railway pavements by Maree et al. (1981) and Li et al. (2016) respectively. These material properties - Tables 4.4, 4.5 and 4.6 were used as guidelines for the estimation of conventional railway substructure properties for the analyses presented in Chapter 5.

Table 4.4: Properties for standard granular materials (Maree et al., 1981)

\begin{tabular}{|c|c|c|c|c|}
\hline \multirow{3}{*}{ Material Description } & \multirow{3}{*}{$\begin{array}{c}\text { Material } \\
\text { Code } \\
\text { (TRH4) }\end{array}$} & \multirow{2}{*}{\multicolumn{2}{|c|}{ Resilient Modulus (MPa) }} & \multirow{3}{*}{$\begin{array}{l}\text { Poisson's } \\
\text { Ratio }\end{array}$} \\
\hline & & & & \\
\hline & & Range & Recommended & \\
\hline High quality crushed stone & $\mathrm{G} 1$ & $175-600$ & 250 & \multirow{5}{*}{$\begin{array}{c}\text { Range } \\
(0.1-0.5) \\
\text { Recommended } \\
(0.35)\end{array}$} \\
\hline $\begin{array}{c}\text { Blends of crushed stone and } \\
\text { natural gravel }\end{array}$ & $\mathrm{G} 2$ & $150-500$ & 250 & \\
\hline Gravel - Base quality & G4 & $100-450$ & 225 & \\
\hline Gravel - Subbase quality & G5 & $75-400$ & 200 & \\
\hline $\begin{array}{c}\text { Gravel - Lower subbase } \\
\text { quality }\end{array}$ & G6 & $50-300$ & 150 & \\
\hline
\end{tabular}

Table 4.5: Recommended properties for subgrade soils (Maree et al., 1981)

\begin{tabular}{|c|c|c|c|}
\hline Material Description & Material Code (TRH4) & Elastic Modulus (MPa) & Poisson's Ratio \\
\hline Gravel Soil & G7 & 120 & \multirow{2}{*}{0.35} \\
\hline Gravel Soil & G8 & 90 & \\
\hline Soil & G9 & 70 & \\
\hline Soil & G10 & 45 & \\
\hline
\end{tabular}

Table 4.6: Railway formation properties (Li et al., 2016)

\begin{tabular}{|c|c|c|}
\hline Material Description & Resilient Modulus (MPa) & Poisson's Ratio \\
\hline Ballast & $\begin{array}{c}140-550 \\
(276-551)\end{array}$ & $0.3(0.3)$ \\
\hline Subballast & $\begin{array}{c}55-105 \\
(138-276)\end{array}$ & $\begin{array}{c}0.3-0.4 \\
(0.35)\end{array}$ \\
\hline Subgrade & $(41-138)$ & 0.35 \\
\hline Bedrock & $(6890)$ & 0.1 \\
\hline
\end{tabular}

* Values in parentheses - GEOTRACK parameters 


\subsection{RAILWAY EQUILIBRIUM INFLUENCE LINES}

Conventional railway equilibrium influence lines were determined by calculating the transient wheel load position (also referred as horizontal distances/boundaries) with a single sensor embedded in the top formation that result in deflections that equate to the total formation deflections relative to the wheel load positioning and the influence line. Subsequently, the total formation deflection can be translated into relative deflections that equate to the local formation deflections for the specified increments or layers as hypothesised by the colour triangles in Figure 4.16. The objective of this analysis is to determine a true influence line, instead of adopting the commonly assumed $45^{\circ}$ influence line for ballasted railway tracks.

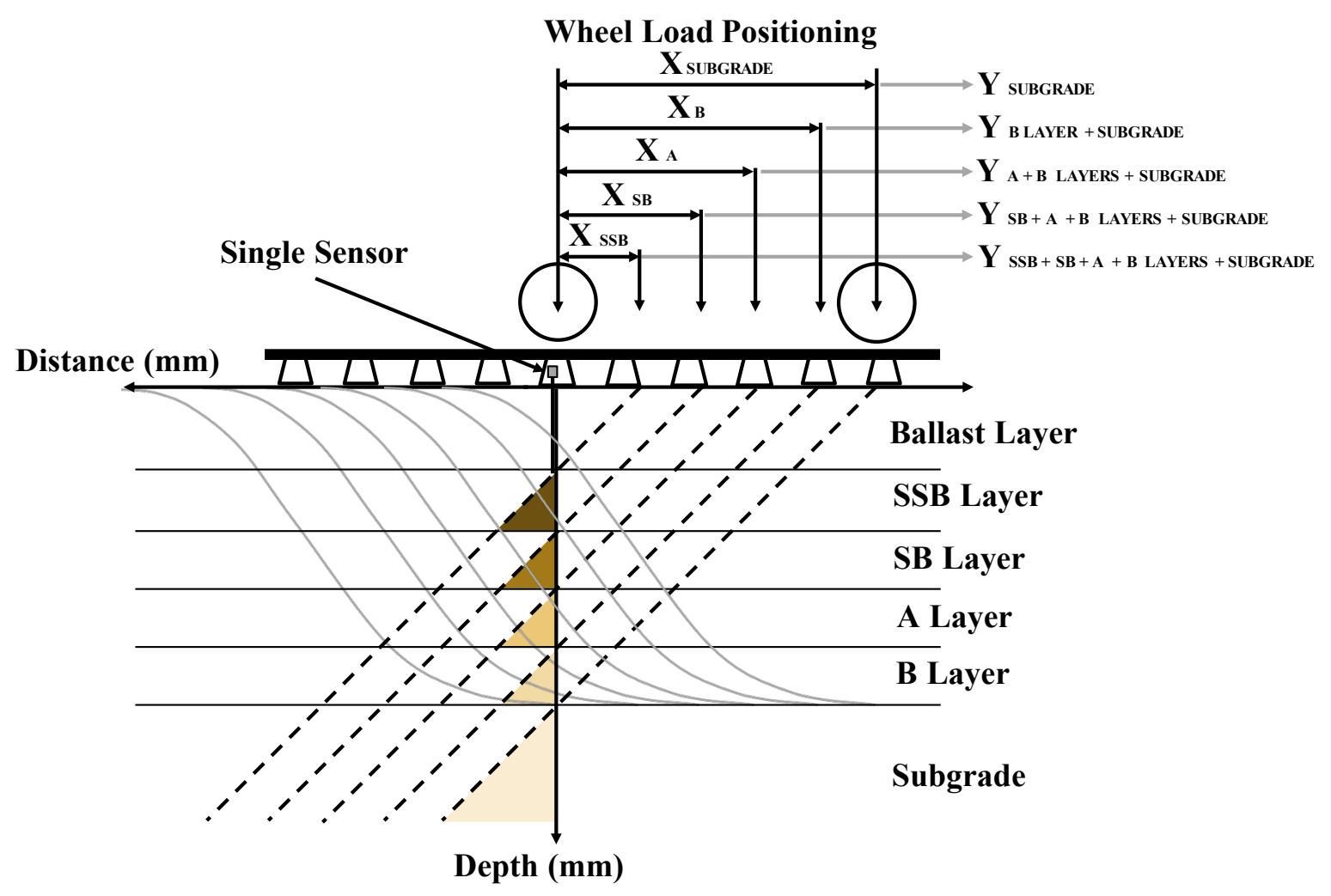

Figure 4.16: Wheel load positioning and influence lines on individual substructure layers

\subsubsection{Sensitivity Analysis of Influence Lines}

The analysis of conventional railway equilibrium influence lines (EILs) is presented on a homogeneous substructure with an elastic modulus of $200 \mathrm{MPa}$; Poisson's ratio of 0.35 ; density of $1850 \mathrm{~kg} / \mathrm{m}^{3}$ and $7 \mathrm{E}$ bogie loading with specific focus on the formation layers at centre-of-sleeper. The EILs are presented from the top of the formation to approximately $2600 \mathrm{~mm}$ depth. 
The following definitions are important for understanding the analyses in this section:

- Transient deflections are total formation deflection measured at a singular point as a function of numerous load applications at increasing distances;

- Local deflections are total formation deflection measured at numerous points with depth as a function of a singular centred load application.

For comparative purposes transient and local deflections were superimposed as shown in Figure 4.17. The EILs were estimated by means of correlating local and transient formation deflections with the objective of determining the wheel load distances that equate to each $200 \mathrm{~mm}$ increment of formation. Figure 4.17 shows this process in five steps $(\boldsymbol{a}-\boldsymbol{e})$ which are denoted as follows:

a. Formation peak deflection beneath leading wheel load application at centre-of-sleeper;

b. First $200 \mathrm{~mm}$ formation depth;

c. Local formation deflection for the first $200 \mathrm{~mm}$ depth;

d. Transient deflection equivalent to the first $200 \mathrm{~mm}$ formation depth;

e. Corresponding transient distance/boundary equivalent to the first $200 \mathrm{~mm}$ formation deflection. 


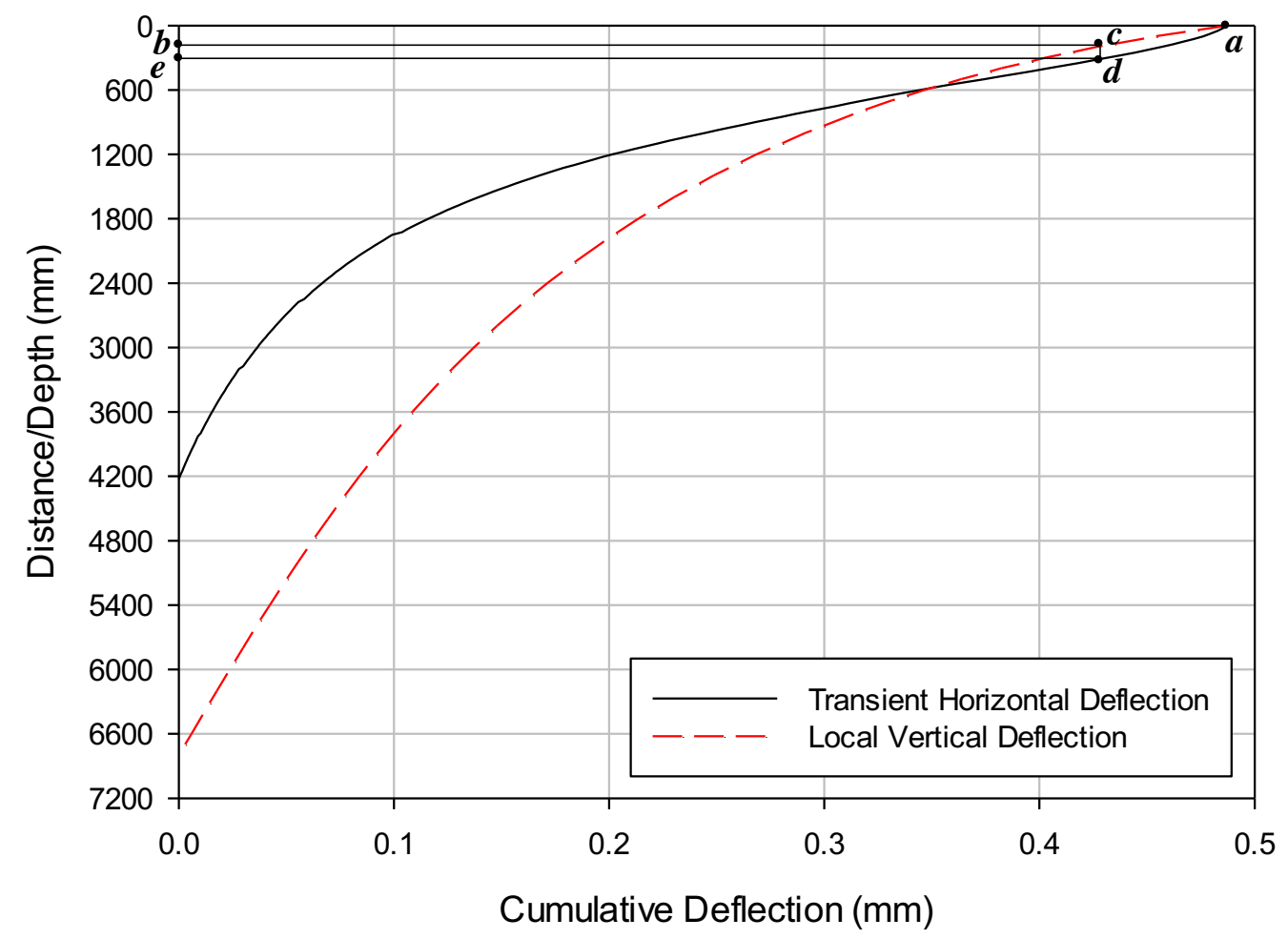

Figure 4.17: Comparison of substructure deflection measurements

For this particular case, the iterative processes were done for increasing increments of $200 \mathrm{~mm}$ allowing for the estimation of increasing transient distances corresponding to the individual formation increments. Table 4.7 presents the calculated equivalent distances from top of the formation to $2600 \mathrm{~mm}$ depth with the respective relative deflections per increment. Furthermore, Figure 4.18 illustrates the EILs in terms of vertical depth and horizontal distances. 
Table 4.7: Details on estimated equilibrium influence line

\begin{tabular}{|c|c|c|c|}
\hline Depth $(\mathrm{mm})$ & Distance $(\mathrm{mm})$ & $\begin{array}{c}\text { Cumulative } \\
\text { Deflection }(\mathrm{mm})\end{array}$ & $\begin{array}{c}\text { Relative } \\
\text { Deflection }(\mathrm{mm})\end{array}$ \\
\hline 0 & 0 & 0.4872 & 0.0308 \\
\hline 200 & 318 & 0.4564 & 0.0528 \\
\hline 400 & 472 & 0.4037 & 0.0591 \\
\hline 600 & 592 & 0.3446 & 0.0520 \\
\hline 800 & 703 & 0.2926 & 0.0481 \\
\hline 1000 & 805 & 0.2445 & 0.0430 \\
\hline 1200 & 897 & 0.2016 & 0.0341 \\
\hline 1400 & 983 & 0.1674 & 0.0282 \\
\hline 1600 & 1063 & 0.1393 & 0.0232 \\
\hline 1800 & 1141 & 0.1161 & 0.0209 \\
\hline 2000 & 1216 & 0.0951 & 0.0154 \\
\hline 2200 & 1296 & 0.0797 & 0.0130 \\
\hline 2400 & 1373 & 0.0667 & 0.0123 \\
\hline 2600 & 1454 & 0.0544 & - \\
\hline
\end{tabular}

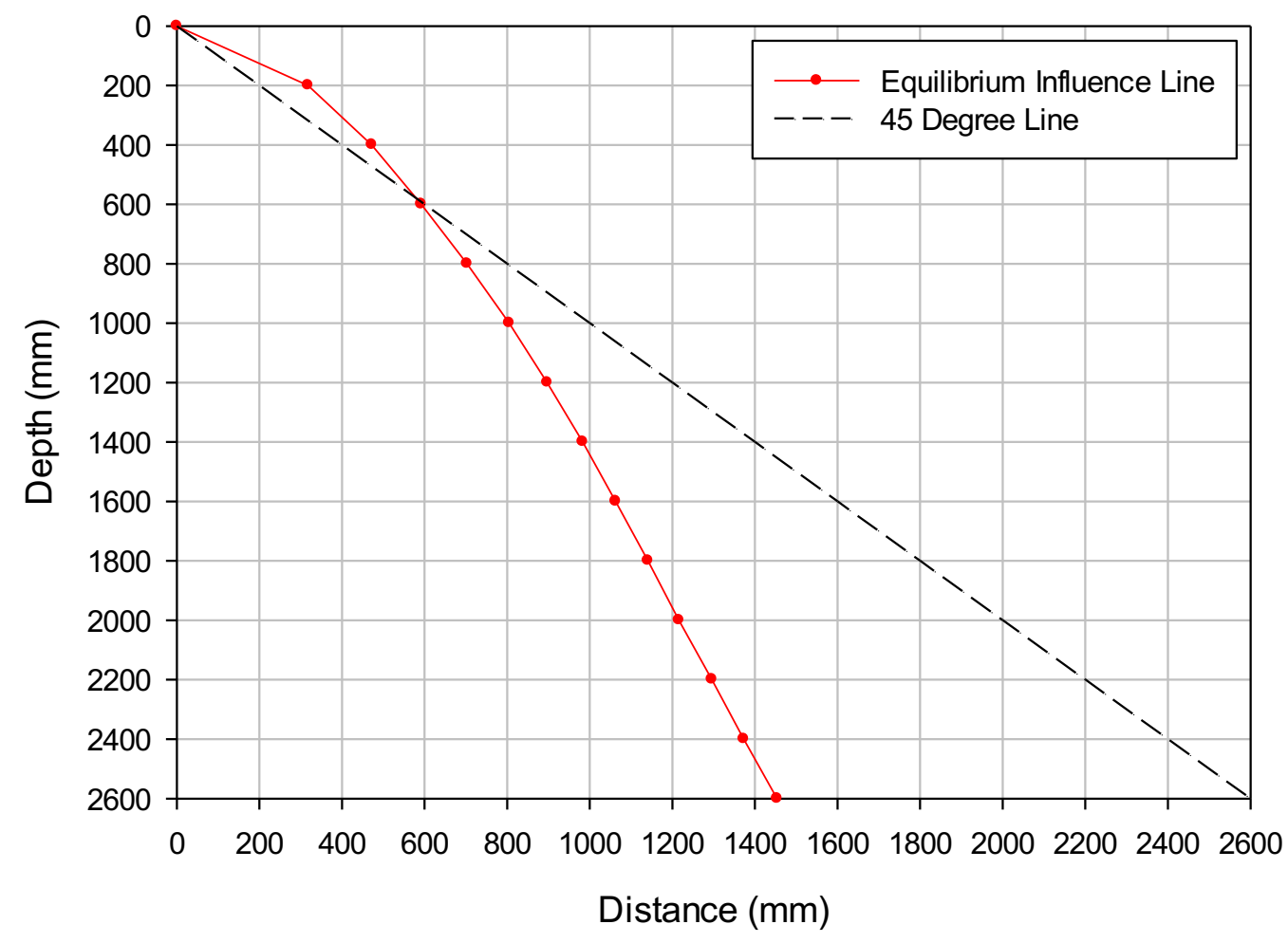

Figure 4.18: Equilibrium influence line

Figure 4.19 presents EILs for the substructure alternatives discussed in Section 4.3. The observed EILs follow a power function regardless of the formation material properties and structural composition (homogeneous or heterogeneous), thus, confirming that superstructure discontinuous support and its 
indirectly induced stresses resulted in a different zone of influence than the prescribed $45^{\circ}$ influence line for directly induced stresses. However, it is noticed that the smooth influence line was associated with the investigated homogenous and uniformly decreasing heterogeneous substructures types, since typical heterogeneous substructure types were seen to differ in relation to formation modular ratios, as later discussed in Chapter 5.

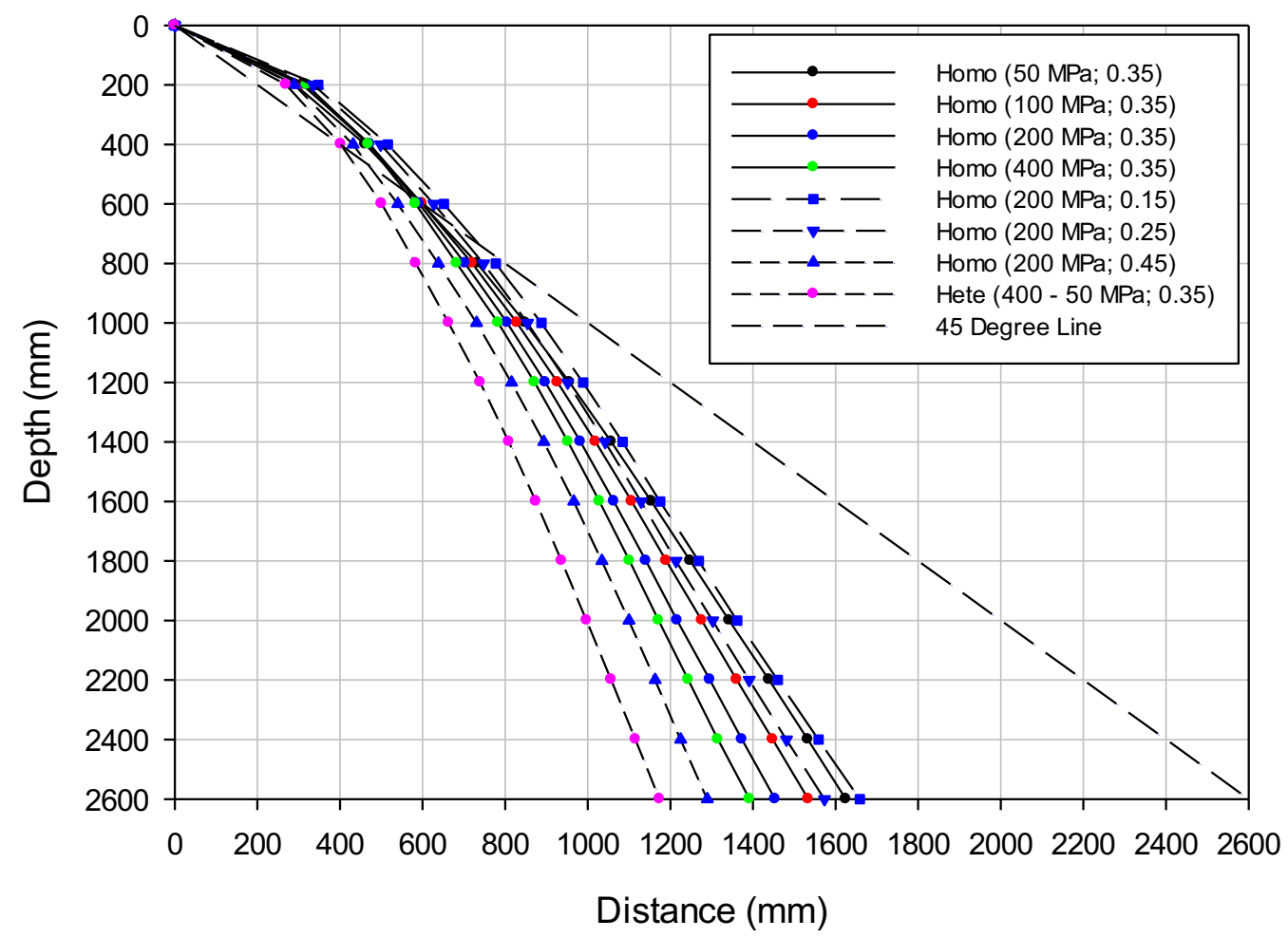

Figure 4.19: Comparison of equilibrium influence lines

It is fundamental to comprehend that EILs are estimated distances along transient deflection basins that equate to the unmeasurable substructure deflections with depth, allowing to evaluate the actual substructure condition (stiffness) under real train transient loading. Thus, overcoming the differences in behaviour observed between static and dynamic loading testing and allowing moving deflection measurement at a magnitude and frequency of loading relevant to in-service conditions (Brown and Selig, 1991) without the need for destructive instrumentation. 


\subsection{SUMMARY OF FINITE ELEMENT RESULTS}

Linear elastic finite element modelling is a reliable tool for characterisation of conventional railway track which allows investigation of the effect of superstructure and substructure characteristics on formation deflection and stress measurements. Railway equilibrium influence lines were developed based on transient and local deflection measurements.

The superstructure sensitivity analysis showed that substructure transient deflections should be measured at centre-of-sleeper due to the fact that vertical stresses dissipate in a continuous and monotonic manner at this position as a result of a lesser influence of adjacent sleeper's load distribution. This results in the most reliable alternative for characterisation of the formation. Moreover, only similar bogies shall be considered since substructure deflection peak, spread and curvature are affected by the superposition of wheels (tonnes/axles, axles/bogie and bogie length) on the superstructure (sleeper spacing and ballast depth).

The substructure sensitivity analysis confirmed that elastic moduli and Poisson's ratio have an effect on substructure transient deflection measurements. It was observed that both elastic moduli and Poisson's ratio can affect peak, spread and deflection curvature. Therefore, material properties were adopted from a previously verified investigation to simplify the otherwise large number of permutations of model parameters. Thus, granular materials were further modelled with a constant Poisson's ratio of 0.35 .

The analysis of equilibrium influence lines showed that by relating local to transient deflection measurements, it is possible to estimate relative formation deflections using an inversion principle from train transient deflection measurements. It was also shown that conventional railway tracks have a distinct influence line due to rail resiliency and indirect superstructure load transfer. However, additional analysis is required to evaluate actual equilibrium influence lines of heterogeneous substructure types, further determining the suitability of the inverse method for formation characterisation. The supporting analyses assuring the reliability of the hypothesised method are further presented in Chapter 5. 


\section{DISCUSSION OF RESULTS}

This chapter discusses the inverse method developed based on the finite element model described in Chapter 4 . The sensitivity of the method to dynamic loading effects, travelling speed and axle loading are considered. These factors are discussed with regard to their effect on deflection measurements. The underlying assumptions made for the development of the method are discussed, followed by the validation of the inverse method through the Bloubank data. Furthermore, the Bloubank long-term deformation was characterised as a case study to determine the applicability of the inverse method for long-term condition assessment. Lastly, the method was implemented on remote video monitoring measurements.

\subsection{SENSITIVITY ANALYSIS OF DEFLECTION MEASUREMENTS}

This section is dedicated to proving the reliability of the inverse method under changing influencing variables. The analysis consisted of characterising and normalizing all possible dynamic effects due to train transient loading, thus minimizing the inherent variability in substructure deflection measurements. The effect of travelling speed and axle loading on peak and spread deflection are subsequently analysed.

\subsubsection{Dynamic Effects}

The deflection analysis consists primarily of mitigating possible dynamic effects caused by irregularities due to train transient loading and track geometry through normalization. To this end, left and right rail loads were averaged to find and reduce the influence of wheel and bogie defects as well as vehicle miss alignment. This allows the distribution of any transverse imbalance within the bogie loading as shown in Figure 5.1.

Figure 5.2 illustrates the minimizing of deflection noise through the use of Loess smoothing technique aiding accurate estimation of the peak deflection of all three wheels. Through the peak deflection estimation of the bogie wheel loads, a peak deflection mean was calculated and used to adjusting the first half-spaced deflection basin of the leading axle of the bogie. This process was applied to rebalance any existing dynamic effects related to longitudinal train movement and minimise deflection measurement variability. 


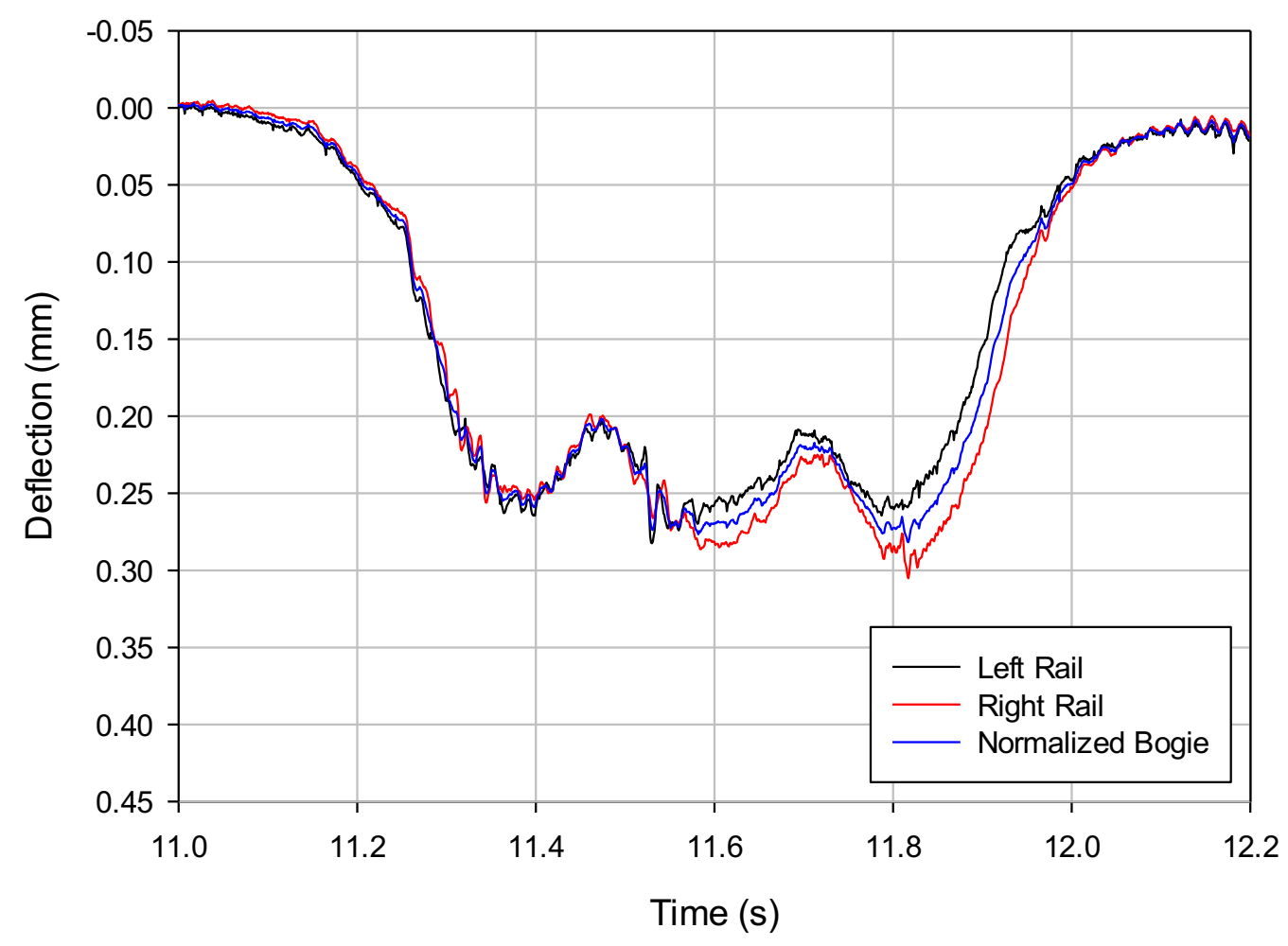

Figure 5.1: Normalization of bogie transverse dynamic effects

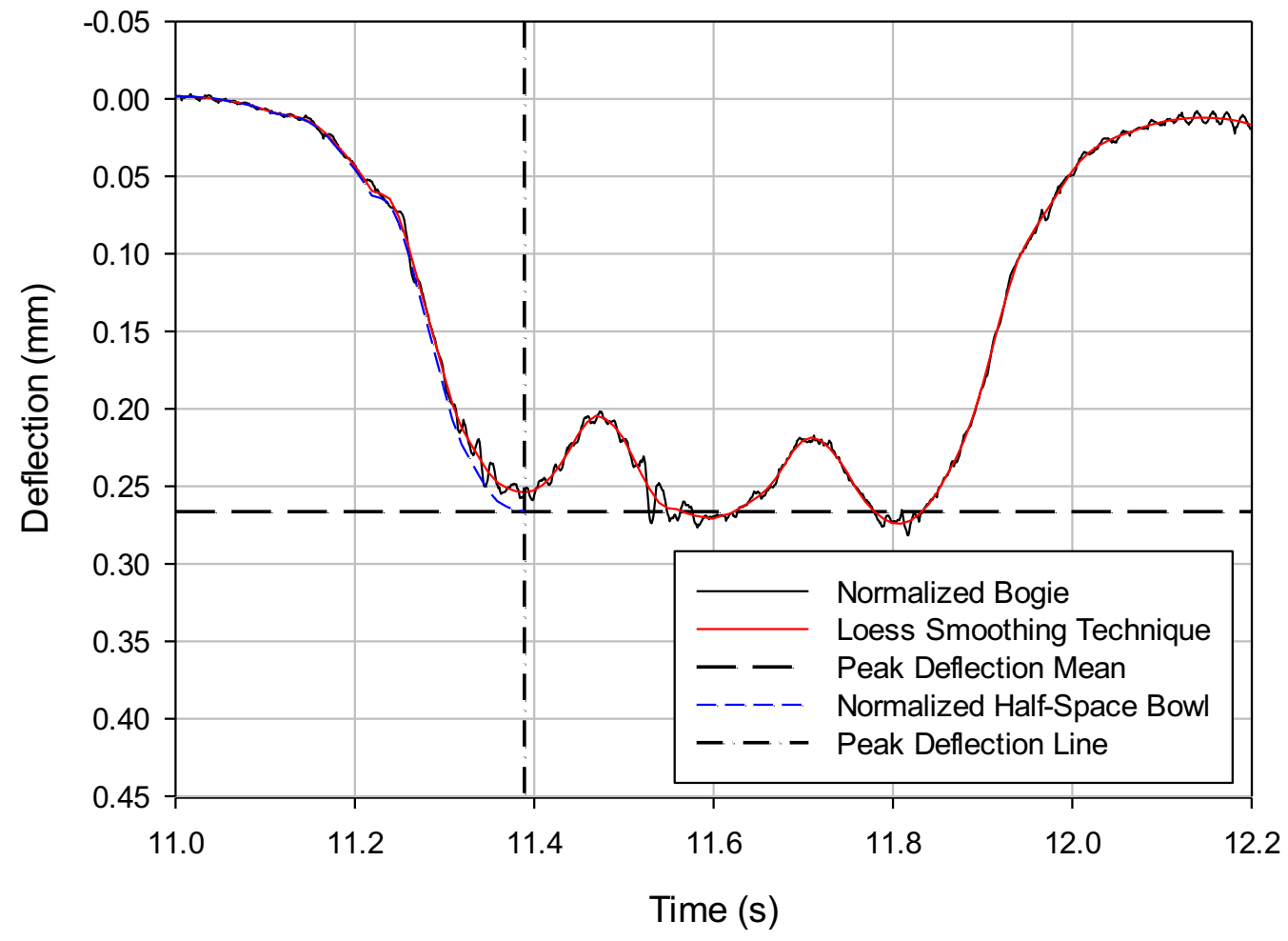

Figure 5.2: Normalization of noise and bogie longitudinal dynamic effects 
Previous studies by Lundqvist and Dahlberg (2005), Priest and Powrie (2009), Yang et al. (2009) and Wilk et al. (2016) have shown that conventional railway track has additional dynamic effects associated with the degree of sleeper support which influences the contact forces, stress path and substructure deflection measurements. Therefore, this research only considered fully supported sleepers as an approach to mitigate such effects.

The studies in the literature however indicated that decreasing the sleeper support predominantly increases the hogging and sagging behaviour of deflection basins, as illustrated in Figure 5.3. Consequently, this research disregards any hogging behaviour by adopting the unloaded zero deflection line as a threshold which defines the zone of interest, also referred to as spread of deflection, subsequently minimizing inconsistencies in deflection measurements.

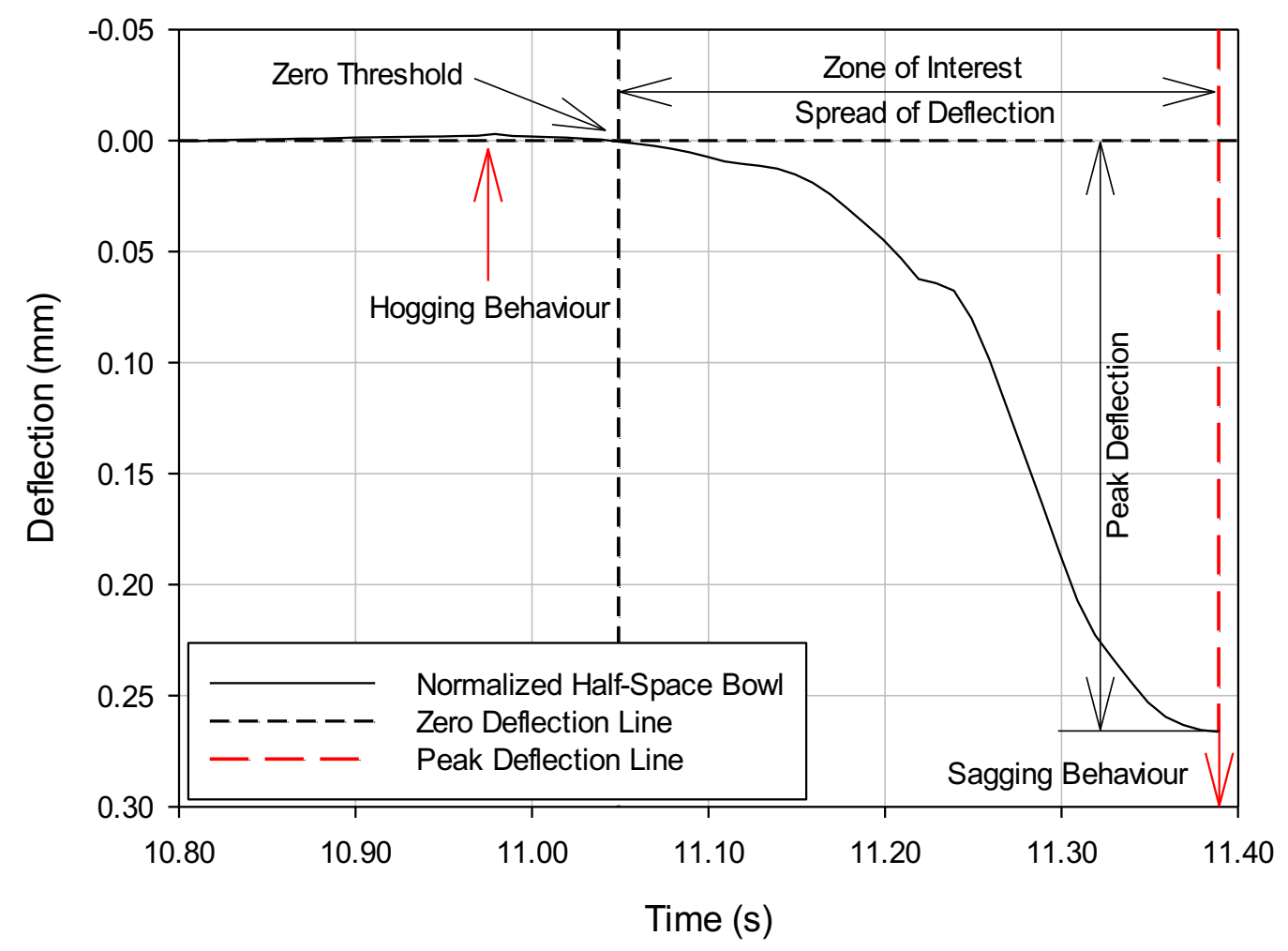

Figure 5.3: Characterisation of half-space deflection measurements and parameters

Additionally, deflection measurements are inherently susceptible to soil vibrations, causing noise and random fluctuations to manifest within the deflection curvature which affect the inverse method outcome. Therefore, non-linear sigmoidal regressions were applied to the deflection measurements to amend the curvature variations. This is illustrated in Figure 5.4. 


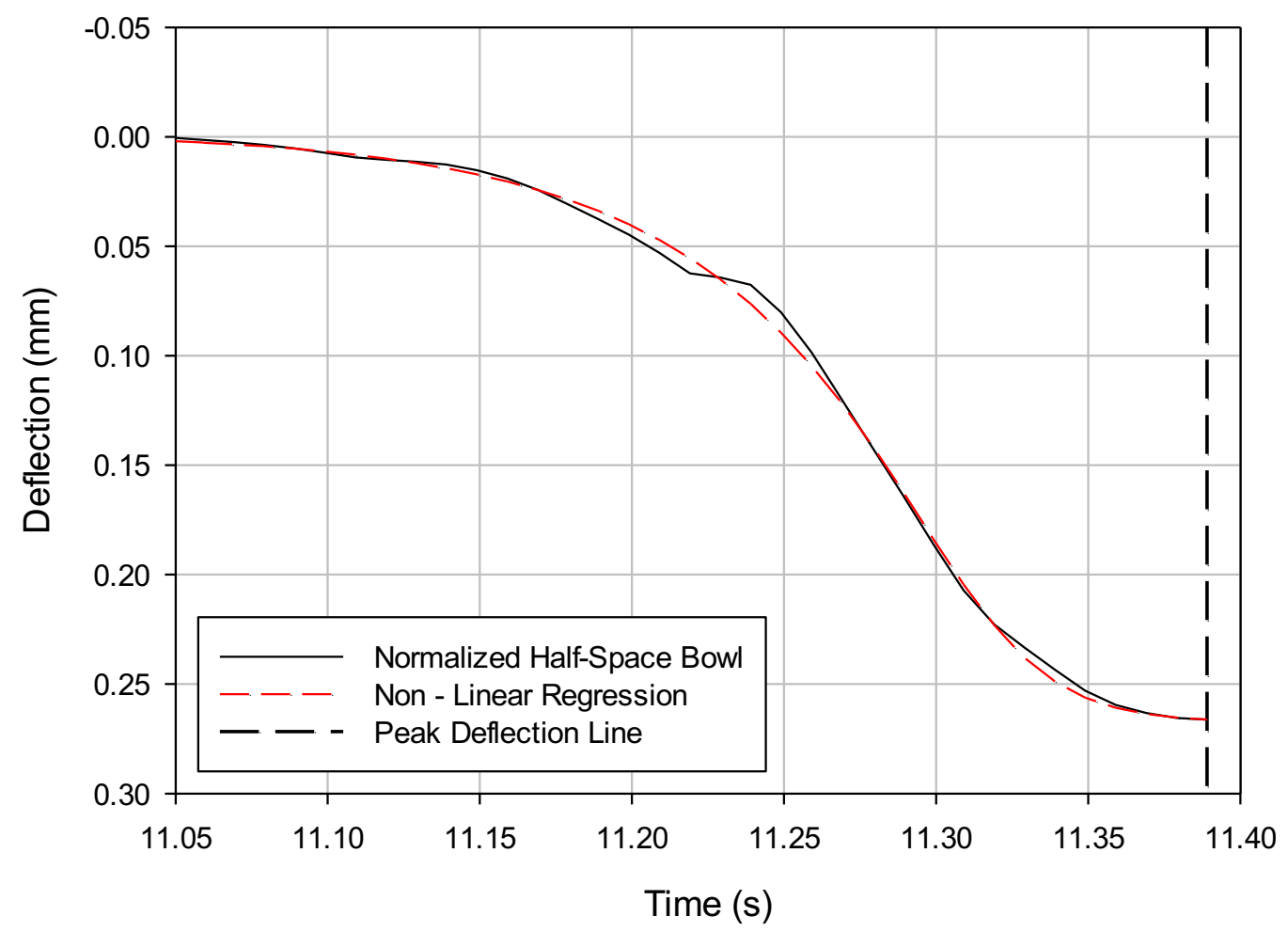

Figure 5.4: Normalization of deflection curvature for inverse analyses

\subsubsection{Effect of Travelling Speed and Axle Loading}

This section deals with determining the influence of travelling speed and axle load on the observed halfspaced deflection basin of the leading axle of the locomotives with particular attention to the deflection basin's spread and peak. The data used to quantify these effects was obtained at the Bloubank test site in 2004 during commissioning of the rehabilitated formation. It is important to note that the data presented in this section has already been normalised for dynamic effects as described in Section 5.1.1.

The investigation into the effects of speed and axle loading considers both 7E and 11E locomotives with 21 and 29 tonnes/axle respectively. The peak deflection and deflection spread are plotted in a scatter plot in Figure 5.5. Increased axle loading affects the peak deflection resulting in larger deflections for $11 \mathrm{E}$ than $7 \mathrm{E}$ locomotives, however, the deflection spread appears to be less sensitive to changes in axle loading due to the fact that all the spread measurements tend to fall within the range of $2500 \mathrm{~mm}$ to $3800 \mathrm{~mm}$. It is also observed that each station responded slightly differently despite the same locomotive passing over the stations, therefore, a statistical analysis was conducted determining the most reliable station. 


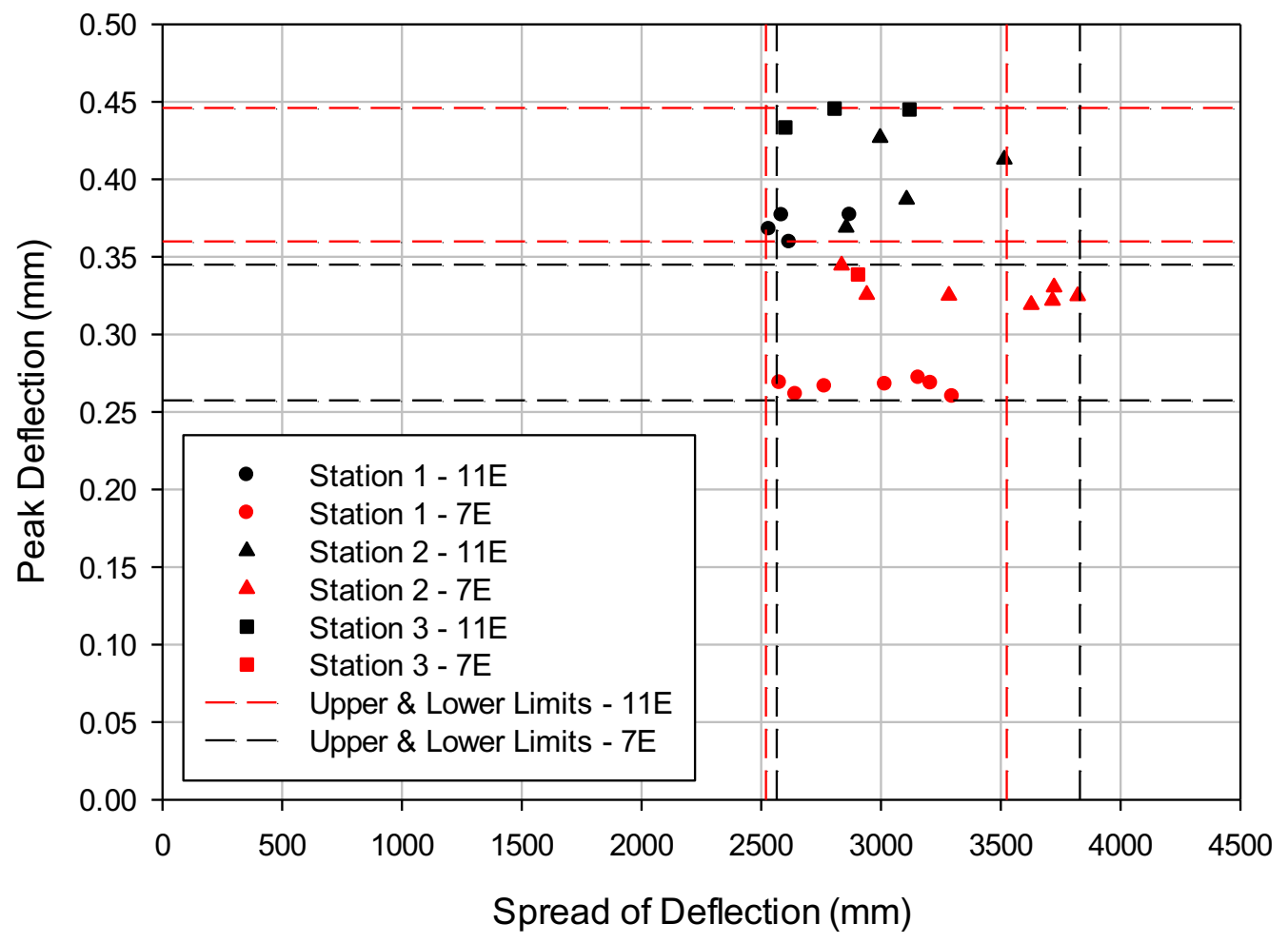

Figure 5.5: Analysis of axle loading on deflection parameters

A statistical analysis of the results presented in Figure 5.5 is summarised in Table 5.1. The results from Station 3 were considered statistically insignificant due to the small sample size which is a result of excessive noise and measurement error. Therefore, it was decided not to include Station 3 in further analysis. The data from Station 1 and 2 are statistically significant and also included comparable locomotive types. The data for Station 1 showed a lower standard deviation for both locomotive types and was therefore used to determine the quantitative effect of travelling speed and axle load. Figure 5.6 subsequently illustrates the effect of travelling speed and axle loading on peak and spread deflection as determined from the Station 1 data.

Table 5.1: Bloubank statistical analysis

\begin{tabular}{|c|c|c|c|c|c|c|}
\cline { 3 - 7 } \multicolumn{1}{c|}{} & \multicolumn{2}{c|}{} & \multicolumn{2}{c|}{ Peak Deflection (mm) } & \multicolumn{2}{c|}{ Spread of Deflection (mm) } \\
\cline { 2 - 7 } \multicolumn{1}{c|}{} & $\begin{array}{c}\text { Locomotive } \\
\text { Type }\end{array}$ & $\begin{array}{c}\text { Sample } \\
\text { Size }\end{array}$ & Mean & $\begin{array}{c}\text { Standard } \\
\text { Deviation }\end{array}$ & Mean & $\begin{array}{c}\text { Standard } \\
\text { Deviation }\end{array}$ \\
\hline \multirow{2}{*}{ Station 1 } & $11 \mathrm{E}$ & 4 & 0.370 & 0.0084 & 2651.35 & 149.74 \\
\cline { 2 - 7 } & $7 \mathrm{E}$ & 7 & 0.266 & 0.0043 & 2952.04 & 289.48 \\
\hline \multirow{2}{*}{ Station 2 } & $11 \mathrm{E}$ & 4 & 0.399 & 0.0259 & 3118.26 & 283.97 \\
\cline { 2 - 7 } & $7 \mathrm{E}$ & 7 & 0.327 & 0.0083 & 3420.66 & 402.91 \\
\hline \multirow{2}{*}{ Station 3 } & $11 \mathrm{E}$ & 3 & 0.441 & 0.0069 & 2841.53 & 261.03 \\
\cline { 2 - 7 } & $7 \mathrm{E}$ & 1 & 0.339 & - & 2903.76 & - \\
\hline
\end{tabular}




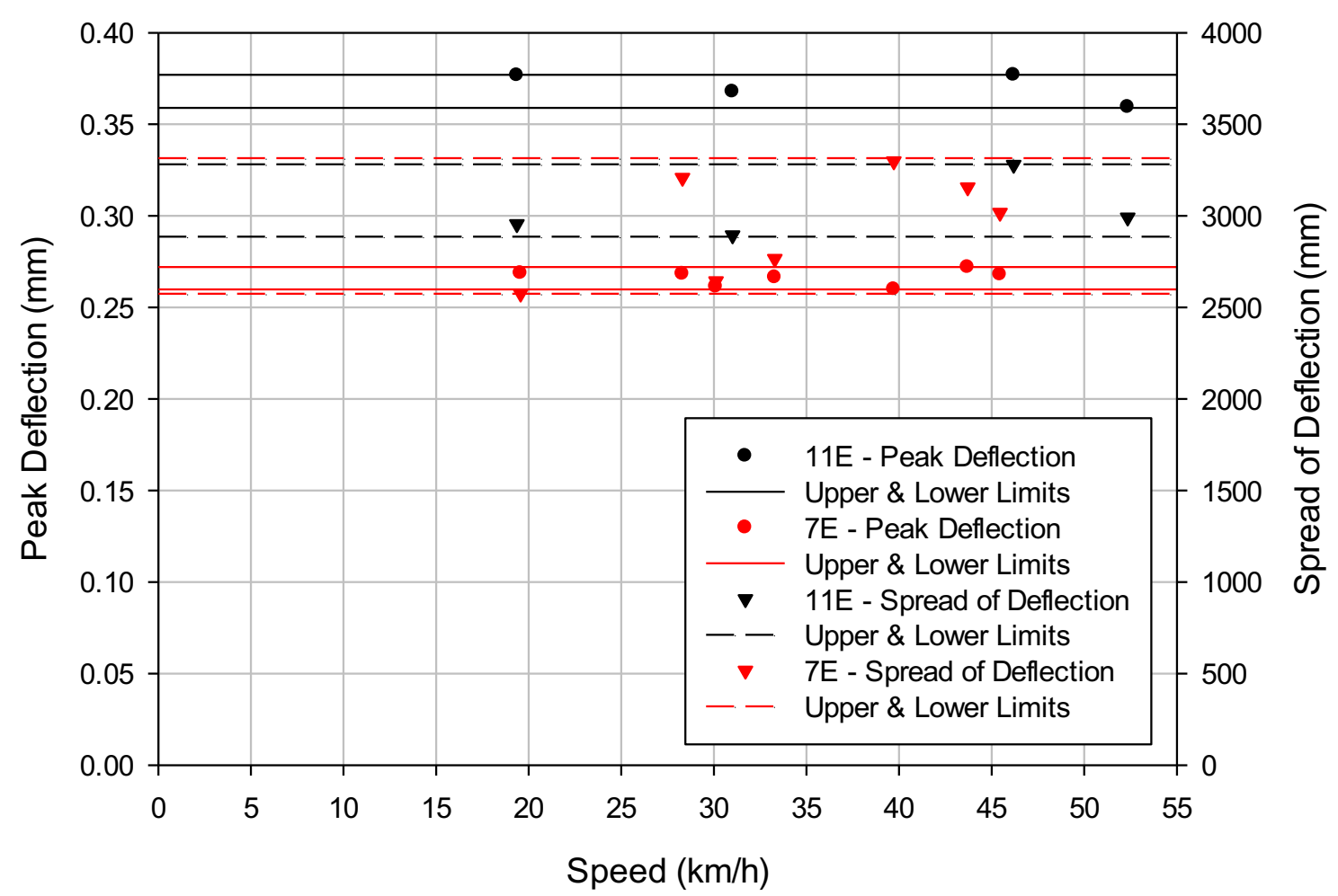

Figure 5.6: Influence of travelling speed and axle loading on deflection parameters

Figure 5.6 shows that axle loading clearly governs peak deflection for the $7 \mathrm{E}$ locomotive (21 tonnes/axle) ranging from $0.26 \mathrm{~mm}$ to $0.27 \mathrm{~mm}$ and from $0.36 \mathrm{~mm}$ to $0.37 \mathrm{~mm}$ for the $11 \mathrm{E}$ locomotive (29 tonnes/axle). This data indicates an estimated incremental increase of $0.0125 \mathrm{~mm}$ of peak deflection per tonne. Furthermore, deflection spread ranged from $2600 \mathrm{~mm}$ to $3300 \mathrm{~mm}$ for both locomotives.

Only travelling speeds ranging from $20 \mathrm{~km} / \mathrm{h}$ to $55 \mathrm{~km} / \mathrm{h}$ were investigated due to the maximum allowable speed on the Transnet Freight Rail (TFR) heavy haul coal export line being $80 \mathrm{~km} / \mathrm{h}$. At this location, it was found that peak deflection and deflection spread are not distinctively influenced by changes in travelling speed, thus confirming that dynamic effects at speeds lower than $60 \mathrm{~km} / \mathrm{h}$ are negligible as described by Jenkins et al. (1974). Additional literature also indicated that dynamic effects on railway formation may only become apparent as the train speed approaches the critical speed $(240 \mathrm{~km} / \mathrm{h})$ causing a resonance effect which increases the soil deflections (Gräbe and Clayton, 2009; Priest and Powrie, 2009; Yang et al., 2009; Priest et al., 2010). On the contrary, static deflection measurements are suspected to have higher peak and spread deflection than transient deflection measurements (for train speeds < critical speeds) since granular materials behave in a viscoelastic manner which is a time-dependent response (Priest and Powrie, 2009). 
From the analysis presented in this section it can be concluded that dynamic effects influence deflection measurements and must be normalized in order to characterise the railway track formation. Therefore, all presented measurements in this research were adjusted according to the method described in Section 5.1.1. Furthermore, it was verified that travelling speed is not a significant influential factor in this research study due to the fact that South African heavy haul coal export lines do not exceed $80 \mathrm{~km} / \mathrm{h}$. However, axle loading clearly affects peak deflection. Deflection spread also affects the results but the degree to which this occurs is less well-defined due to the scatter in the range $2600 \mathrm{~mm}$ to $3300 \mathrm{~mm}$.

The inverse method is further reviewed with focus on the variations of the deflection parameters as a function of the substructure material properties as presented in Section 5.2.

\subsection{INVERSE METHOD}

This section discusses the development of the inverse method by modelling the expected formation layers for South African 26 tonnes/axle heavy haul lines on different in-situ subgrades. The effect of subgrade structural capacity on transient deflection measurements and equilibrium influence lines is thus determined. The inverse method for evaluation of formation structural capacity of in-service lines over time are also presented.

\subsubsection{Inverse Method Development}

This section discusses the development of the inverse method under the following known conditions:

- Loading application: 7E locomotive (21 tonnes/axle);

- Single measurement point located at the intersection of the neutral axis of the rail profile and the centre line of the sleeper, measuring total substructure responses from top of the formation (excluding superstructure and ballast layer).

Table 5.2 shows the formation properties assumed for the analyses. These properties represent typical parameters for a South African 26 tonnes/axle heavy haul line (Transnet Freight Rail, 2006). Furthermore, different in-situ subgrade elastic modulus alternatives were investigated varying from 50 to $400 \mathrm{MPa}$. This was done to represent all possible substructure types from embankments (fills) to excavations (cuts). 
Table 5.2: Substructure material properties

\begin{tabular}{|c|c|c|c|}
\hline Formation Layers & $\begin{array}{c}\text { Poisson's } \\
\text { Ratio }\end{array}$ & $\begin{array}{c}\text { Density } \\
\left(\mathrm{kg} / \mathrm{m}^{3}\right)\end{array}$ & $\begin{array}{c}\text { Elastic Modulus } \\
(\mathrm{MPa})\end{array}$ \\
\hline SSB & 0.35 & 2200 & 300 \\
\hline SB & 0.35 & 2050 & 250 \\
\hline A & 0.35 & 1900 & 150 \\
\hline B & 0.35 & 1850 & 50 \\
\hline Subgrade & 0.35 & $1850-2300$ & $50-400$ \\
\hline
\end{tabular}

Figure 5.7 illustrates the influence of varying subgrade support on the transient deflection basin characteristics namely peak deflection, spread and curvature. The effect of subgrade support on transient deflection curvature was determined through the normalisation of the peak deflection as seen in Figure 5.8.

Figure 5.9 shows the local deflection measurements directly beneath the leading axle of the locomotive. It can be seen that the deflections reduce with increase in subgrade support only and that the formation deflection curvature (300 - $1100 \mathrm{~mm}$ ) remains unchanged for all subgrades considered. Furthermore, the value of the modular ratio (SAPEM, 2014) defined as:

$$
\text { Modular ratio }=\frac{E_{\text {Top Layer }}}{E_{\text {Bottom Layer }}}
$$

affects the refraction angle of the local deflection measurements when transitioning from the B Layer to the subgrade. A higher modular ratio causes a larger angle of refraction at the B Layer/Subgrade interface and can be seen in Figure 5.9. 


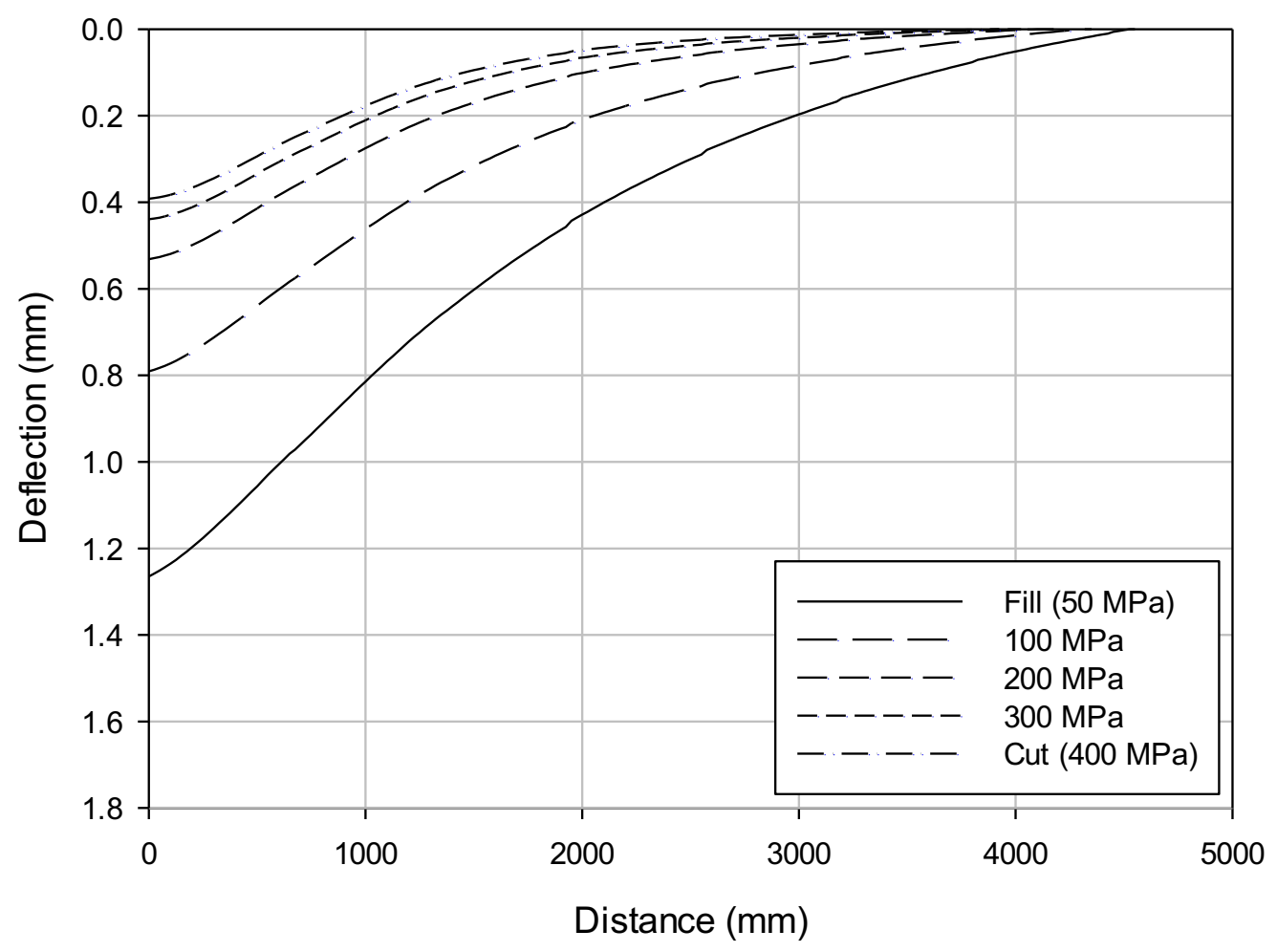

Figure 5.7: Transient substructure deflections converted to the space domain

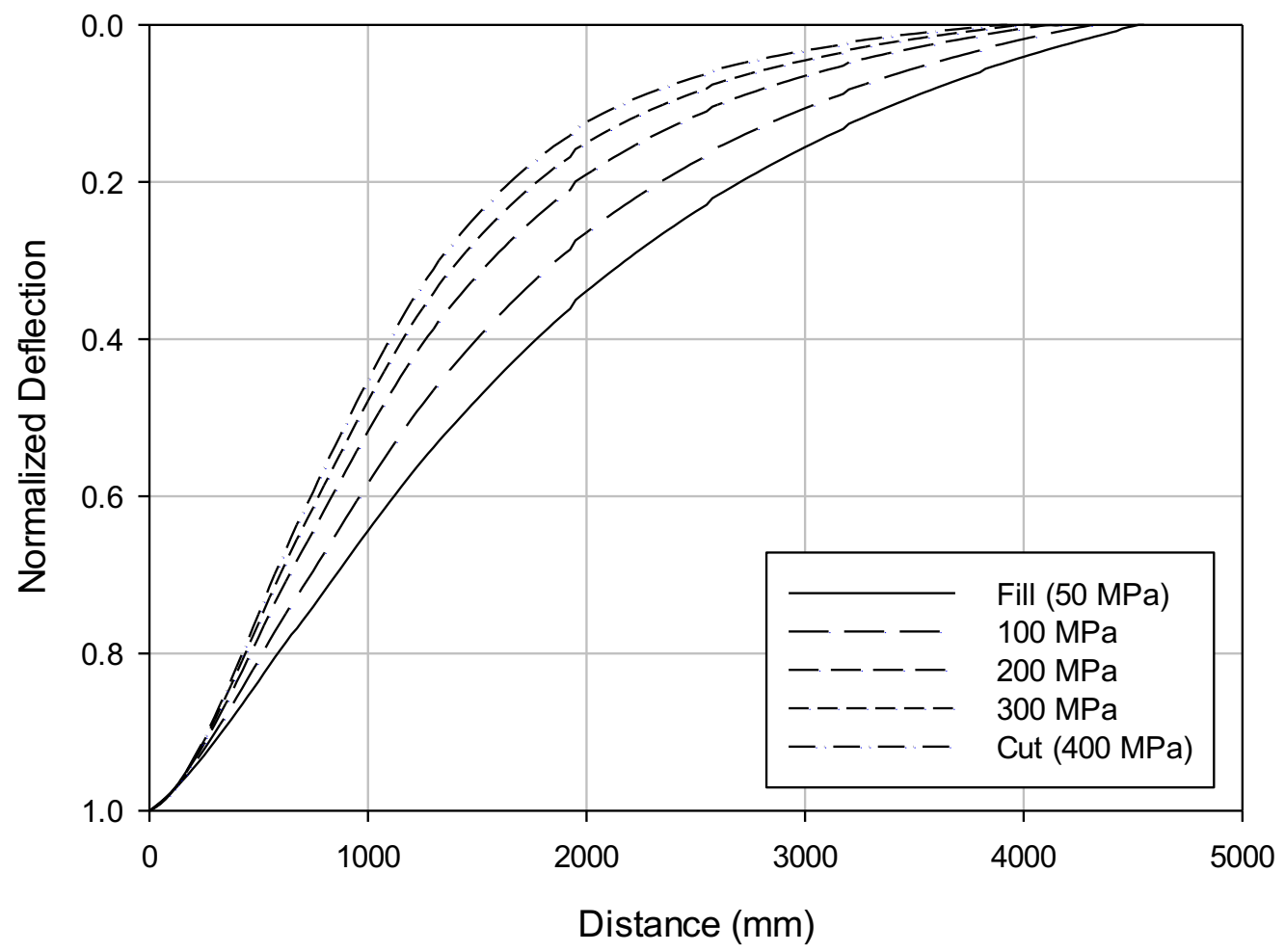

Figure 5.8: Normalization of curvature for transient substructure deflections 


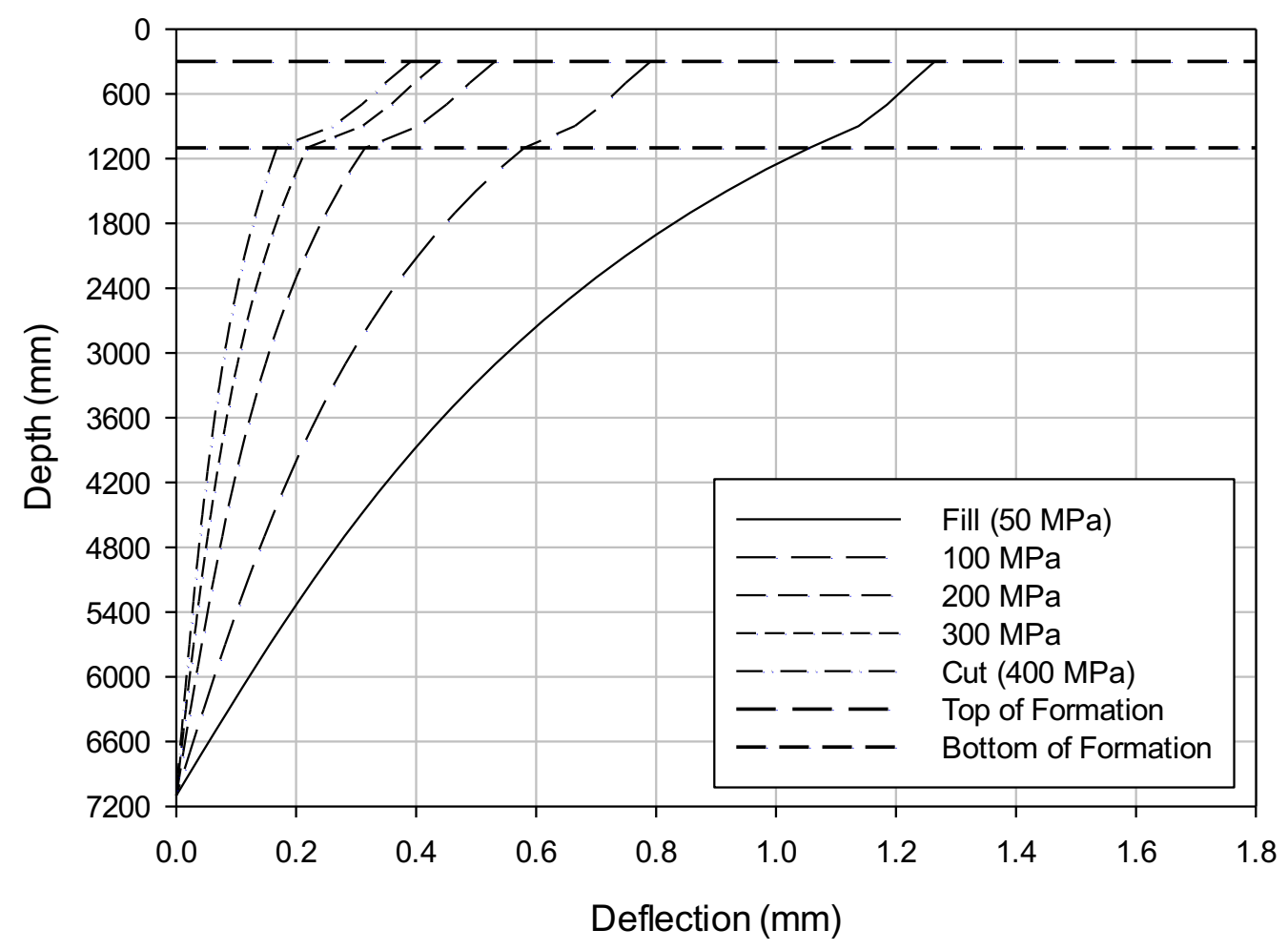

Figure 5.9: Local substructure deflections for different subgrades

In Section 4.4 it was shown that transient and local deflections can be correlated allowing for the determination of equilibrium influence lines (EILs) which can be inversely applied for individual formation characterisation. It was also identified that EILs are products of the change in curvature of both measured deflections which are outcomes of the selected substructure material properties. Figure 5.10 shows the EILs for the different heterogeneous substructure types investigated, determining the influence of different subgrade stiffnesses for the given formation. The observed differences in EILs are predominantly associated with the decrease in modular ratio between the B Layer and the subgrade. 


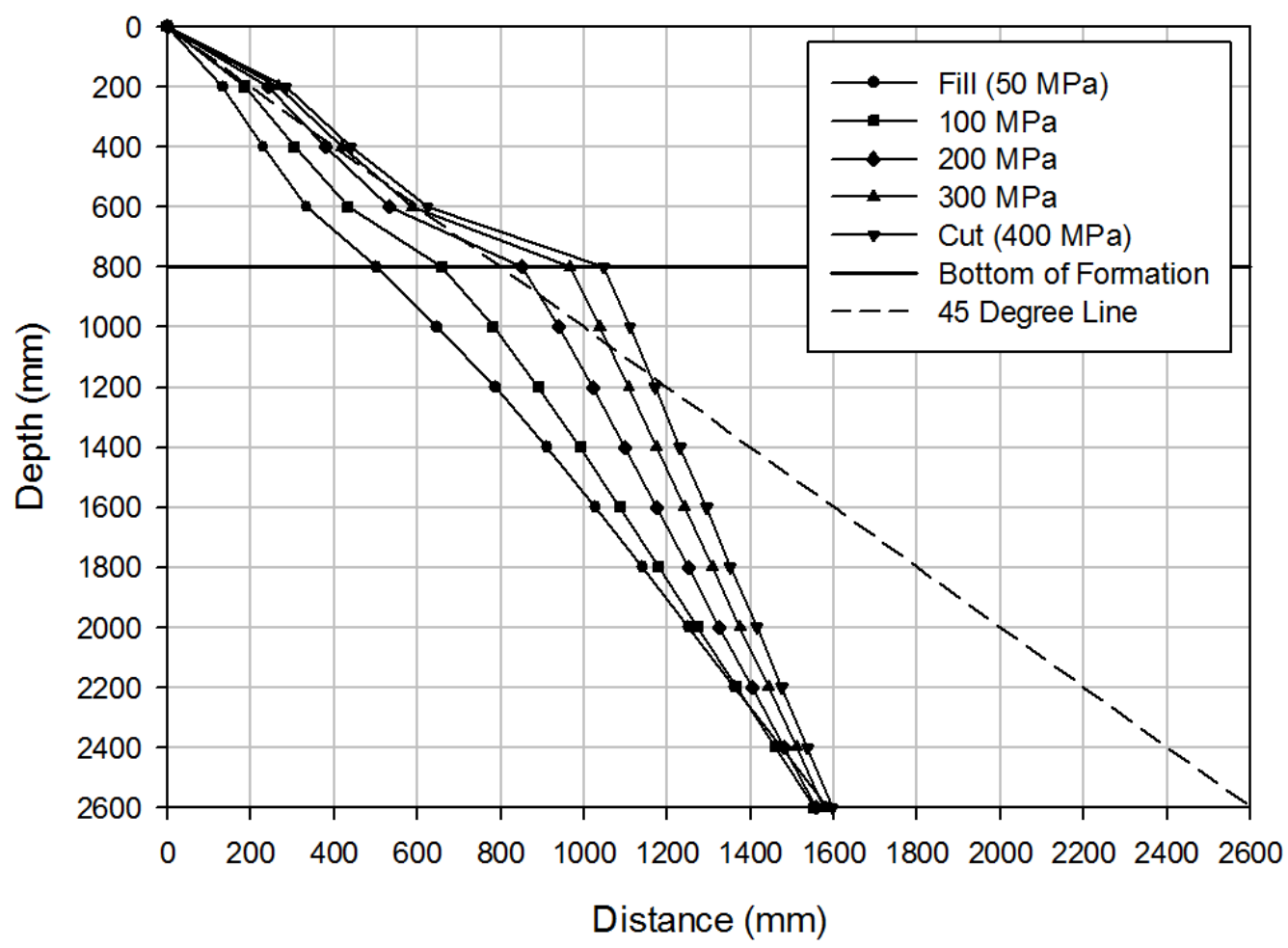

Figure 5.10: Equilibrium influence lines for different subgrades

In this research, the inverse method is focused on assessing the condition of the formation layers (SSB, SB, A and B) only. Therefore, the EILs of the formation must be linearized against the effect of subgrade stiffness on the formation itself. This is shown in Figure 5.11. As a result of the increase in subgrade stiffness, transient deflections reduce at a smaller rate with distance than local deflections with depth. Subsequently, this results in an increase in relative horizontal boundaries per formation layer as seen in Figure 5.11.

The linearization of the formation EILs was shown to be adequate for the overall assessment. It was however unsuitable for back-calculation of individual formation layer deflections due to the significant effect of the induced errors (horizontal difference between calculated and fitted linear regression curves) on the inverse estimated elastic moduli of the formation layers. Alternatively, formation EILs can be accurately approximated using a piecewise regression. This is shown in Figure 5.12. 


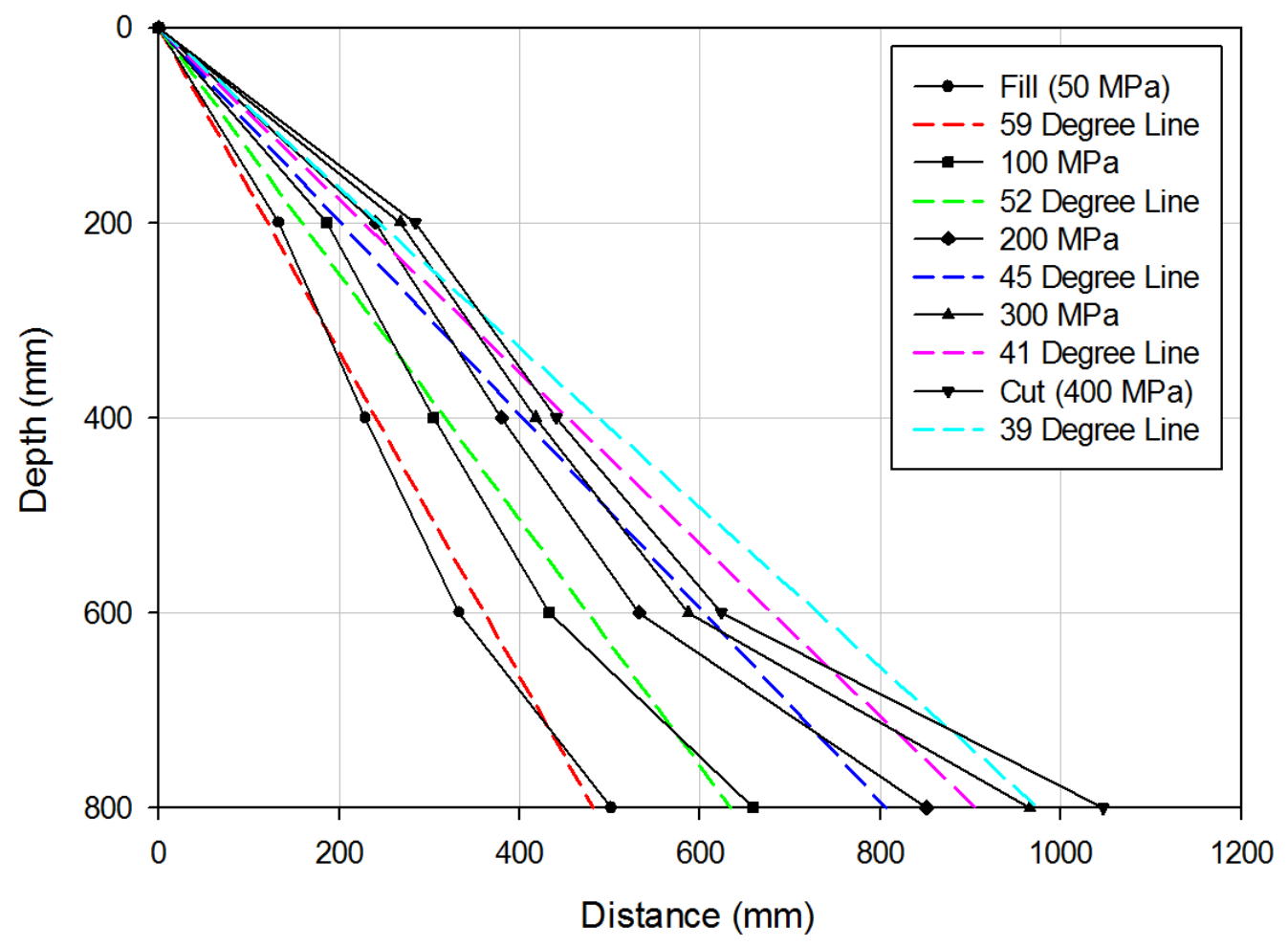

Figure 5.11: Linearization of formation equilibrium influence lines

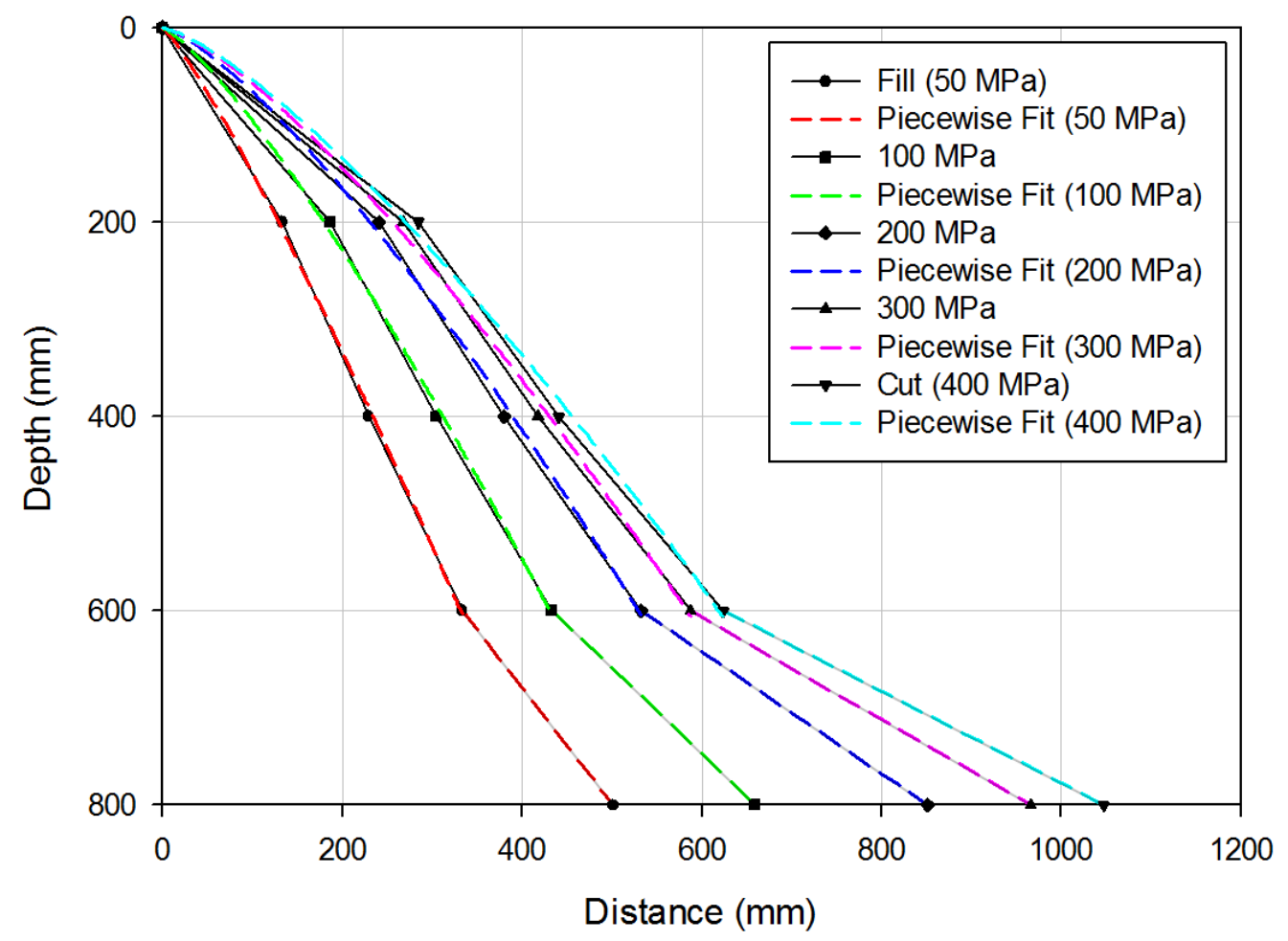

Figure 5.12: Piecewise regression on formation equilibrium influence lines 
The piecewise functions illustrated in Figure 5.12 are mathematically presented by Equations 5.2 - 5.6. It is possible to estimate (through inversion) the relative formation layer deflections based on the EIL equations. The formation strain can subsequently be calculated under the assumption that permanent deformations are negligible. Finally, the structural capacity of the railway formation can be characterised by measuring transient deflection and modelling of the railway substructure vertical stresses, allowing the back-calculation of the formation layer strains and elastic moduli.

$$
\begin{aligned}
& f(y)_{50 M P a}=\left\{\begin{array}{lr}
\sqrt[1.1620]{y / 0.7072}, & 0 \leq y<600 \\
(y-203.49) / 1.1906, & 600 \leq y \leq 800
\end{array}\right. \\
& f(y)_{100 M P a}=\left\{\begin{array}{lr}
1.2583 \sqrt{y / 0.2911}, & 0 \leq y<600 \\
(y-217.51) / 0.8834, & 600 \leq y \leq 800
\end{array}\right. \\
& f(y)_{200 M P a}=\left\{\begin{array}{lr}
\sqrt[1.3267]{y / 0.1462}, & 0 \leq y<600 \\
(y-265.90) / 0.6276, & 600 \leq y \leq 800
\end{array}\right. \\
& f(y)_{300 M P a}=\left\{\begin{array}{lr}
\sqrt[1.3342]{y / 0.1225}, & 0 \leq y<600 \\
(y-289.86) / 0.5282, & 600 \leq y \leq 800
\end{array}\right. \\
& f(y)_{400 M P a}=\left\{\begin{array}{lr}
\sqrt[1.3262]{y / 0.1191}, & 0 \leq y<600 \\
(y-305.17) / 0.4726, & 600 \leq y \leq 800
\end{array}\right.
\end{aligned}
$$

Figure 5.13 presents the vertical stress distribution for the investigated heterogeneous substructures. The formation vertical stress is seen to be reliant on the subgrade support, resulting in either shallow or deep substructure behaviour. The shallow behaviour is apparent in the embankment/fill (50 MPa) since a greater stress dissipation occurs within the formation layers. On the contrary, the excavation/cutting (400 MPa) shows a gradual dissipation of stresses with depth similar to deep substructure behaviour. Nonetheless, allowable stresses at the bottom of the formation differ by no more than $10 \mathrm{kPa}$.

Regarding the inverse method, it is concluded that deflections resulting from a transient wheel load are products of the substructure properties and manifest as changes in deflection basin curvature and peak magnitude. Local deflections below the applied load clearly indicate the proportional contribution of the individual formation layers and subgrade. Therefore, EILs relate both measurements with the objective of evaluating formation layers based on transient substructure deflections measured at a single point. The inverse method is further reviewed for long-term condition assessment as presented in Section 5.2.2. 


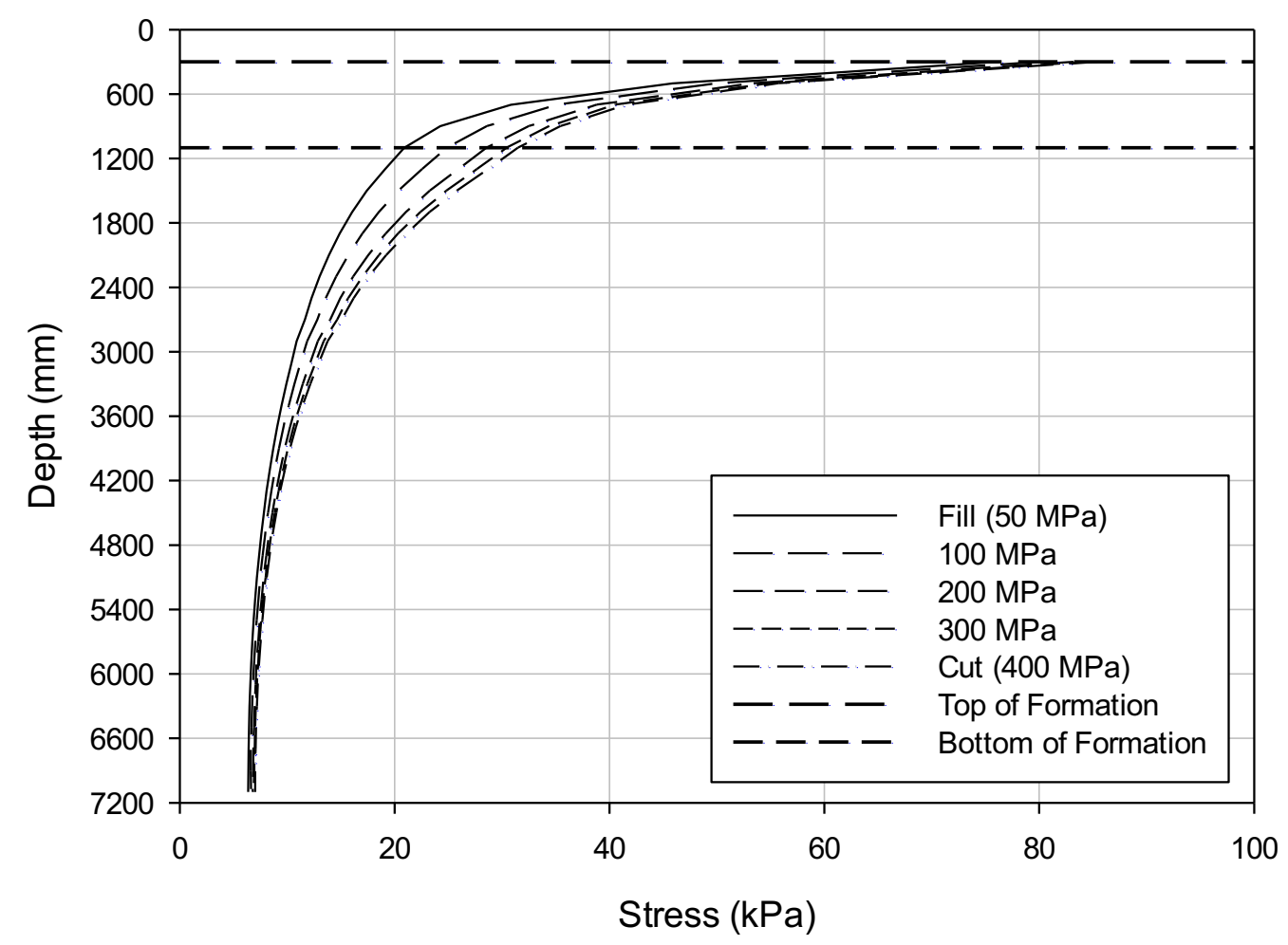

Figure 5.13: Substructure vertical stress for different subgrades

\subsubsection{Long-Term Formation Condition Analysis}

The inverse method for long-term formation condition analysis was founded on the characterisation of continuous multi-depth deflectometer (MDD) measurements with increase in traffic, as presented in Section 5.4. It was found that in-situ subgrades are naturally resilient to the generally low stresses experienced allowing one to assume that the increase in substructure deflection is predominantly due to the formation layers. Formations of varying structural capacity were modelled by incrementally decreasing the elastic modulus of each layer to $75 \%$ and then $50 \%$ of its initial design capacity (given in Table 5.2) with the objective of preliminary assessing the formation condition based on the characterisation of transient substructure deflection measurements. The results of these analyses are illustrated in Figure 5.14.

Figure 5.14 shows that transient deflection measurements increase with reduction in formation structural capacity resulting in a change in deflection curvature from $0 \mathrm{~mm}$ to $2000 \mathrm{~mm}$. It is further observed that the subgrade stiffness has an effect on deflection curvature since cuttings (400 MPa) have a clear change in formation curvature in comparison to fills $(50 \mathrm{MPa})$. The effect on deflection curvature can be evaluated by normalizing the peak deflection as presented in Figure 5.15. Moreover, it is clear 
that substructure deflection measurements are influenced significantly by the formation structural capacity. This is noticeable as the local substructure deflection (formation layers) are particularly affected by the decrease in formation moduli, as shown in Figure 5.16.

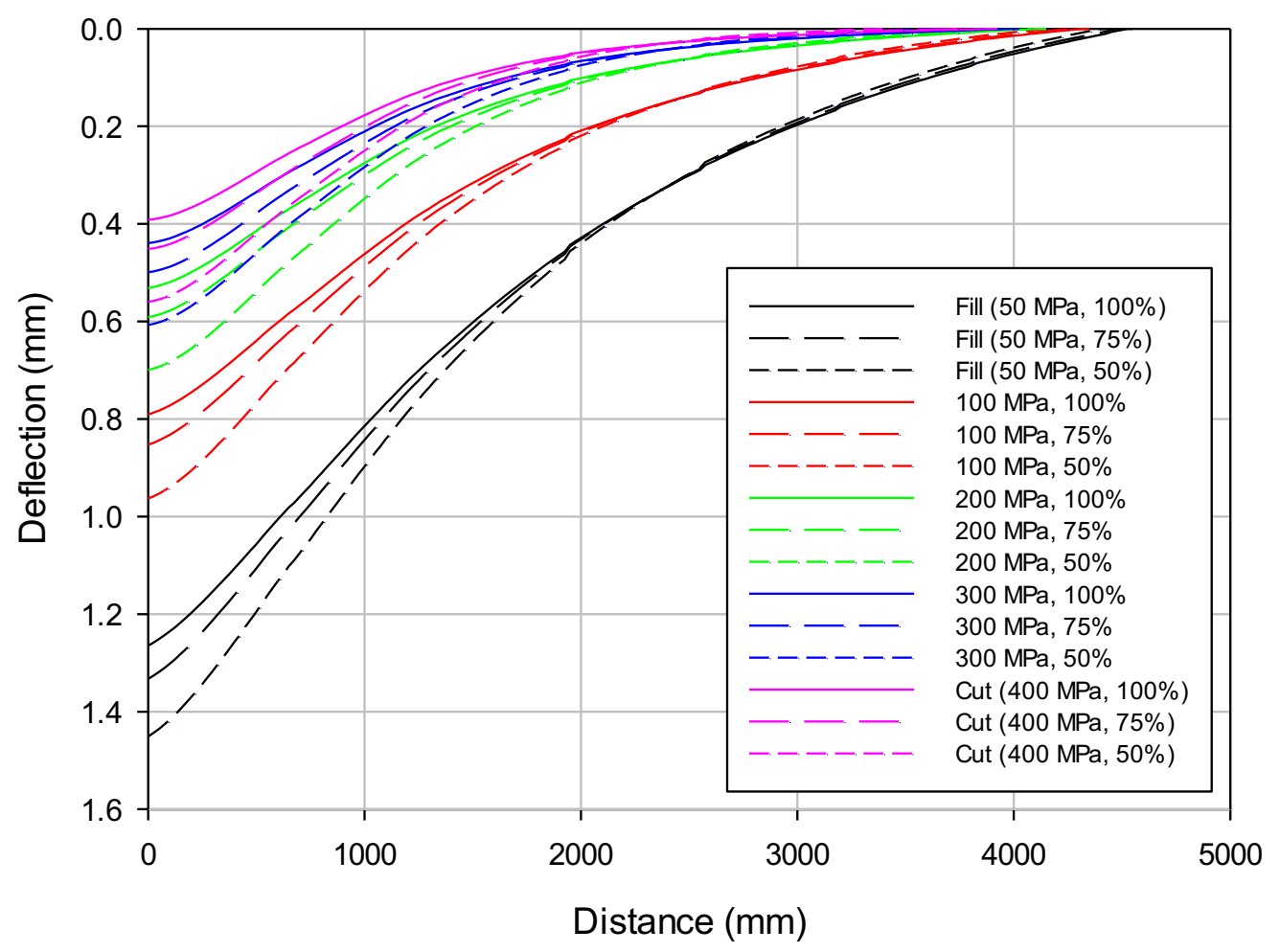

Figure 5.14: Transient substructure deflection measurements for long-term model

Based on the correlation of local and transient deflection measurements, Figure 5.17 illustrates the estimated EILs. The loss of formation structural capacity results in an increase in relative horizontal distances from $0 \mathrm{~mm}$ to $800 \mathrm{~mm}$ depth while remaining constant for the subgrade, due to the fact that the increase in substructure deflection is exclusively associated with the formation itself as revealed by Figure 5.16. Moreover, formation vertical stresses reduce with a decrease of formation structural capacity as presented in Figure 5.18. 


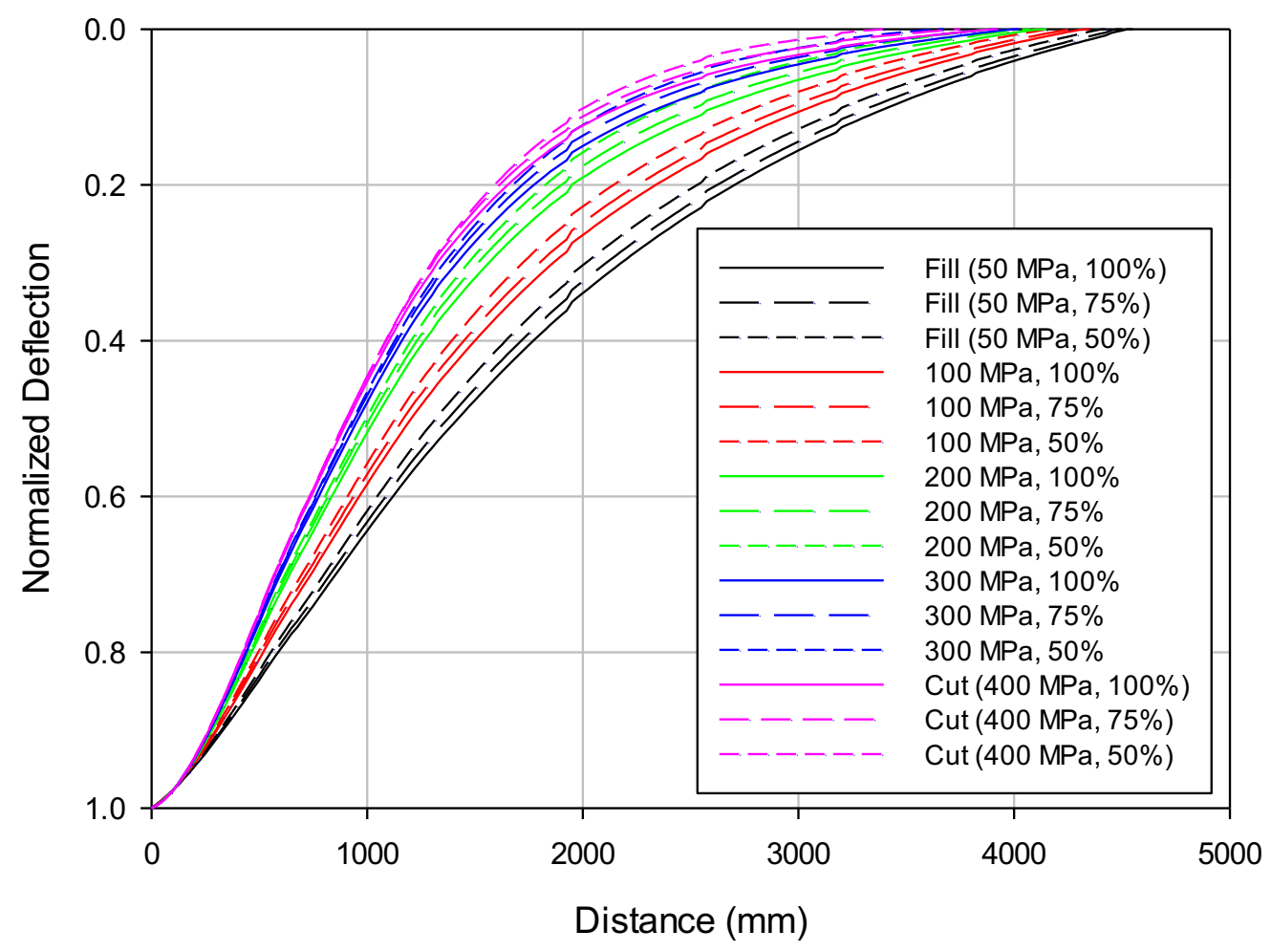

Figure 5.15: Normalization of deflection curvature for long-term model

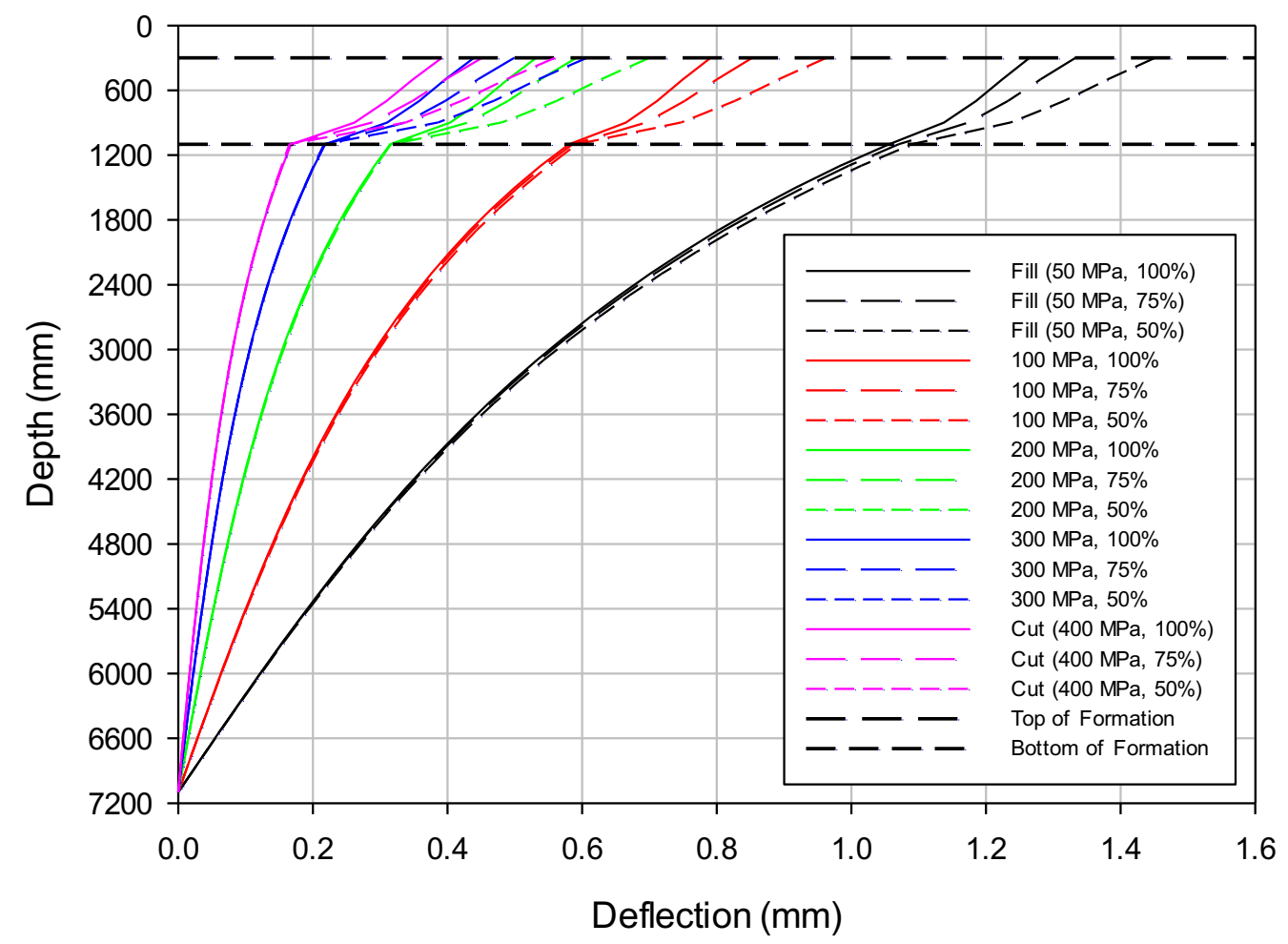

Figure 5.16: Local substructure deflection measurements for long-term model 


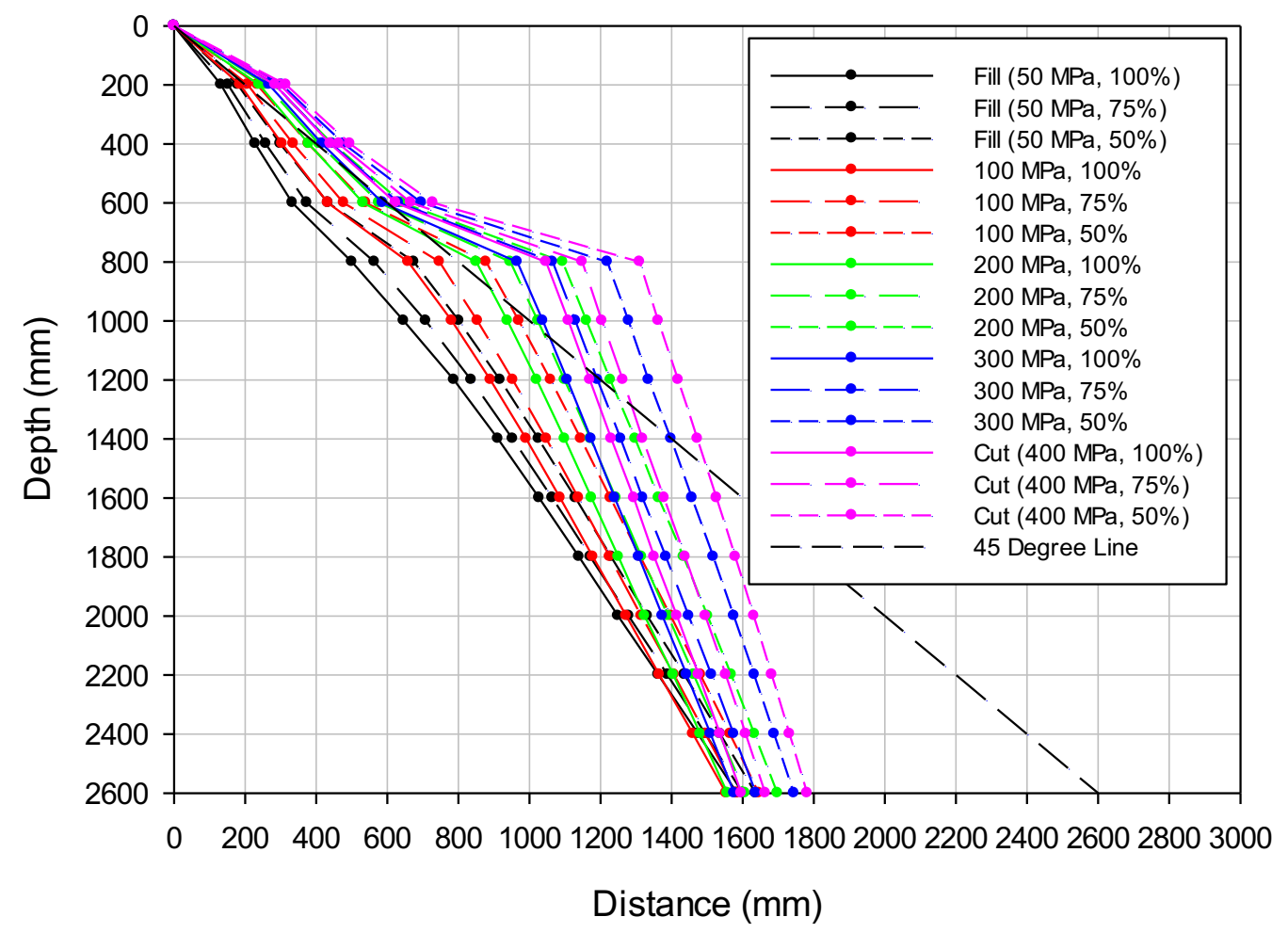

Figure 5.17: Equilibrium influence lines for long-term model

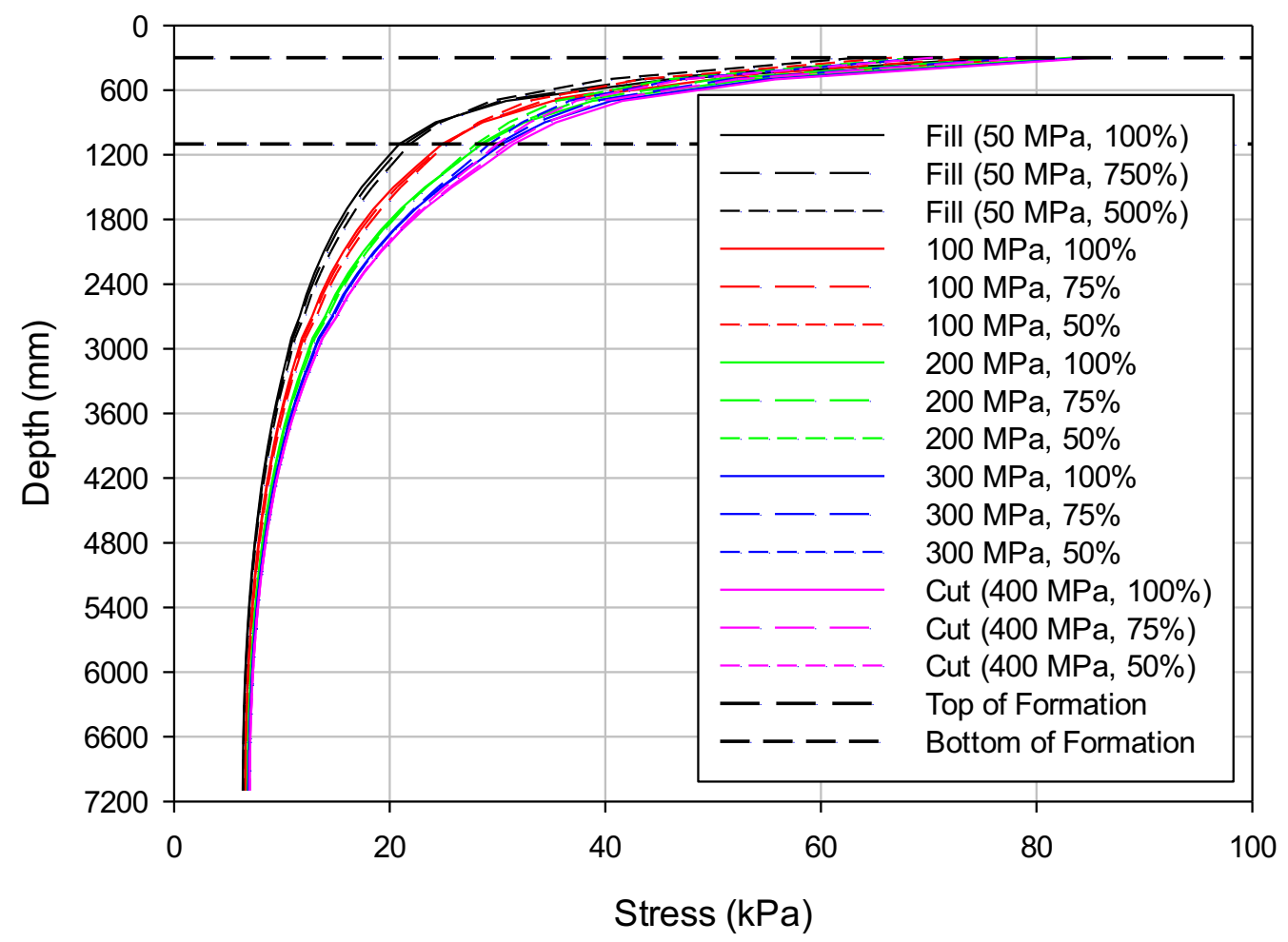

Figure 5.18: Substructure vertical stress for long-term model 
A reduction in formation structural capacity increases the substructure deflection, however, this does not affect the applicability of determining the EILs. This observation suggests that a single $45^{\circ}$ influence line is unsuitable for characterisation of railway track formation and that information regarding track formation condition with increase in tonnage is required to accurately model and evaluate the formation deflections with time, as well as for back-calculation of material properties.

For additional information regarding the characterisation and implementation of the inverse method for long-term analysis, refer to Section 5.4. Furthermore, all modelled heterogeneous substructures are presented in the appendices. The validation of the inverse method is further presented in Section 5.3.

\subsection{VALIDATION OF THE INVERSE METHOD}

This section provides a thorough discussion of the validation of the inverse method against deflection measurements from Station 1 at the Bloubank test site. The validation was done on Bloubank's 2004 data with the focus on the initial formation condition after rehabilitation. The assumptions replicating the conditions present at the Bloubank test site were:

- Formation deflections were measured from a depth of 80 to $2500 \mathrm{~mm}$. These measurements were vertically aligned with the neutral axis of the rail profile as well as with the positions of the MDD arrays presented in Chapter 2. Furthermore, substructure deflections below $2500 \mathrm{~mm}$ were disregarded as the MDD anchor was positioned at this depth and all deflection measurements were referenced to this point;

- Loading application: 7E locomotive bogie (21 tonnes/axle);

- Substructure design: Initial structural capacity as presented by the generic formation properties in Table 5.2, with a $400 \mathrm{MPa}$ in-situ subgrade.

The load application and substructure composition remained unchanged from that presented in Section 5.2. Figure 5.19 illustrates the EILs for the above-mentioned formation assumptions/conditions, beginning at $80 \mathrm{~mm}$ below the ballast/special subballast interface and incrementally increasing with depth as a result of the inter-sleeper deflections and zero-referenced movement at $2500 \mathrm{~mm}$. The piecewise regressions are presented in Equations 5.7 and 5.8. 


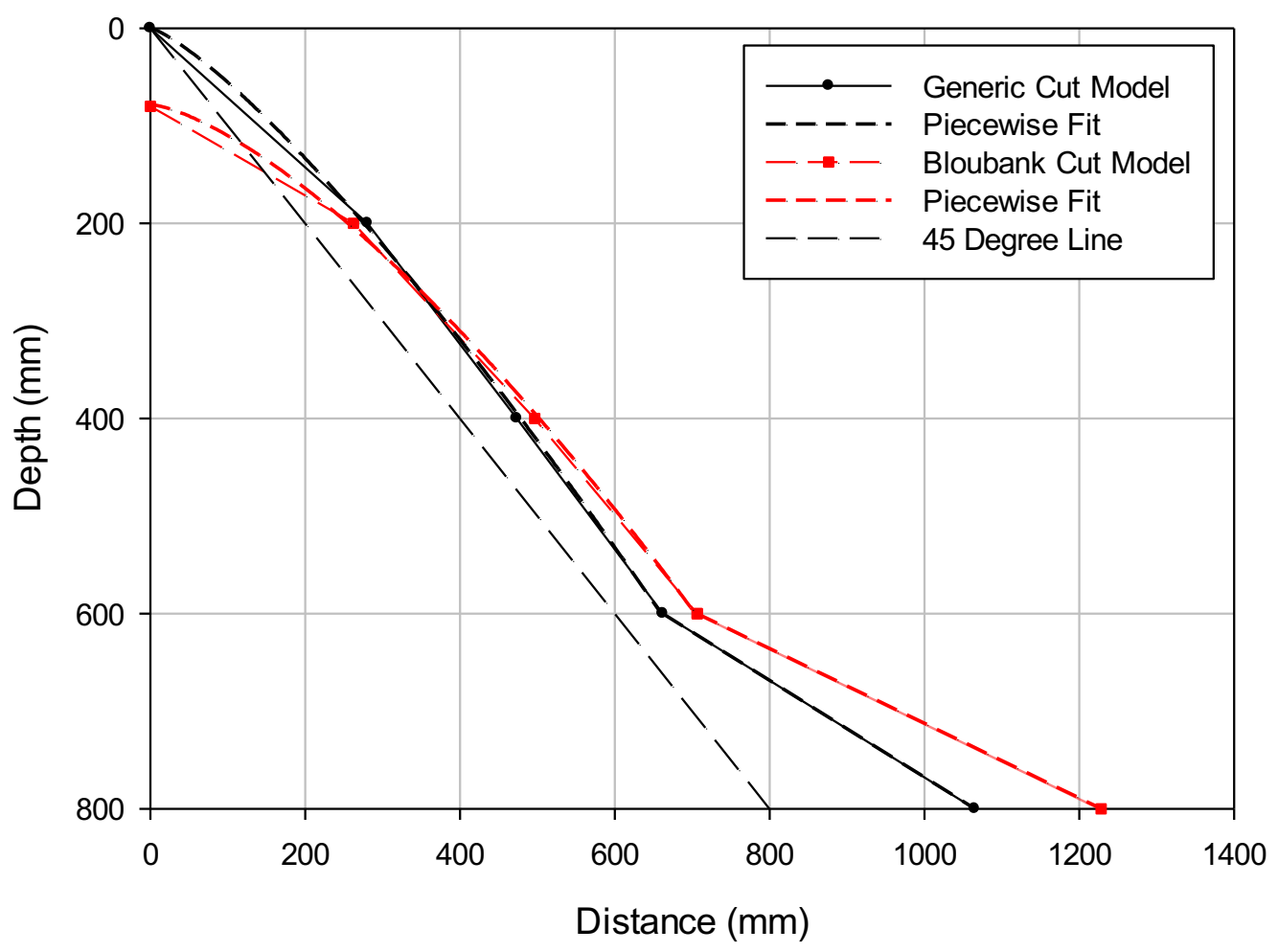

Figure 5.19: Comparison of formation equilibrium influence lines

$$
\begin{aligned}
& f(y)_{\text {Generic }}=\left\{\begin{array}{lr}
\sqrt[1.2607]{y / 0.1672}, & 0 \leq y<600 \\
(y-271.16) / 0.4965, & 600 \leq y \leq 800
\end{array}\right. \\
& f(y)_{\text {Bloubank }}=\left\{\begin{array}{lr}
\sqrt[1.4339]{(y-78.43) / 0.0430}, & 0 \leq y<600 \\
(y-329.14) / 0.3834, & 600 \leq y \leq 800
\end{array}\right.
\end{aligned}
$$

Figure 5.20 shows the local deflections obtained using the inverse model with conditions representative of the formation at Bloubank as well as the actual measured local deflections. The model agrees well with the measured formation deflections, however, a small difference is present within the first $200 \mathrm{~mm}$ of subgrade. This increase in relative deflection is associated with the excavation and re-compaction of the in-situ subgrade during construction, resulting in a less stiff material than the undisturbed subgrade below. This results in higher deflections $\left(\delta_{\text {Data }}\right)$ than those estimated by the Bloubank inverse model $\left(\delta_{\text {Model }}\right)$ which resembled a homogeneous, uniform and undisturbed subgrade. 


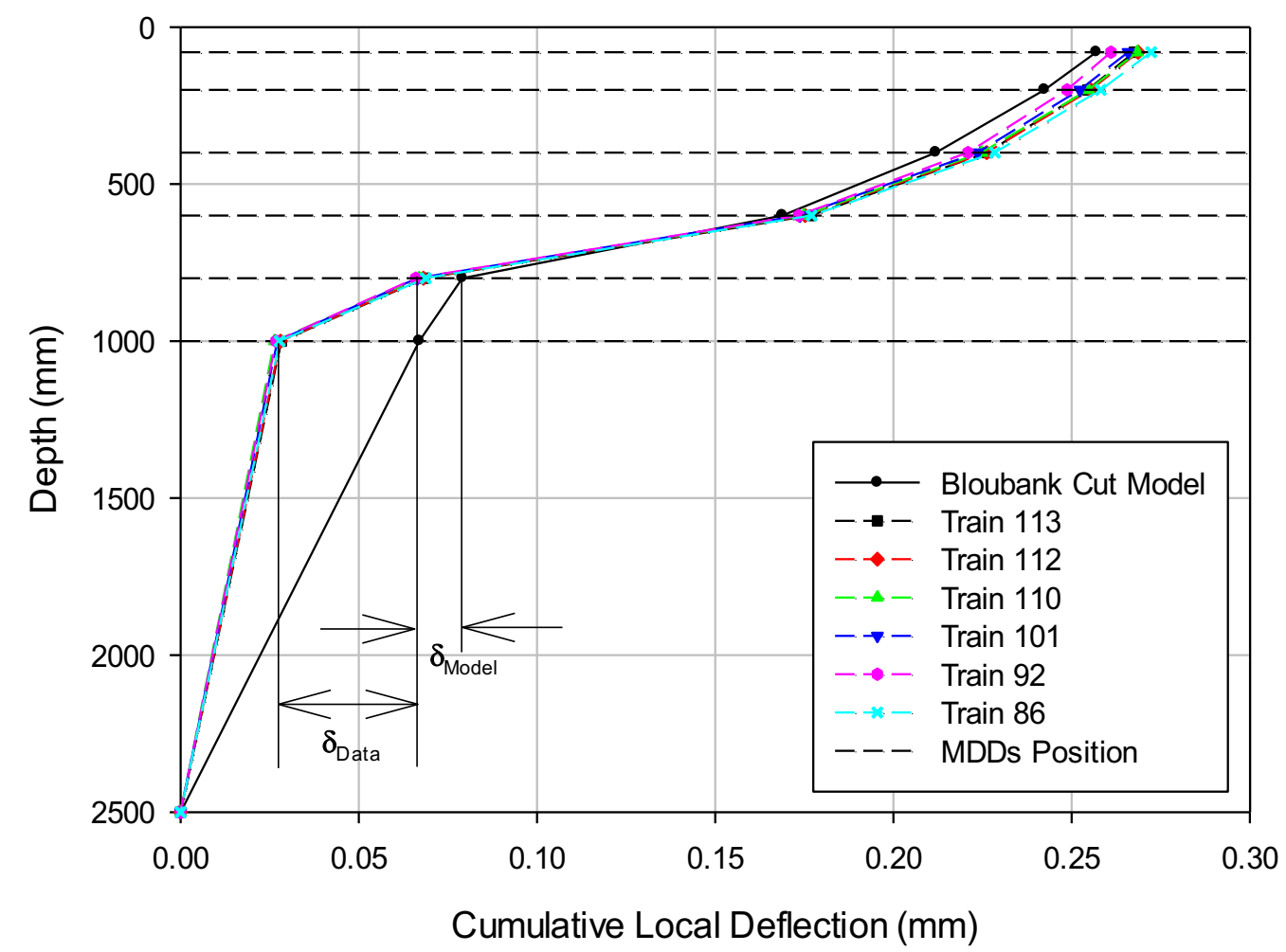

Figure 5.20: Comparison of inverse model and Bloubank local substructure deflections measurements

Figure 5.21 compares the inverse model to the measured transient deflections with regard to their peak, spread and curvature. The inverse model falls within the measured deflection basins showing a clear agreement with the estimated and the measured substructure deflections. Moreover, all measured relative local deflections agree with one another allowing manipulation of the measurements into a single average deflection basin as shown in Figure 5.22. Clear agreement with respect to the peak and curvature of the deflection as well as deflection spread is illustrated since the difference $\left(\delta_{\text {spread }}\right)$ is within the expected ranges shown in Section 5.1. 


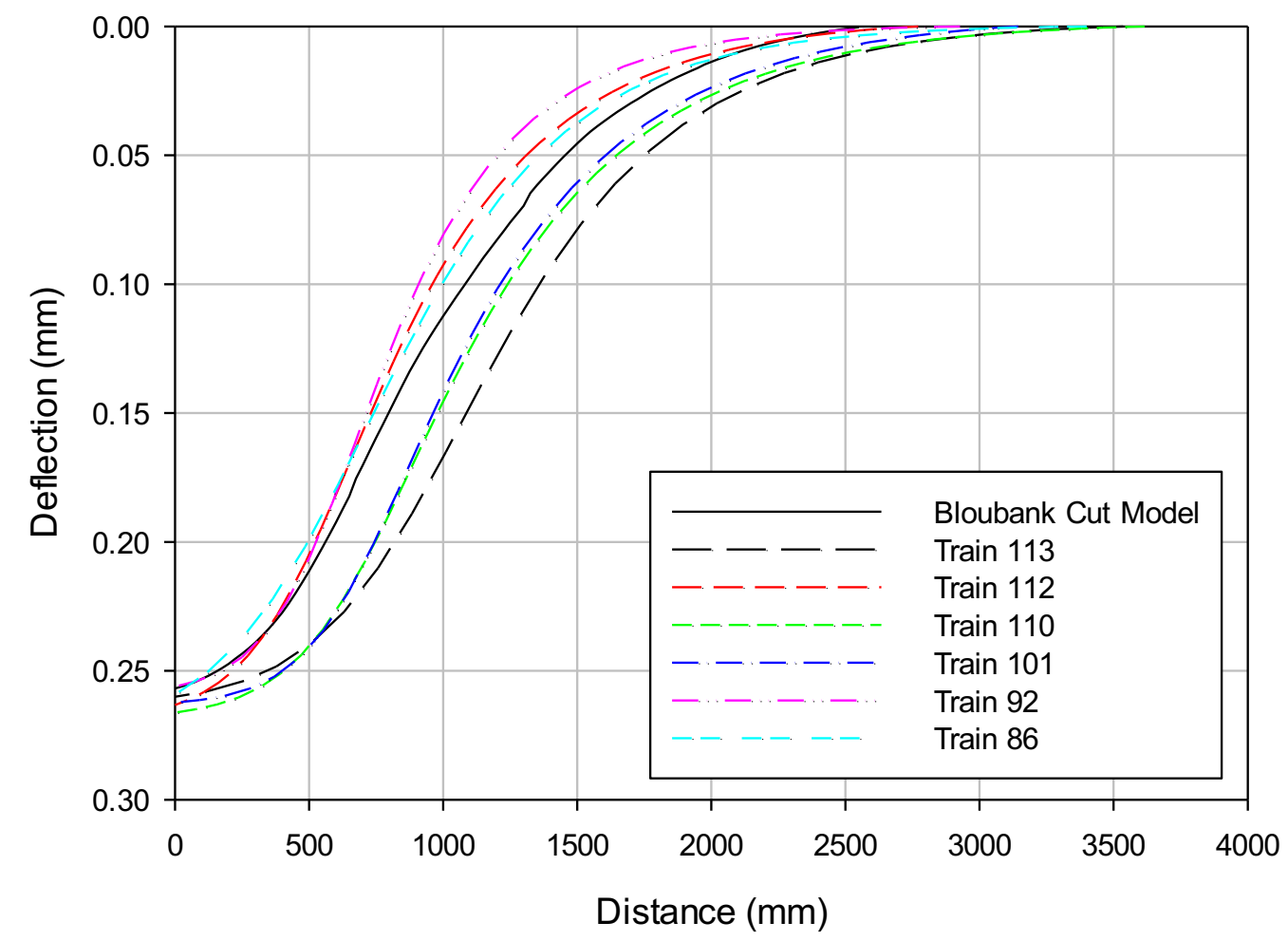

Figure 5.21: Comparison of inverse model and Bloubank transient substructure deflection measurements

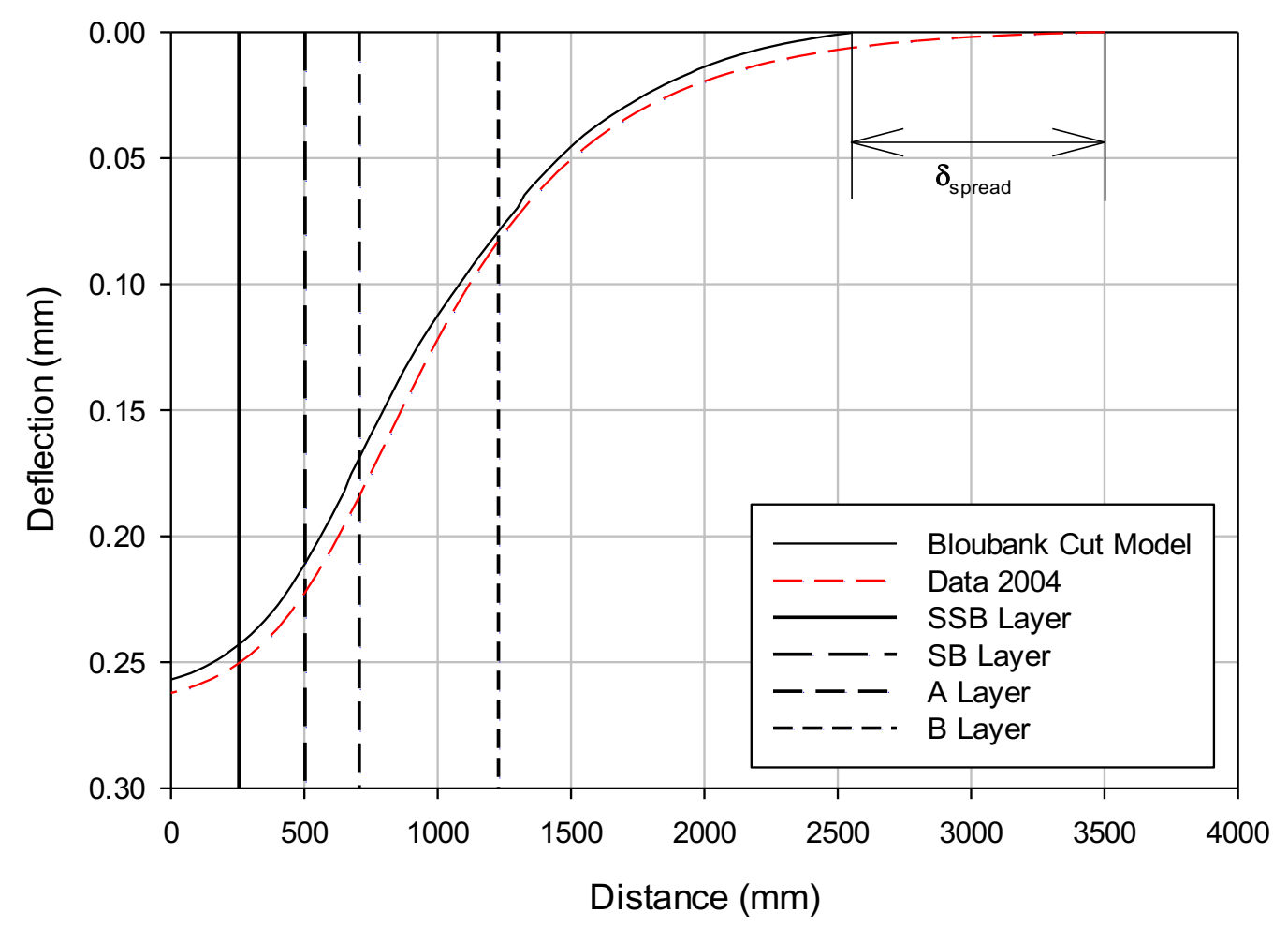

Figure 5.22: Estimated formation layer boundaries on transient substructure deflection measurements 
Validation of the inverse method involves comparison of the deflection estimated via the EIL boundaries (Equation 5.8) and the relative local deflections measured using the MDDs. In this regard, Figure 5.23 compares the transient and locally measured peak strains. The estimated strains differed by no more than $23 \%$ (Layer A) maximum and $10.5 \%$ on average of the actual measured strain. It can therefore be concluded that the inverse method is valid for the back-calculation of railway formation properties, allowing characterisation of a railway track formation by means of transient formation deflections.

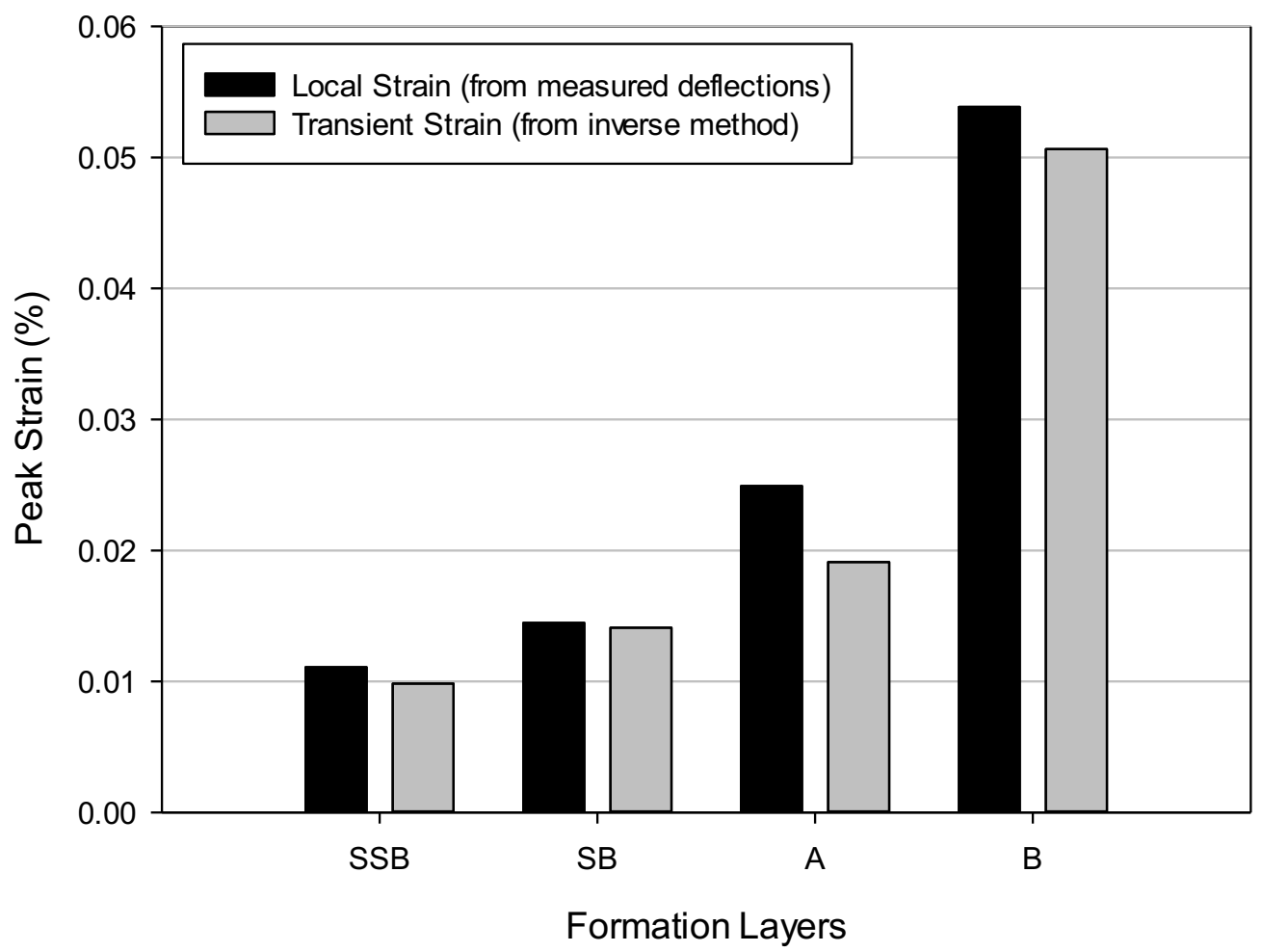

Figure 5.23: Validation of the inverse method through peak strain comparison

Implementation of the mechanistic inverse method to other railway formation designs and loading configurations is possible. However, it is important to understand that the method's accuracy and reliability is dependent on deflection measurement variability, the available track condition information and a comprehension of the deflection basin variability as a function of the track characteristics and formation material properties. Section 5.4 investigates the applicability of the method to estimate the long-term behaviour and response of railway formations using the Bloubank formation as a case study. 


\subsection{CHARACTERISATION OF LONG-TERM FORMATION BEHAVIOUR}

This section focuses on an evaluation of the applicability of the inverse method in modelling the longterm response of railway formation materials with in-service loading over time. Thus, measured formation responses were fundamental for the development of the inverse method for long-term condition assessment as shown in Section 5.1.2. The applicability of long term formation behaviour is assessed by comparing transient and local deflections. The evaluation of long-term formation response is established on all available data from 2004 to 2017, considering only Station 1 and $7 E$ locomotives.

The formation behaviour was assessed through the analysis of cumulative local formation deflections. Figure 5.24 shows the cumulative local deformation data available from 2004 to 2017. It is observed that local formation deflections increase in a non-uniform manner as a result of the decrease of vertical stress levels with depth, consequently resulting in a greater increase in deflection at the top ( $\left.\delta_{\text {Top Def }}\right)$ than at the bottom ( $\left.\delta_{\text {Bottom Def }}\right)$ of the formation. Furthermore, formation layer deflections are observed to increase monotonically with traffic, however, the top formation layers display a different response captured by the illustration in Figure 5.25 showing the individual layer deflections.

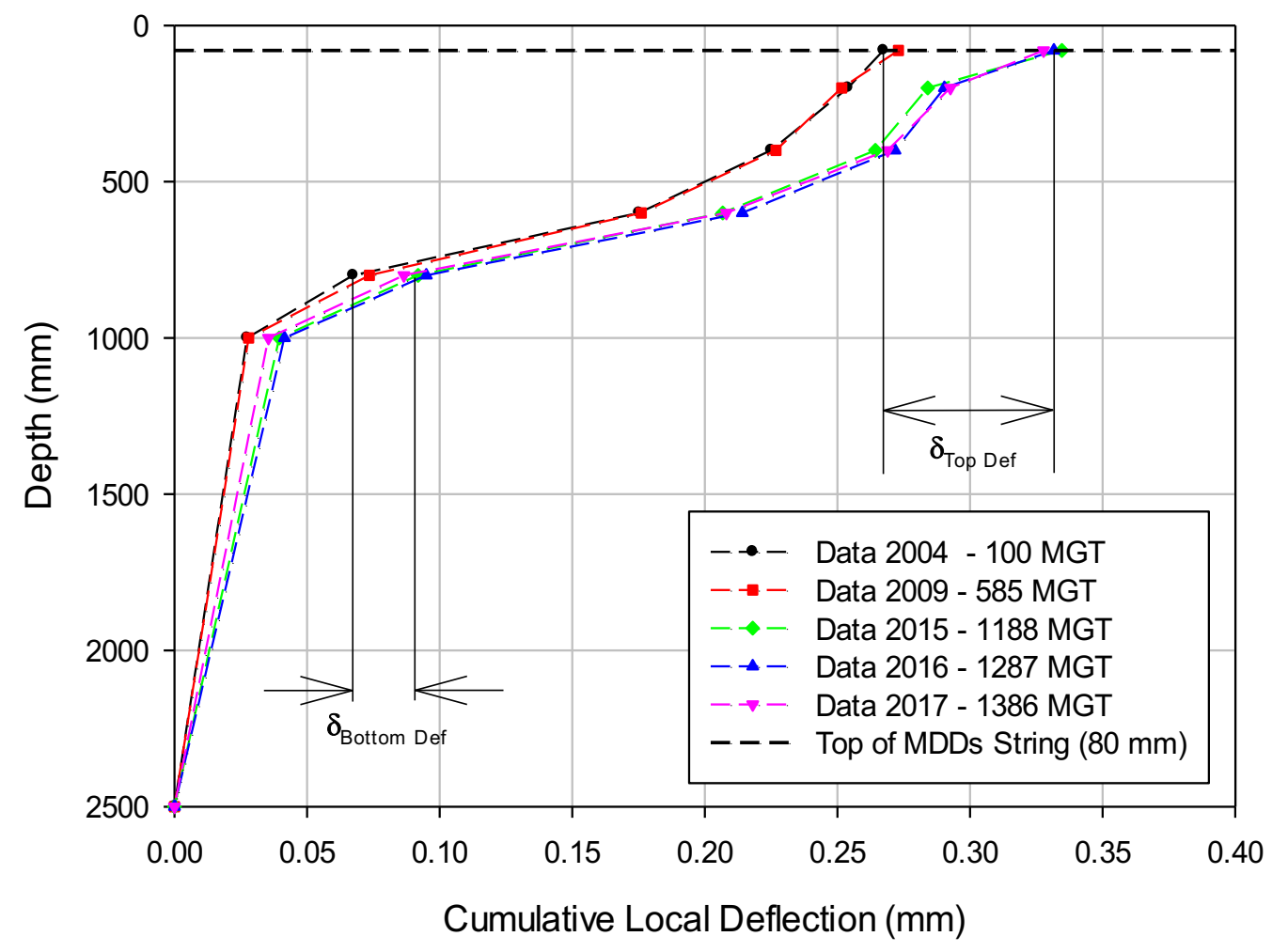

Figure 5.24: Long-term analysis of cumulative local deflection measurements 
From Figure 5.25 it can be seen that formation moulding predominately occurs within the special subballast (SSB) and subballast (SB) layers in a manner which appears to counterbalance one another. It is believed that changes in the SSB deflection are associated with an increase in the stress path propagating through the ballast as a result of a combination of sleeper movement, ballast fouling and an increase in layer thickness with time. In addition, Chang et al. (1980) specified that ballast depth and sleeper spacing are the most significant variables influencing vertical track deflections under train loading. Therefore, higher stresses and deflections within the SSB subsequently reduce stresses and deflections within the SB layer. As a result, stresses at deeper locations remained fairly stable resulting in a constant increase in relative peak deflection as observed within the A and B layers as progressive breakdown and weakening occurred with load applications.

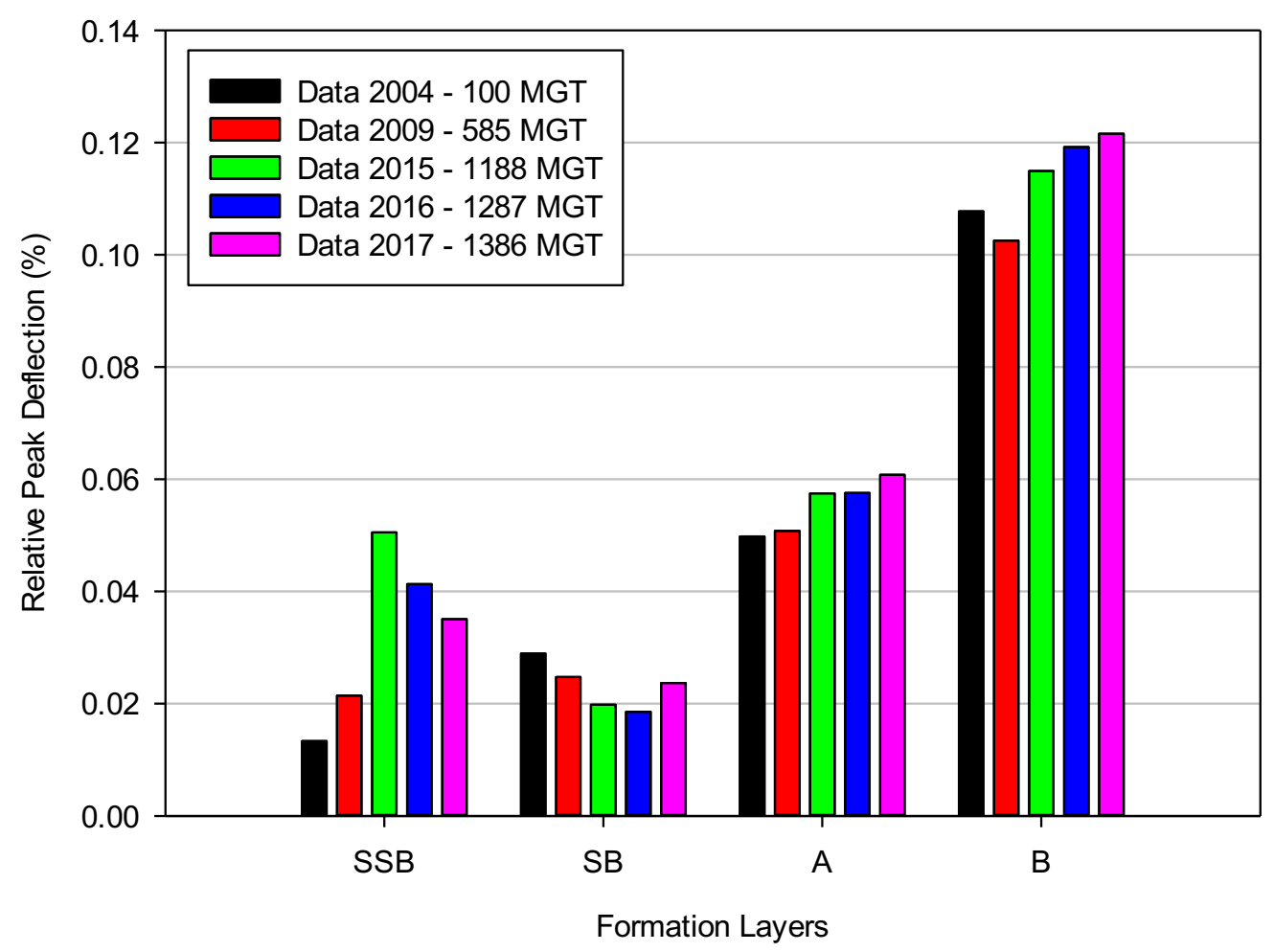

Figure 5.25: Long-term deflection analysis of formation layers

From the results presented, it is demonstrated that the increase in local substructure deflection is related to changes within the formation only, due either to an existing structural impairment or an increase in stresses. Furthermore, granular materials have inherently complicated responses due to traffic and environmental changes resulting in complexities related to the modelling of their behaviour. This is especially true when predicting each individual layer's behaviour. In order to mitigate the identified complexities, long-term behavioural modelling was simplified by assuming that the formation layers deteriorate uniformly with traffic. The modelling of the long-term response of the rail track formation 
was thus conducted by incrementally decreasing the elastic modulus of all formation layers equally (SSB, SB, A and B). The implementation of the inverse method consisted of assessing and determining the structural condition by means of comparing the modelled substructures and the measured transient deflections as shown in Figure 5.26.

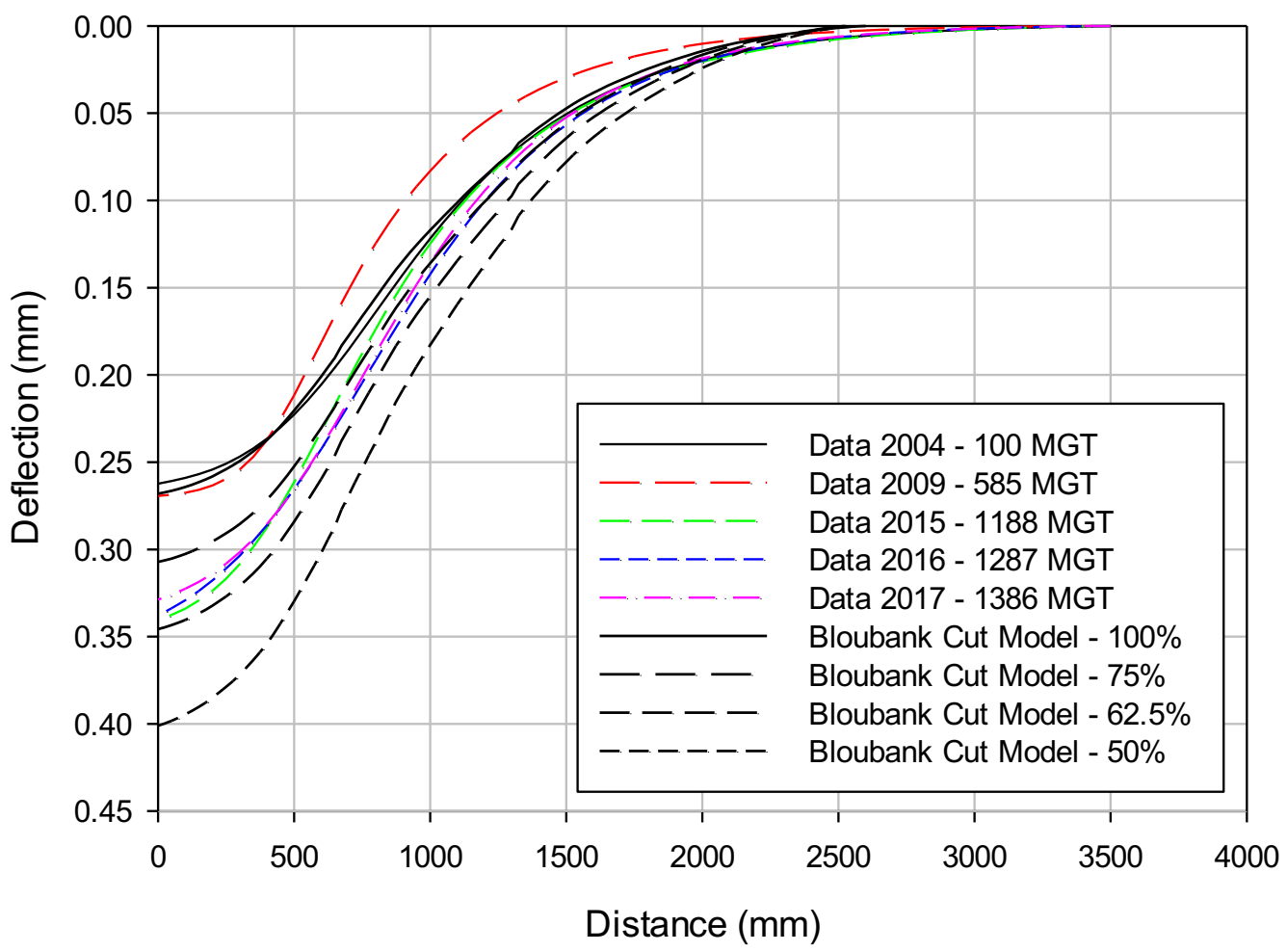

Figure 5.26: Long-term analysis of cumulative transient deflection measurements

From Figure 5.26 it can be seen that higher peak deflection occurs with increasing traffic tonnage. Furthermore, a difference in curvature from $0 \mathrm{~mm}$ to $500 \mathrm{~mm}$ (SSB and SB boundaries) is observed agreeing with the localised responses determined using the inverse method. Similarly, the decrease in formation structural capacity of the inverse model $(100 \%, 75 \%, 62.5 \%$ and $50 \%)$ also resulted in an increase in peak deflection and a slight change in curvature, corresponding to the measured deflections. Through these observations it can be concluded that the Bloubank rail track formation remained unchanged up to 2009 , further reducing to approximately $62.5 \%$ of its initial structural capacity (2004) - Table 5.2 - as it closely coincided with the current measurements from 2015 to 2017.

In this regard, Figure 5.27 shows the EILs for $100 \%$ and $62.5 \%$ structural capacity by means of estimating formation layer boundaries, subsequently calculating the individual layers' strain and determining the suitability of the inverse method for long-term analysis. The piecewise influence lines in Figure 5.27 are shown in Equations 5.9 and 5.10. Alternatively, the formation layer boundaries can 
be estimated from the presented EILs in Figure 5.27. The reliability of the method was investigated by applying the calculated formation layer boundaries to the transient deflection measurements in Figure 5.26, comparing relative local and transient formation strains. The results thereof are presented in Figure 5.28.

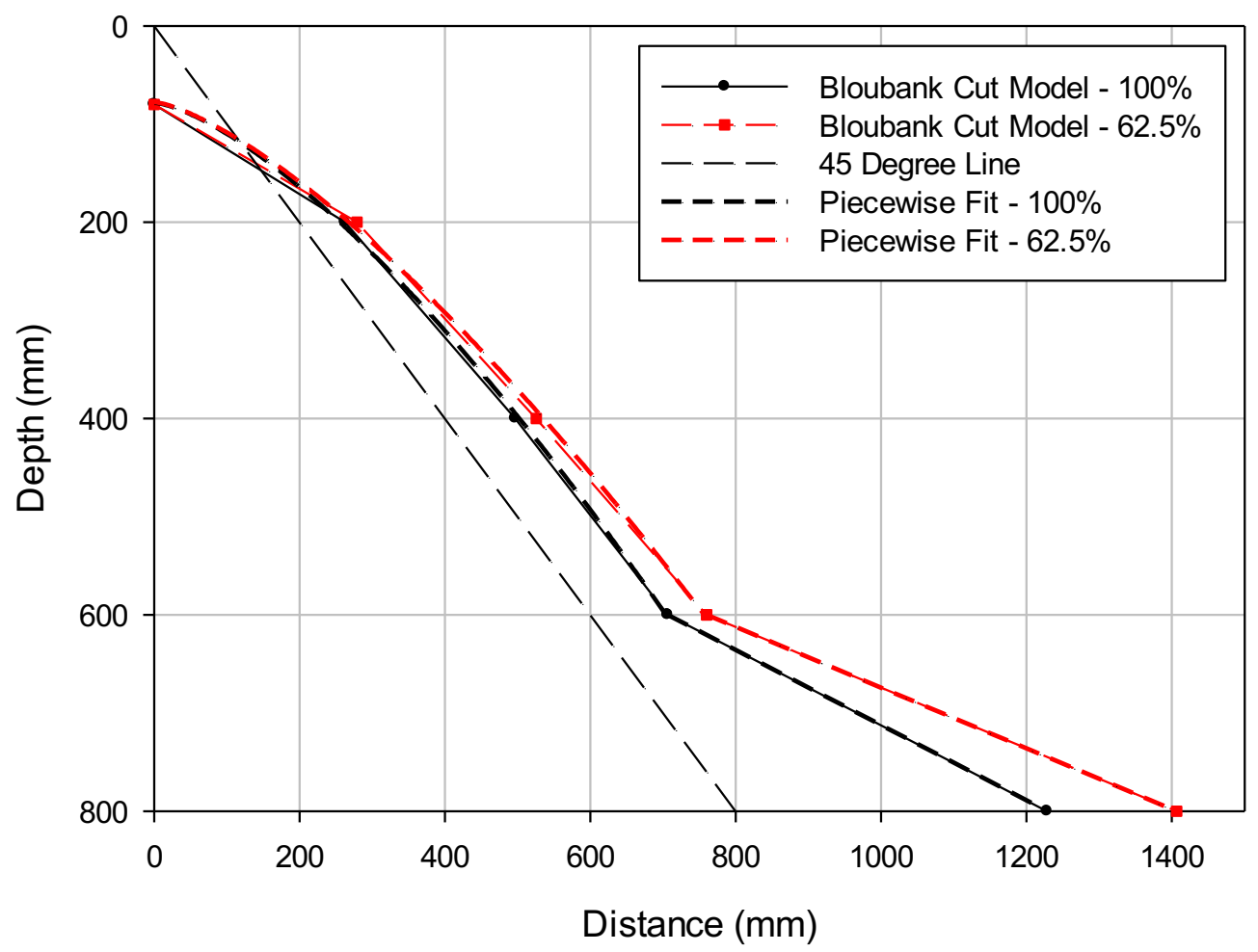

Figure 5.27: Long-term analysis of formation equilibrium influence lines

$$
\begin{aligned}
& f(y)_{100 \%}=\left\{\begin{array}{lr}
\sqrt[1.4339]{(y-78.43) / 0.0430}, & 0 \leq y<600 \\
(y-329.14) / 0.3834, & 600 \leq y \leq 800
\end{array}\right. \\
& f(y)_{62.5 \%}=\left\{\begin{array}{lr}
1.3974 & 0 \leq y<600 \\
(y-364.87) / 0.3094, & 600 \leq y \leq 800
\end{array}\right.
\end{aligned}
$$




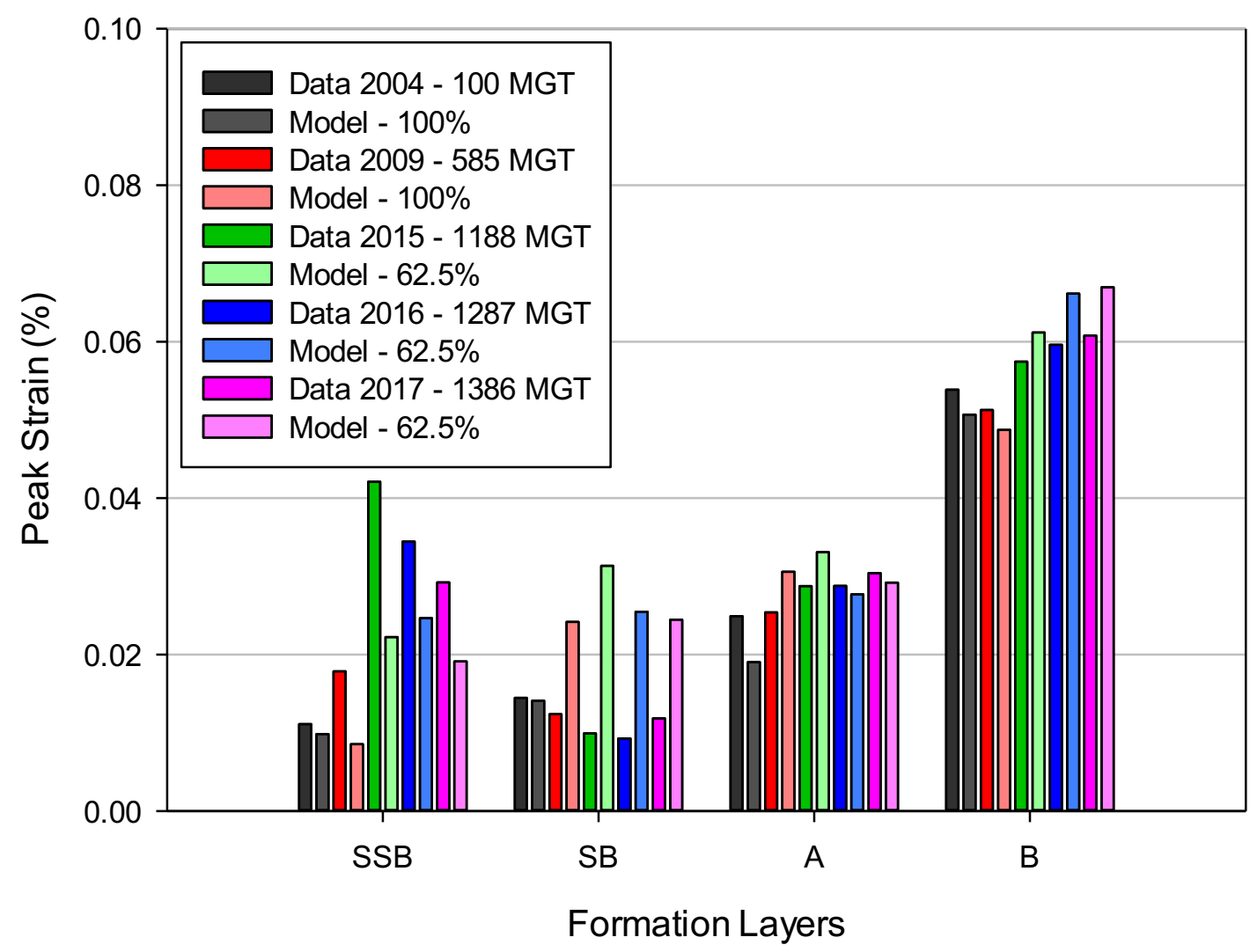

Figure 5.28: Analysis of the inverse method for long-term condition assessment

It is observed that the estimated and measured individual strains differ between the top and the bottom of the formation, particularly as a result of the moulding of the SSB and SB layers resulting in nonmonotonic behaviour. The inverse method, when applied to long-term behaviour prediction, conservatively estimated the expected relative strains, however, it underestimated the measured SSB and over-estimated the SB Layer strains respectively. This is due to the fact that the model does not account for the erratic formation response displayed by the SSB and SB layers. However, the A and B Layers confirm that the inverse model can indeed be utilised for long-term condition assessment of railway formation layers due to the good agreement between the measured and predicted strains within these layers. Furthermore, Section 5.5 proceeds with implementation of the inverse method on total substructure deflections measured under train transient loading. 


\subsection{APPLICATION OF THE INVERSE METHOD}

This section deals with the application of the inverse method on train transient substructure deflections measured through remote video monitoring (RVM). This deflection instrument was selected as an economical and practical alternative for deflection measurements at a single measuring point under train loading. The implementation of the method consisted of evaluating the modelled and measured deflection measurements and determining its reliability based on the analysis of the estimated and backcalculated elastic moduli of the formation layers. The application of the inverse method consists of the following steps:

- Modelling the measured substructure deflections;

- Estimating the model EILs;

- Using the above information to characterise the actual formation condition in relation to the measured substructure deflections.

Train transient substructure deflections were measured from the top of the formation (excluding superstructure and ballast layer). Only fully supported sleepers were considered in order to minimize variations in RVM deflection measurements. The inverse model used was adapted to account for the conditions under which the RVM measurements were recorded in the field namely:

- Loading application: 21E Locomotive bogie (26 tonnes/axle);

- Deflection measurements: A single point measurement at edge of sleeper and aligned with the centre line of sleeper;

- The formation layer moduli were reduced to $62.5 \%$ of that illustrated in Table 5.2 according to the estimated structural capacity for 2016 as presented in Section 5.4. For further information on the structural estimation procedure, refer to Section 5.4.

Figures 5.29 and 5.30 presents the formation EILs and substructure stress distribution for the conditions mentioned above. The deflections from the model are directly compared to those obtained from the RVM measurements in Figure 5.31. 


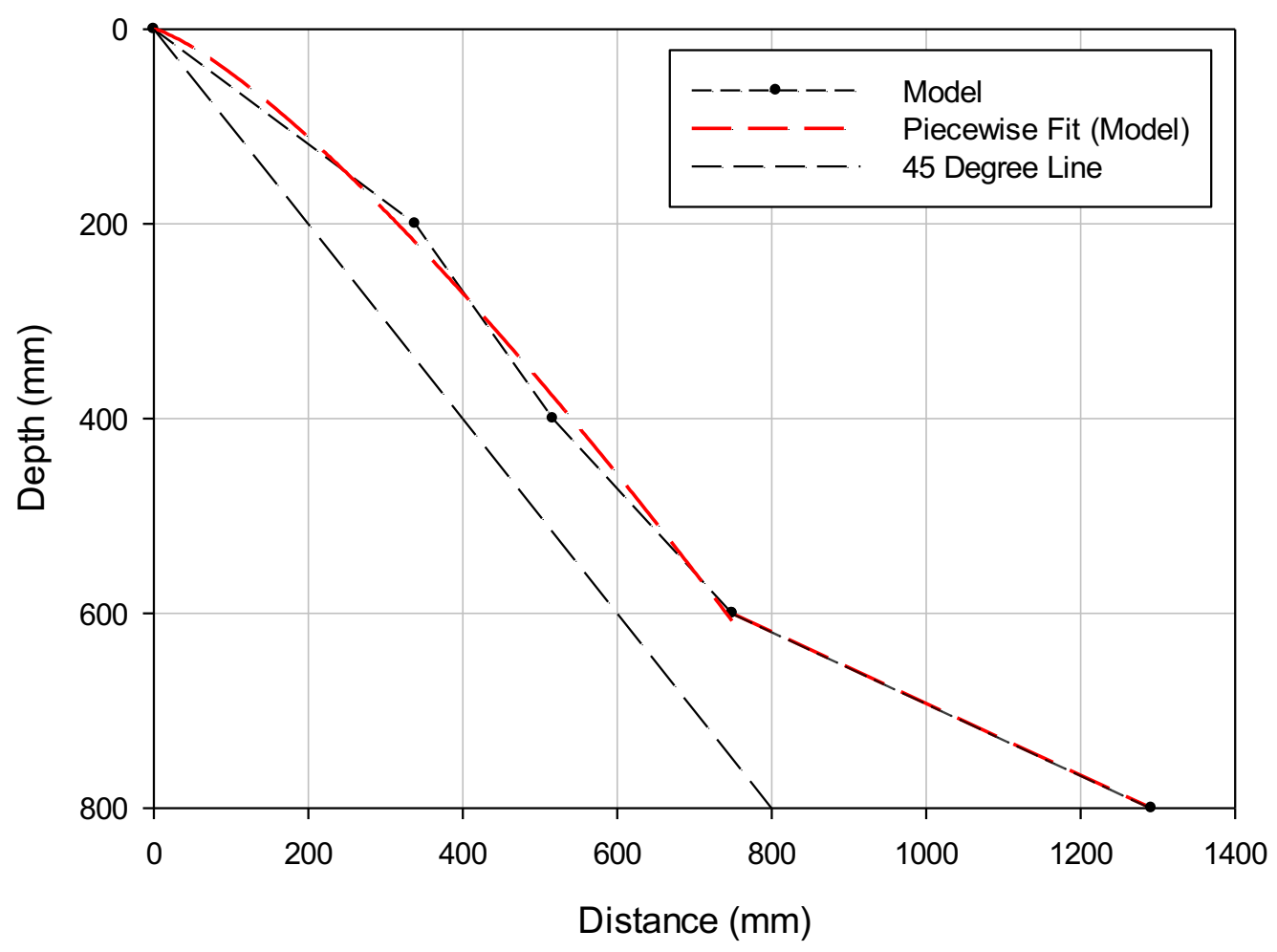

Figure 5.29: Formation equilibrium influence line for the modelled conditions

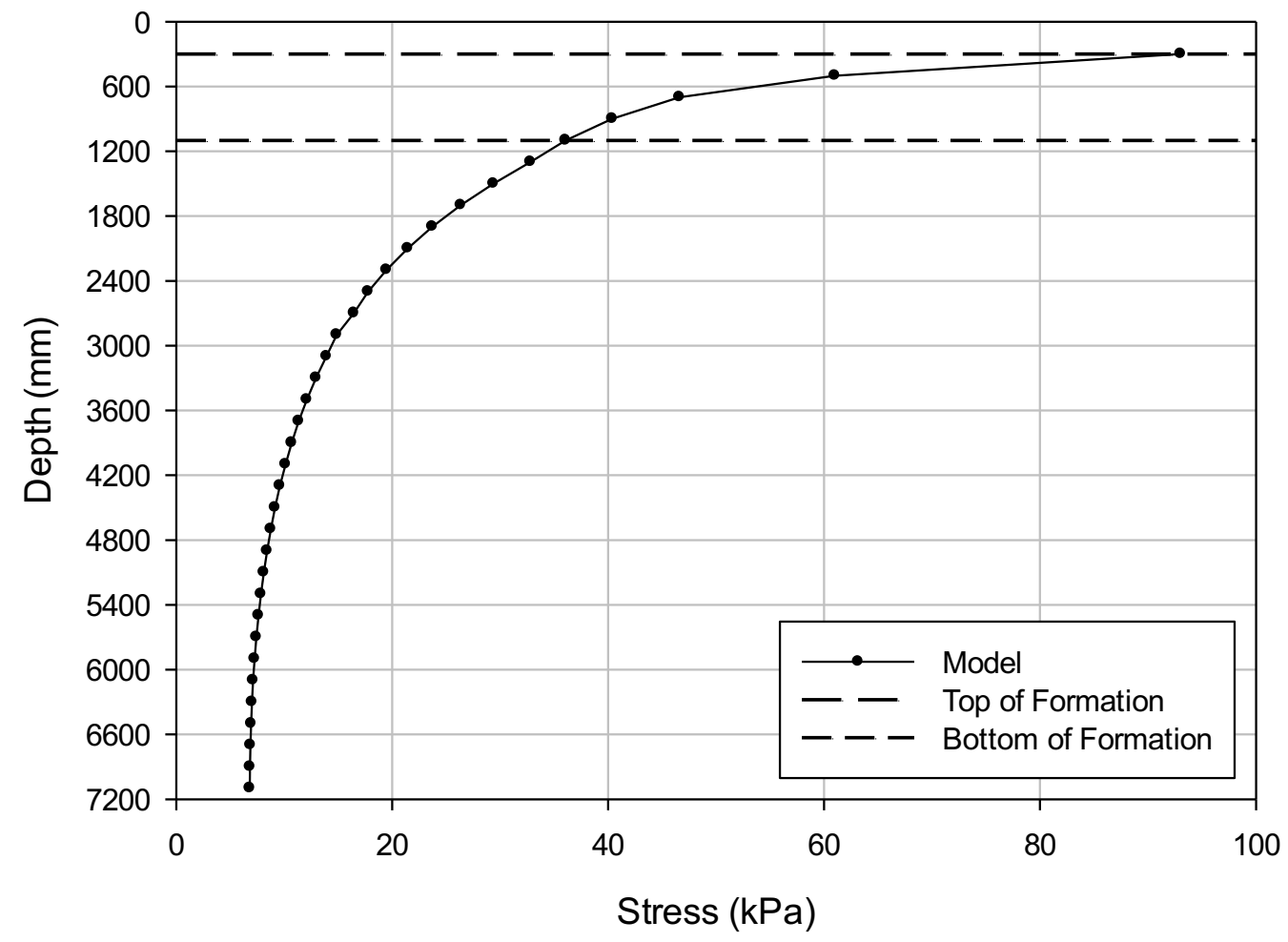

Figure 5.30: Vertical Substructure stress for the modelled conditions 


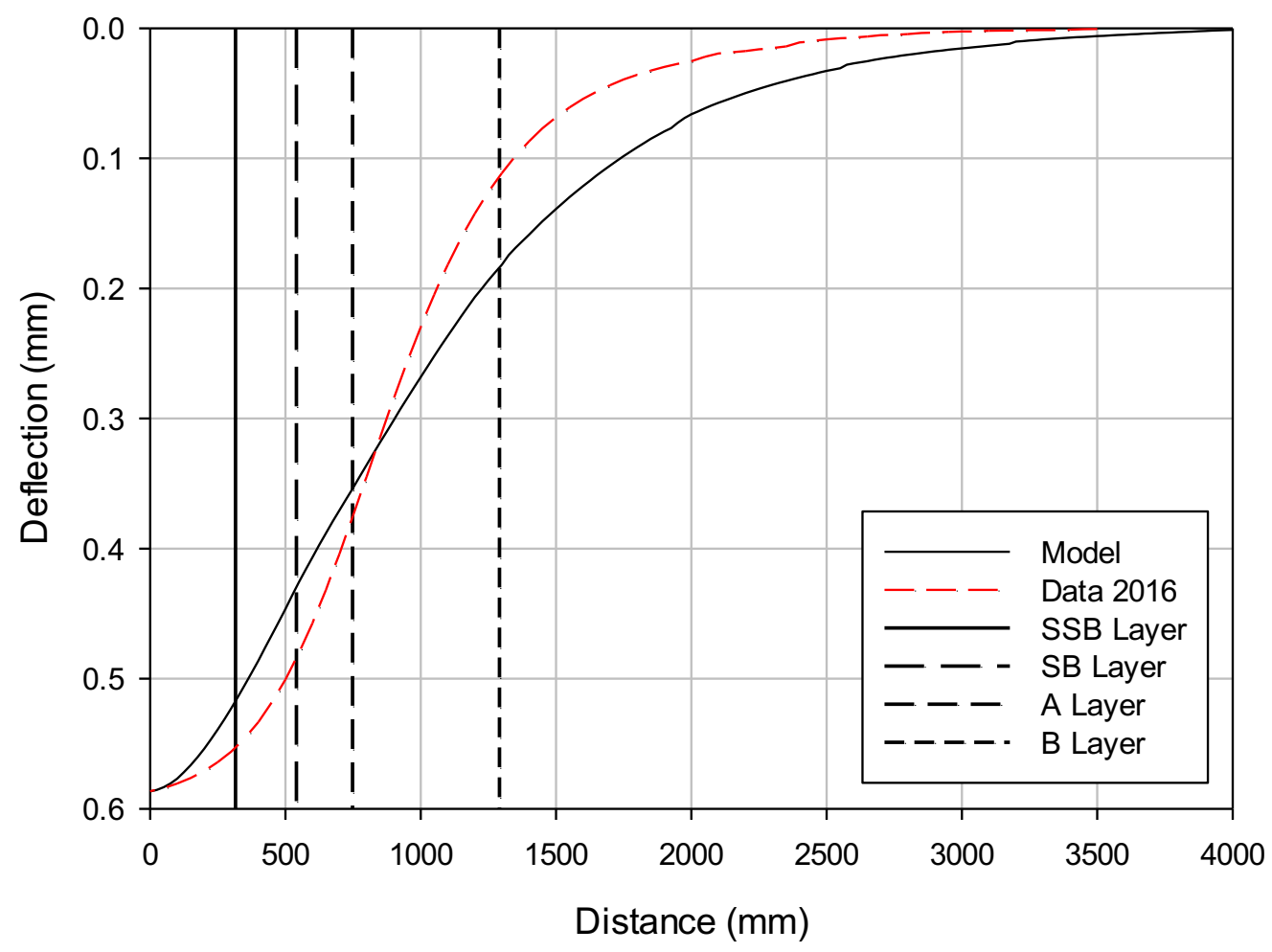

Figure 5.31: Inverse method on remote video monitoring measurements

As seen in Figure 5.31, the model accurately replicates the substructure deflection with a difference never exceeding $0.07 \mathrm{~mm}$ (B layer boundary). The maximum difference in the distribution of the load in terms of deflection spread is roughly $500 \mathrm{~mm}$. Additionally, Priest et al. (2010) confirmed that linear elastic models are reliable for formation deflection characterisation, however, an inherent difference in curvature is commonly seen due to the fact that granular materials actually behave in an elasto-viscoplastic manner. Table 5.3 shows the estimated relative strain and back-calculated elastic moduli for each individual formation layer with regard to the formation layer boundaries presented in Figure 5.31.

Table 5.3: Comparative analysis of results

\begin{tabular}{|c|c|c|c|}
\cline { 2 - 4 } \multicolumn{1}{c|}{} & \multicolumn{3}{c|}{ RVM Data (2016) } \\
\hline $\begin{array}{c}\text { Formation } \\
\text { Layer }\end{array}$ & Strain (\%) & Stress (kPa) & $\begin{array}{c}\text { Elastic Modulus } \\
(\mathrm{MPa})\end{array}$ \\
\hline SSB & 0.017 & 73.86 & 433.27 \\
\hline SB & 0.034 & 52.31 & 152.48 \\
\hline A & 0.054 & 42.88 & 79.40 \\
\hline B & 0.130 & 38.38 & 29.44 \\
\hline
\end{tabular}

\begin{tabular}{|c|}
\hline $\mathbf{6 2 . 5 \%}$ Model (2016) \\
\hline $\begin{array}{c}\text { Elastic Modulus } \\
(\mathrm{MPa})\end{array}$ \\
\hline 187.50 \\
\hline 156.25 \\
\hline 93.75 \\
\hline 31.25 \\
\hline
\end{tabular}


As observed in Table 5.3, the measured formation condition gradually deteriorated with traffic to a state which is similar to that given by the estimated $62.5 \%$ model as confirmed by the A, B and SB elastic moduli. This reduction in formation structural capacity may be predominantly associated with the formation mechanical weathering due to traffic as postulated by Vandoorne et al. (2017). In contrast, the SSB strain hardened with traffic as an increase in elastic modulus was noticed in comparison to the initial or expected values in Tables 5.2 and 5.3 respectively.

Previous investigations at the Bloubank test site have also indicated signs of strain hardening of formation layers (Vorster and Gräbe, 2013). It is however assumed that the indication of hardening could also be related to numerous factors involving RVM setup and installation, resulting in measurements with slight conformance errors. This could be due to the ballast shoulders commonly being disturbed, possibly affecting adjacent sleepers' stress distribution, subsequently causing a structural impairment and particularly reducing the stress levels within the SSB layer resulting in the SSB deflection seen in Figure 5.31.

In conclusion, the inverse method is thus established as a reliable alternative for formation characterisation to determine the structural condition based on transient deflection measurements since good agreement was found for the A, B and SB layers. It is however important to comprehend that various permutations of substructure properties and characteristics can lead to similar deflection behaviour. This research therefore focuses on assessing formation layer condition under low plastic deformation and negligible climatic changes, as well as based on a predetermined subgrade modulus only. Hence, some predetermined rail track condition information is necessary to model the substructure deflection and accurately estimate the formation structural capacity through the inverse process thus assuring the reliability of the method. 


\section{CONCLUSIONS AND RECOMMENDATIONS}

The conclusions and recommendations of this research are presented in Sections 6.1 and 6.2 respectively.

\subsection{CONCLUSIONS}

The conclusions drawn in this research are summarised with respect to the application of finite element analysis, the deflection measurement variability under train loading, the railway equilibrium influence lines, the long-term behaviour of railway track formation and the application of the inverse method for characterisation of railway track formations.

\subsubsection{Finite Element Modelling}

The following conclusions are made with regard to the finite element analysis for characterisation of railway track formation response:

- Finite element analysis proves to be a useful engineering tool that allows detailed investigation of track superstructure influence and various substructure compositions on railway formation behaviour in a simple, economical and practical manner;

- Railway track formation response differs with respect to the bogie loading positioning on the superstructure. The results of the two loading cases considered namely: between sleepers and centre-of-sleeper with identical substructure material properties exhibit different substructure deflections and vertical stresses. Loading positions did not have a large influence on transient deflection basins. However, loading at centre-of-sleeper was the most reliable load case to use due to the monotonic dissipation of stresses into the formation. This subsequently minimised the variability and assured a higher level of repeatability for inverse deflection analysis;

- The simulation of different locomotive loadings showed that the increase in peak deflection was directly proportional to the axle loading and inversely proportional to the bogie spacing. The deflection spread was less well-defined as the degree at which this occurred was attributed to the complex superposition of bogie wheel loads (axles/bogie and bogie length) and the specific superstructure interaction;

- The substructure sensitivity analysis established that the peak and spread of the deflection measurements are governed by the elastic moduli and Poisson's ratio respectively. Nonetheless, both material properties affect the overall shape of the transient deflection basins; 
- Finite element analysis allows estimation of railway equilibrium influence lines (EILs). The EILs under simulated train transient loading can be expressed as the relationship between transient and local deflection measurements.

\subsubsection{Sensitivity Analysis of Deflection Measurements}

The following conclusions are made with regard to the sensitivity analysis of transient deflection measurements with the aim of investigating and normalising the dynamic effects that may affect the shape and variability of measured deflection basins:

- The transverse dynamic effects influence the shape of transient bogie deflection basins, subsequently increasing the formation deflection measurement variability. As a result, the averaging of left and right formation deflection measurements was found suitable for normalising and distributing any transverse imbalance in the deflection measurements;

- Longitudinal dynamic effects further increased the peak deflection variability between the wheels of a single bogie. Therefore, the leading wheel peak deflection basin was normalised to the bogie peak deflection mean, decreasing the deflection measurement variability;

- The deflection peak and spread variability is significantly reduced by only considering fully supported sleepers and adopting the unloaded zero deflection threshold line respectively;

- The train vibration was found to induce noise and random fluctuations in the deflection basin curvature affecting the inverse method outcome. This was amended through the implementation of Loess smoothing technique and non-linear sigmoidal regression;

- The effect of travelling speed is not an influential factor for formation peak deflection in the case of a South African heavy haul line with travelling speed less than $80 \mathrm{~km} / \mathrm{h}$. However, formation deflection responses under static nor dynamic loading (critical speeds) were investigated;

- The increase in formation peak deflection was found to be directly proportional to the increase in axle loading;

- It was observed that neither travelling speed nor axle load have a well-defined trend regarding their influence on the deflection basin spread. However, the deflection spread varied from $2600 \mathrm{~mm}$ to $3300 \mathrm{~mm}$ for travelling speeds between 20 and $55 \mathrm{~km} / \mathrm{h}$ and axle loads between 21 and 29 tonnes/axle. 


\subsubsection{Equilibrium Influence Lines for Railway Track formation}

The following conclusions are made with regard to the investigation of ballasted railway track equilibrium influence lines (EILs):

- The commonly assumed $45^{\circ}$ influence line is found to be an oversimplification for inverse deflection analysis of railway track formations. This can be attributed to the indirect load transfer and the superposition of bogie wheel loads on the discontinuous track superstructure support;

- The railway EILs was found to be significantly influenced by the substructure elastic moduli and Poisson's ratio. Furthermore, it was observed that the EILs of homogenous and uniformly decreasing heterogeneous substructures are less affected than the non-uniform heterogeneous substructures due to the greater change and effect of the modular ratio on the formation response;

- The variation in subgrade support significantly affects the total substructure EILs.

- It was observed that an increase in subgrade modulus whilst maintaining identical formation material properties produced an increase in the spread of the formation EILs. This is associated with the transition from shallow to deep substructure behaviour which defines the formation deflections in relation to the subgrade support;

- Furthermore, a significant reduction in formation layers' modulus results in an increase in the spread of the formation EILs. This variation in the formation structural capacity predominantly affects the shape of formation EILs, rather than the total substructure EILs due to the constant subgrade support and unaffected substructure behaviour.

\subsubsection{Long-Term Behaviour of Railway Track Formation}

The following conclusions are made with regard to the long-term behaviour of railway track formation:

- The cumulative local formation deflection decreases with depth in a non-uniform manner with increasing traffic tonnage. This is because the vertical stresses dissipate with increasing depth, thus experiencing greater stresses and deflection at top the of the formation, reducing towards the bottom of the formation;

- In the case of the Bloubank formation, a progressive breakdown and weakening is hypothesised to have had occurred with increase in traffic, thus producing a gradual loss in formation structural capacity and an increase in transient deflection measurements; 
- The Bloubank formation experienced a non-monotonic deformation with traffic as shown by the compensation of stresses of the special subballast (SSB) and subballast (SB) layers over time. This indicated that the variation of ballast stress path, which is influenced by the sleeper movement, sleeper spacing, ballast depth and fouling content, has a significant influence on the formation response;

- Furthermore, the A and B formation layers exhibit a continuous increase in deflection under fairly constant stress levels given the compensation of stresses within the SSB and SB layers. The gradual increase of relative formation deflection is related to the mechanical formation weathering with traffic, thus causing a reduction in formation structural capacity;

- From the Bloubank results, it is deduced that the top of the formation may be significantly influenced by the superstructure load distribution. Nonetheless, formation layers are expected to gradually deteriorate and experience increased deflections over time.

\subsubsection{Inverse Method}

The following conclusions are made with regard to the inverse method for characterisation of railway track formation:

- The inverse method is suitable for accurate estimation of the formation elastic modulus and characterisation of the formation condition through the interpretation of the full deflection basins under real train transient loading;

- The method is simple and relatively fast to apply in comparison to other deflection methods. This is because the inverse method analysis can be conducted on formation deflections measured with practical and cost-effective deflection measurement instrumentation;

- The reliability of the method is dependent on the available track condition information as for any other mechanistic-empirical method. This is because there are numerous permutations of material properties that may lead to similar deflection basins, deeming it a necessity to simplify the complexity of the possible permutations through adequate track condition information;

- The method conservatively models a homogeneous, uniform and undisturbed substructure. Subsequently, the model accurately agreed with specific measured local substructure deflections. However, a minor difference was found at the top of subgrade due to a less homogenous, non-uniform and disturbed soil layer, resulting in greater deflections;

- Through the use of transient formation deflection basins and railway influence lines, the inverse method allows estimation of deflection and elastic moduli of individual formation layers; 
- The method is suitable for formation strain estimation as compared to multi-depth deflectometer (MDD) measurements. The estimated relative formation strains differed by no more than $23 \%$ (Layer A) and $10.5 \%$ on average from the measured peak strains;

- The developed inverse method is adequate for calculation of elastic moduli of formation layers. Through the use of measurements at a specific site, it was found that the elastic moduli can be accurately determined. The measured moduli of the mechanical weathered layers differed by no more than $8.8 \%$ on average from those estimated by the model;

- The inverse method strongly agreed with the long-term measured formation peak strains. However, the long-term method does not account for non-linear formation deterioration, instead it provides a more conservative estimative of the formation responses based on the assumption that formation layers with fairly constant subgrade support, deteriorate progressively and uniformly over time.

In conclusion, railway track structures exhibit complex substructure deflection responses which are primarily affected by the bogie length, axles/bogie, axle loading, sleeper spacing and support as well as the substructure condition. The inherent deflection variability under train transient loading can be minimised for inverse analysis. The railway influence lines were characterised and the $45^{\circ}$ influence line was determined unsuitable for formation characterisation. The individual formation layers' deflection and elastic moduli were quantified through the use of the inverse method using transient substructure deflection measurements. Thus, the method was found suitable for estimation of formation condition over the design life.

It is clear that the method can at best provide an estimate of the formation structural condition over time, due to the significant influence of the bogie loading/superstructure interaction, sleeper movement, ballast support and substructure structural capacity on the formation deflection response. These variables can vary significantly over the design period of any ballasted track substructure. It is therefore advised to investigate railway track formations with the support of information about the track substructure composition and condition, as the key to the inverse method is to accurately determine the EILs for the specific substructure conditions. Furthermore, any railway track formation deflection analysis using this mechanistic-empirical method should conform to the following guidelines until further research reinforces the method:

- The inverse analysis of railway track formation shall be complemented with practical experience, visual surveys and laboratory testing if required. 
- The analysis of elastic moduli of track formation layers shall be conducted with the support of track condition information regarding the track design and material specification.

- The results shall be evaluated with clear understanding of the approximations and assumptions inherent to the method.

\subsection{RECOMMENDATIONS}

The following recommendations are made for future research in the field:

- Field or desk studies could be conducted to investigate and characterise the complex formation responses in terms of numerous bogie loading configurations on different superstructures;

- The effect of travelling speed on formation peak and spread deflection should be further investigated as it is uncertain whether there is a relationship between the change in deflection parameters and train speed;

- Continuous data collection and analysis will aid in determining and understanding the longterm formation behaviour under in-service conditions. This will furthermore allow improvement for inverse deflection analysis of railway track formations;

- The inverse method could be further investigated with the objective of developing a more generic approach for characterisation of railway track formation;

- The effect of dynamic loading, non-linearity, non-uniformity and stress dependence on railway track formation behaviour should be investigated. 


\section{REFERENCES}

Bush, A. J. and Baladi, G. Y., editors (1989), Nondestructive testing of pavements and backcalculation of moduli. American Society of Testing and Materials ASTM STP 1026. Philadelphia, PA.

Brown, S.F., (1996). Soil mechanics in pavement engineering. Geotechnique, 46(3), pp.383-426.

Brown, S.F. and Selig, E.T., (1991). The design of pavement and rail track foundations. Cyclic loading of soils, pp.249-305.

Bowness, D., Lock, A.C., Powrie, W., Priest, J.A. and Richards, D.J., (2007). Monitoring the dynamic displacements of railway track. Proceedings of the Institution of Mechanical Engineers, Part F: Journal of Rail and Rapid Transit, 221(1), pp.13-22.

Chang, C. S., Adegoke, C. W., and Selig, E. T. (1980). The GEOTRACK model for railroad track performance. Journal of Geotechnical Engineering Division, ASCE, Vol. 106, No. GT11, 1201-1218.

Collins, I.F. and Boulbibane, M., (2000). Geomechanical analysis of unbound pavements based on shakedown theory. Journal of Geotechnical and Geoenvironmental Engineering, 126(1), pp.50-59.

Costa, R., Motta, R., Moura, E., Pires, J., and Bernucci, L.L.B., (2017). Measuring device for in situ determination of the track modulus in a heavy haul track. In $12^{\text {th }}$ international heavy haul association conference. Cape Town, South Africa.

De Beer, M., Horak, E. and Visser, A.T., (1989). The multidepth deflectometer (MDD) system for determining the effective elastic moduli of pavement layers. In Nondestructive Testing of Pavements and Backcalculation of Moduli. ASTM International, STP 1026.

Dunnicliff, J., (1993). Geotechnical Instrumentation for Monitoring Field Performance. John Wiley \& Sons.

Eisenmann, J., (1975). Dynamic wheel load fluctuations-road stress. Strasse und Autobahn, 4(2), pp.127-128.

Freeme, C.R., (1983). Evaluation of pavement behaviour for major rehabilitation of roads. NITRR Technical Report RP/19/83. Pretoria: CSIR. 
Gräbe, P.J., (2002). Resilient and permanent deformation of railway formations under principal stress rotation. PhD Thesis, University of Southampton, Department of Civil and Environmental Engineering, UK.

Gräbe, P.J., (2009). Track deflection measurement using particle image velocimetry. Civil Engineering: Magazine of the South African Institution of Civil Engineering, pp. 18-22.

Gräbe, P.J., Clayton, C.R.I. and Shaw, F.J., (2005). Deformation measurement on a heavy haul track formation.

Gräbe, P.J. and Clayton, C.R., (2009). Effects of principal stress rotation on permanent deformation in rail track foundations. Journal of Geotechnical and Geoenvironmental Engineering, 135(4), pp.555565.

Gräbe, P.J. and Shaw, F.J., (2010). Design life prediction of a heavy haul track foundation. Proceedings of the Institution of Mechanical Engineers, Part F: Journal of Rail and Rapid Transit, 224(5), pp.337344.

Hoffman, M.S. and Thompson, M.R., (1982). Comparative study of selected non-destructive testing devices. Transportation Research Record TRR 1117, 1987, pp.21-24.

Horak, E., (1988). Aspects of deflection basin parameters used in a mechanistic rehabilitation design procedure for flexible pavements in South Africa. PhD thesis, Department of Civil Engineering, University of Pretoria, Pretoria.

Horak, E., (2008). Benchmarking the structural condition of flexible pavements with deflection bowl parameters. Journal of the South African Institution of Civil Engineering, 50(2), pp.2-9.

Horak, E. and Emery, S., (2006). Falling weight deflectometer bowl parameters as analysis tool for pavement structural evaluations. Proceedings, $22^{\text {nd }}$ Australian Road Research Board (ARRB) International Conference.

Horak, E., Emery, S. and Maina, J., (2015). Review of falling weight deflectometer deflection benchmark analysis on roads and airfields. In Proceedings of 11 th Conference on Asphalt Pavements for Southern Africa.

Huang, Y.H., (2004). Pavement Analysis and Design. Second Edition, Pearson Prentice Hall. 
Jenkins, H. H., Stephenson, J. E., Clayton, G. A., Morland, G. W. and Lyon, D. (1974). The effect of track and vehicle parameters on wheel/rail vertical dynamic forces. Railway Engineering Journal, Vol.3 No.2, pp.2-16.

Jooste, F.J., (1992). Structural classification of granular base pavements using measured deflection bowl parameters. Master Dissertation, Department of Civil Engineering, University of Johannesburg.

Jooste, F.J., (2002) Some influences of layer thickness variations on backcalculation and rehabilitation design. $21^{\text {st }}$ Annual South African Transport Conference (SATC).

Lekarp, F., Isacsson, U. and Dawson, A., (2000a). State of The Art. I: Resilient response of unbound aggregates. Journal of Transportation Engineering, 126(1), pp.66-75.

Lekarp, F., Isacsson, U. and Dawson, A. R., (2000b). State of the Art. II: Permanent strain response of unbound aggregates. Journal of Transportation Engineering, 126(1), pp.76-83.

Li, D. and Selig, E. T. (1996). Cumulative plastic deformation for fine-grained subgrade soils. Journal of Geotechnical Engineering, 122(12), pp.1006-1013.

Li, D., Hyslip, J., Sussmann, T. and Chrismer, S., (2016). Railway Geotechnics. CRC Press.

Li, D., (1991). Effect of strain rate on strength and stiffness properties of soils. Geotechnical Report No. AAR 91-384R. Department of Civil Engineering, University of Massachusetts, Amherst, MA.

Logan, D.L., (2011). A First Course in the Finite Element Method. Cengage Learning.

Lundqvist, A. and Dahlberg, T., (2005). Load impact on railway track due to unsupported sleepers. Proceedings of the Institution of Mechanical Engineers, Part F: Journal of Rail and Rapid Transit, 219(2), pp.67-77.

Lytton, R.L., (1989). Backcalculation of pavement layer properties. In nondestructive testing of pavements and backcalculation of moduli. ASTM International, STP 1026.

Maina, J.W., Horak, E., Van Wijk, I., Hefer, A., Jordaan, G., Olivier, P. and de Bruin, P.W., (2009). Revision of the South African pavement design method. Draft Contract Report SANRAL. SAPDM/B2/2009-01. 
Maree, J.H. and Freeme, C.R., (1981). The mechanistic design method used to evaluate the pavement structures in the catalogue of the draft TRH4 1980. No. RP/3/81.

Monismith, C.L., Ogawa, N. and Freeme, C.R., (1975). Permanent deformation characteristics of subgrade soils due to repeated loading. Transportation Research Record, 537.

Priest, J.A. and Powrie, W., (2009). Determination of dynamic track modulus from measurement of track velocity during train passage. Journal of Geotechnical and Geoenvironmental Engineering, 135(11), pp.1732-1740.

Priest, J.A., Powrie, W., Yang, L., Grabe, P.J. and Clayton, C.R.I., (2010). Measurements of transient ground movements below a ballasted railway line. Géotechnique, 60(9), pp.667-677.

Scullion, T., Briggs, R.C. and Lytton, R.L., (1989). Using the multidepth deflectometer to verify modulus backcalculation procedures. In Nondestructive Testing of Pavements and Backcalculation of Moduli. ASTM International, STP 1026.

Selig, E. T. and Chang, C. S. (1981). Soil failure modes in undrained cyclic loading. Journal of the Geotechnical Engineering Division, ASCE.

Selig, E.T. and Waters, J.M., (1994). Track Geotechnology and Substructure Management. First Edition, Thomas Telford, Ltd.

Shaw, F.T. (2005). Railway track formation stiffness. MSc Dissertation, University of Pretoria, South Africa.

Soliman, H. and Shalaby, A., (2015). Permanent deformation behavior of unbound granular base materials with varying moisture and fines content. Transportation Geotechnics, 4, pp.1-12.

South African National Roads Agency Limited (SANRAL), (2014). South African Pavement Engineering Manual (SAPEM). Technical Manual Report. No.1998/09584/06. Republic of South Africa.

Stubstad, R.N., Jiang, Y.J., Clevenson, M.L. and Lukanen, E.O., (2006). Review of the long-term pavement performance backcalculation results - Final Report. Publication No. FHWA-HRT-05-150, US Department of Transportation, Office of Infrastructure Research and Development, Federal Highway Administration (LTPP), McLean, Virginia. 
Sussmann, T.R. and Selig, E.T., (2000). Resilient modulus backcalculation techniques for track. In Performance Confirmation of Constructed Geotechnical Facilities, pp. 401-411.

Tam, W. S., (1985). Report on design of overlays for bituminous pavements. Report No. WST/1. Department of Civil Engineering. University of Nottingham.

Theyse, H., du Preez, R. and Kannemeyer, L., (2015). FWD deflection analysis: fact or fiction?. In $11^{\text {th }}$ Conference on Asphalt Pavements for Southern Africa (CAPSA15), Sun City, South Africa.

Transnet Freight Rail (TFR), (2000). Manual for track maintenance. Internal Technical Specification.

Transnet Freight Rail (TFR), (2006). Specification for railway earthworks (S410). Internal Technical Specification.

Transnet Freight Rail (TFR), (2010). Specification for vertical and lateral rail load gauges. Internal Technical Specification.

Ullidtz, P., (1987). Pavement Analysis. New York: Elsevier.

Ullidtz, P., (2002). Analytical tools for design of flexible pavements. In Keynote Address delivered at the 8th ISAP Conference held in Copenhagen.

Vandoorne, R., Mpye, G.D., and Gräbe. P.J., (2017). Permanent and resilient deformation behaviour of heavy haul formation materials subjected to environmental changes. In $12^{\text {th }}$ international heavy haul association conference. Cape Town, South Africa.

Vorster, D.J. and Gräbe, P.J., (2013). The effect of axle load on track and foundation resilient deformation under heavy haul conditions. In $10^{\text {th }}$ international heavy haul association conference, New Delhi, India.

White, D.J., Take, W.A. and Bolton, M.D., (2003). Soil deformation measurement using particle image velocimetry (PIV) and photogrammetry. Geotechnique, 53(7), pp.619-632.

Wilk, S.T., Stark, T.D. and Rose, J.G., (2016). Evaluating tie support at railway bridge transitions. Proceedings of the Institution of Mechanical Engineers, Part F: Journal of Rail and Rapid Transit, 230(4), pp.1336-1350. 
Yang, L.A., Powrie, W. and Priest, J.A., (2009). Dynamic stress analysis of a ballasted railway track bed during train passage. Journal of Geotechnical and Geoenvironmental Engineering, 135(5), pp.680689.

Yoder, E.J. and Witczak M.W., (1975). Principles of Pavement Design. 2nd Edition, John Wiley \& Sons.

Zakeri, J.A. and Mosayebi, S.A., (2016). Study of ballast layer stiffness in railway tracks. Gradevinar, 68(4), pp.311-318. 
APPENDIX A

(7E LOCOMOTIVE) 


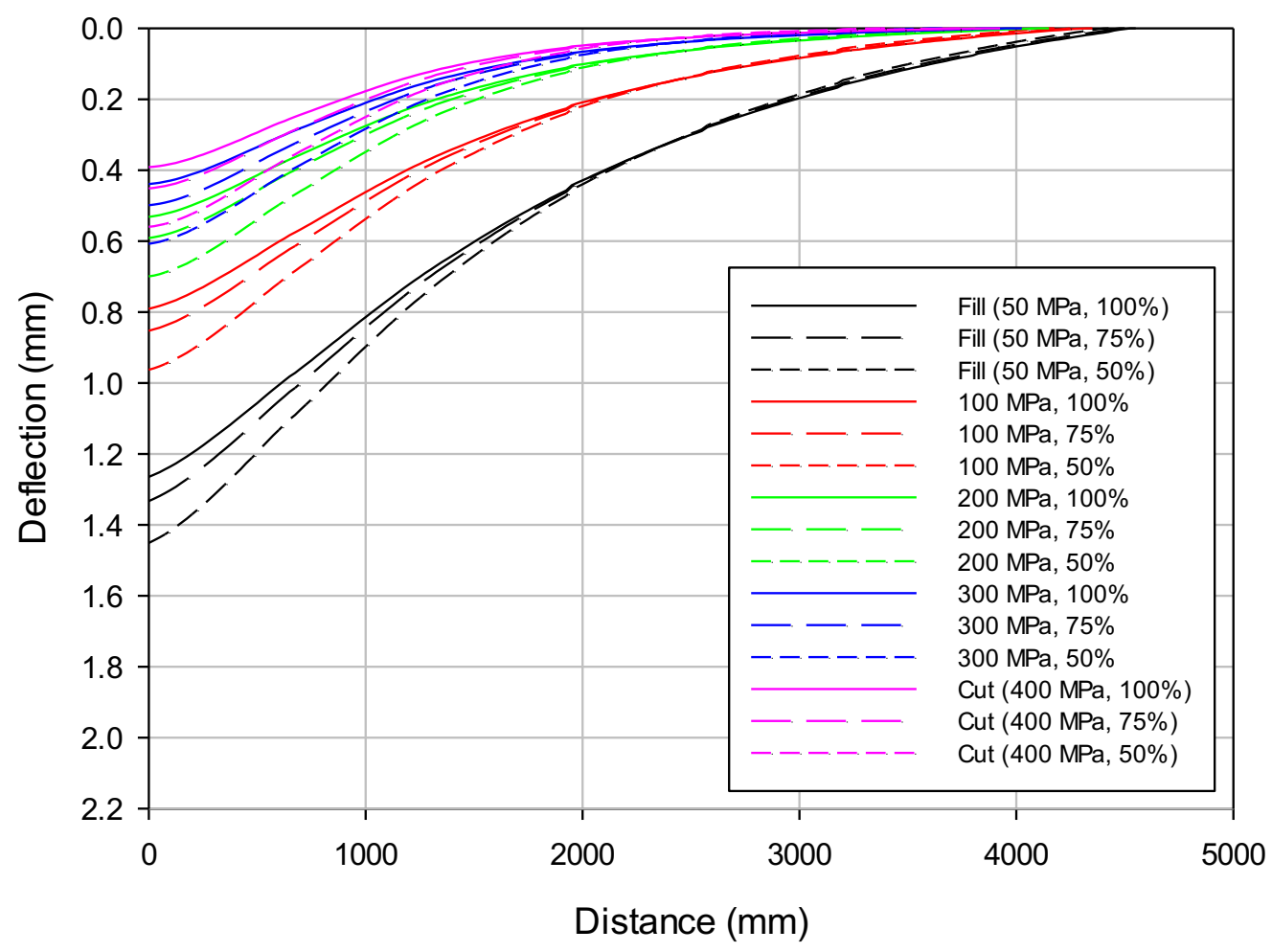

Figure A.1: Transient substructure deflection measurements for long-term model (7E Locomotive)

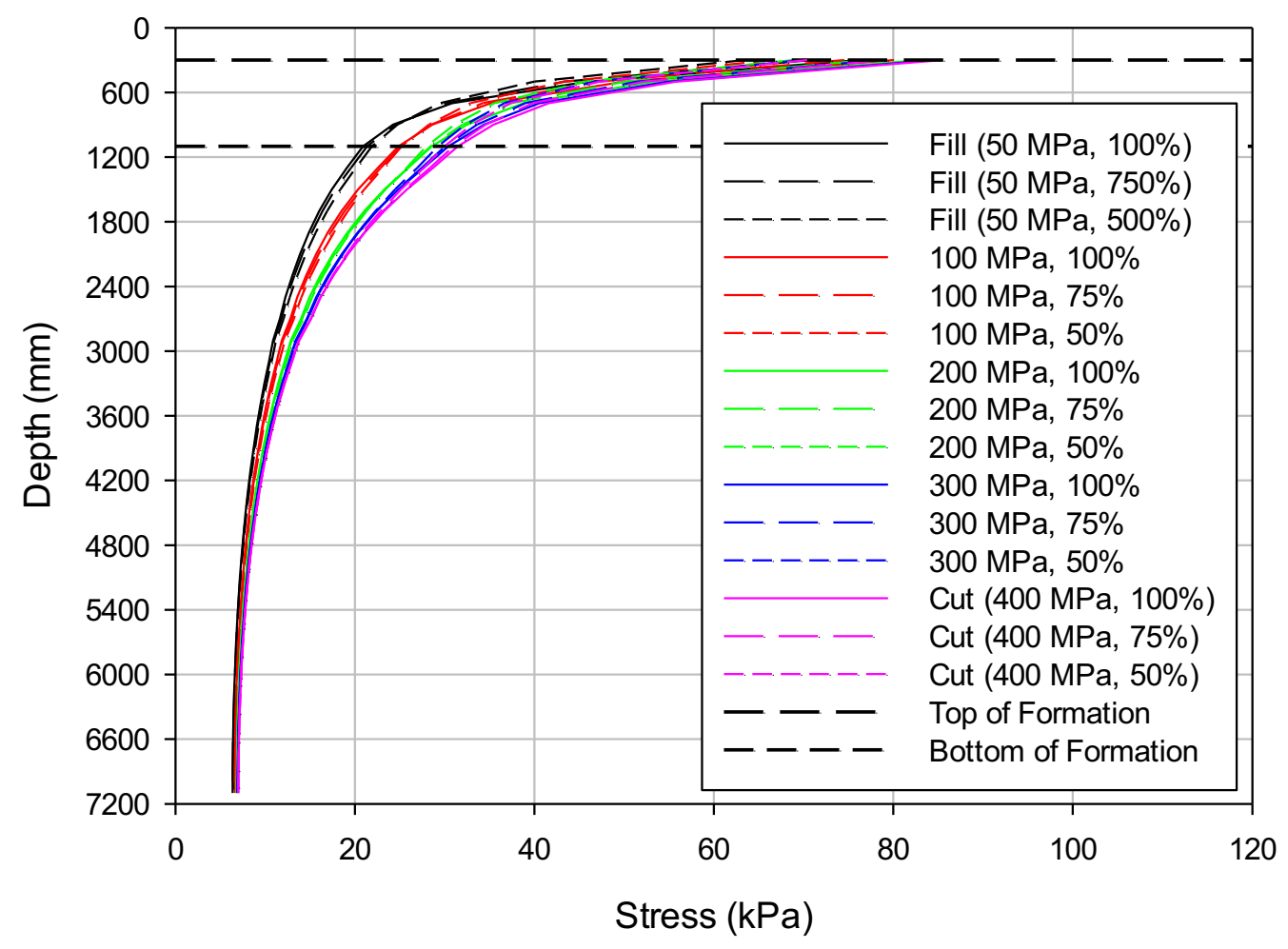

Figure A.2: Substructure vertical stress for long-term model (7E Locomotive) 


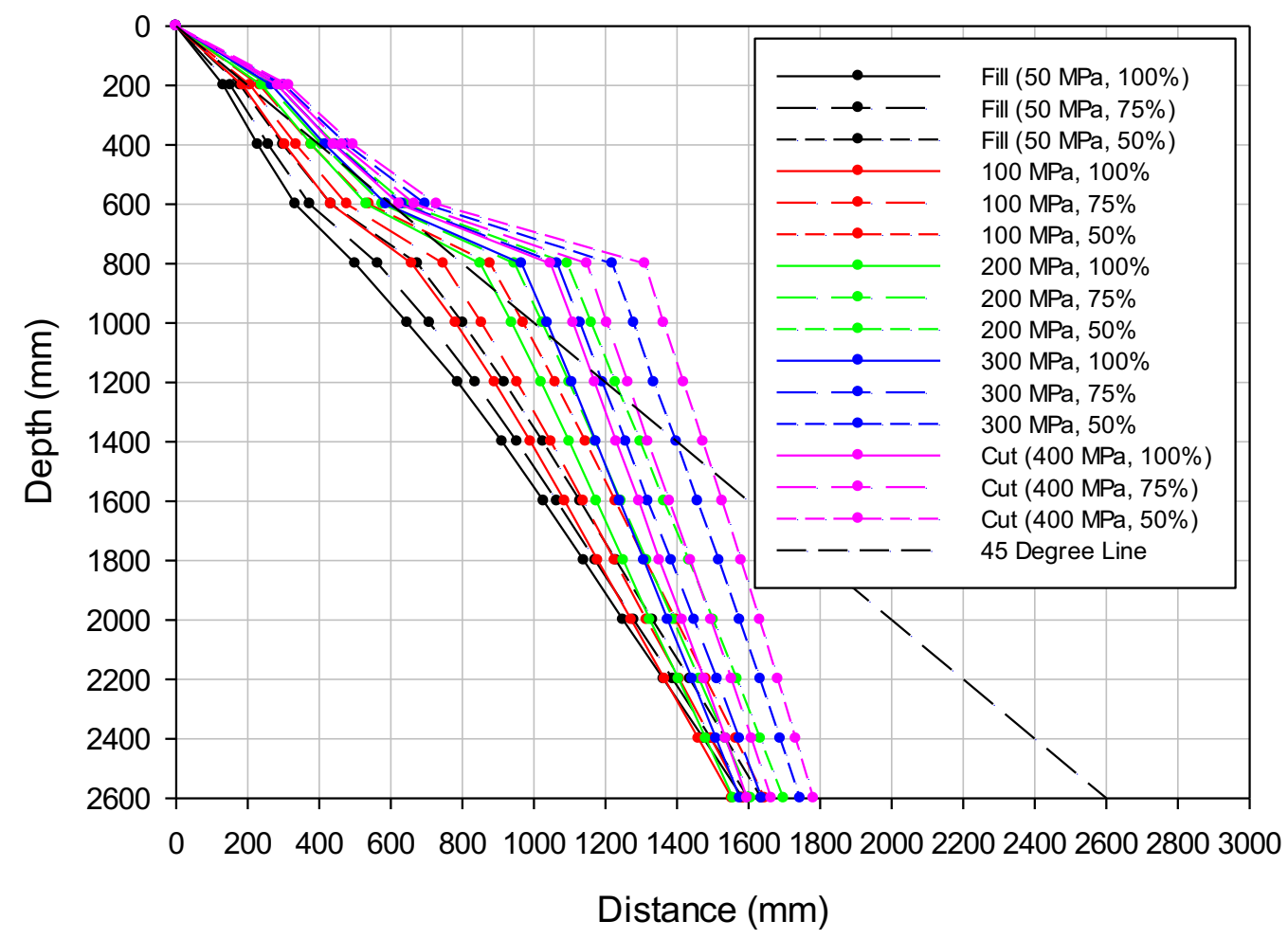

Figure A.3: Equilibrium influence lines for long-term model (7E Locomotive)

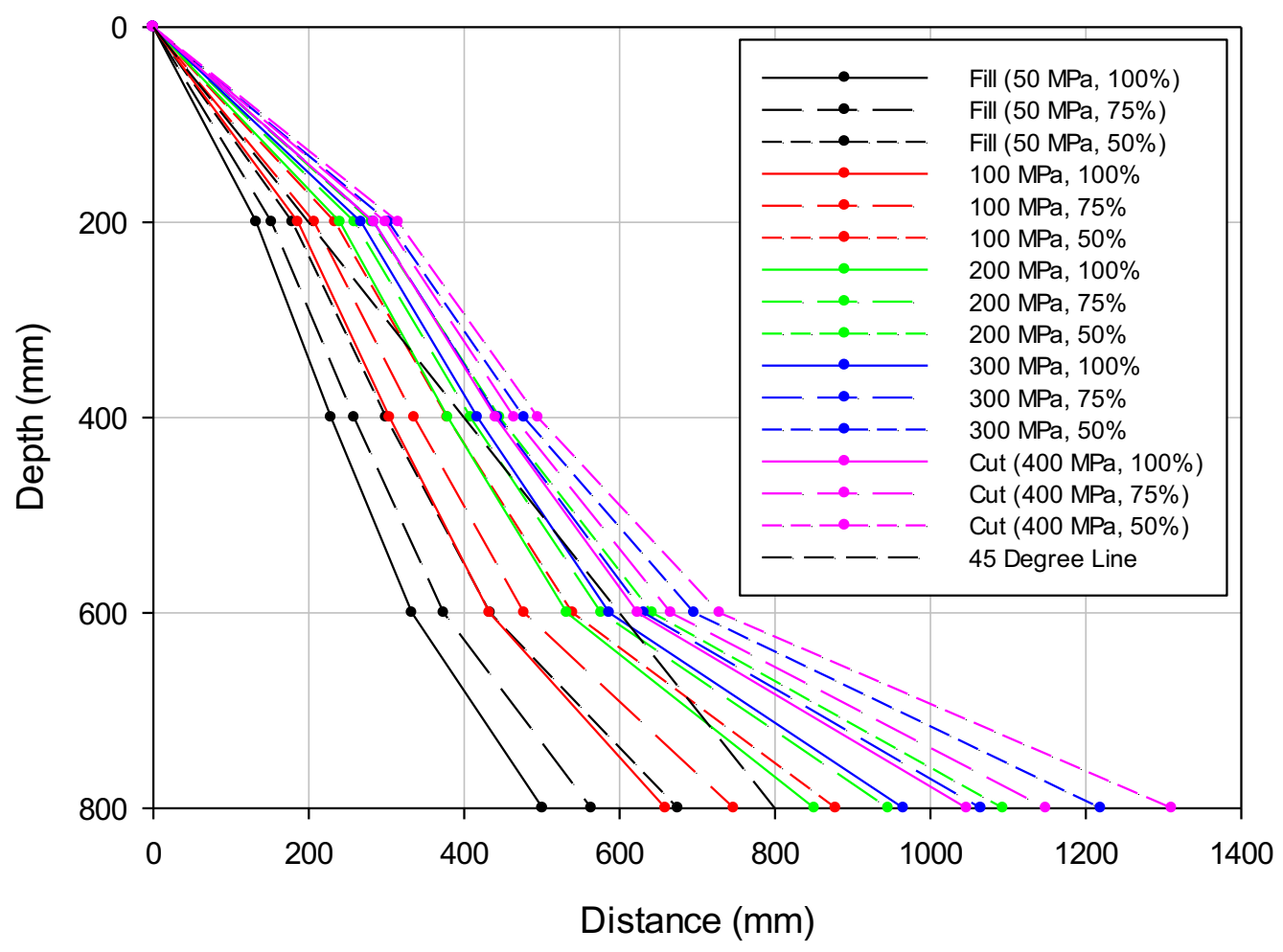

Figure A.4: Formation equilibrium influence lines for long-term model (7E Locomotive) 


\section{APPENDIX B}

(11E LOCOMOTIVE) 


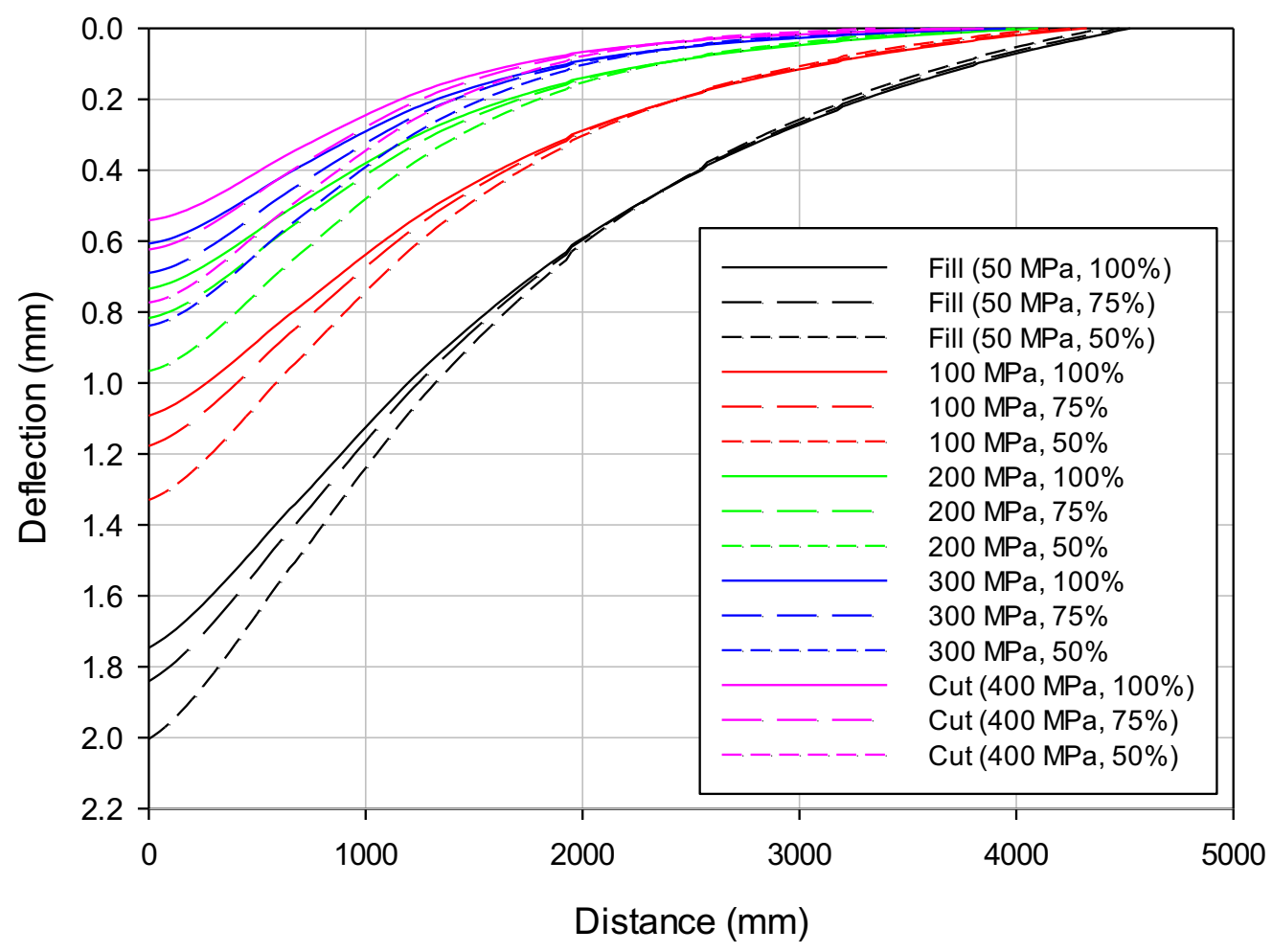

Figure B.1: Transient substructure deflection measurements for long-term model

(11E Locomotive)

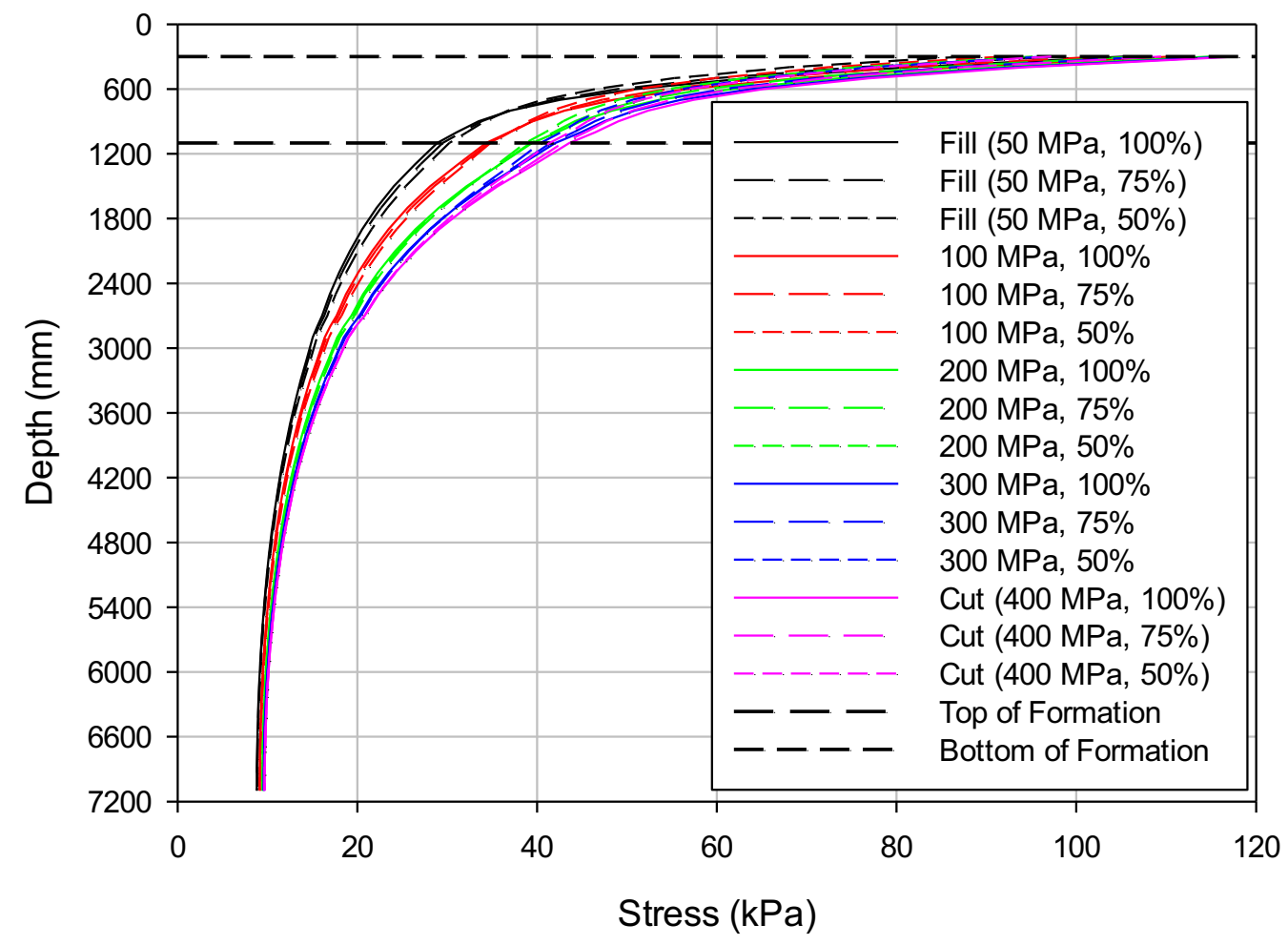

Figure B.2: Substructure vertical stress for long-term model (11E Locomotive) 


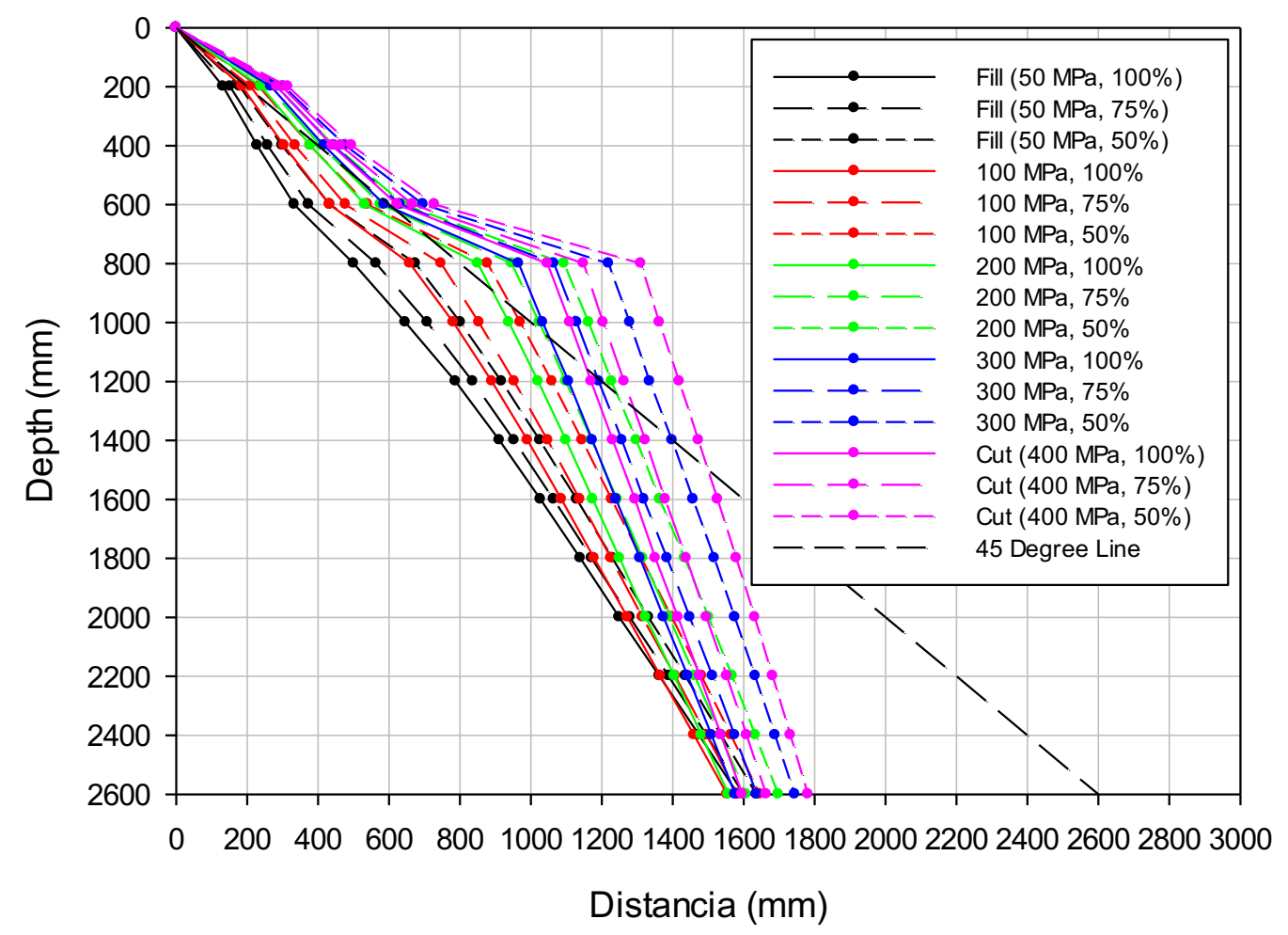

Figure B.3: Equilibrium influence lines for long-term model (11E Locomotive)

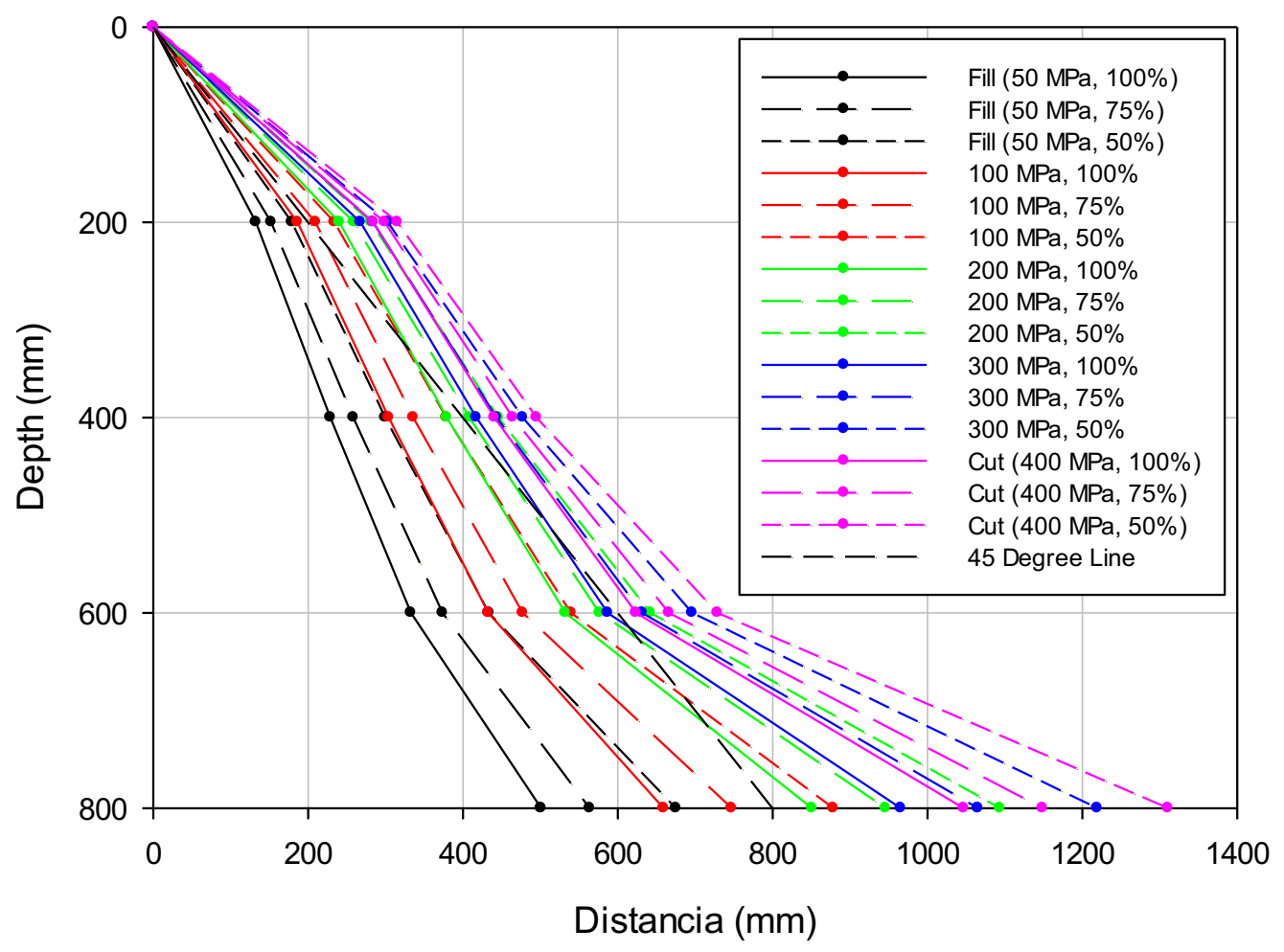

Figure B.4: Formation equilibrium influence lines for long-term model (11E Locomotive) 


\section{APPENDIX C}

(19E LOCOMOTIVE) 


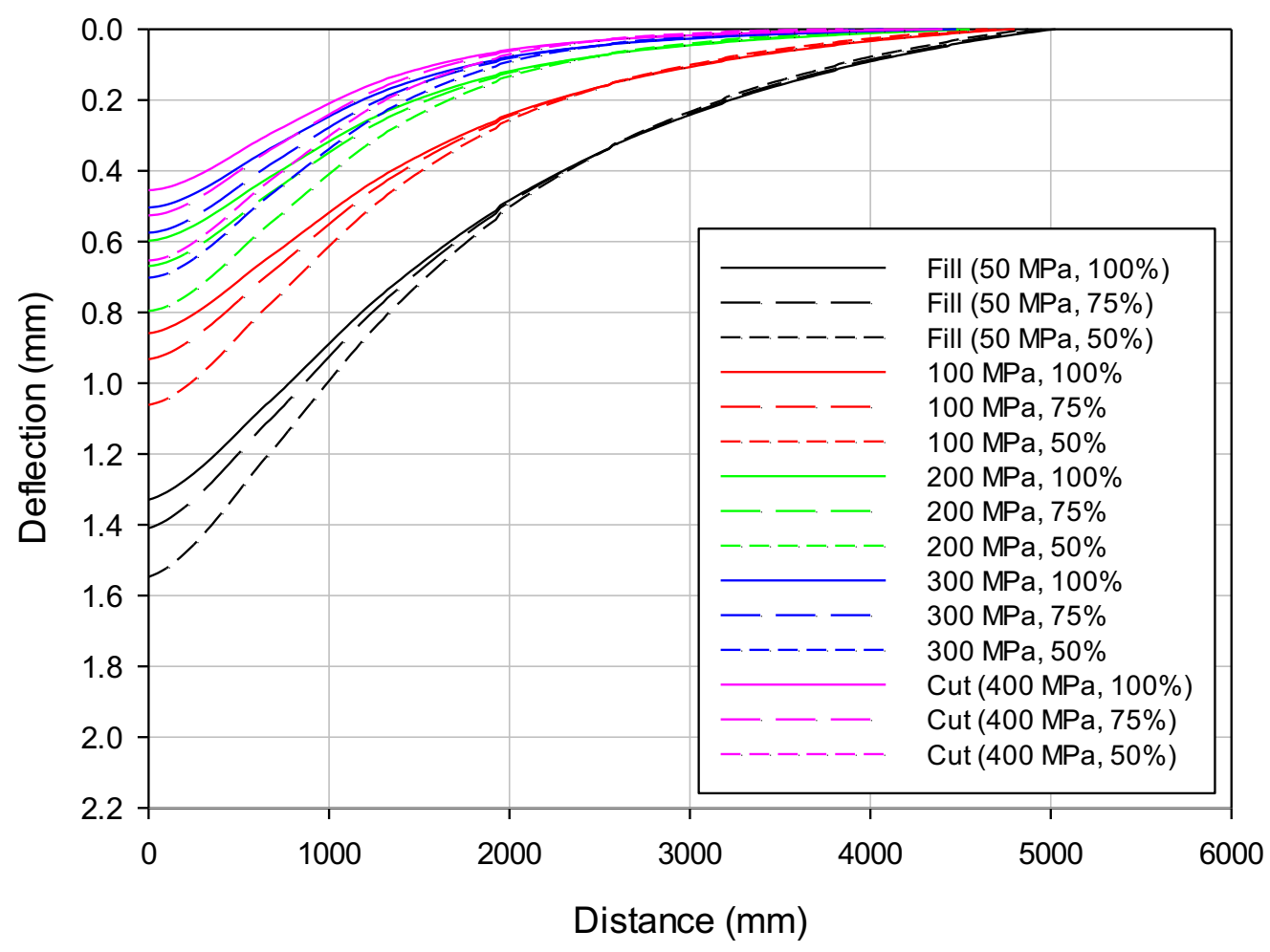

Figure C.1: Transient substructure deflection measurements for long-term model

(19E Locomotive)

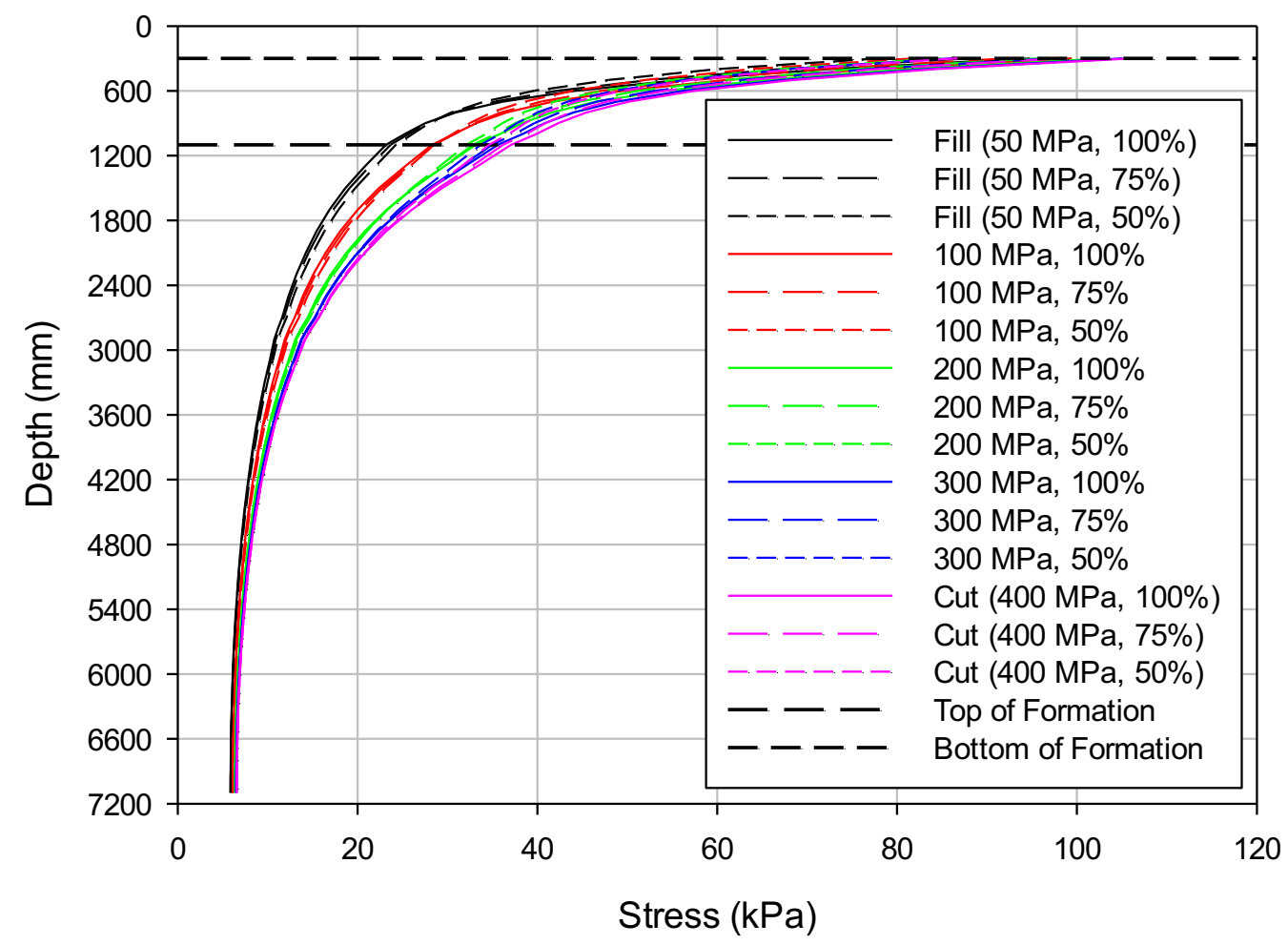

Figure C.2: Substructure vertical stress for long-term model (19E Locomotive) 


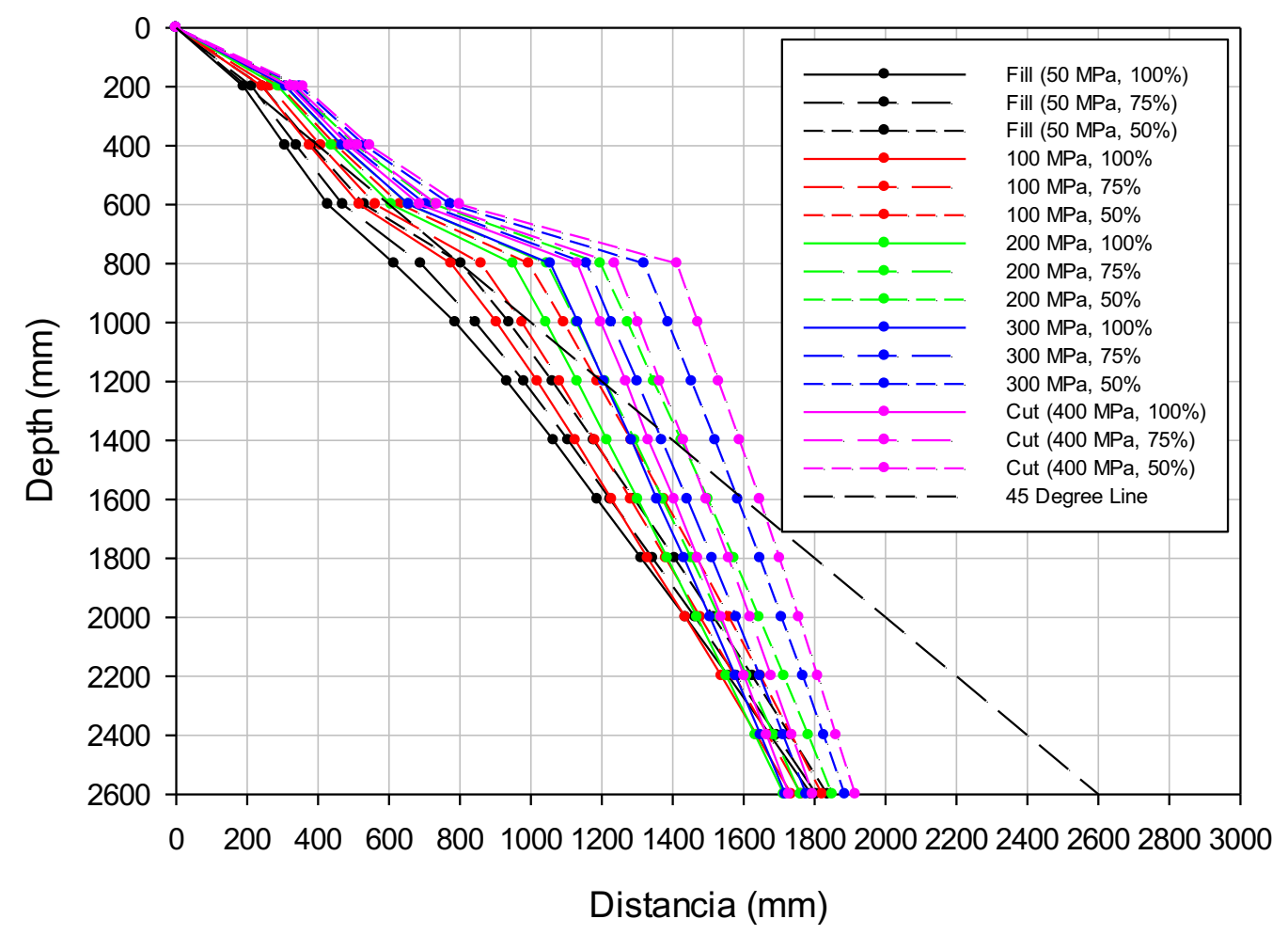

Figure C.3: Equilibrium influence lines for long-term model (19E Locomotive)

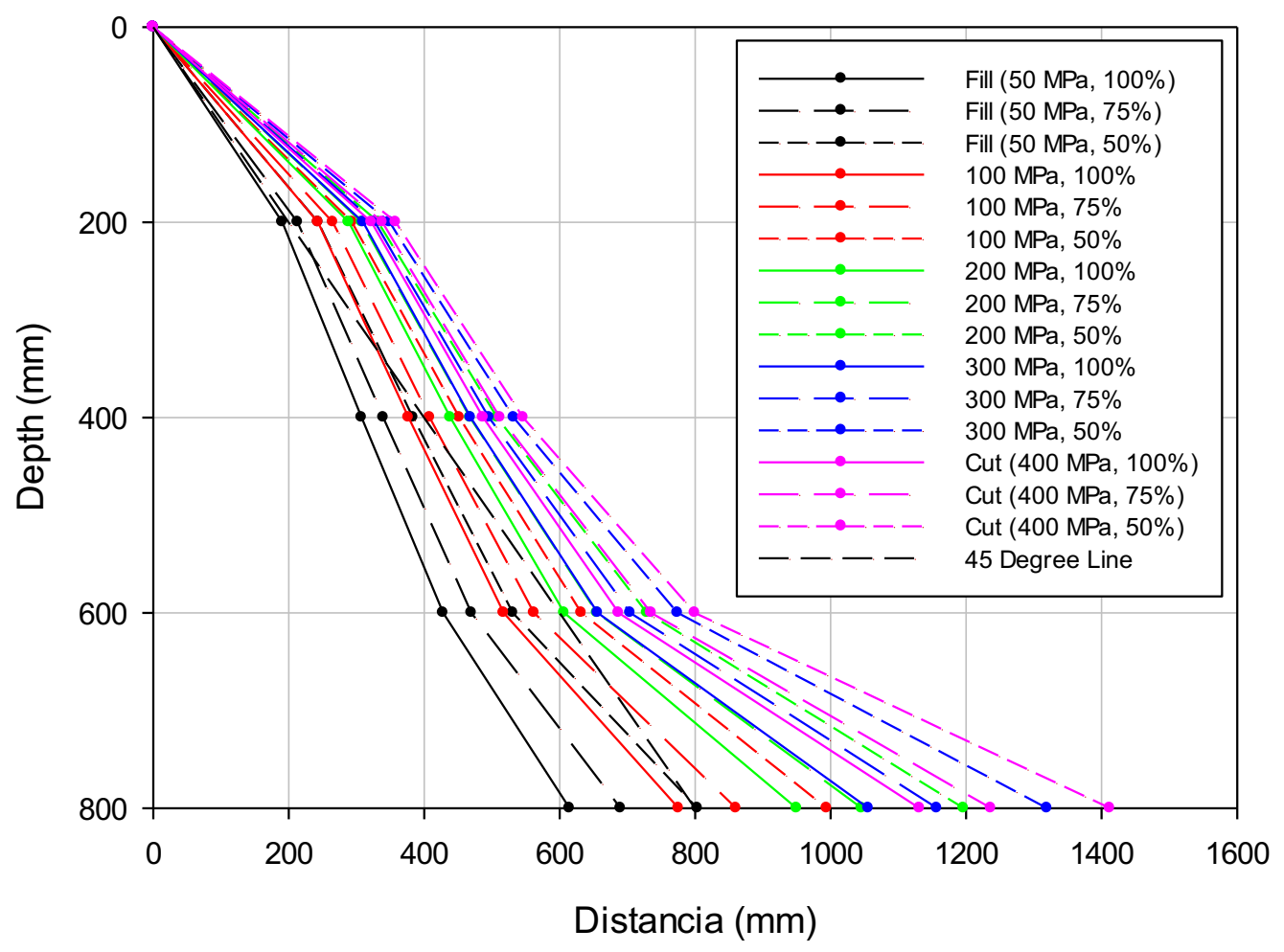

Figure C.4: Formation equilibrium influence lines for long-term model (19E Locomotive) 


\section{APPENDIX D}

(21E LOCOMOTIVE) 


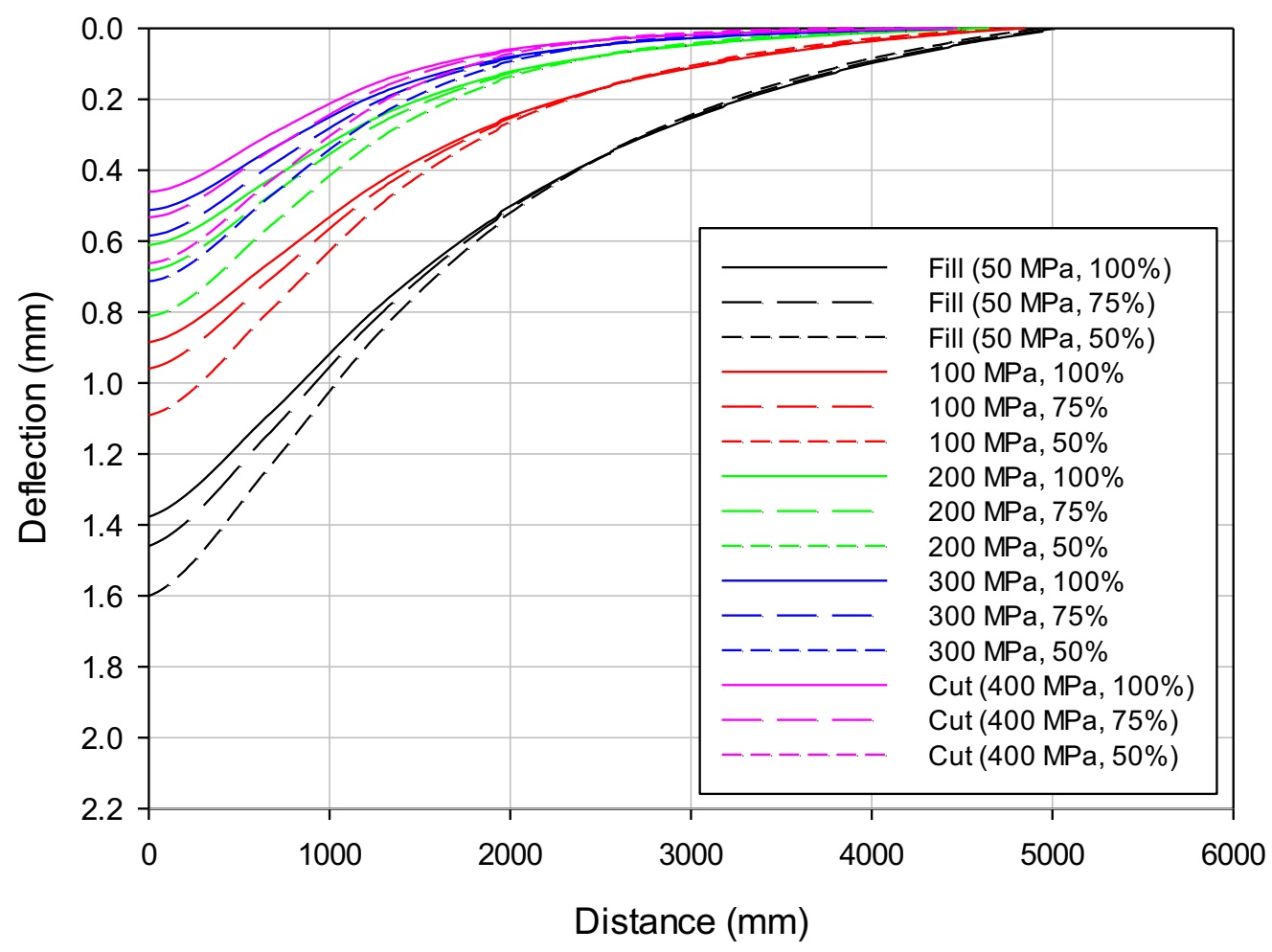

Figure D.1: Transient substructure deflection measurements for long-term model

(21E Locomotive)

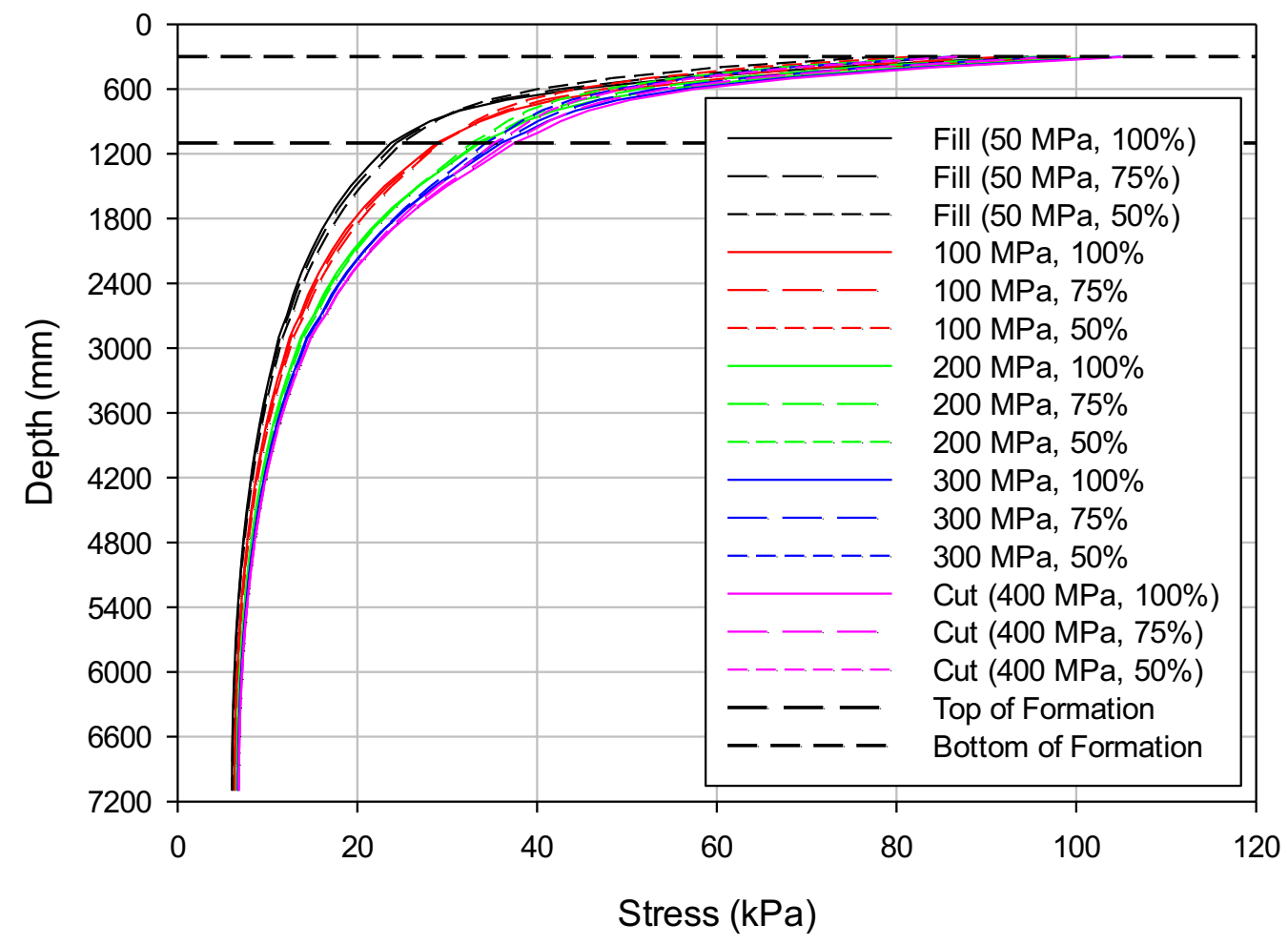

Figure D.2: Substructure vertical stress for long-term model (21E Locomotive) 


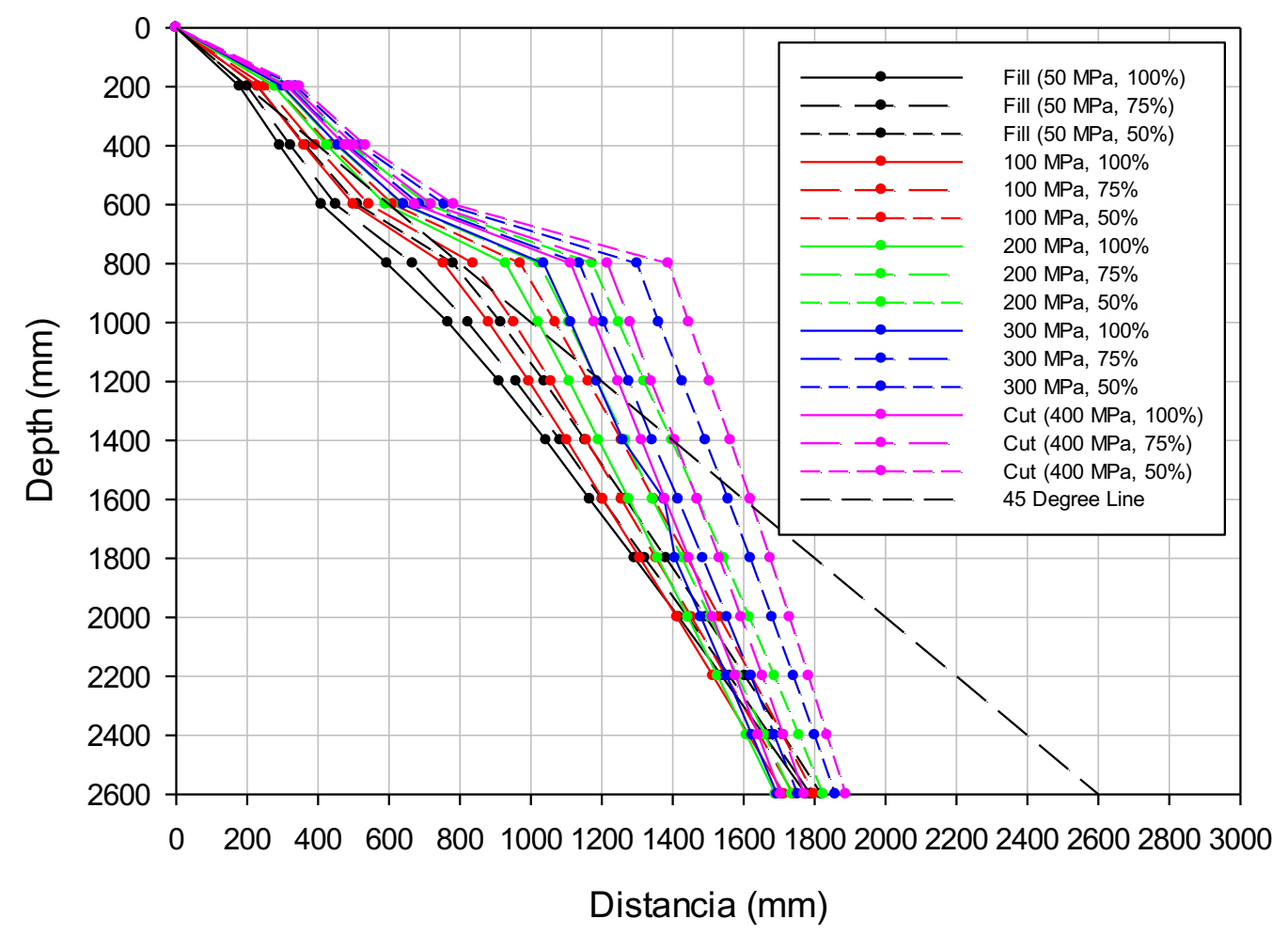

Figure D.3: Equilibrium influence lines for long-term model (21E Locomotive)

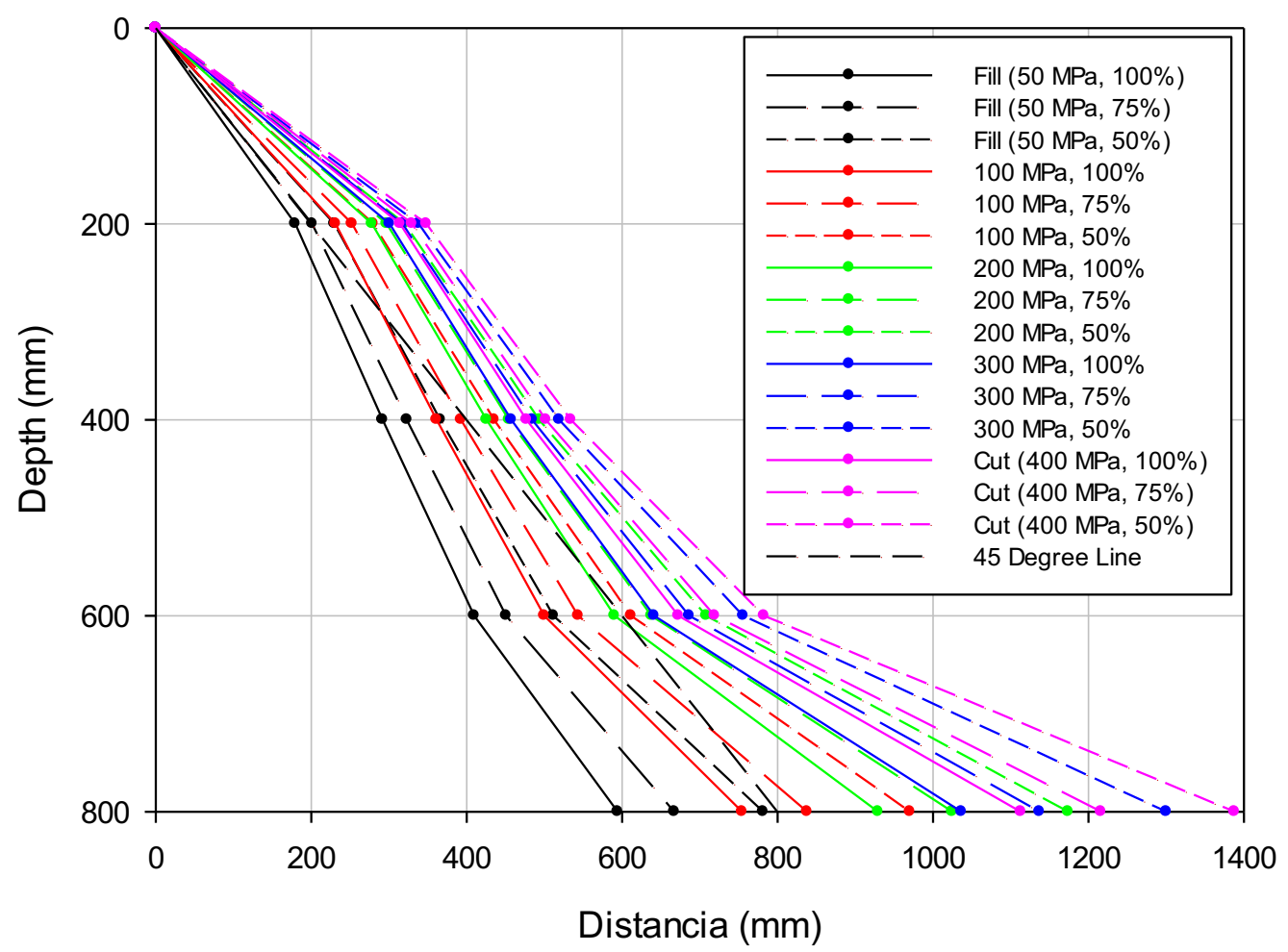

Figure D.4: Formation equilibrium influence lines for long-term model (21E Locomotive) 